
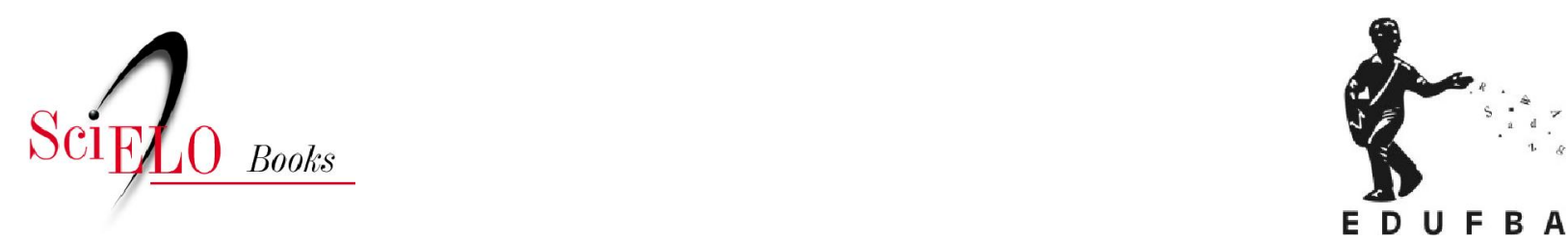

\title{
Termodinâmica da fratura
}

uma nova abordagem do problema da fratura nos sólidos

João Augusto de Lima Rocha

ROCHA, JAL. Termodinâmica da fratura: uma nova abordagem do problema da fratura nos sólidos [online]. Salvador: EDUFBA, 2010, 192 p. ISBN 978-85-232-1235-3. Available from SciELO Books $<\underline{\text { http://books.scielo.org }>\text {. }}$

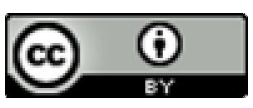

All the contents of this work, except where otherwise noted, is licensed under a Creative Commons Attribution 4.0 International license.

Todo o conteúdo deste trabalho, exceto quando houver ressalva, é publicado sob a licença Creative Commons Atribição 4.0.

Todo el contenido de esta obra, excepto donde se indique lo contrario, está bajo licencia de la licencia $\underline{\text { Creative }}$ Commons Reconocimento 4.0. 


\section{TERMODINÂMICA DA FRATURA}

uma nova abordagem do problema da fratura nos sólidos 
UNIVERSIDADE FEDERAL DA BAHIA

Reitor

Naomar Monteiro de Almeida Filho

Vice-reitor

Francisco José Gomes Mesquita

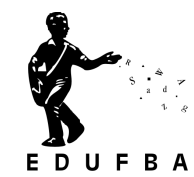

EDITORA DA UNIVERSIDADE FEDERAL DA BAHIA

Diretora

Flávia Goulart Mota Garcia Rosa

Conselho Editorial

Titulares

Angelo Szaniecki Perret Serpa

Alberto Brum Novaes

Caiuby Alves da Costa

Charbel Ninõ El-Hani

Dante Eustachio Lucchesi Ramacciotti

José Teixeira Cavalcante Filho

Maria Vidal de Negreiros Camargo

Suplentes

Antônio Fernando Guerreiro de Freitas

Cleise Furtado Mendes

Evelina de Carvalho Sá Hoisel

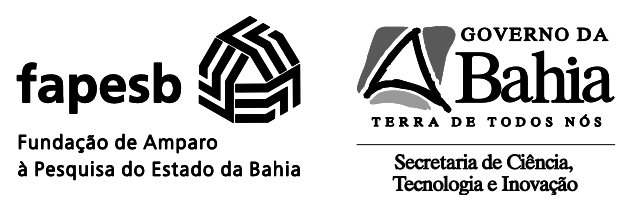


JOÃO AUGUSTO DE LIMA ROCHA

Prefácio de Luiz Bevilacqua

\section{TERMODINÂMICA DA FRATURA}

uma nova abordagem do problema da fratura nos sólidos 
(C)2010, by João Augusto de Lima Rocha. Direitos desta edição cedidos à EDUFBA.

Feito o depósito legal.

\section{Normalização: Tatiana Campos da Hora}

Revisão: Leila de França Rocha

Capa: Angela Garcia Rosa

Sistema de Bibliotecas - UFBA

Rocha, João Augusto de Lima.

Termodinâmica da fratura : uma nova abordagem do problema da fratura nos sólidos João Augusto de Lima - Salvador : EDUFBA, 2010.

$192 \mathrm{p}$.

ISBN 978-85-232-0695-6

1. Termodinâmica. 2. Mecânica da fratura. 3. Mecânica dos sólidos. 4. Mecânica dos meios contínuos. I. Título.

EDUFBA

Rua Barão de Jeremoabo, s/n

Campus de Ondina

40170-115 Salvador-Bahia

Tel: (55 71) 3283-6160/6164/6777

edufba@ufba.br www.edufba.ufba.br

EDUFBA editora filiada à 


\section{AGRADECIMENTOS}

Qualquer trabalho, mesmo que tido por concluído, nunca deixa de ser provisório. Portanto, cabe agradecer, em primeiro lugar e previamente, a quem, no futuro, tiver interesse em aperfeiçoá-lo.

Por outro lado, existem aqueles que nos deram o suporte necessário para a construção daquilo que, em anos de trabalho, depois de muitas idas e vindas, veio a ser o texto que ora sai publicado. Cabe, nesse caso, o primeiro agradecimento a Aydil, Leila, Vladimir e Pedro, membros da pequena tribo familiar, pelo incentivo, carinho e paciência.

Ao Luiz Bevilacqua, orientador do mestrado, na COPPE/UFRJ, e pioneiro da matemática aplicada à engenharia em nosso País que,nos idos de 1974, me fez partir das frações parciais de Padé e chegar à mecânica da fratura, assunto ainda pouco estudado entre nós, naquela época de grande entusiasmo em torno do Gradcon, grupo informal de pesquisa que tantos frutos veio a produzir.

Ao Prof. Wilson S. Venturini, orientador do doutorado, na Escola de Engenharia de São Carlos - USP, que me deu o rumo para que pudesse chegar ao que agora se publica, cuja recente perda deixa nos amigos um grande vazio.

Ao Prof. Sergio P. B. Proença, responsável pela minha ida, em 1995, para o doutorado em São Carlos, no ambiente saudável de estudo e pesquisa do Departamento de Engenharia de Estruturas que muito deve à sua grande disponibilidade e conhecimento.

Ao conterrâneo Abimael F. D. Loula, do Laboratório Nacional de Computação Científica, do CNPq, que leu os originais e deu importantes sugestões iniciais, as quais procurei incorporar ao texto final.

À Fundação de Amparo à Pesquisa da Bahia (Fapesb), pelo apoio financeiro, e à Editora da UFBA (Edufba), responsável pela bem cuidada edição. 



\section{LISTA DE ABREVIATURAS E SIGLAS}

ASTM

BEM

BSI

DIN

EPD

EPT

ISO

MEF

RILEM
American Standard for Testing and Materials

Boundary Element Method

Britsh Standards Institute

Deutsche Industrie Normen

Estado plano de tensão

Estado plano de deformação

International Standard Organization

Método dos Elementos Finitos

Réunion Internationale des Laboratoires d'Éssais et de

Recherches sur les Matériaux et les Constructions 


\section{LISTA DE SÍMBOLOS}

Grandezas escalares são aqui representadas com auxílio de letras latinas, minúsculas ou maiúsculas, em itálico. Caracteres desse mesmo tipo são também utilizados para representar funções, coeficientes, conjuntos, sólidos, partes de sólidos ou pontos.

Letras latinas minúsculas, em negrito, indicam vetores (em $I R^{2}$, ou em $\left.I R^{3}\right)$; letras latinas maiúsculas, em negrito, indicam tensores de segunda ordem (transformações lineares de $I R^{2}$ em $I R^{2}$, ou de $I R^{3}$ em $\left.I R^{3}\right)$.

No texto, o significado de cada um dos símbolos utilizados é sempre indicado na primeira vez que aparece. A seguir, são descritos os principais símbolos.

\section{CARACTERES LATINOS}

$\begin{array}{ll}A & \text { Área da base de um cilindro, ou seção transversal } \\ a & \text { Semieixo maior de uma elipse; parâmetro de fratura } \\ \mathbf{b} & \text { Densidade de forças de corpo, por unidade de volume } \\ b & \text { Semieixo menor de uma elipse } \\ B & \text { Corpo deformável } \\ C & \text { Capacidade térmica de um sólido } \\ C_{0} & \text { Configuração de referência de um sólido, no } I R^{3} \\ C_{\mathrm{t}} & \text { Configuração atualizada de um sólido, no instante } t, \text { no } I R^{3} \\ \mathbf{D} & \text { Tensor taxa de deformação } \\ \mathbf{e} & \text { Vetor unitário da direção de propagação da fissura } \\ \mathbf{e}_{\mathrm{i}} & \text { Vetor unitário na direção de um eixo coordenado } \\ E & \text { Energia interna; módulo de Young } \\ E_{\mathrm{d}} & \text { Energia de deformação } \\ \mathbf{f} & \text { Densidade de forças de corpo, por unidade de massa } \\ F & \text { Força } \\ \mathbf{g} & \text { Densidade volumétrica genérica (de forças de corpo, de } \\ G & \text { quantidade de calor trocada com o exterior etc.) } \\ G_{\mathrm{t}} & \text { Energy release rate } \\ h & \text { Parâmetro termodinâmico de fratura } \\ \mathbf{I} & \text { Espessura de uma chapa } \\ J & \text { Tensor identidade } \\ J_{\mathrm{Ic}} & \text { Integral } J: \text { parâmetro de fratura } \\ K & \text { Parâmetro experimental: integral } J, \text { medida no ponto a partir } \\ K_{\mathrm{I}}, K_{\mathrm{II}}, K_{\mathrm{III}} & \text { do qual a fissura passa a ter um crescimento estável } \\ K_{\mathrm{Ic}}, K_{\mathrm{II}}, K_{\mathrm{III}} & \text { Conjunto } \\ \mathbf{n} & \text { Fatores de intensidade de tensão } \\ N_{\mathrm{o}}(P) & \text { Valores críticos dos fatores de intensidade de tensão } \\ & \text { Vetor normal unitário, em um ponto de uma superfície, ou } \\ & \text { curva regular } \\ \text { Vizinhança de raio } \rho, \text { de um ponto } P\end{array}$




\begin{tabular}{|c|c|}
\hline$P, p{ }^{\prime}$ & Pressão \\
\hline$p_{\mathrm{j}}$ & Componente de traction (BEM) \\
\hline$p_{\mathrm{ij}}{ }^{*}$ & Componente de traction da solução fundamental (BEM) \\
\hline$P$ & Parte de um sólido; ponto fonte (BEM) \\
\hline$P_{0}$ & $\begin{array}{l}\text { Representação da parte } P \text {, de um sólido, na configuração de } \\
\text { referência }\end{array}$ \\
\hline$P_{\mathrm{t}}$ & Representação atualizada da parte $P$, de um sólido \\
\hline $\mathbf{q}$ & Vetor fluxo de calor \\
\hline$Q$ & Quantidade de calor \\
\hline$q$ & Quantidade de calor, por unidade de volume \\
\hline$r$ & $\begin{array}{l}\text { Taxa de calor fornecido a um sólido, por unidade de massa; } \\
\text { medida algébrica da distância entre um ponto fonte e um } \\
\text { ponto de colocação (BEM) }\end{array}$ \\
\hline$S, s$ & Entropia \\
\hline $\mathbf{S}$ & Densidade de força, por unidade de área \\
\hline$S$ & Ponto de colocação (BEM) \\
\hline$S_{\mathrm{f}}(t)$ & $\begin{array}{l}\text { Representação de referência, da superfície de avanço de uma } \\
\text { fissura, relativa ao instante } t\end{array}$ \\
\hline$S_{\mathrm{f}}(t)$ & $\begin{array}{l}\text { Representação atualizada, da superfície de avanço de uma } \\
\text { fissura, no instante } t\end{array}$ \\
\hline$t$ & Tempo \\
\hline $\mathbf{t}$ & Vetor de Cauchy (traction) \\
\hline$\overline{\mathbf{t}}$ & Valores de tractions aplicadas no contorno $\Omega_{\mathrm{t}}$ \\
\hline$T$ & Temperatura absoluta \\
\hline $\mathbf{T}$ & Tensor tensão, de Cauchy \\
\hline$T_{\mathrm{ij}}$ & Componentes cartesianas do tensor $\mathbf{T}$ \\
\hline $\mathbf{u}$ & Vetor deslocamento \\
\hline$u_{\mathrm{j}}$ & Componentes cartesianas do vetor deslocamento \\
\hline$u_{\mathrm{ij}}{ }^{*}$ & Componente de deslocamento da solução fundamental (BEM) \\
\hline$U$ & Energia potencial elástica \\
\hline$v$ & Volume, na configuração atualizada do sólido \\
\hline $\mathbf{v}$ & Derivada material no tempo, do vetor posição (velocidade) \\
\hline$V$ & Volume, na configuração de referência do sólido \\
\hline$W$ & Trabalho mecânico \\
\hline$w$ & Quantidade de trabalho mecânico, por unidade de volume \\
\hline $\mathbf{x}$ & $\begin{array}{l}\text { Vetor que define a posição de um ponto da configuração } \\
\text { atualizada de um sólido }\end{array}$ \\
\hline$x_{\mathrm{i}}$ & componentes cartesianas do vetor $\mathbf{x}$; eixos coordenados \\
\hline $\mathbf{X}$ & $\begin{array}{l}\text { Vetor que define a posição de um ponto da configuração de } \\
\text { referência }\end{array}$ \\
\hline$X_{\mathrm{i}}$ & Componentes cartesianas do vetor $\mathbf{X}$ \\
\hline
\end{tabular}

\section{OUTROS CARACTERES}
$\phi \quad$ Densidade de energia de deformação, por unidade de volume
$\Phi(\mathbf{x}, t) \quad$ Campo genérico, escalar, ou vetorial, da equação geral de balanço termomecânico (definido no volume da configuração atualizada do sólido)
$\Phi \cdot(\mathbf{x}, t) \quad$ Campo genérico, escalar, ou vetorial, da equação geral de


balanço termomecânico (definido nas superfícies de avanço da fissura)

$\delta_{\text {ik }}$

$\varepsilon$

$\varepsilon^{*}$

$\varepsilon$

$\Omega_{\mathrm{u}}$

$\partial \Omega$

Y

$\partial P_{\mathrm{t}}$

$\partial P_{0}$ $\nabla$ grad
Delta de Kronecker

Energia interna por unidade de massa, ou energia interna, por unidade de volume

Energia interna superficial, por unidade de massa

Tensor deformação

Componentes cartesianas do tensor deformação

Energia superficial, por unidade de área de avanço da fissura Energia superficial termodinâmica de fratura, por unidade de área

Módulo de elasticidade transversal

Valor crítico do parâmetro termodinâmico de fratura

Fronteira de uma região plana

Fronteira da zona de processo da fissura

Faces planas de uma fissura

Entropia por unidade de massa

Entropia superficial, por unidade de massa

Taxa de dissipação de energia, por unidade de volume

Coeficiente de Poisson

Densidade de massa, ou massa específica. Raio de uma vizinhança

Massa superficial, por unidade de área

Tensão de tração, aplicada no infinito, no contorno de uma chapa

Tensor de Eshelby

Parâmetro escalar, da análise de sensibilidade

Taxa de produção de entropia, por unidade de massa

Energia livre de Helmholtz, por unidade de massa

Energia livre de Helmholtz superficial, por unidade de massa

Energia livre de Helmholtz, de um sólido

Região plana fechada

Região do contorno de um sólido, com tractions prescritas

Região do contorno de um sólido, com deslocamentos prescritos

Fronteira da região plana $\Omega$

Indica uma grandeza genérica, para qual faz sentido sua aplicação ao vetor $\mathbf{n}$ (tensor tensão, vetor fluxo de calor etc.)

Fronteira de $P_{\mathrm{t}}$.

Fronteira de $P_{0}$.

Gradiente material

Gradiente espacial 


\section{SUMÁRIO}

$\begin{array}{ll}\text { PREFÁCIO } & 13\end{array}$

APRESENTAÇÃO 15

INTRODUÇÃO

1 ELEMENTOS DE TERMODINÂMICA

PROCESSO TERMODINÂMICO REVERSÍVEL 38

A PRIMEIRA E A SEGUNDA LEI DA TERMODINÂMICA 40

INTERPRETAÇÃO TERMODINÂMICA DO PROCESSO DE DEFORMAÇÃO
DE UM SÓLIDO

2 O FENÔMENO DA FRATURA À LUZ DA MECÂNICA DO CONTÍNUO

DESCRIÇÃO MATEMÁTICA DO PROCESSO DE CRESCIMENTO

DE UMA FISSURA

LEIS DA TERMODINÂMICA APLICADAS AOS SÓLIDOS CONTÍNUOS 53

ABORDAGEM TERMODINÂMICA DO PROBLEMA DA FRATURA 55

Passagem das equações de balanço global às equações de balanço local 55

Formas gerais das equações de balanço local $\quad 58$

TEORIA TERMODINAMICAMENTE CONSISTENTE DA FRATURA 61

Equações de balanço $\quad 62$

3 CRITÉRIO TERMODINAMICAMENTE CONSISTENTE DE FRATURA

A FORMA ORIGINAL DE OBTENÇÃO DO CRITÉRIO DE GRIFFITH

VERSÃO TERMODINÂMICA DO CRITÉRIO DE GRIFFITH

A DINÂMICA DA PROPAGAÇÃO DE UMA FISSURA E O CRITÉRIO
DE GRIFFITH

CRITÉRIO TERMODINAMICAMENTE CONSISTENTE DE FRATURA

4 A ANÁLISE DE SENSIBILIDAdE APLICADA AO PROBLEMA DA FRATURA

A INTEGRAL $J$ DE RICE

DERIVADA MATERIAL DA ENERGIA DE DEFORMAÇÃO 96

A SIMULAÇÃO DO AVANÇO DA FISSURA VIA ANÁLISE DE
SENSIBILIDADE

DISCUSSÃO SOBRE O SIGNIFICADO E A OBTENÇÃO DOS
PARÂMETROS $J$ E $G_{\mathrm{T}}$

PARTICULARIZAÇÃO DE $G_{\mathrm{T}}$ PARA O CASO DE UMA CHAPA DE ESPESSURA 
5 O MÉTODO DOS ELEMENTOS DE CONTORNO APLICADO AO CÁLCULO

DA INTEGRAL $J$ E DO PARÂMETRO TERMODINÂMICO DE FRATURA

ESQUEMA TEÓRICO PARA A DETERMINAÇÃO APROXIMADA DE $G_{\mathrm{T}}$ NO ESTADO PLANO DE DEFORMAÇÃO

OBTENÇÃO DA(S) DIREÇÃO(ÇÕES) SEGUNDO A(S) QUAL(AIS)

A FISSURA VAI AVANÇAR

OBTENÇÃO APROXIMADA DA INTEGRAL $J$ NO ESTADO PLANO

DE DEFORMAÇÃO

O MÉTODO DOS ELEMENTOS DE CONTORNO BEM APLICADO A PROBLEMAS

BIDIMENSIONAIS DE ELASTICIDADE

A técnica de subelementação

A integração numérica no subelemento

A APLICAÇÃO DO MÉTODO DOS ELEMENTOS DE CONTORNO

AO PROBLEMA DA FRATURA

\section{ASPECTOS EXPERIMENTAIS E NORMATIVOS SOBRE PARÂMETROS} DE FRATURA

ENSAIOS PARA AS MEDIDAS DA INTEGRAL $J$ E DO CTOD

OUTROS ENSAIOS PADRONIZADOS

OS PROCEDIMENTOS NORMATIVOS MAIS RECENTES DE ENSAIOS

SUGESTÃO DE EXPERIMENTO PARA A DETERMINAÇÃO DO PARÂMETRO TERMODINÂMICO CRÍTICO $\gamma_{\mathrm{E}}$

\section{FUNDAMENTOS MATEMÁTICOS}

ELEMENTOS DE ÁLGEBRA E DE ANÁLISE TENSORIAL

Tensores

DIFERENCIAÇÃO

GRADIENTE E DIVERGÊNCIA

TEOREMA DA DIVERGÊNCIA (GAUSS)

TEOREMA DA LOCALIZAÇÃO

DERIVAÇÕES MATERIAIS NO TEMPO

ANÁLISE DE SENSIBILIDADE À MUDANÇA DE FORMA DO DOMÍNIO

Cálculo de $u$ no caso em que vé arbitrado como uma translação dos pontos 


\section{PREFÁCIO}

Excelente iniciativa do Prof. João Augusto de Lima Rocha. Faltam-nos textos elaborados por autores brasileiros que além da exposição do tema central coloquem-nos imersos na nossa cultura científica e tecnológica. Isto é, apresentem o assunto com o contorno da nossa própria formação e construção da ciência e tecnologia cuja individualidade é rica e certamente necessária para apresentar os pontos de vista que nos distinguem, contribuindo para o avanço do conhecimento universal. Traduzir um livro tem sem dúvida seu valor, mas a tradução fica sempre imersa no ponto de vista do autor e nunca do tradutor. Tradução cabe mais em situações em que o assunto ainda encontra-se imaturo na comunidade científica e tecnológica.

Ressalto este primeiro aspecto, com grande satisfação, porque está claro no texto o reflexo da formação do autor ao longo de sua vida acadêmica, desde os tempos de estudante até sua atuação como pesquisador e professor na UFBA. O fio condutor que orienta a ênfase dada aos diversos temas que se distribuem nos sete capítulos reflete claramente a nossa tradição já emergente na área de mecânica dos sólidos.

$\mathrm{O}$ tratamento do tema introduz aspectos originais com o enfoque da mecânica da fratura no contexto da termodinâmica do contínuo. A facilidade com que o autor trata do ferramental matemático e computacional agrega à física do problema particular elegância. O uso da análise de sensibilidade permitiu o cálculo apurado do parâmetro $G_{t}$ que é termodinamicamente consistente e oferece informação complementar a outros fatores introduzidos por outros autores.

O texto é claro e o autor teve o cuidado de apresentar os aspectos mais fundamentais da física do problema bem como do ferramental analítico permitindo uma leitura relativamente fácil. O desenvolvimento da teoria da fratura desde os primeiros trabalhos importantes de Griffith até os recentes resultados mais importantes dão uma consistência histórica que auxilia no melhor entendimento do fenômeno. Os exemplos são bem-vindos, completando os resultados teóricos com segurança.

A mecânica da fratura vem se tornando um dos pontos críticos nos projetos de estruturas para as mais variadas utilizações. O desenvolvimento de novos materiais, particularmente os não homogêneos, exige a análise da vida útil e dos diversos riscos que podem levar uma estrutura ao colapso sendo a progressão da fratura um importante fenômeno que necessita de análise cuidadosa. O livro do Prof. Lima Rocha é um ótimo texto, tanto para 
estudantes de Engenharia como para engenheiros encarregados do projeto de estruturas que exigem alto grau de confiabilidade, como as que estão presentes em aeronaves, plantas nucleares, navios e outros veículos, para dar alguns exemplos.

Não posso encerrar estas palavras introdutórias sem externar minha imensa satisfação de ver um dos meus estimados ex-alunos contribuindo significativamente para o progresso da Engenharia brasileira, agregando conhecimento verdadeiramente autônomo a um setor de capital importância para a prática da Engenharia. Que este exemplo possa ser imitado por tantos outros professores e pesquisadores, demonstrando a maturidade a que chegamos na área de Engenharia.

Finalmente devo dizer que este livro é de certa forma a história da vida acadêmica do Prof. João Augusto de Lima Rocha (o João Menino dos velhos tempos) e em menor escala da minha própria.

Obrigado João, por ter escrito este livro.

Luiz Bevilacqua

Outubro de 2009. 


\section{APRESENTAÇÃo}

A mecânica da fratura é um campo científico de grande relevância, hoje em dia, atestado pela quantidade de abordagens distintas do problema crucial da caracterização do limite último de resistência dos sólidos. Tem seu começo na década de 1920, quando A. A. Griffith formulou o primeiro critério de iniciação do processo de fissura nos sólidos.

A repercussão do trabalho de Griffith, então engenheiro e pesquisador da empresa inglesa Rolls-Royce, deu-se por ter sido ele o responsável pela introdução de um material composto, ou compósito, que ainda tem importante presença no cenário da construção: a fibra de vidro.

Além da repercussão tecnológica que causou, o trabalho de Griffith teve o mérito de examinar o problema da fratura utilizando, mesmo que não explicitamente, a primeira lei da termodinâmica (ou lei de conservação da energia). A interpretação, posterior, segundo a qual o critério de fratura resultante de sua abordagem do problema, levava em conta a primeira lei, acabou por abrir a perspectiva de continuidade e refinamento de sua pioneira pesquisa, o que agora se intenta.

A despeito de ter experimentado um desenvolvimento bastante extenso, com a abertura de vasto campo de aplicações tecnológicas dispersas nas Engenharias Mecânica, de Minas, Civil, Metalúrgica, Naval e Aeroespacial, a mecânica da fratura ainda necessita de fundamentação teórica mais unificadora, o que abriu oportunidade para o tipo de investigação desenvolvida na presente obra.

O aperfeiçoamento da ideia de Griffith, com a inclusão da segunda lei da termodinâmica no estudo da fratura, configura a, assim chamada, teoria termodinamicamente consistente, objetivo principal deste trabalho. Além da consistência com a primeira e com a segunda lei, cuja construção está fundada em extensa utilização da mecânica do contínuo no estudo da fratura, aqui desenvolvida em todos os seus detalhes, busca-se utilizar ferramentas recentes, tais como a análise de sensibilidade e o método dos elementos de contorno, na busca de facilitar a criação de um novo critério de iniciação da fratura.

A iniciativa da aproximação entre a mecânica da fratura, a termodinâmica, a mecânica do contínuo, a análise de sensibilidade e o método dos elementos de contorno, tomada no presente trabalho, contribuiu para o refinamento dos instrumentos teóricos e numéricos de análise, com um objetivo bem delineado: atacar o problema da fratura, a partir da busca de uma alternativa à hipótese introduzida por Griffith, segundo a qual seria legítima a aplicação 
do princípio da mínima energia potencial total à interpretação de um fenômeno essencialmente dissipativo, como o da fratura. Quando se imagina que, além de Grifith, Irwin e Rice também desenvolveram suas importantes concepções a partir da ideia de energy release rate - maltraduzida por taxa de dissipação de energia, calculada como a derivada diferença entre a energia potencial elástica, antes e depois do processo de avanço da fratura, em relação a um parâmetro geométrico da fissura -, percebe-se que o presente trabalho contribui, de fato, com novos elementos para a discussão dos fundamentos do problema em estudo.

Embora a proposta de uma teoria termodinamicamente consistente da fratura não seja original, alguns resultados aqui apresentados o são. Dentre eles, destaca-se a obtenção da equação geral do balanço termomecânico local, nos pontos da superfície de avanço de uma fissura, resultado que decorre da ideia de utilizar-se, diretamente, a definição da integral de Riemann para a obtenção de derivadas materiais no tempo. Também parece ser uma contribuição original a aplicação da função energia livre de Helmholtz para chegar-se a um critério de iniciação de fratura, no caso quase estático e isotérmico, trilhando-se um caminho semelhante ao de Griffith.

Dentre outras contribuições trazidas pelo presente trabalho, destacam-se, no campo teórico: 1) A forma de utilização do método dos elementos de contorno, tanto para o cálculo da integral $J$ quanto do novo parâmetro termodinamicamente consistente, $G_{\mathrm{t}}$, e 2) A utilização da análise de sensibilidade no cálculo desse último parâmetro.

Embora não se trate de um trabalho de caráter experimental, aqui se destaca a proposta de um ensaio de laboratório para a determinação do valor crítico de $G_{\mathrm{t}}$, com o auxílio de extensômetros elétricos de resistência [strain gages], que poderá levar, no futuro, à elaboração de procedimentos de normalização.

A percepção de que a energia livre de Helmholtz pode ser utilizada, no caso particular do regime isotérmico, para o estudo da iniciação e do avanço de uma fissura, ao estilo da análise de Griffith, forneceu uma saída importante para a obtenção do parâmetro termodinâmico $G_{\mathrm{t}}$, útil à construção de um novo critério de previsão do avanço da fissura e da direção desse avanço.

Embora o recurso à mecânica do contínuo tenha sido fundamental para o embasamento das conclusões práticas que emergiram ao final, é certo que só os problemas em regime quase estático e isotérmico foram satisfatoriamente abordados, restando ainda os problemas dinâmicos e os não isotérmicos. No caso dos problemas não isotérmicos, o método a ser desenvolvido tende a ser bastante distinto do utilizado no caso isotérmico. Mas, 
certamente, a base foi construída. Acredita-se, assim, que o fundamento teórico encontra-se seguramente colocado e que a investigação de parâmetros experimentais capazes de permitir o estudo termodinamicamente consistente da fratura, também no caso não isotérmico, fica como proposta para a continuidade deste trabalho.

A utilização do método dos elementos de contorno como ferramenta numérica para a obtenção da integral $J$ e do parâmetro $G_{\mathrm{t}}$ revela-se bastante promissora, por conta de sua praticidade, na medida em que a obtenção de $G_{\mathrm{t}}$ (também a integral $J$ ) é praticamente um trabalho de pós-processamento, desde que sejam fornecidas as informações sobre as distribuições de tensões e dos gradientes de deslocamento, advindas de programas automáticos que não precisam ser, necessariamente, especializados em mecânica da fratura ou em elementos de contorno. Espera-se, no entanto, que a ideia da utilização do método dos elementos de contorno, tal como aqui é aplicada a problemas planos de fratura, possa ser estendida para os casos tridimensionais, placas e cascas, com a utilização de domínios de integração (no caso do programa automático aqui apresentado, o caminho é elíptico) tomados sobre as superfícies dos sólidos.

A organização do texto tem o objetivo de tornar a obra autocontida, o estritamente necessário para a compreensão do esboço da nova teoria sobre a fratura nos sólidos. Daí a exigência de uma introdução extensa, que busca dar conta das diversas formas atuais de ataque ao problema da fratura nos sólidos.

No capítulo 1, apresenta-se um apanhado dos conceitos básicos da termodinâmica aplicados à interpretação do processo de deformação que se desenvolve nos sólidos.

No capítulo 2, que contém a principal contribuição trazida pelo presente trabalho, desenvolve-se a pesquisa da possibilidade de extensão, ao caso da fratura, do balanço termomecânico típico da mecânica do contínuo, que permite a passagem das equações globais às equações locais, tanto nos pontos interiores quanto em pontos das superfícies de avanço das fissuras. $\mathrm{O}$ desenvolvimento apresentado nesse capítulo é uma alternativa àquele proposto por Zhang e Karihaloo (1993), baseado no teorema de transporte de Reynolds. Optou-se por um novo caminho para chegar a uma forma geral da equação de balanço local, válida para cada ponto das superfícies de avanço das fissuras. De posse desse resultado, partiu-se para a interpretação, uma a uma, das cinco equações locais. Assim, conseguiu-se preencher algumas lacunas existentes no trabalho há pouco citado.

O capítulo 3 centra-se na busca de conexão entre o método ora proposto e aquele sugerido por Griffith $(1921,1924)$, cujo conhecido critério de iniciação da fratura tem a limitação de somente considerar a conservação da energia (primeira lei da termodinâmica) em 
sua fundamentação. Assim, realizou-se o exercício de interpretar termodinamicamente o critério de Griffith, agregando-se a primeira e a segunda lei, no exame do caso particular em que o fenômeno se dá, por hipótese, em regime quase estático e isotérmico. Daí, chegou-se a uma explicação sobre a razão pela qual o original critério de Griffith não dá conta, completamente, do fenômeno.

No capítulo 4, apresenta-se a potente ferramenta matemática cuja utilização facilita a generalização, até para os casos de problemas tridimensionais, tanto do cálculo da integral $J$, de Rice (1968), quanto da obtenção do parâmetro termodinâmico de fratura sugerido no presente trabalho. Trata-se da análise de sensibilidade à variação de forma do domínio, um campo de estudo cujas aplicações tradicionais encontram-se na área da otimização estrutural, mas que foi adaptado com sucesso à mecânica da fratura, principalmente por Taroco (1996).

No capítulo 5 desenvolve-se, com o auxílio do método dos elementos de contorno boundary element method $(B E M)$-, uma aplicação simples que permite a programação automática do esquema de cálculo aproximado, tanto do parâmetro termodinâmico quanto da integral $J$. Trata-se do clássico problema da chapa contendo um entalhe. O programa automático, denominado Elcfrat, em linguagem Fortran, desenvolvido com base no conteúdo desse capítulo, utiliza um elemento de contorno retilíneo, isoparamétrico, com interpolação linear, subelementação automática e a possibilidade de colocação de nós duplos. Não é propósito desse capítulo fornecer uma descrição minuciosa do $B E M$, na medida em que é uma ferramenta numérica cuja fundamentação exige rigor. Espera-se, no entanto, que o leitor possa captar o essencial, que é o fato de ser o $B E M$ bastante adaptado à natureza própria do problema da fratura.

No capítulo 6 discorre-se sobre a análise experimental na mecânica da fratura, destacando-se os métodos correntes de ensaio, basicamente aqueles propostos pela American Standard for Testing and Materials (ASTM) para os aços. Apresenta-se, também, o esboço de uma proposta original de ensaio de laboratório que, em associação com a experimentação numérica, realizada sobre um modelo do mesmo corpo de prova ensaiado, poderá fundamentar o critério de fratura baseado no valor crítico do parâmetro termodinamicamente consistente de fratura, aqui sugerido.

No capítulo 7 apresentam-se, sumariamente, alguns resultados da álgebra e da análise tensorial úteis aos desenvolvimentos matemáticos realizados nos capítulos anteriores. Além disso, inclui-se uma revisão dos conceitos básicos da mecânica do contínuo, sobre a aplicação deformação e sobre a derivação material no tempo, além de uma apresentação da análise de sensibilidade, tal como se aplica ao problema da fratura. 
Finalmente, no apêndice A, encontra-se uma rápida descrição do programa automático Elcfrat através do qual a experimentação numérica pode ser realizada, com a utilização do BEM. Também são apresentados exemplos de aplicação da programação automática a problemas reais, junto com a análise desses resultados, incluindo-se a comparação, para um mesmo problema retirado da literatura, entre a solução obtida pelo método dos elementos finitos (MEF) a aquela que aqui se obtém, através do BEM. 


\section{INTRODUÇÃO}

Já foi observado que as tentativas anteriores de interpretação do fenômeno da fratura nos sólidos padecem de inconsistência termodinâmica, isto é, são elas organizadas sem que se considerem, no processo de sua construção, a primeira e a segunda lei da termodinâmica, conjuntamente. Diante desse vazio, o que aqui se pretende é dar os passos iniciais para a organização de uma teoria termodinamicamente consistente da fratura. Naturalmente, poderia ser sugerido que, antes desta iniciativa, fosse examinado o importante aspecto microscópico no fenômeno da ruptura de um corpo sólido. Seria uma interpretação do ponto de vista local, como se a iniciação da fratura representasse o começo do afastamento do corpo de uma configuração estável de equilíbrio, isto é, o processo estaria colocado diante de uma bifurcação que o obrigaria, por assim dizer, a escolher, em certo instante, um dos ramos possíveis para a evolução do processo de deformação.

No entanto, sem que se desconsidere a importância de tal aspecto na compreensão do fenômeno da fratura, o fundamento para a formulação da teoria termodinamicamente consistente será buscado através da idealização macroscópica, auxiliada pela termodinâmica, em que corpo é considerado contínuo, e o processo de fissuração é entendido como resultante da evolução de superfícies, também contínuas, imersas no interior do sólido.

A ideia chave da termomecânica do contínuo clássica é a passagem das cinco equações de balanço global - massa, quantidade de movimento linear, quantidade de movimento angular, energia, princípio da irreversibilidade ou desigualdade de ClausiusDuhem -, tomadas como axiomas, para as respectivas equações locais, nos pontos interiores do sólido. A novidade está em examinar-se a possibilidade da extensão desse procedimento ao caso de um sólido contendo vazios, isto é, fissuras, cujas superfícies internas possam evoluir, podendo nelas estar presente uma componente irreversível nos deslocamentos dos pontos dessas superfícies.

Embora a proposta de tratamento do fenômeno da fratura aqui apresentada seja de caráter essencialmente teórico, inclui-se no texto, de passagem, a sugestão da verificação de sua validade prática, com o auxílio de um método que associa experimentação de laboratório a experimentação numérica, porém restrita a problemas isotérmicos.

Para evitar dubiedade na aplicação de dois termos que aparecem com bastante frequência no contexto do estudo do fenômeno aqui examinado, e que, na língua portuguesa, costumam ter aplicação ambígua, define-se: 
Fratura (fracture), como o fenômeno, em geral irreversível, caracterizado pelo crescimento das áreas das superfícies internas dos vazios de um sólido em processo de deformação.

Fissura, como um ente cuja extensão física é caracterizada somente pela medida de sua fronteira. A medida de seu crescimento é dada pelo acréscimo da área de sua fronteira, ocorrido no processo de fratura. É nesse sentido que ela se identifica com o vazio. O valor da área da superfície de uma fissura é sempre, por hipótese, diferente de zero, isto é, toda fissura é resultante da evolução de uma situação inicial, caracterizada por um vazio preexistente. Existem fissuras que ficam totalmente imersas no interior do sólido (cracks), e outras que adentram a partir da fronteira do sólido (notches).

As características essenciais da teoria termodinamicamente consistente da fratura são:

1) A parcela de energia dissipada nas superfícies de avanço das fissuras deve ser considerada, para efeito de balanço;

2) Associada ao processo de avanço de uma fissura, incluída em uma parte arbitrária do sólido, aparece uma grandeza, a densidade termodinâmica superficial de fratura, que é definida em cada ponto da superfície de avanço. Com o auxílio dessa grandeza podese aferir como o acoplamento de influências entre a temperatura absoluta e a velocidade de propagação influencia na estabilidade do processo de fissuração;

3) No caso do regime quase estático e isotérmico verifica-se a emergência de uma grandeza, denominada parâmetro termodinâmico de fratura, cuja determinação, através da análise de sensibilidade, decorre da consideração das leis da termodinâmica.

- Modelo físico

a) Tal como na mecânica do contínuo, parte-se do pressuposto que, para um sólido sujeito à fratura, sempre são atendidas as cinco equações termomecânicas de balanço global, inclusive nos pontos das superfícies de avanço das fissuras; a primeira e a segunda leis da termodinâmica fornecem a base para a construção de um critério de fratura termodinamicamente consistente; 
b) No caso particular em que o regime de deformação é quase estático e isotérmico, o processo termodinâmico só progredirá, espontaneamente, entre dois estados, se a função energia livre de Helmholtz (para todo o sólido) sofrer um decréscimo, de um estado para o outro;

c) O crescimento das fissuras é, em geral, irreversível, embora a simples ocorrência de um decréscimo na função energia livre de Helmholtz não seja condição suficiente para indicar que tenha sido provocado pelo avanço de uma fissura. $\mathrm{O}$ decréscimo da energia livre de Helmholtz é, pois, uma condição necessária, mas não suficiente, para a ocorrência de fissuração no sólido. Isto porque podem ocorrer outros fenômenos dissipativos durante a deformação dos sólidos, tais como a plasticidade e o dano;

d) A evolução do processo de fissuração pode ser modelada tal como se estivesse ocorrendo uma sequência de iniciações de fratura, após cada uma das quais o domínio do problema precisará ser atualizado

- Modelo matemático

a) Ditado pela física do problema, esse modelo busca acompanhar, nas sucessivas representações atualizadas do corpo, a interação contínua entre fenômenos que ocorrem no $I R^{3}$ (pontos interiores não atingidos pela fissuração) e outros que ocorrem, simultaneamente, no $I R^{2}$ (superfícies de avanço das fissuras);

b) A alternativa à ideia de energy release rate, devida a Griffith e Irwin, será o parâmetro termodinâmico de fratura, calculado como sendo a derivada material da energia de deformação do sólido em relação a um parâmetro geométrico de fratura. A análise de sensibilidade à variação de forma, da otimização estrutural, será utilizada como ferramenta, no cálculo dessa derivada.

Como orientação básica para a abordagem do problema da iniciação da fratura nos sólidos foram examinadas detalhadamente, na fonte, as publicações tidas como fundamentais no estudo da fratura, a partir do trabalho pioneiro de Griffith (1921). E a pesquisa do instrumental adequado aos objetivos propostos exigiu um aprofundamento teórico geral nos campos da mecânica do contínuo, da análise de sensibilidade e dos métodos numéricos da física matemática, com destaque para o método dos elementos de contorno (BEM). 


\section{Síntese histórica}

Visando prever o limite da capacidade resistente dos materiais, busca-se compreender, desde os primórdios, o mecanismo do rompimento das ligações interiores, responsável pela perda da integridade dos corpos sólidos submetidos a ações externas.

Se se acompanha a evolução dos procedimentos utilizados nesse tipo de previsão, na fase mais recente da história, marcada pela aplicação do conhecimento científico à compreensão dos fenômenos da resistência dos materiais, verifica-se que Galileo Galilei (1564-1642) foi o pioneiro nesse terreno. Tido como um dos precursores da mecânica dos sólidos, Galilei (1945) destaca em sua obra Diálogos acerca de duas novas ciências, a preocupação com "a coerência das partes nos corpos sólidos" e com a "resistência dos sólidos à fratura", temas sobre os quais desenvolve a conversação entre os personagens Salviati, Sagredo e Simplício nas duas primeiras jornadas de seu famoso livro. Aí apresenta proposições que já revelam uma clara compreensão dos mecanismos da resistência dos materiais, alimentada certamente pela necessidade prática imediata de resolver os problemas surgidos nas atividades de projeto e construção, que então desenvolvia no Arsenal de Veneza. A ênfase de Galilei foi colocada na busca da resistência à fratura, isto é, na obtenção de informações sobre a capacidade resistente do material no momento da ruptura.

Diferente foi a orientação decorrente das experiências de Robert Hooke (1635-1703) com molas. Baseado na analogia que intuiu entre elas e o comportamento dos materiais, Hooke levou a então incipiente mecânica dos sólidos a optar pela hipótese da linearidade da relação força $x$ deslocamento nas peças e estruturas, cujo reflexo é evidente na simplificação dos modelos para o estudo dos fenômenos dessa área. Isso parece ser a razão fundamental para o abandono da ênfase na questão da fratura, isto é, a resistência limite dos materiais, prevalecendo, até recentemente, a opção pelo limite elástico como referência básica no estudo do comportamento mecânico dos materiais.

Saint-Venant (1797-1886), com sua plasticodinâmica, deu os primeiros e seguros passos, segundo Timoshenko (1953), no sentido do desenvolvimento da teoria da plasticidade. E a ele se seguiu um grande número de contribuições relevantes, levando a que se reforçasse a volta à ênfase original de Galilei, centrada no comportamento limite dos materiais, a partir da década de 20 do século passado. Dentre elas, a contribuição de Griffith $(1921,1924)$, a quem se deve o início da mecânica da fratura.

É curioso verificar-se que a ideia fundamental, base para a retomada da ênfase na resistência limite de fratura, iniciada por Griffith, decorre do aproveitamento criativo de 
resultados da própria elasticidade linear, a saber, da análise de problemas sobre concentração de tensão em torno de reentrâncias e orifícios, divulgada num trabalho de Inglis (1913), inspirado em problemas práticos da indústria naval. A proposta teórica de Griffith parte do pressuposto de que não se criam fissuras no interior de um sólido, e sim que elas crescem a partir de vazios preexistentes. Assim, em seu modelo plano, a fissura é assimilada a um furo elíptico cujas dimensões lineares variam, no processo de deformação, de acordo com um único parâmetro, o comprimento $a$ do semi-eixo maior da elipse. Admitindo o carregamento externo constante, Griffith calcula $a$ variação da energia potencial elástica da chapa contendo o furo elíptico, quando $a$ aumenta para $a+d a$. Obtém, assim, a expressão $d U / d a$, que revela a sensibilidade da energia potencial elástica em relação à variação ocorrida no comprimento $a$, quando o tamanho do furo varia. A grandeza $G=d U / d a$, denominada mais tarde strain-energy release rate, é considerada, desde Griffith, um parâmetro-chave na caracterização do fenômeno da fratura. O problema, portanto, é reduzido à verificação da estabilidade de uma fissura.

Quando ocorre o crescimento da fissura, alguma quantidade de energia deve estar associada à área da superfície do furo acrescida nesse processo. Griffith propõe quantificar essa energia com base em um parâmetro que denomina densidade superficial de energia, que seria, segundo a sua compreensão, uma propriedade intrínseca do material. Em função dos resultados dessa análise concluiu que, se fosse possível uma intervenção no processo de produção do material, com o intuito de diminuir-se o tamanho médio dos vazios em seu interior, então a tensão limite de fratura poderia ser artificialmente aumentada.

Devido ao sucesso tecnológico representado pela síntese de um material de alta resistência - a fibra de vidro -, com base nessa ideia, foi que se deu a grande difusão do critério de iniciação de fratura proposto por Griffith. Ao diminuir as dimensões dos vazios no interior do vidro, Griffith conseguiu aumentar bastante o valor da tensão limite de ruptura desse material. Chegou a esse objetivo através da produção de finíssimas fibras que seriam depois aglomeradas em uma matriz de resina, para formar painéis de fácil moldabilidade e grande resistência. Em síntese, como consequência da formulação do critério que leva o seu nome, Griffith (1924) chamou atenção para o fato muito relevante de que a resistência do material não estava relacionada somente com a coesão entre as moléculas, mas, também, com os espaços vazios existentes entre elas. Assim, segundo ele, para bem caracterizar mecanicamente os materiais, não bastaria apenas o conhecimento dos limites de resistência, mas também a determinação experimental de alguma(s) grandeza(s) capaz(es) de dar conta da tenacidade, (toughness ou fracture toughness) do material, uma propriedade associada à 
capacidade do material de impedir o crescimento de fissuras em seu interior. Para isso seria fundamental, em um sólido sujeito a ações e a restrições a seu deslocamento, a determinação da denominada energy release rate. Na visão de Griffith, a comparação dessa grandeza com a tenacidade do material (uma característica associada à densidade superficial de energia $\gamma$ ) forneceria um critério para aferir a integridade mecânica do sólido.

Com o objetivo de estender a aplicação do critério de Griffith aos materiais dúcteis, Orowan (1952) sugeriu que, além da grandeza $\gamma$, deveria ser considerada mais outra, notada por $\gamma_{p l}$, que faria às vezes de uma espécie de componente plástica da densidade de energia superficial, servindo para corrigir o critério de Griffith nesses casos. A experiência mostra que tal parcela assume, de fato, valores muito maiores que $\gamma$. A rigor, a soma dos dois parâmetros produziria um valor crítico que seria uma característica do material. Assim:

$G_{\text {crit }}=2 \gamma+\gamma_{p l}$,

onde $G_{\text {crit }}$ serviria para caracterizar o material, sendo uma grandeza macroscópica capaz de permitir a ampliação das aplicações da mecânica da fratura à análise dos problemas correntes da engenharia estrutural, principalmente naqueles em que os materiais utilizados tivessem um comportamento predominantemente dúctil.

O passo seguinte ao de Griffith, no sentido do aperfeiçoamento da utilização da mecânica da fratura na caracterização da integridade dos sólidos e na síntese de novos materiais, deve-se a Irwin, e está baseado numa série de trabalhos por ele realizados na década de 1950. Embora tivesse o mesmo sentido da contribuição de Orowan (1950), que seria estender as possibilidades da mecânica da fratura para além do estudo dos materiais frágeis, a ideia central de Irwin (1957) conduz a uma nova interpretação da energy release rate, a qual, por possuir dimensão de força por unidade de área, permitiria ser por ele interpretada da seguinte maneira:

Quando a fissura cresce, alguma energia passa de mecânica (ou de deformação) para outras formas, na vizinhança da fissura. O processo é tal que predomina a energia calorífica. A grandeza G dá a medida dessa energia externa associada com a extensão unitária da fissura e pode ser considerada como a força tendente a causar o crescimento da fissura. (IRWIN, 1957, p. 363)

Utilizando as expressões das componentes de tensão e de deslocamento apresentadas por Westergaard (1939), Irwin analisa o caso de uma chapa de espessura unitária, em estado 
plano, através da aplicação da teoria das funções de variável complexa à elasticidade plana, sendo a(s) fissura(s) simulada(s) por segmento(s) de reta contido(s) no plano médio da chapa. Tal análise também facilitou a simulação geométrica de uma faixa com dimensões finitas, sendo apresentada, no citado trabalho de Irwin, a solução para um exemplo muito útil: uma faixa de comprimento infinito, porém com largura finita, submetida à tração uniforme aplicada no infinito.

O problema tratado por Irwin, embora sofrendo da mesma limitação do de Griffith, por situar-se no âmbito da elasticidade linear, revelou uma característica que passou a influenciar grandemente o estudo da fratura. Trata-se da observação da ocorrência de um tipo especial de singularidade nas componentes do tensor tensão, em problemas planos de fratura (da ordem de 1 , onde $r$ é a distância do ponto considerado à extremidade da fissura), evidenciada em todos os cinco exemplos apresentados no seu histórico trabalho (IRWIN, 1957).

Ora, se as expressões das componentes de tensão apresentam alguma parcela singular, então elas tendem para infinito quando $r$ tende para zero. No entanto, no tratamento matemático do problema só é possível trabalhar-se com as hipóteses da elasticidade linear enquanto as componentes de tensão estiverem abaixo do limite elástico. Isso conduz, portanto, a uma contradição, que só pode ser resolvida se forem excluídas do domínio do problema as zonas de acomodação plástica situadas próximas das extremidades das fissuras. A consideração dessas zonas passou a ser, então, um novo problema, porque elas só poderiam ser incluídas se o modelo constitutivo previsse a dissipação de parte da energia associada ao avanço das fissuras.

Irwin (1957) procurou fugir dessa exigência, mediante o seguinte raciocínio: se os deslocamentos calculados são da ordem de $\sqrt{r}$, então o trabalho empregado na abertura da fissura deverá ser finito, na medida em que é calculado através de uma integral cujo integrando envolve o produto de força (que teria o mesmo tipo de singularidade da tensão, isto é, $1 / \sqrt{r}$ ) por deslocamento, na vizinhança das extremidades das fissuras. É certo que isso eliminaria a singularidade, o que ele desejava, mas não eliminaria a existência de calor, por ele considerada inadequadamente, como trabalho reversível. Vê-se, portanto, que Irwin (1957) recorre à mesma simplificação de Griffith, cuja ideia de energia superficial equivale à de trabalho desenvolvido na zona próxima à extremidade da fissura. Isto quer dizer que, usando a elasticidade linear, Irwin intuiu um resultado que dá conta da plastificação local na vizinhança da extremidade da fissura, o que, a despeito de ser coerente com a sugestão de 
Orowan (1950), é inconsistente, do ponto de vista teórico, porque a produção de calor e sua dissipação durante o processo não poderia ser incluída, por deficiência intrínseca do modelo linear.

A partir da hipótese de que a região plastificada em torno da extremidade da fissura é muito pequena, Irwin (1957), introduziu os fatores de intensidade de tensão, $K_{\mathrm{I}}, K_{\mathrm{II}}$ e $K_{\mathrm{III}}$, grandezas-chave da chamada mecânica da fratura linear, que são os coeficientes das parcelas não-lineares presentes nos respectivos desenvolvimentos em séries que aproximam os valores das componentes planas do tensor tensão, em cada um dos três modos de fratura sugeridos por Irwin. Esses modos são denominados: de abertura $\left(K_{\mathrm{I}}\right)$, de deslizamento $\left(K_{\mathrm{II}}\right)$ e de rasgamento $\left(K_{\mathrm{III}}\right)$. Os fatores de intensidade de tensão estão funcionalmente relacionados com os respectivos valores da energy release rate associados aos três modos, e com o módulo de elasticidade, $E$, do material. Tais grandezas, segundo Irwin, seriam capazes de caracterizar, do ponto de vista da fratura, o estado de uma peça submetida a esforços, desde que a zona de acomodação plástica próxima à extremidade da fissura não tivesse extensão relevante. Segundo Irwin, a avaliação da integridade de um sólido contendo fissuras seria feita mediante a comparação entre tais grandezas, calculadas para determinada configuração de ações aplicadas e deslocamentos prescritos no contorno do sólido, e os respectivos valores críticos, $K_{\text {Ic }}, K_{\text {IIc }}$ e $K_{\text {IIIc }}$, determinados experimentalmente.

Segundo Knott (1993), a contribuição de Irwin deu vez ao surgimento da Engenharia da Fratura, enquanto Griffith seria, para ele, o criador da Ciência da Fratura. No entanto, como antes aqui foi dito, a introdução dos fatores de intensidade de tensão, por Irwin, faz uso da mesma base física utilizada por Griffith, isto é, o recurso à elasticidade linear, que não resolve a questão do caráter irreversível do fenômeno da fratura. A diferença dos dois enfoques está somente em que, para simular a fissura, Irwin substituiu o orifício elíptico, usado no modelo de Griffith, por um segmento de reta, tirando daí conclusões sobre a interpretação da energy release rate como sendo uma força por unidade de área da superfície de avanço da fissura. Embora possa parecer que os valores críticos dos $K^{r} \mathrm{~s}$, os fatores de intensidade de tensão, obtidos experimentalmente, sejam capazes de caracterizar os materiais, do ponto de vista da fratura, diferentemente da grandeza densidade de energia superficial de Griffith, isso não é verdade, pelo fato de que a determinação experimental dos fatores críticos depende de uma série de variáveis, tais como a escala da peça ensaiada e outras grandezas relacionadas com o meio ambiente.

Uma importante vertente teórica na interpretação do fenômeno da fratura deve-se à chamada Escola Russa, liderada por G. I. Barenblatt, que, entre 1959 e 1961, apresentou uma 
série de trabalhos nos quais elabora um princípio geral (válido, segundo ele, para uma série de fenômenos da mecânica do contínuo), aplicável particularmente ao fenômeno da fratura. Em sua interpretação, busca adaptar a ideia de Griffith à consideração de aspectos microscópicos do fenômeno presentes nas extremidades das fissuras. O princípio é baseado, segundo seu autor, na formulação de hipóteses físicas fundadas em observações experimentais capazes de assegurar a unicidade da solução de problemas dependentes de parâmetros.

No caso da mecânica da fratura, a busca de tais hipóteses físicas teria, segundo Barenblatt (1960), a finalidade de assegurar a finitude das tensões nas extremidades das fissuras. Tais ações caracterizariam um efeito coesivo capaz de produzir uma variação gradual da tensão em uma minúscula zona especial de interação entre as duas faces da fissura, próxima à extremidade. A exigência da finitude da tensão induziria, segundo ele, à necessidade de uma concordância tangencial entre as duas faces, na extremidade da fissura, conformando algo com o aspecto de uma cúspide. É importante observar, também, que outra das preocupações de Barenblatt (1960) é a formulação de uma mecânica da fratura capaz de dar conta da pressão de fluidos no interior de maciços rochosos fissurados. Essa exigência de concordância tangencial entre as faces nas extremidades da fissura também estaria relacionada com suas observações experimentais nesse campo (BARENBLATT, 1959, 1960, 1964).

A contribuição de Barenblatt (1960) lança novos elementos à discussão sobre o caráter do fenômeno da fissuração, se reversível ou irreversível. Conhecedor que era das contribuições de Westergaard e de Irwin a respeito das distribuições de tensão e de deslocamento, típicas dos modelos matemáticos do problema de fratura, introduz fatos exteriores à teoria da elasticidade, a saber, a interação material ao nível microscópico, nas extremidades de fissuras, para justificar a reversibilidade. Não há dúvida de que o aproveitamento de suas ideias na formulação de modelos adequados a materiais caracterizados pela grande presença de micro-fissuras, durante a evolução do fenômeno da fratura, permitiu o desenvolvimento paralelo de uma interpretação que associa a reversibilidade do processo ao comportamento coesivo do material na vizinhança das extremidades de fissuras.

Essa interpretação deu origem a modelos, aplicados principalmente ao concreto, dentre os quais se destaca o da fissura fictícia, assim denominado por seu principal autor, Hillerborg, para quem: 
do crescimento de fissuras, pode também ser usado para a análise da formação de fissuras. (HILLERBORG, 1991, p. 97)

Isto significa a introdução de uma hipótese essencialmente distinta da tradicional (devida a Griffith) que não admite a possibilidade de a fissura surgir no sólido, só podendo crescer a partir de um vazio preexistente. Afirma ainda Hillerborg (1991), no artigo antes citado: "Como uma fissura real não pode transferir tensão entre suas faces, a fissura que admite transferência de tensão foi chamada de físsura fictícia - daí o nome do modelo". E continua:

\begin{abstract}
A expressão modelo de fissura fictícia tem sua origem derivada nas aplicações do método dos elementos finitos onde tem sido adotado, nas quais não se admite nem fissura fictícia nem zona de fissuração infinitamente estreita, adotando-se, no entanto, que a deformação adicional ocorrida dentro da zona de fissuração tem de ser considerada como derivada de uma relação tensão-deslocamento. (HILLERBORG, 1991, p. 97)
\end{abstract}

Pelo que se percebe, o modelo da fissura fictícia parece ficar mais adequadamente incluído em outro campo da mecânica dos materiais, a saber, a mecânica do dano, segundo a qual a interpretação do fenômeno da fratura ganha sentido enquanto considerado em sequência, no processo deformação dos sólidos, desde a situação de total integridade até a ruptura, que, em geral, inicia-se pelo comportamento elástico, passa pelo plástico (ou elastoplástico), a este se seguindo o regime de dano e, finalmente, o de fratura. A passagem do regime de dano para o de fratura decorreria da exaustão de um estado de microfissuração distribuída (dano), a partir do qual ocorreria a localização do fenômeno em uma região limitada do sólido, na qual se instalaria uma macro-fissura preferencial, caracterizadora da bifurcação do equilíbrio local, gerando uma bem determinada porção amolecida do material, por onde a ruptura, finalmente, teria curso (LEMAITRE; CHABOCHE, 1990).

A partir da década de 1960 as investigações no campo da mecânica da fratura intensificam-se bastante, estendendo-se para uma ampla gama de materiais, que vai dos metálicos aos derivados de polímeros, passando pelos compósitos, particularmente o concreto. O desenvolvimento ocorreu segundo duas principais vertentes: a primeira, no campo experimental, que se orienta para a pesquisa de parâmetros caracterizadores, e sua consequente determinação em laboratório, visando à quantificação da tenacidade dos materiais. Nesse particular, destacam-se os métodos da ASTM para a determinação de valores críticos dos fatores de intensidade de tensão em materiais metálicos, e o método normalizado pela Réunion Internationale des Laboratoires d'Éssais et de Recherches sur les Matériaux et 
des Constructions (RILEM), para a determinação da energia de fratura, aplicada ao concreto. A segunda vertente é a da pesquisa de métodos numéricos, visando à determinação aproximada de parâmetros caracterizadores da iniciação e da evolução do fenômeno da fratura. Tais parâmetros estão relacionados, seja com o método de Irwin (1957), dos fatores de intensidade de tensão, seja com o método de Rice (1968), através da integral J, uma grandeza que resulta da adoção de um modo conveniente de integração de certa função de tensões, cujo resultado leva a que a integral se torne independente do caminho.

$\mathrm{Na}$ aplicação de métodos numéricos ao cálculo aproximado dos fatores de intensidade de tensão ou da integral $J$ destaca-se a utilização do $M E F$. Mais recentemente, a partir da década de 1980, no entanto, o BEM passou a ser também aplicado intensamente. As principais contribuições nesse campo estão sintetizadas em Venturini (1995a, 1995b).

Um dos mais difíceis problemas da mecânica da fratura é a obtenção, por via analítica, da energy release rate, particularmente porque, para ser feita de forma direta, é necessário o conhecimento da expressão que forneça a energia potencial total do sólido fissurado, em função de parâmetros de fissura. Em geral, os métodos da mecânica da fratura partem da análise da evolução de um vazio preexistente em que uma dimensão característica das fisuras é tomada como variável.

Tal dificuldade pode ser superada, mesmo que para um número ainda limitado de casos, através do cálculo da grandeza denominada integral $J$, mediante a integração realizada sobre qualquer contorno regular que circunde uma região em que a extremidade de fissura esteja situada em seu interior. O método da integral $J$ foi inspirado, segundo revela seu próprio criador, J. Rice (1968), na componente estática do tensor momentum energia, uma grandeza introduzida por Eshelby (1956) para caracterizar forças generalizadas atuando sobre discordâncias e defeitos pontuais em meios elásticos. O significado físico dessa integral (originalmente com dimensão de $\mathrm{J} / \mathrm{m}^{2}$ ) é, segundo Rice, o de uma grandeza associada ao estado médio da deformação na vizinhança da extremidade da fissura. Além disso, possui a seguinte propriedade: se realizada em qualquer contorno de um meio contínuo não contendo fissura passível de avançar, o valor da integral $J$ é nulo.

Recentemente, a aplicação da integral Jganhou engenhoso suporte matemático, com o qual é possível identificá-la com a energy release rate - o mesmo que a derivada da energia potencial total em relação a certo parâmetro geométrico de fratura -, sem que seja necessário conhecer-se uma expressão explícita dessa energia em função do parâmetro de fratura (TAROCO, 1996). Isso está baseado em uma adaptação da análise de sensibilidade à variação de forma do domínio e da fronteira do sólido ao problema da fratura. Com o auxílio dessa 
técnica, advinda da otimização estrutural, pode-se construir um modelo teórico do problema da fratura a partir da analogia deste com o problema da deformação (mecânica do contínuo), num caso em que se considera que a evolução da fissura configura uma variação de forma do domínio e do contorno do sólido. Isto permite que o cálculo da integral $J$ seja feito na configuração atualizada do sólido, na qual o parâmetro que controla a variação do domínio e do contorno do sólido torna-se nulo. Segundo essa interpretação, a integral $J$ pode ser calculada com o auxílio da derivada material da energia potencial elástica associada ao sólido fissurado, em relação a um parâmetro que tem a propriedade de poder simular uma especial alteração geométrica do domínio e da fronteira do sólido. Isso consiste, em suma, na simulação de um movimento relativo entre a fissura que avança e a fronteira distante de uma região que contém essa fissura, que se aproxima. Foi com o auxílio dessa ferramenta que se tornou possível, mesmo que somente para problemas isotérmicos (no presente trabalho), chegar-se a algum resultado numérico que serve para aquilatar a potencialidade prática do desenvolvimento teórico aqui intentado.

O objetivo principal deste trabalho é contribuir para a formulação de uma teoria termodinamicamente consistente da fratura, a partir da qual se busca construir uma base para a elaboração de critérios de iniciação e de propagação de fissuras. Para isso, utiliza-se a análise de sensibilidade, particularizada para o problema da fratura, como instrumento útil à construção de um esquema de resolução numérica aproximada do problema.

Inicialmente, estabelecem-se as condições para a aplicação dos princípios da mecânica do contínuo à mecânica da fratura, propondo-se a introdução, em cada uma das cinco equações clássicas do balanço termomecânico global, de uma parcela nova, referente ao que ocorre na superfície de avanço das fissuras. Aparece, então, em decorrência da operação de passagem da equação de balanço global da energia para a correspondente equação local, nos pontos da superfície de avanço da fissura (ROCHA; VENTURINI, 1997), um critério termodinâmico generalizado de fratura.

$\mathrm{Na}$ sequência, adotando-se o método de Griffith (mais em sua forma do que no conteúdo) faz-se a utilização da análise de sensibilidade para chegar-se a um critério de fratura válido para casos em que o processo é quase estático e isotérmico. Já orientando para o uso do $B E M$, obtém-se a variação da energia de deformação do sólido fissurado, que pode ser reduzida a uma função definida na fronteira regular, por partes, de uma região interior arbitrária contendo a extremidade de uma fissura iniciada no contorno do sólido. É um procedimento em tudo semelhante ao desenvolvido por Taroco (1996) para o caso do cálculo 
da integral $J$; só que, naquele caso, como já se disse, foi utilizada a energia potencial total, e não a energia potencial elástica ou de deformação, tal como aqui é feito.

A opção de método aproximado para o cálculo do novo parâmetro, alternativo à integral $J$, aqui denominado parâmetro termodinâmico de fratura $G_{\mathrm{t}}$ recaiu sobre o BEM. A opção de realizar-se o cálculo automático, tanto desse parâmetro quanto da integral $J$, obedeceu ao interesse da comparação com resultados existentes na literatura sobre essa última grandeza, através do MEF, particularmente os obtidos por Cunha et al. (1995), que também utiliza o recurso da análise de sensibilidade aplicada à mecânica da fratura.

No caso da fratura frágil, à semelhança do que ocorre com a fadiga e com o impacto, manifesta-se a dependência do fenômeno à escala, isto é, ao tamanho (volume) do sólido. Uma discussão sobre esse fato foi realizada com o apoio da interpretação estatística fundada na conjectura conhecida como hipótese do elo mais fraco, introduzida no estudo da resistência dos materiais por Weibull (1939). Baseado na hipótese do caráter aleatório da resistência, ponto a ponto, nos sólidos, Weibull mostrou que, para um dado material, se são feitas duas séries de ensaios de tração, em corpos de prova com os volumes $V_{l}$ e $V_{2}$, respectivamente, os correspondentes valores da resistência última obedecem à seguinte relação:

$\frac{\left(\sigma_{u l t}\right)_{1}}{\left(\sigma_{u l t}\right)_{2}}=\left(\frac{V_{2}}{V_{1}}\right)^{1 / m}$

onde $m$ é uma constante do material, qualquer que seja o tamanho dos corpos de prova. Os experimentos sugeridos por Weibull (1939) foram realizados por Davidenkov (1947), que obteve resultados bastante concordantes com a teoria.

Uma abordagem recente e promissora do problema da fratura busca recuperar essa importante contribuição de Weibull. A chave dessa vertente é a articulação do comportamento local, na vizinhança da extremidade da fissura, com o comportamento à distância, medido em um caminho situado no interior do sólido contendo a fissura, com auxílio da integral $J$.

Enfatizada por Beremin (1983), Minami e colaboradores (1992), Rugggieri e Dodds (1996a 1996b), o essencial dessa abordagem parte da constatação de que os problemas práticos de verificação da integridade de componentes de estruturas não podem se valer diretamente dos resultados de ensaios de laboratório, tais como projetados e incorporados às normas técnicas correntes. Isto é devido devido ao que denominam a diferença do nível de restrição do campo de tensão entre o ensaio de laboratório e as estruturas reais. 
Distribuições de Weibull (1939) de dois ou de três parâmetros costumam ser utilizadas nessas análises, cujo objetivo é estabelecer a correlação entre, por um lado, a tensão $\sigma_{\mathrm{w}} \mathrm{e} o$ parâmetro $m$, de Weibull, determinados em função de uma interpretação estatística do fenômeno localizado (na vizinhança da fratura) e, pelo outro, a integral $J$, associada ao carregamento atuante e a configuração física do sólido considerado como em regime elastoplástico, na vizinhança da extremidade da fissura. Ruggieri et al. (1997) desdobra ainda mais essa análise, em relação ao significado do parâmetro de escala $m$, questionando sobre se, de fato, pode, ou não, ser ele considerado um parâmetro característico do material, no contexto do estudo da dependência de $m$ com a temperatura, no regime de transição dúctilfrágil dos aços.

Tudo leva a crer que o resultado almejado pelo presente trabalho será útil ao aperfeiçoamento da vertente que acaba de ser analisada, pelo fato de que o tratamento estatístico parece ser o mais adequado para a análise de um fenômeno, tal como o da fratura, em que está fortemente presente a interação entre os níveis micro e macroscópico, ressaltando-se as heterogeneidades e as singularidades em nível local. Contudo, a possibilidade do uso da hipótese da continuidade, no nível global do sólido, é plenamente factível. Neste sentido, este trabalho pode contribuir para o aperfeiçoamento do modelo físico da fratura, já que está centrado na consideração da produção e dissipação de calor no processo de avanço das fissuras no interior do sólido.

A despeito de todo o grande desenvolvimento até agora experimentado no estudo da fratura, as teorias em voga só consideram, seja de forma explícita, tal como em Griffith, ou implicitamente, tal como em Irwin e Rice, o princípio de conservação da energia, isto é, a primeira lei da termodinâmica. Por isso, há muito que o estudo do fenômeno necessita de um tratamento teórico capaz de dar conta dos aspectos termodinâmicos relacionados com a parcela irreversível do processo de fissuração. Sabe-se que as teorias de Griffith, de Irwin e da integral $J$, de Rice, não consideram a segunda lei da termodinâmica, razão pela qual não conseguem dar conta do fato de que a fissuração é, no geral, um fenômeno irreversível.

A despeito da grande preocupação, particularmente dos engenheiros, com o problema da fratura, pelo fato de ele estar intimamente relacionado com sua responsabilidade profissional, diante da incerteza dos comportamentos locais na mecânica dos sólidos, físicos e matemáticos também são responsáveis por importantes caminhos investigativos nesse campo. Vale, como exemplo, as seguintes observações: 
Paralelamente à mecânica da fratura, a física também tem contribuído na busca de modelos para explicar, do ponto de vista microscópico, particularmente a resistência dos sólidos cristalinos. (VOLTERRA, 1907)

As imperfeições detectadas na rede cristalina (discordâncias) são utilizadas para explicar os fenômenos da resistência e da fratura nesse tipo de sólido. $\mathrm{O}$ movimento das discordâncias no interior da rede cristalina, ocasionado pela aplicação de esforços, faz com que elas aflorem na superfície. O número de discordâncias contadas na superfície externa do sólido está diretamente relacionado com o estado de tensão no interior. Foram desenvolvidos métodos para a contagem dessas discordâncias e isso permitiu importantes interpretações úteis ao interesse tecnológico, particularmente no campo da metalurgia. O comportamento dúctil (tomado como distinto do comportamento frágil de um material), particularmente na extremidade de fissuras, tem merecido um sem -número de interpretações, também à base do conceito de discordância. (RICE ; THOMSON, 1974, p. 74)

Espera-se que a contribuição teórica trazida pelo presente trabalho, centrada no aperfeiçoamento do modelo físico do fenômeno da fratura e nas possibilidades matemáticas de sua interpretação, possa ser desdobrada em novos métodos de ensaio de materiais e na construção de uma base conceitual que sirva, tanto à concepção de novos modelos matemáticos quanto ao melhor aproveitamento dos potentes métodos de cálculo aproximado de que dispomos, para o melhor conhecimento do fenômeno da fratura nos sólidos. 


\section{ELEMENTOS DE TERMODINÂMICA}

Termodinâmica é a parte da física que trata do calor e da temperatura, fazendo a ponte com a mecânica através da equivalência entre calor e trabalho, cujo fator de conversão foi determinado por Joule, em meados do século XIX. A obtenção precisa desse fator de conversão é um marco fundamental na construção conceitual da termodinâmica, reforçando-a enquanto instrumento de interpretação da interação entre trabalho e energia. Tanto que as leis nas quais se fundamenta, a partir da sistematização feita por Clausius, em torno do ano de 1850, dão-lhe uma característica bastante geral e de grande importância na compreensão de fenômenos no universo. É através da termodinâmica que se chega, por exemplo, a uma explicação, ao nível macroscópico da matéria, sobre a origem física da flecha do tempo, isto é, sobre a razão pela qual os fenômenos físicos parecem caminhar em um só sentido, marcando com isso a distinção entre passado e futuro. (NUSSENZVEIG, 1990)

São quatro as leis da termodinâmica: a chamada lei zero, que dá sentido ao conceito de temperatura, baseado no equilíbrio térmico, segundo o qual dois corpos estarão à mesma temperatura somente se ambos estiverem em equilíbrio térmico com um terceiro; a primeira e a segunda lei, que são as de maior utilização prática, sendo discutidas em detalhes, a seguir, e a terceira, segundo a qual a temperatura possui um limite inferior, chamado zero absoluto.

Em geral, a aplicação da termodinâmica é útil quando há interesse na caracterização de sistemas formados por grande número de partículas, com o auxílio de variáveis tais como pressão e temperatura, que representam o estado médio dessas partículas, refletindo, no fundo, uma abordagem estatística dos fenômenos da natureza. Daí a razão de sua grande utilização no estudo dos fluidos e, mais recentemente, também na mecânica dos sólidos. Nesse último caso o interesse se concentra na pesquisa da resposta do sólido às ações externas, tanto aquelas associadas a campos, quanto as que derivam do contato direto do sólido com outros corpos.

O estudo com base na termodinâmica é uma opção que, além de permitir a consideração do calor como uma forma de energia presente nas interações entre os corpos, também permite uma interpretação mais rigorosa da aplicação dos conceitos de trabalho e energia, fundamentais para a compreensão das transformações sofridas, em particular, pelos corpos deformáveis.

De acordo com Brophy e outros (1972, p. 1): 
As leis da termodinâmica são generalizações da experiência comum. Podemos tomar medidas simples de pressão, volume, temperatura, composição química e outras quantidades apropriadas; tais dados determinam o estado do objeto ou região de interesse (sistema) e todas suas propriedades. Se um sistema não estiver sujeito a perturbações, então atingirá, depois de certo tempo, o equilíbrio, e todas as suas propriedades não mais variarão em função do tempo.

\section{PROCESSO TERMODINÂMICO REVERSÍVEL ${ }^{1}$}

A capacidade térmica, $C$, de um corpo, é definida como a relação entre variação do calor a ele transferido, $\Delta Q$, e a variação de temperatura, $\Delta T$, que sofre nesse processo. Como $C$ é uma grandeza proporcional à massa do corpo, e a variação da temperatura é dada por $\Delta T=\Delta Q / C$, tal variação pode tornar-se muito pequena, se for bastante grande o corpo que transfere calor para o sistema em estudo. No caso limite, se esse corpo tivesse massa infinita, o sistema observado não sofreria qualquer aumento de temperatura. Um corpo infinito, com essa característica, denomina-se reservatório térmico. A atmosfera e o oceano são exemplos de reservatórios térmicos. No entanto, para fins práticos, até corpos menores podem ser também considerados, aproximadamente, reservatórios térmicos.

A figura 1 ilustra como pode ser feita a transferência de calor a um sistema, de maneira reversivel. $\mathrm{O}$ tracejado em torno do corpo indica que as paredes estão isoladas termicamente. A inferior é uma parede diatérmica, em contato com o reservatório térmico, através da qual a transferência de calor é livremente permitida. $T_{\mathrm{i}}$ é a temperatura inicial do sistema (representado em contato com um reservatório térmico, a essa temperatura). Em seguida submete-se o sistema a um reservatório térmico de temperatura $T_{\mathrm{i}}+\mathrm{d} T$, aguardando-se até que se estabeleça o equilíbrio térmico. Daí, nova transferência é feita, agora para um reservatório térmico de temperatura $T_{\mathrm{i}}+2 \mathrm{~d} T$, aguardando-se mais uma vez até que o novo equilíbrio térmico se estabeleça; e assim sucessivamente, até que seja atingida a temperatura final, completando-se a transferência de calor desejada.

\footnotetext{
${ }^{1}$ A elaboração do texto e das ilustrações dessa seção baseia-se em Nussenzveig (1990), texto recomenado para quem desejar maiores detalhes sobre os fundamentos da termodinâmica.
} 


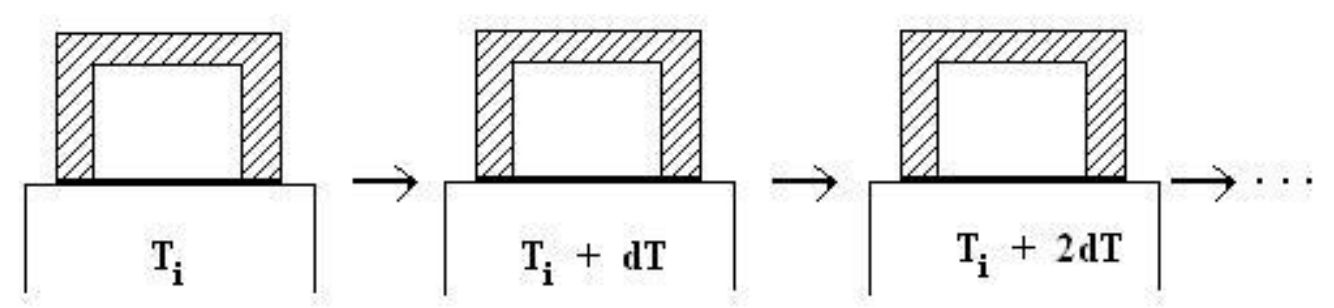

Figura 1 - Transferência reversível de calor a um sistema Fonte: Adaptada de Nussenzveig (1990).

No sentido de exemplificar a possibilidade de um processo termodinâmico reversível, a figura 2 ilustra o caso de um gás em equilíbrio térmico, ocupando um recipiente cilíndrico de área da base $A$ e altura $x$, sendo o volume $V=A x$, sujeito a uma pressão $p$. A base superior é um pistão que se supõe poder deslocar, sem atrito, no contato com as paredes laterais do reservatório. Imaginando que a força, $F=p A$, esteja equilibrada pelo peso de um monte de areia colocado sobre o pistão, suponha-se que o gás sofra uma expansão, decorrente de um deslocamento $\mathrm{d} x$, do pistão, para cima (devido à retirada de um grão de areia do monte, por exemplo). O trabalho realizado pelo gás, nessa expansão, é: $\mathrm{d}^{\prime} W=F \mathrm{~d} x=p A \mathrm{~d} x=p \mathrm{~d} V$. Conforme será retomado adiante, a razão de usar-se a notação d' $W$, em lugar de $\mathrm{d} W$, é para enfatizar que a função $W$ não é, necessariamente, uma diferencial exata.

Se esse procedimento for repetido, pode-se, gradativamente, atingir a expansão finita desejada para o gás. Com a recolocação da areia, grão a grão, pode-se voltar, pelo caminho inverso, ao estado inicial. Um processo assim realizado é chamado de reversível. Em síntese, para que o processo termodinâmico seja considerado reversivel é necessário que as seguintes condições sejam satisfeitas: a) Deve ser realizado muito lentamente e b) $\mathrm{O}$ atrito deve ser desprezível.

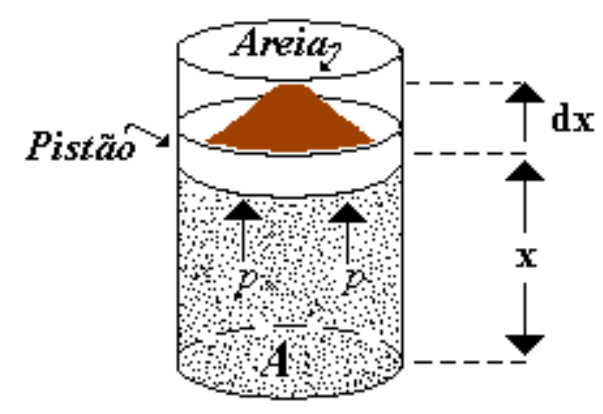

Figura 2 - Processo termodinâmico reversível

Fonte: Adaptada de Nussenzveig (1990). 
Para que a condição (a) seja atendida, o lapso de tempo entre determinado estado do sistema e um estado de equilíbrio termodinâmico deve ser um infinitésimo, o que caracteriza o processo denominado quase-estático. Imaginando-se que a condição (b) não fosse atendida, isto é, que houvesse atrito entre o pistão e as paredes, então a pressão do gás seria $p p^{\prime}<p$, sendo o trabalho realizado na expansão igual a $p^{\prime} \mathrm{d} V<p \mathrm{~d} V$, a diferença representando o calor gerado por atrito.

$\mathrm{Na}$ reversão do processo de expansão quase-estático e sem atrito, chega-se à situação inicial, realizando-se um trabalho positivo igual a $-p \mathrm{~d} V$ (isso porque, nesse caso, o volume sofre uma diminuição). Obviamente, na hipótese de haver atrito entre o pistão e as paredes do cilindro, mesmo que o processo inverso fosse conduzido lentamente, o sistema não voltaria a atingir a situação inicial.

\section{A PRIMEIRA E A SEGUNDA LEI DA TERMODINÂMICA}

A primeira lei da termodinâmica é uma generalização do princípio de conservação da energia, sendo sua característica marcante a consideração do calor como uma forma de energia, em certo sentido distinta das demais, porque é para ela que todas as outras parecem tender. Por essa razão, o calor é a forma de energia cuja observação permite uma oposição mais nítida entre energia e trabalho, este entendido como outra categoria de interação entre os sistemas físicos. Útil à formulação da primeira lei da termodinâmica, concebe-se a energia interna de um sistema como uma função de estado (isto porque não depende do caminho de qualquer processo), correspondendo à soma do trabalho realizado sobre esse sistema com a diferença entre o calor cedido ao sistema e o calor cedido pelo sistema.

Citando ainda Brophy et al. (1972, p. 3):

De acordo com a Segunda Lei, o calor jamais poderá ser inteiramente convertido em trabalho ${ }^{2}$, e ele nunca se transforma espontaneamente em trabalho. Tal comportamento é descrito pela maximização de uma nova função de estado, a entropia, que cresce à medida que o sistema se aproxima do equilíbrio, e se torna máxima no equilibrio. Calor e trabalho são quantidades relativamente fáceis de se medir e permitem a previsão do estado de equilíbrio de qualquer sistema termodinâmico. A ocorrência

\footnotetext{
${ }^{2}$ A respeito dessa afirmação, de que é impossível a transformação total de calor em trabalho, convém observar que ela só é verdadeira se for aplicada a um processo cíclico. Ver páginas 332 e 333 de Nussenzveig (1983).
} 
espontânea de um evento natural pode ser descrita em termos da diminuição na função energia livre ${ }^{3}$ apropriada.

Entropia é uma palavra cunhada por Clausius, a partir do grego, significando transformação. Para compreender seu significado é necessário o conhecimento dos processos em que é possível a transformação de calor em trabalho, dos quais se pode tirar proveito para a construção de máquinas térmicas, tais como a máquina a vapor, o motor térmico e o refrigerador.

A prática comprova que só é possível construir-se uma máquina térmica se ela for composta de uma fonte quente e de uma fonte fria. Para que se possa realizar trabalho com o auxílio de um sistema denominado motor térmico, por exemplo, é preciso que se forneça a esse sistema uma quantidade de calor $Q_{1}$, a uma temperatura absoluta $T_{1}$, e seja retirada uma quantidade $Q_{2}$, a uma temperatura absoluta $T_{2}$. Admitidas as quantidades $Q_{1}$ e $Q_{2}$ com sinal positivo, então, para que o motor possa funcionar é necessário que o valor do trabalho mecânico $W=Q_{1}-Q_{2}$, produzido no processo, seja maior que zero. Portanto, $Q_{1}$ tem de ser maior do que $Q_{2}$. A experiência mostra que, para isso, $T_{1}$ tem de ser, obrigatoriamente, também maior do que $T_{2}$. O principal responsável por essa descoberta foi engenheiro francês Sadi Carnot que, ao pesquisar a máquina térmica de máxima eficiência, concluiu que tal situação ideal só poderia ocorrer se a relação de entrada, $Q_{1} / T_{1}$, fosse igual à relação de saída, $Q_{2} / T_{2}$. Esse seria o caso da máquina ideal, na qual não ocorresse qualquer perda de energia interna.

Adotando-se, nesse exemplo da máquina térmica, uma nova convenção de sinal segundo a qual o calor será positivo quando fornecido ao sistema, então $Q_{1}$ terá sinal positivo e $Q_{2}$, sinal negativo. Usando essa convenção, e sintetizando a contribuição de Carnot, Clausius mostrou que, em cada ciclo reversível do processo, na máquina térmica ideal, a condição para a produção do trabalho, $W$, exige que a seguinte equação seja satisfeita:

$$
\frac{Q_{1}}{T_{1}}+\frac{Q_{2}}{T_{2}}=0
$$

Generalizando o resultado, na forma de um teorema que hoje leva seu nome, Clausius mostrou que, em um ciclo contínuo de uma máquina térmica qualquer, real ou ideal, no qual o

\footnotetext{
${ }^{3}$ Essa grandeza, que adiante definida, segundo a versão de Helmholtz, tem importante papel no desenvolvimento da interpretação termodinâmica da fratura aqui proposta.
} 
calor seja fornecido em parcelas infinitesimais, impondo sucessivos estados de equilíbrio ao sistema, vale a seguinte expressão:

$\circ \frac{\mathrm{d} Q}{T} \quad 0$

que é a síntese do chamado teorema de Clausius, segundo o qual não é possível um processo termodinâmico cujo único efeito seja a conversão total de calor em trabalho.

$\mathrm{Na}$ Eq.(1.2), a igualdade vale para os ciclos reversíveis, como, por exemplo, o da máquina térmica ideal, explicitado pela Eq.(1.1). Já a desigualdade aplica-se a ciclos irreversíveis, que é o caso da máquina térmica real e de todos os fenômenos que ocorrem espontaneamente na natureza. A Eq.(1.2) fornece uma descrição, ao invés de uma explicação, dos fenômenos abordados à luz da termodinâmica. Para o cumprimento dessa finalidade, introduz-se a noção de entropia, uma variável termodinâmica que permite tornar mais clara a interação entre calor e trabalho, principalmente no caso dos fenômenos caracterizados pela irreversibilidade. A análise da máquina térmica ideal de Carnot permite uma boa compreensão do significado da entropia. No processo nela realizado, como se viu, vale tanto o princípio de conservação da energia, quanto também se conserva a relação $Q / T$ na entrada e na saída. A relação $\left(Q_{1} / T_{1}\right)$, correspondente à entrada, isto é, ao que foi fornecido pelo exterior à máquina térmica, seria a entropia de entrada, e ao final, a relação $\left(Q_{2} / T_{2}\right)$, referente ao que foi devolvido por ela, seria a entropia de saída da máquina. Se, ao invés de uma máquina ideal, ela fosse uma máquina real, haveria algum calor gerado pelo atrito interno, o que faria aumentar a entropia de saída. Isto justifica a afirmação básica da segunda lei da termodinâmica, segundo a qual a entropia do conjunto formado pelo exterior e pela máquina térmica, sempre tende a crescer, quando qualquer processo termodinâmico é levado a efeito no universo.

Para o caso de um ciclo reversível, como já foi dito, vale a igualdade na Eq.(1.2). No caso em que a análise é feita entre dois estados $A$ e $B$ quaisquer, no caminho seguido pelo processo termodinâmico, vale analisar a integral:

$$
{ }_{A}^{B} \frac{\mathrm{d} Q_{\text {rev }}}{T}
$$

que, em razão da hipótese de reversibilidade, só deve depender dos estados inicial e final, e não do caminho. O integrando da Eq. (1.3) é, portanto, uma diferencial exata, a saber: 
$\mathrm{d} s=\frac{\mathrm{d} Q_{r e v}}{T}$

onde $s$ é definida como a entropia, que é uma função de estado, na medida em que só depende dos estados inicial e final.

Pela Eq. (1.2), e de acordo com a discussão acima, conclui-se que, para uma mesma mudança de estado:

$\mathrm{d} Q_{\text {rev }}>\mathrm{d} Q_{\text {irrev }}$.

Considerando-se uma mudança de estado arbitrariamente pequena, na qual é transferida a quantidade de calor $\mathrm{d} Q$ ao sistema, então, de acordo com a Eq.(1.5):

$\mathrm{d} Q \leq \mathrm{d} Q_{\text {rev }}$

Entretanto, devido ao fato de que é determinada apenas pelos estados inicial e final, a variação de entropia do sistema independe de o processo ser reversível ou irreversível, daí:

$\mathrm{d} s_{s i s t}=\frac{\mathrm{d} Q_{r e v}}{T}$.

Como $\mathrm{d} Q$ é infinitesimal, a vizinhança do sistema pode voltar a seu estado inicial mediante a reposição do calor $\mathrm{d} Q$. Então, a variação da entropia dessa vizinhança (que a ele havia fornecido o calor $\mathrm{d} Q$ ) é:

$\mathrm{d} s_{v i z}=\frac{-\mathrm{d} Q}{T}$

Assim sendo, a variação líquida de entropia, ocorrida em consequência de uma mudança diferencial de estado, tal como acima, será:

$\mathrm{d} s_{l i q}=\mathrm{d} s_{s i s t}+\mathrm{d} s_{v i z}=\frac{\mathrm{d} Q_{r e v .}-\mathrm{d} Q}{T} \geq 0$

onde a igualdade, uma vez mais, refere-se à reversibilidade.

Um processo que ocorre espontaneamente, por natureza, é irreversível; do contrário, não ocorreria. A reversibilidade só pode ser atingida quando o equilíbrio está tão próximo que 
nenhuma mudança observável possa acontecer. A Eq.(1.9) revela, portanto, que há sempre um aumento da entropia líquida, quando ocorre um evento espontâneo. E a igualdade, naquela equação, revela que a entropia torna-se máxima no equilíbrio.

A consequência mais importante do que acima foi dito liga-se à constatação de que a parte da energia que não pode ser transformada em trabalho, em um dado processo, está associada à variação líquida da entropia (do conjunto formado pelo sistema e sua vizinhança). Mas, na maioria das vezes, quando se procura calcular a variação total da entropia que acompanha um evento determinado, verifica-se que a união do sistema com sua vizinhança é algo tão complicado, que tais cálculos são muito trabalhosos, senão impossíveis. Daí surge a necessidade da introdução de uma função, denominada energia livre de Helmholtz, $\Psi$, que retira da energia interna, $E$, o produto temperatura absoluta $T \times$ entropia $s$ do sistema, como forma de evidenciar a parcela da energia interna disponível para a transformação em trabalho. Assim:

$\Psi=T S$.

De fato, a afirmação de que a entropia do conjunto exterior-sistema tende sempre a crescer, é o mesmo que dizer que a energia livre do sistema isolado tende sempre para um valor mínimo. Com maior rigor, e no interesse do propósito deste trabalho, $\Psi$ pode ser também definida como a máxima quantidade de energia interna do sistema que, num processo irreversível, está disponível para a realização de trabalho.

\section{INTERPRETAÇÃO TERMODINÂMICA DO PROCESSO DE DEFORMAÇÃO DE UM SÓLIDO}

Com o intuito de fixar conceitos, será apresentada, a seguir, uma ilustração do uso da termodinâmica na interpretação do processo de deformação de um sólido, supondo-se que nele ainda não se encontre instalado qualquer processo de deformação capaz de gerar calor, seja plasticidade, dano ou fratura. Admitindo-se que as grandezas aqui tratadas, referentes ao sólido deformável, estejam associadas exclusivamente a volume, a expressão do balanço energético (primeira lei da termodinâmica), tomada entre dois estados infinitesimalmente próximos, é a seguinte:

$\mathrm{d} E=\mathrm{d} Q+\mathrm{d} W$ 
onde $E$ corresponde à energia interna do sólido; $Q$ à quantidade de calor trocada entre o sólido e o exterior, e $W$ ao trabalho mecânico realizado no processo. Aqui, o valor de $W$ será tomado como positivo quando se referir a trabalho fornecido ao sistema (e não pelo sistema, como normalmente se considera no estudo das máquinas térmicas). $Q$ será positiva quando corresponder a calor fornecido ao sistema pelo ambiente. Observe-se que $W$ equivale à energia de deformação armazenada no sólido. Como antes já foi observado, d' $Q$ e d'W indicam diferenciais inexatas, e elas de fato o são, porque nem calor nem trabalho são funções de estado, e sim funções do caminho seguido pelo processo, que inclui a deformação e a troca de calor com o ambiente. Sua soma, no entanto, de acordo com a Eq. (1.11), é uma diferencial exata, porque a energia interna caracteriza-se como função de estado.

Diferenciando-se a Eq. (1.10), no mesmo sentido anterior, em que a diferencial é entendida como a variação sofrida pela grandeza, entre estados infinitesimalmente próximos, e considerando a Eq. (1.11), tem-se:

$\mathrm{d}=\mathrm{d}^{\prime} Q+\mathrm{d}^{\prime} W-T \mathrm{~d} s-s \mathrm{~d} T$.

Na hipótese de um processo de deformação reversível, isto é, que não haja geração interna de calor, e o regime seja quase-estático, a entropia será dada por $\mathrm{d}^{\prime} Q=T \mathrm{~d} s$,

que levada à Eq. (1.12), dá:

$\mathrm{d} \quad=\mathrm{d}^{\prime} W-s \mathrm{~d} T$.

Como o fenômeno de deformação ocorre no meio ambiente, e este é, por hipótese, um reservatório térmico, então, sempre se estabelece o equilíbrio térmico de tal forma que a variação de $T$ é desprezível. Diz-se, portanto que o fenômeno ocorre em condições isotérmicas. Assim, d $T=0$, o que leva Eq. (1.13) a:

$d \Psi=\mathrm{d}^{\prime} W$.

Isso quer dizer que, na ausência de fenômenos que levem á geração interna de calor, um sólido sujeito a deformação e troca de calor com o seu entorno apresenta uma variação de energia livre, entre dois estados de equilíbrio termodinâmico, equivalente à variação de sua energia de deformação. A Eq. (1.14) confirma, portanto, a definição de energia livre como a parcela da energia interna disponível para a realização de trabalho. 
No capítulo seguinte, os conceitos termodinâmicos aqui apresentados serão utilizados em um grau mais avançado de generalidade, no exame das condições para a aplicação da mecânica do contínuo à mecânica da fratura. 


\section{O FENÔMENO DA FRATURA À LUZ DA MECÂNICA DO CONTÍNUO}

Desde quando Irwin, a partir do final da década de 1940 e durante a seguinte, passou a divulgar sua importante contribuição ao estudo do fenômeno da fratura, generalizou-se a aplicação do modelo da elasticidade plana, resolvido com o auxílio das funções de variável complexa, no exame do problema do surgimento e da propagação de fissuras nos sólidos. Nascia, assim, a mecânica da fratura elástica linear, com a esperança de que desse importante passo na superação das deficiências identificadas no modelo de Griffith (1921). A principal dessas delas era a limitação da validade do critério de fratura estabelecido por ele à previsão do início da fratura somente aos sólidos constituídos por materiais de comportamento frágil. Outra deficiência residia no fato de que a energia superficial específica, o parâmetro experimental proposto por Griffith, não ser, de fato, uma característica do material.

Com base em resultados obtidos por Westergaard (1939), que utilizou os potenciais complexos concebidos por Kolossov-Muskhelishivili (alternativa às funções de Airy da elasticidade), no estudo dos problemas da elasticidade bidimensional, Irwin (1957) introduziu os stress intensity factors - fatores de intensidade de tensão. Imediatamente essas grandezas viriam a ser associadas à energy release rate, denominação devida a Irwin e identificada por ele como a força responsável pelo avanço da fissura. Tal grandeza que, ainda sem essa denominação fora usada por Griffith (1921), na formulação de seu critério, corresponde à variação da energia potencial elástica do sólido contendo uma fissura, em relação a um parâmetro geométrico que equivale à metade do comprimento do eixo maior de uma elipse achatada, identificada com a fissura.

Obtidos através da elasticidade linear, os resultados de Westergaard (1939) baseavamse na forma das séries de funções, uma para cada componente do tensor tensão dos problemas formulados para chapas planas, as quais apresentavam, nos cinco casos aproveitados no trabalho de Irwin (1957), certa característica comum: cada uma de tais séries de funções continha uma parcela singular do tipo $1 / \sqrt{r}$, onde $r$ é a distância de um ponto genérico do plano médio da chapa até à extremidade da fissura contida nesse plano. O surgimento de tal tipo de singularidade em problemas da elasticidade linear ocorre por conta de que, no modelo matemático, a fissura é simulada como um segmento de reta (algo que pode ser entendido como o caso limite da elipse usada por Griffith, quando o eixo menor tende para zero). 
A razão para a difusão da ideia de que a fratura envolve, necessariamente, singularidade nas expressões das componentes de tensão, decorre dessa idealização de Irwin. Seguramente, ela tem similaridade com a proposta de Griffith, na qual o raio de curvatura na extremidade da elipse achatada que simula a fissura deve ser bem pequeno, embora nunca nulo, exatamente para evitar as tensões infinitas, dada a existência da singularidade. Como consequência de seu modelo, Irwin identificou nos coeficientes das parcelas singulares das citadas séries de funções, nas diversas representações das componentes de tensão, em três casos simples, grandezas que denominou fatores de intensidade de tensão.

Em síntese, tais parâmetros derivam da simulação da fissura como um segmento de reta localizado no plano médio de uma chapa de material elástico-linear, submetida a cargas situadas nesse mesmo plano. A utilização prática de tais grandezas, portanto, teria que ser feita com base na consciência precisa da limitação da teoria que lhe dá suporte. Essa teoria elástico-linear, no entanto, fornece expressões para as componentes do tensor tensão que contêm parcelas singulares, as quais encerram uma contradição, pois, na vizinhança da extremidade do segmento de reta que representa a fissura, as componentes de tensão teriam de ser infinitas. A impossibilidade física da ocorrência de tensões infinitas levaria a que o material se acomodasse plasticamente, na extremidade da fissura, porém isto não pode caber num modelo de comportamento elástico.

Assim, a idealização de Irwin, do segmento de reta ou corte matemático usado para simular o vazio (fissura) preexistente, deveria incluir a delimitação, a priori, de um entorno da extremidade do segmento em cujos pontos a hipótese de plasticidade do material pudesse ser adotada. No entanto, se assim fosse, os resultados não mais envolveriam singularidade e, em consequência, não mais apareceriam os fatores de intensidade de tensão! Entretanto, a justificativa para atenuar-se, na metodologia de Irwin, a não consideração da acomodação plástica do material na extremidade da fissura, como necessidade, está em admitir-se que seja muito pequena a região onde isso ocorre, sendo desprezível, portanto, a quantidade de calor associada a esse fenômeno. O problema está em que, para uma teoria ser consistente, é necessário que nela se inclua a delimitação de seu campo de validade. Para isso, deveria ser bem estabelecida a região, na vizinhança da extremidade da fissura, dentro da qual a hipótese de comportamento linear do material não mais pudesse ser adotada. Isso, entretanto, não é cogitado na proposta teórica de Irwin.

A complementação dessa proposta exige a determinação experimental dos valores críticos dos fatores de intensidade de tensão, cuja comparação com os respectivos valores calculados, para um sólido elástico qualquer, serviria para aferir sua integridade, mediante um 
critério de fratura. Muito foi feito nesse terreno, visando à determinação desses parâmetros críticos em laboratório, a despeito das controvérsias.

A metodologia de Irwin, de fato, instalou-se fortemente entre os estudiosos - mais ainda entre os usuários - da mecânica da fratura, como se fosse verdade definitiva, acabando por cristalizar uma cultura tecnológica que, do ponto de vista da mecânica dos materiais apresenta graves inconvenientes. Quer dizer, o fenômeno da fratura, essencialmente não linear e irreversível, não pode ter sua complexidade, enquanto fenômeno de deformação, abarcada, como quer Irwin, apenas por três modos simples de fratura: abertura, deslizamento e rasgamento. Do ponto de vista da concepção de tensão de Cauchy é evidente que o problema do acoplamento de influências entre componentes tangenciais e componentes normais, em tensão e em deformação, é muito complexo para ser tratado com base num critério que conta com o auxílio de somente três modos simples de fratura.

$\mathrm{Na}$ elaboração de modelos físicos e matemáticos para simular o início da fratura, consideram-se duas opções: 1) O processo de fissuração inicia-se a partir de um vazio preexistente, tal como Griffith e Irwin sugerem, ou 2) A fissura poderá surgir a partir do estado completamente íntegro do material, tal como propõe Hillerborg (1991).

Do ponto de vista físico, dado que a maior parte do interior dos sólidos é constituída de vazios, a hipótese do vazio preexistente parece ter mais sentido. O problema está no modelo matemático, que deveria estar apto a considerar tantos e tão irregulares vazios no sólido real, a partir dos quais o processo de fissuração pudesse, potencialmente, avançar. O tratamento da questão do surgimento de uma descontinuidade no sólido, considerado inicialmente íntegro e contínuo, parece mais complexo que no caso de uma fissura que cresce a partir de um vazio preexistente. Por isso, aqui se adota a hipótese do vazio preexistente para simular a situação inicial da fissura genérica, suposta contida no interior do material.

A contribuição de Griffith, responsável pelo primeiro modelo matemático do problema da fratura, faz com que seja ele unanimemente considerado o criador da mecânica da fratura. Sua refinada intuição do fenômeno físico, mais tarde também aceita por Irwin, ao admitir que tudo ocorreria como se as fissuras crescessem a partir de vazios preexistentes, permitiu a justificativa para a observação separada entre fenômenos associados a volume e outros que ocorrem nas superfícies de avanço da fissura, após iniciado o fenômeno da fratura. Isso é aqui retomado, em outra perspectiva, na intenção de organizar-se uma teoria da fratura cuja característica básica seja a utilização de recursos da mecânica do contínuo e da termodinâmica. 
O exame minucioso dessa possibilidade é o objetivo do presente capítulo, que trata da formulação de um modelo matemático do problema da fratura em um sólido, considerado inicialmente como um meio contínuo contendo vazios, a partir dos quais fissuras poderão se desenvolver. A aproximação aqui realizada entre a mecânica da fratura (um campo de estudos ainda carente de fundamentação científica segura), a mecânica do contínuo e a termodinâmica, visa a aproveitar as vantagens do status científico das duas últimas, em proveito da consolidação da primeira.

O suporte teórico para a linha de investigação aqui desenvolvida encontra-se no pioneiro estudo de Eftis e Liebowitz (1976), que afirma a insuficiência da formulação original de Griffith, na perspectiva de aperfeiçoá-la, isto é, assegura que a energia superficial específica, parâmetro-chave da teoria e Griffith, não é uma propriedade do material, tal como parecia. Em seu lugar, a interpretação termodinâmica da fratura, segundo Eftis e Liebowitz, faria aparecer uma grandeza mais complexa, dotada da seguinte característica: uma função de ponto, nas faces de avanço das fissuras, composta por três parcelas associadas, respectivamente, à energia livre, à temperatura e à energia cinética. É a partir da tentativa de interpretação dada por Eftis e Liebowitz (1976) que hoje se constrói a base para a concepção de modelos não lineares e termodinamicamente consistentes na mecânica da fratura.

Também representa uma considerável contribuição, no sentido da linha aqui adotada, o trabalho de Zhang e Karihaloo (1993) segundo o qual a condição necessária para o crescimento de fissuras em um meio é o cumprimento das leis de balanço, não somente no volume do sólido, mas, também, nas superfícies das fissuras que vão sendo criadas em seu interior. Ao provar que é possível a passagem das equações de balanço global às de balanço local, inclusive nos pontos das superfícies de avanço das fissuras, com apoio na equação de transporte de Reynolds, encontra-se naquele trabalho o instrumental metodológico adequado ao tratamento termodinamicamente consistente do problema da fratura.

Ao adotar uma alternativa ao recurso matemático da equação de transporte de Reynolds, Rocha (1999) obtém a confirmação dos resultados obtidos por Zhang e Karihaloo (1993), mas permite uma melhor interpretação deles, além de chegar a resultados numéricos mediante a utilização da análise de sensibilidade e do método dos elementos de contorno. Os dois últimos trabalhos citados representam significativo avanço, em relação ao de Eftis e Liebowitz (1976), embora este tenha o mérito de tentar, pela primeira vez, a interpretação termodinâmica consistente, mas concluindo pela impossibilidade do tratamento do problema da fratura com o auxílio da mecânica do contínuo. 
A interpretação aqui adotada advém, pois, da extensão da mecânica do contínuo à mecânica da fratura, que só se tornou possível a partir do trabalho de Eftis e Liebowitz (1976). O maior mérito, entretanto, fica para o trabalho de Zhang e Karihaloo (1993), que justifica a introdução, nas equações globais de balanço termomecânico, de parcelas próprias das grandezas associadas às superfícies de avanço das fissuras. Partindo dessa sugestão e dos desenvolvimentos posteriores apresentados por Rocha (1999), o presente trabalho, tal como se verá, contribui para que os novos resultados possam ser colocados na perspectiva de aplicação tecnológica imediata. Para isso, propõe a realização de um ensaio numérico sobre um modelo espacial do sólido em estudo que, ao ser comparado com um modelo semelhante, ensaiado em laboratório, até atingir a condição crítica, forneça os elementos para o novo critério termodinamicamente consistente de fratura aqui proposto.

\section{DESCRIÇÃO MATEMÁTICA DO PROCESSO DE CRESCIMENTO DE UMA FISSURA}

O pressuposto da continuidade de um corpo sólido, $B$, permite que se faça uma associação entre ele e um conjunto limitado, fechado e de fronteira suave, denominado configuração de referência $\left(C_{0} \subset I R^{3}\right)$. Convém observar que, não necessariamente, a configuração de referência coincide com a posição inicial do sólido. Imagina-se que a evolução desse corpo deformável poderá ser acompanhada mediante uma sequência de aplicações biunívocas, capazes de associar, instante a instante, cada ponto $X \in C_{0}$ a um e um só ponto $x \in C_{\mathrm{t}}$, onde $C_{\mathrm{t}} \subset I R^{3}$ é a configuração, dita atualizada, do corpo $B$, no instante $t$. Cada aplicação dessa sequência (chamada deformação) é biunívoca, de $C_{0} \mathrm{em} C_{\mathrm{t}}$, além de contínua, inversível e com inversa também contínua, isto é, um homeomorfismo.

Diferentemente do modelo clássico da mecânica do contínuo acima descrito, o modelo útil ao presente trabalho precisará permitir a possibilidade da evolução de fissuras a partir de vazios pre-existentes, durante o processo de deformação do sólido. Embora pareça estranho que um sólido contínuo possa incluir algo descontínuo como uma fissura, a solução será buscada através da admissão da presença de superfícies contínuas em evolução no interior do sólido. Seriam elas as superfícies de avanço das fissuras. Vale observar que nada impede que o modelo inclua mais de uma fissura no interior de $B$ (o número delas sendo naturalmente finito), porém, a generalidade não estará sacrificada no caso em que a análise estiver centrada 
numa parte $P \subseteq B$ que contiver somente uma fissura. Na configuração de referência tal parte será representada por $P_{0}$, sendo $P_{\mathrm{t}}$ a sua representação na configuração atualizada, correspondente ao instante $t$. Portanto, $P_{0} \subseteq C_{0}$ e $P_{\mathrm{t}} \subseteq C_{\mathrm{t}}$.

Diz-se que um ponto pertence à fronteira de um conjunto genérico, $K$, se qualquer vizinhança desse ponto possuir ao menos um ponto do interior e outro do exterior de $K$. Define-se, então, como o contorno $\partial P_{\mathrm{t}}$ a fronteira da configuração atualizada $P_{\mathrm{t}}\left(\partial P_{0}\right.$, no caso da configuração de referência $P_{0}$ ). Admite-se que as representações do contorno de um vazio preexistente em $P$, tanto a de referência quanto a atualizada, serão consideradas como pertencentes a $P_{0}$ e $P_{\mathrm{t}}$, respectivamente. Suponha-se, agora, a existência de um conjunto $S_{\mathrm{f}}(t) \subset P_{0}$, com o auxílio do qual será feito o registro do crescimento da fissura com o tempo, mediante uma sequência de aplicações $g^{*}$, que leva pontos de $S_{\mathrm{f}}(t) \subset P_{0}$ a pontos do conjunto $s_{\mathrm{f}}(t) \subset P_{\mathrm{t}}$. Vale enfatizar que se considera $\mathrm{S}_{\mathrm{f}}(\mathrm{t})$ como imerso em $P_{0}$ e não contido no contorno da parte, isto é em, $\partial \mathrm{P}_{0}$.

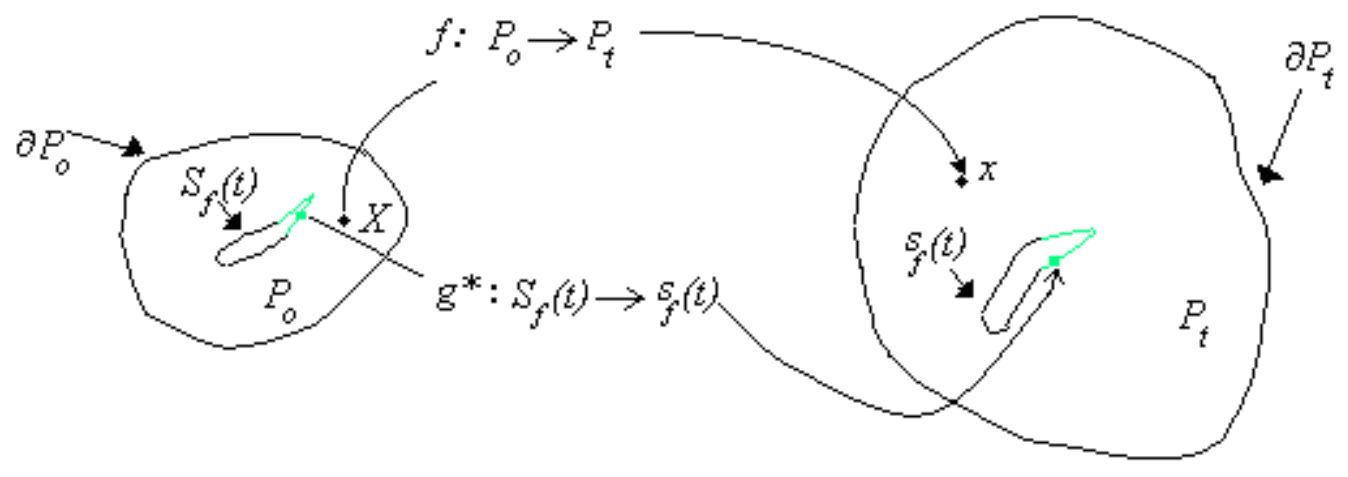

Figura 3 - A deformação no caso de um sólido contendo uma fissura

Na opção de modelo de fissuração aqui adotado por princípio, a fissura nunca poderá surgir no sólido, mas crescer a partir de um vazio preexistente. A figura 3 ilustra o modelo clássico da mecânica do contínuo, no caso em que no interior do corpo preexiste um vazio. Enquanto o movimento do corpo realizar-se em condições de reversibilidade (regime elástico, por exemplo), a alteração das dimensões do vazio será consequência de fenômenos associados a volume. No entanto, no caso dos fenômenos espontâneos em que ocorre a fissuração, propriamente dita, a componente irreversível faz-se presente, isto é, ocorre um avanço definitivo da fissura, e a superfície do vazio preexistente, a partir do qual a fissura evolui, sofre acréscimo irreversível na área de sua fronteira ou contorno. 
Do ponto de vista termodinâmico, a incoerência do modelo de Griffith $(1924)^{4}$ está relacionada com o fato de sua formulação ser baseada na hipótese do comportamento elástico linear do material. Naquele modelo não há como ser assimilada a energia superficial, incluída em sua formulação, como estando relacionada com a produção de calor e consequente dissipação associada à componente irreversível do processo de avanço da fissura.

A aplicação da interpretação termomecânica consistente a uma parte genérica $P \subseteq B$ conduz a que se postulem as equações de balanço global (massa, quantidade de movimento linear, quantidade de movimento angular, energia e princípio da irreversibilidade ou desigualdade de Clausius-Duhem). A sistemática clássica da mecânica do contínuo, que parte das equações de balanço global, chegando às relações diferenciais válidas ao nível local, será ampliada para o caso de meios fissurados, da forma como será mostrado a seguir.

\section{LEIS DA TERMODINÂMICA APLICADAS AOS SÓLIDOS CONTÍNUOS}

Definem-se os campos escalares $\varepsilon$ e $\eta$, energia interna e entropia, por unidade de massa, respectivamente. Daí, a entropia e a energia interna relativas a uma parte genérica, $P$, do sólido, serão dadas, respectivamente, no instante $t$, por:

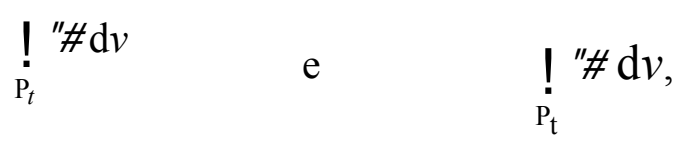

onde $\rho$ é a massa específica (função de ponto) e $\mathrm{d} v$ é o elemento de volume, tomado na representação atualizada $P_{\mathrm{t}}$. A energia total, $E(P, t)$, dessa parte, composta da energia interna e da energia cinética, será dada, em cada instante, por:

$E(P, t)=\int_{\mathrm{P}_{t}} \rho \varepsilon \mathrm{d} v+\frac{1}{2} \int_{\mathrm{P}_{\mathrm{t}}} \rho \mathbf{v} \cdot \mathbf{v} \mathrm{d} v$,

sendo $\mathbf{v}$ a velocidade do ponto $\mathbf{x}=\mathbf{x}(\mathbf{X}, t), \operatorname{com} \mathbf{x} \in P_{\mathrm{t}}$.

Admitindo-se que, de alguma maneira, seja fornecido (ou retirado) calor de $P_{\mathrm{t}}$, numa troca entre essa parte e o exterior, quantifica-se essa possibilidade através de uma taxa $r$, de

\footnotetext{
${ }^{4}$ Ver capítulo 1.
} 
calor fornecido por unidade de massa, em $P_{\mathrm{t}}$, e pelo vetor fluxo calorífico $\mathbf{q}$, na fronteira $\partial P_{\mathrm{t}}$. Daí obtém-se as seguintes grandezas:

$\int_{P_{t}} \rho r d v \quad$ e $\quad-\int_{\mathcal{P}_{\mathrm{t}}} \mathbf{q} \cdot \mathbf{n} \mathrm{d} s$

ambas com dimensão de potência mecânica, correspondendo às taxas temporais de variação da energia, no interior e na fronteira de $P_{\mathrm{t}}$, respectivamente. Observe-se que o sinal negativo na segunda expressão decorre da convenção para o vetor unitário normal $\mathbf{n}$ que é considerado positivo quando dirigido para o exterior, em cada ponto de $\partial P_{\mathrm{t}}$. Isso significa que a quantidade de calor é convencionada positiva quando fornecida à parte $P_{\mathrm{t}}$ do sólido (sistema).

A partir das potências das forças aplicadas (b.v, por unidade de volume, e s.v, por unidade de área), onde b é a densidade das forças de corpo, por unidade de volume, e s é a densidade das forças por unidade de superfície, tem-se, a seguir, a expressão matemática da primeira lei da termodinâmica, que equivale à lei de conservação da energia, isto é:

$\frac{D}{D t} E(P, t)=\int_{P_{\mathrm{t}}}(\rho r+\mathbf{b . v}) d v+\int_{\partial P_{t}}(\mathbf{s . v}-\mathbf{q . n}) d s$,

onde $D / D t$ indica derivada material no tempo.

Substituindo-se o valor de $E(P, t)$, da Eq. (2.1), na Eq. (2.2), tem-se:

$$
\frac{D}{D t} \int_{P_{t}} \rho\left(\varepsilon+\frac{1}{2}\right) \mathbf{v} \cdot \mathbf{v d} v=\int_{P_{t}}(\rho r+\mathbf{b . v}) \mathrm{d} v+\int_{\partial P_{t}}(\mathbf{s . v}-\mathbf{q . n}) \mathrm{d} s .
$$

A taxa de calor trocado com o exterior, relativa a $P_{\mathrm{t}}$, é:

$$
Q(P, t)=\int_{P_{t}} \rho r d v-\int_{\partial P_{t}} \mathbf{q} \cdot \mathbf{n} d s
$$

De acordo com a segunda lei da termodinâmica, a taxa de entropia produzida em $\mathrm{P}_{\mathrm{t}} \mathrm{e}$ sempre maior ou igual à taxa de energia trocada entre essa parte e o exterior, no volume e no contorno, dividida pela temperatura absoluta. Daí: 


$$
\frac{D}{D t} \int_{\mathrm{P}_{t}} \rho \eta d v=\int_{\mathrm{P}_{t}} \rho \dot{\eta} d v \geq \int_{\mathrm{P}_{t}} \rho \frac{r}{T} d v-\int_{\partial \mathrm{P}_{t}} \frac{\mathbf{q} \cdot \mathbf{n}}{T} d s,
$$

onde o ponto sobre a variável indica derivada material no tempo.

Observe-se, na Eq (2.5), que a passagem da derivada material, $D / D t$, para dentro da integral só afetou a variável $\eta$. Essa propriedade da derivada material, que adiante será bastante utilizada, tanto para a integração no volume quanto na superfície, pode ser demonstrada com o auxílio das Eqs. (7.107) e (7.117), levada em conta a conservação da massa expressa pela Eq. (2.23).

\section{ABORDAGEM TERMODINÂMICA DO PROBLEMA DA FRATURA}

O tratamento clássico dos problemas da mecânica da fratura, baseado nas contribuições de Griffith e de Irwin, leva em conta a primeira lei da termodinâmica, ainda que não explicitamente. Como já foi dito, o trabalho de Zhang e Karihaloo (1993) é o primeiro que, a par de caracterizar os tratamentos anteriores como insuficientes, adota uma estratégia para a construção da teoria termodinamicamente consistente. Com isso, ele examina o caráter irreversível do fenômeno, cuja análise exige a consideração da evolução da entropia do sólido.

A seguir, será montado o esquema teórico visando ao exame do fenômeno da fratura, mediante a consideração, nas equações de balanço global, de parcelas relativas a volume separadas das que são relativas às superfícies internas, estas que, ao serem acrescidas, consubstanciam o avanço irreversível das fissuras. Essa separação, distinta da maneira clássica dos balanços da mecânica do contínuo, foi introduzida no estudo do fenômeno da fratura por Zhang e Karihaloo (1993).

\section{Passagem das equações de balanço global às equações de balanço local}

Em nível global, aplicado a uma parte $P$ do sólido (este considerado como um meio contínuo), postulam-se cinco princípios, denominados princípios de balanço termomecânico, cuja validade é o ponto de partida para a construção do modelo capaz de enquadrar o estudo do movimento de um corpo, incluída a deformação como possibilidade. Os cinco balanços globais são: de massa, de momentum linear, de momentum angular, de energia e de entropia (desigualdade de Clausius-Duhem ou princípio da irreversibilidade). 
Para o estudo do sólido contendo vazios, e considerando a possibilidade do processo de crescimento irreversível das superfícies internas desses vazios, assimilados às fissuras, introduz-se, tal como já foi dito, em cada uma das cinco equações de balanço global, uma nova parcela, a saber, uma integral calculada sobre as superfícies de avanço da fissura, mais precisamente sobre a parte irreversível da expansão sofrida pelos vazios no curso do processo.

Com o objetivo de síntese, será desenvolvido, a seguir, um procedimento geral capaz de enquadrar formalmente os cinco princípios termomecânicos clássicos, estendidos da mecânica do contínuo para a mecânica da fratura. Quatro deles são princípios de conservação: massa, momentum linear, momentum angular e energia. O quinto é o princípio da irreversibilidade que, embora dado por uma desigualdade, pode, mediante artifício, ser colocado na forma de uma igualdade, para enquadrar-se no procedimento geral. Após, o modelo deverá ser especializado para cada um dos, assim chamados, cinco princípios da termomecânica.

Sejam $\Phi$ e $\Phi^{*}$ dois campos (ambos escalares ou ambos vetoriais) definidos em $P_{\mathrm{t}}$ e em $s_{\mathrm{f}}(t)$ respectivamente. O balanço global, em sua forma geral, expressa-se por:

$$
\frac{D}{D t} \int_{P} \Phi d v+\frac{D}{D t} \int_{s_{f}(t)} \Phi^{*} d s=\int_{\partial P_{t}} Y . \mathbf{n} d s+\int_{P_{t}} \mathbf{g} d v .
$$

O primeiro membro dessa equação geral desdobra-se em duas parcelas, uma associada ao volume e outra à superfície de avanço da fissura (desconhecida a priori). O segundo membro da Eq. (2.6), que expressa a interação da parte $P_{\mathrm{t}}$ com o exterior, tem duas parcelas: a primeira é uma integral sobre a fronteira dessa parte, e a segunda é outra integral, realizada no volume. A notação $\Upsilon$ representa grandezas para as quais faz sentido a aplicação ao vetor $\mathbf{n}$, podendo vir a ser, ora um vetor, ora um tensor de segunda ordem, tal como o fluxo de calor, o tensor tensão de Cauchy etc. Finalmente, g expressa uma densidade volumétrica (de forças de corpo, de quantidade de calor trocada com o exterior etc.). Todas as grandezas são tomadas na configuração atualizada $P_{\mathrm{t}}$. O vetor normal unitário externo, $\mathbf{n}$, é referido a pontos de $\partial P_{\mathrm{t}}$, fronteira considerada regular o suficiente para que só exista um único valor de $\mathbf{n}$ em cada ponto de fronteira. O elemento infinitesimal, $d v$, refere-se ao volume de $P_{\mathrm{t}}$, e $d s$ ao contorno $\partial P_{\mathrm{t}}$, ou à superfície de avanço da fissura $s_{f}(t)$.

A seguir, será desenvolvido o artifício que permite dar a forma de igualdade à desigualdade que representa o quinto princípio (da irreversibilidade). O objetivo é enquadrar a Eq. (2.5) na forma geral representada pela Eq.(2.6). 
Tomando-se a Eq. (2.5) como referência, a ela se adiciona, em seu primeiro membro, a integral a ser realizada numa possível superfície de avanço da fissura. Nela aparecem as densidades $\rho *$ e $\eta *$, análogas daquelas que ocorrem na integral de volume, só que, agora, a primeira é a massa específica, mas associada superfície, e a segunda, a densidade de entropia, por unidade de massa associada à superfície. Então, a equação de balanço de entropia, na parte considerada do sólido, supondo que nela haja uma fissura em crescimento, será dada por:

$$
\frac{D}{D t} \int_{\mathrm{P}_{t}} \rho \eta d v+\frac{D}{D t} \int_{s_{f}(t)} \rho^{*} \eta^{*} d s-\int_{\mathrm{P}_{t}} \rho \frac{r}{T} d v+\int_{\partial \mathrm{P}_{t}} \frac{\mathbf{q} \cdot \mathbf{n}}{T} d s \geq 0
$$

ou, de acordo com a derivação de integrais explicitadas através das Eqs. (7.107) e (7.117):

$$
\int_{t} \rho\left(\frac{D}{D t} \eta-\frac{r}{T}\right) d v+\int_{s_{f}(t)} \rho^{*} \frac{D}{D t} \eta^{*} d s+\int_{\partial \mathrm{P}_{t}} \frac{\mathbf{q} \cdot \mathbf{n}}{T} d s \geq 0
$$

Define-se, em seguida, uma taxa $\xi(\geq 0)$ de produção de entropia por unidade de massa, associada a $P_{\mathrm{t}}$, tal que:

$$
\int_{P_{t}} \rho \xi \mathrm{d} v=\int_{P_{t}} \rho\left(\frac{D}{D t} \eta-\frac{r}{T}\right) \mathrm{d} v+\int_{s_{f}(t)} \rho^{*} \frac{D}{D t} \eta^{*} \mathrm{~d} s+\int_{\partial P_{t}} \frac{\mathbf{q} \cdot \mathbf{n}}{T} \mathrm{~d} s \geq 0 .
$$

Assim, chega-se ao princípio da irreversibilidade, de modo a que tenha a forma de igualdade, enquadrando-se, portanto, na Eq. (2.6), isto é:

$$
\frac{D}{D t} \int_{P_{t}} \rho \eta d v+\frac{D}{D t} \int_{S_{f}(t)} \rho^{*} \eta^{*} d s=\int_{P_{t}} \rho\left(\frac{r}{T}+\xi\right) d v-\int_{\partial P_{t}} \frac{\mathbf{q} \cdot \mathbf{n}}{T} d s .
$$

O próximo passo, no caso da mecânica do contínuo tradicional, é a passagem das equações de balanço global (na forma integral), para as respectivas equações de balanço local (na forma diferencial). Esse processo de passagem é um importante recurso que atesta a versatilidade da metodologia da mecânica do contínuo, porquanto evidencia as leis de Newton da mecânica e a primeira e segunda lei da termodinâmica como os fundamentos básicos da formulação. 
A seguir, inspirado em Zhang e Karihaloo (1993), embora seguindo um caminho distinto do utilizado naquele trabalho, será realizado o desenvolvimento matemático que conduz à passagem das equações de balanço global para as correspondentes equações de balanço local, a partir da forma geral dada pela Eq. (2.6), adequada aos casos em que vazios podem crescer, irreversivelmente, dentro do meio contínuo.

\section{Formas gerais das equações de balanço local}

Supondo-se $\Phi(x, t)$ um campo contínuo e limitado, em todo ponto $x \in P_{\text {t }}$, onde $x=x(X, t)$, sendo $X \in P_{0}$, então a integral de volume, no sentido de Riemann, será:

$$
\int_{P_{t}} \Phi(x, t) d \mathrm{v}=\lim _{n \rightarrow \infty} \sum_{l=1}^{n} \Phi\left(x\left(X_{i}, t\right), t\right) \Delta \mathrm{v}_{i}
$$

O segundo membro da Eq.(2.10) expressa que a integral pode ser obtida através da partição de $P_{\mathrm{t}}$ em subdomínios de medidas $\Delta v_{i}(i=1 \ldots n)$, sendo cada ponto $x_{i}=x\left(X_{i}, t\right)$, obrigatoriamente, um ponto interior do correspondente subdomínio de $P_{\mathrm{t}}$. Para as condições em que $\Phi(x, t)$ foi acima definido, obtém-se, portanto, segundo Riemann, um e um só valor para o limite do segundo membro da Eq.(2.10), independentemente do modo de partição do volume de $P_{\mathrm{t}}$.

Por definição, a derivada material no tempo da integral de volume do primeiro membro da Eq.(2.6) é:

$$
\frac{D}{D t} \int_{P_{t}} \Phi(x, t) d v=\lim _{\Delta t \rightarrow 0} \frac{\Delta\left(\int_{P_{t}} \Phi(x, t) d v\right)}{\Delta t}
$$

que, de acordo com a Eq. (7.107) (ver capítulo 7 ), resulta em

$$
\frac{D}{D t} \int_{P_{t}} \Phi d v=\int_{P_{t}}\left[\frac{D \Phi}{D t}+\Phi \operatorname{div} \mathbf{v}\right] d v
$$

Na sequência, será calculada a derivada material no tempo da segunda parcela do primeiro membro da Eq. (2.6), através de um procedimento em tudo semelhante ao anterior (ver capítulo 7), a partir da seguinte definição: 
$\frac{D}{D t} \int_{s_{f}(t)} \Phi^{*}(x, t) d s=\lim _{\Delta t \rightarrow 0} \frac{\Delta\left(\int_{s_{f}(t)} \Phi^{*}(x, t) d s\right)}{\Delta t}$

que resulta em

$\frac{D}{D t} \int_{s_{f}} \Phi^{*} d s=\int_{s_{f}}\left[\frac{D \Phi^{*}}{D t}+\Phi^{*} d i v \mathbf{v}\right] d s$

onde, por simplicidade, coloca-se $s_{f}(t)=s_{f}$ nas integrais onde aparece, daqui em diante.

Levando as Eqs.(2.12) e (2.14) à Eq.(2.6), tem-se:

$\int_{P_{t}}\left[\frac{D \Phi}{D t}+\Phi \operatorname{divv}\right] \mathrm{d} v+\int_{s_{f}}\left[\frac{D \Phi^{*}}{D t}+\Phi^{*} \operatorname{div} \mathbf{v}\right] \mathrm{ds}=\int_{\partial P_{t}} \Upsilon . \mathbf{n d s}+\int_{P_{t}} \mathbf{g d} v$.

Observação: A grandeza genérica $\Upsilon$ pode ser, ora um vetor, ora um tensor de segunda ordem, e a notação usada permite os seguintes possíveis significados: a) $\Upsilon . \nabla$ equivale a $\operatorname{div} \Upsilon$; b) Quando $\Upsilon$ for um vetor, $\Upsilon$.n significa o produto interno dos dois vetores e c) Quando $\Upsilon$ for um tensor de segunda ordem, $\Upsilon$.n equivale à aplicação de um tensor a um vetor. $\mathrm{O}$ símbolo $\nabla$ indica gradiente espacial, entendido como um operador vetorial cujas componentes são, respectivamente, as derivadas parciais nas direções dos três eixos do sistema cartesiano ortogonal.

No caso de não haver crescimento da fissura, desde o instante inicial até o instante $t$, a função $\Phi$ será identicamente nula, e a Eq.(2.15) corresponderá à tradicional expressão do balanço global da mecânica do contínuo. Admitida essa hipótese, o exame do que ocorre numa vizinhança infinitesimal $V(a)$, de um ponto qualquer $a \in P_{\mathrm{t}}$, mediante a aplicação do teorema de Gauss (da divergência) à primeira parcela do segundo membro da Eq.(2.15), conduz a:

$\int_{v(a)}\left[\frac{D \Phi}{D t}+\Phi \operatorname{divv}-\Upsilon . \nabla-\mathbf{g}\right] d v=\mathbf{0}$

Desde que o ponto $a P_{t}$ é genérico, tem-se então, a seguinte expressão para o balanço local, em cada ponto não atingido pelo avanço da fissura: 
$\frac{D \Phi}{D t}+\Phi \operatorname{divv}-. \quad \nabla-\mathbf{g}=0, \quad \forall a \in P_{\mathrm{t}}$

Caso haja crescimento da fissura, por hipótese contida na parte $P_{\mathrm{t}}$, então, para cada ponto $a \in P_{\mathrm{t}}$, pode-se construir uma vizinhança de raio tão pequeno que a fissura passará por fora dela. Nesse caso, a situação configura-se idêntica à anterior.

Imagine-se, no entanto, um ponto $a_{1} \in P_{\mathrm{t}}$ que, exatamente no instante $t$, passasse a pertencer à superfície de avanço da fissura. Então, os balanços relativos a esse ponto teriam de ser feitos, daí em diante, não mais com base em vizinhanças infinitesimais contidas no $I R^{3}$, mas no $I R^{2}$, isto é, qualquer vizinhança de $a_{1}$, para efeito de balanço, passará a estar contida em $s_{f}(t)$. Tomando-se certa vizinhança de um ponto genérico $a \quad P_{t}$, cujo raio permitisse uma intercessão, $s_{f}$, dela com $s_{f}(t)$, então, a Eq.(2.15), particularizada para $V(a)$, no instante $t$, levaria a:

$\int_{V(a)}\left[\frac{D \Phi}{D t}+\Phi \operatorname{div} \mathbf{v}\right] \mathrm{d} v+\int_{\Delta s_{f}}\left[\frac{D \Phi^{*}}{D t}+\Phi^{*} \operatorname{div} \mathbf{v}\right] \mathrm{ds}=\int_{\partial V(a)} Y \cdot \mathbf{n d s}+\int_{V(a)} \mathbf{g d} v$.

Aplicando-se o Teorema da Divergência à primeira integral do segundo membro da Eq. (2.18) e arrumando-se adequadamente, vem:

$\int_{V(a)}\left[\frac{D \Phi}{D t}+\Phi \operatorname{divv}-\Upsilon . \nabla-\mathbf{g}\right] \mathrm{d} v+\int_{\Delta s_{f}}\left[\frac{D \Phi^{*}}{D t}+\Phi^{*} \operatorname{div} \mathbf{v}\right] \mathrm{ds}=0$

Porém, de acordo com a Eq. 2.17, cuja validade é assegurada para cada ponto $a P_{t}$, tem-se que a primeira dessas integrais é identicamente nula. Então:

$\int_{\Delta s_{f}}\left[\frac{D \Phi^{*}}{D t}+\Phi^{*} \operatorname{div} \mathbf{d}\right]=0$

Na medida em que a extensão de $s_{f}$ pode ser regulada pelo raio do volume da vizinhança contida em $P_{t}$ que lhe deu origem, então, ela pode ser tornada tão pequena quanto se queira, para cada ponto de $s_{f}(t)$. Daí, para um ponto um genérico de, tem-se: 
$\frac{D \Phi^{*}}{D t}+\Phi^{*} \operatorname{div} \mathbf{v}=0$

Essa equação, cuja análise será desenvolvida adiante, sintetiza um dos principais objetivos do presente trabalho, que é demonstrar a possibilidade de utilização da mecânica do contínuo na análise do fenômeno da fratura.

\section{TEORIA TERMODINAMICAMENTE CONSISTENTE DA FRATURA}

De posse dos resultados obtidos na seção anterior, é possível organizar-se uma teoria termodinamicamente consistente, desenvolvida com base no suporte conceitual da mecânica do contínuo. Como adiante será constatado, o presente trabalho opta por não esgotar, ainda, toda a generalidade aberta pelos resultados obtidos neste capítulo. Isto porque algumas grandezas surgidas no bojo do desenvolvimento teórico, para que sejam suficientemente caracterizadas, irão demandar um trabalho de interpretação que está fora do objetivo pretendido neste momento. De toda forma, aqui será ao menos esboçada uma análise do significado desses resultados.

As novas grandezas surgidas, associadas à superfície de avanço da físsura, são as seguintes: a densidade $\rho$, com dimensão de massa por unidade de superfície; $\eta$ e $\varepsilon$, entropia e energia interna, ambas por unidade de massa, respectivamente, definidas em pontos da superfície de avanço da fissura, $s_{\mathrm{f}}(t)$. Vale destacar que o aparecimento de tais grandezas já ocorre no trabalho de Eftis e Liebowitz (1976). Para Zhang e Karihaloo (1993), o surgimento delas fornece a base para uma nova interpretação do parâmetro energia superficial específica, $\gamma$, concebido por Griffith. Nesse último trabalho, a nova grandeza, $\gamma$, seria a densidade de energia superficial termodinâmica de fratura, dada por: $\gamma=\rho[\psi+T \eta+(1 / 2) . \mathbf{v . v}]$, onde $T$ é a temperatura absoluta e $\psi$ é a densidade superficial de energia livre (por unidade de massa), compatível com a definição da energia livre de Helmholtz, que seria dada, em variáveis definidas na superfície, por: $\psi=\varepsilon-T \eta$.

No presente trabalho, que abre a possibilidade um exame mais detalhado das expressões matemáticas aparecidas em Eftis e Liebowitz (1976) e Zhang e Karihaloo (1993), surge uma nova interpretação, quiçá mais simplificada, do problema.

Sejam definidas em $P_{\mathrm{t}}$ as grandezas $\rho$, massa específica; $\varepsilon, \eta, r, \xi, T$ e $\Lambda$, a energia interna, a entropia, a taxa de fornecimento de calor e a taxa de produção de entropia, todas por 
unidade de massa; a temperatura absoluta e a dissipação interna por unidade de volume, respectivamente. Sejam também, $\mathbf{x}, \mathbf{v}, \mathbf{f}, \boldsymbol{n}$ e $\boldsymbol{q}$ os vetores de posição, velocidade, força de corpo por unidade de massa, vetor normal unitário externo e fluxo de calor; e T, D, os tensor tensão de Cauchy e o tensor taxa de deformação, respectivamente.

Com o auxílio dessas grandezas, a seguir serão particularizadas as equações globais e as equações locais de balanço, com apoio nos resultados do desenvolvimento geral obtido na Seção 2.3. Mediante a especialização da Eq. (2.6) para cada um dos cinco princípios do balanço termomecânico, os campos $\Phi$ e $\Phi$ serão identificados adequadamente a cada um dos casos das leis de conservação: da massa, da quantidade de movimento linear, da quantidade de movimento angular, da energia. Analogamente, o mesmo será aplicado ao caso do princípio da irreversibilidade, reduzido à forma de igualdade, conforme mostra a Eq. (2.9).

A Eq.(2.6), portanto, é a equação de balanço global, e a Eq.(2.17) a equação de balanço local, em cada ponto do volume de $P_{\mathrm{t}}$. Finalmente, através da Eq. (2.20), será obtida a equação de balanço local, em cada ponto da superfície de avanço da fissura.

\section{Equações de balanço}

a) Para o caso do princípio de conservação da massa, a identificação das grandezas, na Eq. (2.6), será a seguinte:

$\Phi=\rho, \quad \Phi=\rho, \quad=\mathbf{0} \quad$ e $\quad \mathbf{g}=\mathbf{0}$.

Equação global:

$\frac{D}{D t} \int_{P_{t}} \rho \mathrm{d} v+\frac{D}{D t} \int_{f_{f}(t)} \rho^{*} \mathrm{~d} s=0$.

Equação local, válida para pontos do interior do sólido fora da superfície de avanço da fissura

Usando-se a Eq.(2.17), com as grandezas particularizadas pelas Eqs.(2.21), tem-se:

$\rho+\rho \operatorname{divv}=0$.

Equação local, nos pontos situados nas faces das fissuras

Usando-se a Eq.(2.20), com as grandezas particularizadas pela Eq.(2.21), tem-se: 
$\rho^{*}+\rho^{*} \operatorname{divv}=0$

b) Para o princípio de conservação da quantidade de movimento linear, as grandezas são:

$\Phi=\rho \mathbf{v}, \quad \Phi=\rho \mathbf{v}, \quad=\mathbf{T} \quad$ e $\quad \mathbf{g}=\rho \mathbf{b}$.

Equação global

De acordo com as Eqs. (2.6) e (2.25), tem-se:

$\frac{D}{D t} \int_{P_{t}} \rho \mathbf{v} \mathrm{d} v+\frac{D}{D t} \int_{s_{f}(t)} \rho^{*} \mathbf{v} \mathrm{d} s=\int_{\partial P_{t}} \mathbf{T} \cdot \mathbf{n} \mathrm{d} s+\int_{P_{t}} \rho \mathbf{b} \mathrm{d} v$.

Equação local, válida para pontos do interior do sólido fora da superfície de avanço da fissura

Fazendo-se uso da Eq.(2.17), particularizada para o caso, e usando-se as grandezas definidas pelas Eqs. (2.25), chega-se a:

$\frac{D(\rho \mathbf{v})}{D t}+\rho \mathbf{v} \operatorname{div} \mathbf{v}-. \nabla-\rho \mathbf{f}=0$

ou

$\rho \mathbf{v}+\rho \mathbf{v}+\rho \mathbf{v} \operatorname{div} \mathbf{v}-\mathbf{T} . \nabla-\rho \mathbf{f}=\mathbf{0}$,

ou ainda:

$\rho \mathbf{v}+(\rho+\rho \operatorname{div} \mathbf{v}) \mathbf{v}-\mathbf{T} . \nabla-\rho \mathbf{f}=\mathbf{0}$.

Considerando-se a Eq. (2.23), que expressa o princípio de conservação da massa, a Eq. (2.29) passa a:

$\mathbf{T} . \nabla+\rho(\mathbf{f}-\mathbf{v})=\mathbf{0}$,

que corresponde à equação de equilíbrio dinâmico, num ponto do interior do sólido.

Equação local, nos pontos situados nas superfícies de avanço das fissuras 
Levando-se em conta a Eq.(2.20), utilizados os valores das Eqs.(2.25), tem-se:

$\frac{D\left(\rho^{*} \mathbf{v}\right)}{D t}+\rho^{*} \mathbf{v} \operatorname{div} \mathbf{v}=\mathbf{0}$

ou, após a adequada rearrumação:

$\left(\rho^{*}+\rho^{*} \operatorname{div} \mathbf{v}\right) \mathbf{v}-\rho^{*} \mathbf{v}=\mathbf{0}$.

Considerando-se o princípio de conservação da massa nas superfícies de fissuras, expresso pela Eq.(2.24), chega-se, finalmente, a:

$\rho^{*} \mathbf{v}=\mathbf{0}$

Esse é um resultado importante, porque conduz à conclusão de que a aceleração é uma função identicamente nula na superfície de avanço da fissura, o que significa que a velocidade é constante, em qualquer ponto dessa superfície, durante o processo de fratura. Esse resultado revela que a propagação de fissuras num sólido dá-se a velocidade constante, em cada ponto da superfície de avanço da fissura.

c) No caso do princípio de conservação da quantidade de movimento angular, as variáveis são:

$\Phi=\rho \mathbf{p} \times \mathbf{v}, \quad \Phi=\rho \mathbf{p} \times \mathbf{v}, \quad=\mathbf{p} \times \mathbf{T} \quad$ e $\quad \mathbf{g}=\rho \mathbf{p} \times \mathbf{f}$,

onde $\mathbf{p}=\mathbf{x}-\mathbf{x}_{\mathbf{0}}$.

Equação global

$\frac{D}{D t} \int_{P_{t}} \rho \mathbf{p} \times \mathbf{v} \mathrm{d} v+\frac{D}{D t} \int_{s_{f}(t)} \rho^{*} \mathbf{p} \times \mathbf{v} \mathrm{d} s=\int_{\partial P_{t}}(\mathbf{p} \times \mathbf{T}) \cdot \mathbf{n} \mathrm{d} s+\int_{P_{t}} \rho \mathbf{p} \times \mathbf{f} \mathrm{d} v$.

Observação: Para que a notação $Y=\mathbf{p} \times \mathbf{T}$ faça sentido, considera-se que a operação $(\mathbf{p} \times \mathbf{T}) . \mathbf{n}$ é equivalente a $\mathbf{p} \times($ T.n). 
Equação local, válida para pontos do interior do sólido fora da superfície de avanço da fissura

Usando-se a Eq.(2.17), com os valores particulares da Eq.(2.34), tem-se:

$\frac{D(\rho \mathbf{p} \times \mathbf{v})}{D t}+(\rho \mathbf{p} \times \mathbf{v}) \operatorname{div} \mathbf{v}-(\mathbf{p} \times \mathbf{T}) \cdot \nabla-\rho(\mathbf{p} \times \mathbf{f})=0$

ou:

$\dot{\rho}(\mathbf{p} \times \mathbf{v})+\rho(\dot{\mathbf{p}} \times \mathbf{v}+\mathbf{p} \times \dot{\mathbf{v}})+\rho(\mathbf{p} \times \mathbf{v}) \operatorname{div} \mathbf{v}-(\mathbf{p} \times \mathbf{T}) \cdot \nabla-\rho(\mathbf{p} \times \mathbf{f})=0$.

Reagrupando-se convenientemente, e levando em conta que $\dot{\mathbf{p}} \times \mathbf{v}=\mathbf{0}$, tem-se:

$(\mathbf{p} \times \mathbf{v})(\rho+\rho \operatorname{div} \mathbf{v})-(\mathbf{p} \times \mathbf{T}) \cdot \nabla-\rho \mathbf{p} \times(\mathbf{f}-\mathbf{v})=\mathbf{0}$.

Levando-se em conta o princípio de conservação da massa, expresso pela Eq.(2.23), e o princípio de conservação do momentum linear, expresso pela Eq.(2.30), obtém-se, então, a expressão representativa do princípio de conservação da quantidade de movimento angular, isto é:

$(\mathbf{p} \times \mathbf{T}) \cdot \nabla=\mathbf{p} \times(\mathbf{T} \cdot \nabla)$

Para provar que tal expressão responde pela simetria do tensor tensão de Cauchy, premultiplicam-se (produto interno), inicialmente, ambos os membros dessa igualdade por um deslocamento infinitesimal rígido arbitrário, w, integrando-se após, o que dá:

$\int_{P_{t}} \mathbf{w} \cdot[(\mathbf{p} \times \mathbf{T}) \cdot \nabla] \mathrm{d} v=\int_{P_{t}} \mathbf{w} \cdot[\mathbf{p} \times(\mathbf{T} \cdot \nabla)] \mathrm{d} v$

Mediante a aplicação do teorema de Gauss (da divergência), o primeiro membro dessa equação fica:

$\int_{P_{t}} \mathbf{w} \cdot[(\mathbf{p} \times \mathbf{T}) \cdot \nabla] \mathrm{d} v=\int_{\partial P_{t}} \mathbf{w} \cdot[(\mathbf{p} \times \mathbf{T}) \cdot \mathbf{n}] \mathrm{d} s$.

Usando a propriedade do produto misto, tem-se: 


$$
\int_{\partial P_{t}} \mathbf{w} \cdot[(\mathbf{p} \times \mathbf{T}) \cdot \mathbf{n}] \mathrm{d} s=\int_{\partial P_{t}} \mathbf{w} \cdot[(\mathbf{p} \times \mathbf{T n})] \mathrm{d} s=\int_{\partial P_{t}}(\mathbf{T n}) \cdot(\mathbf{w} \times \mathbf{p}) \mathrm{d} s
$$

Aplicando-se à última expressão a definição de tensor transposto, e reutilizando o Teorema da Divergência para fazer a integral voltar ao volume, tem-se:

$$
\int_{\partial P_{t}}(\mathbf{T} \cdot \mathbf{n}) \cdot(\mathbf{w} \times \mathbf{p}) \mathrm{d} s=\int_{\partial P_{t}}\left[\mathbf{T}^{\mathrm{T}}(\mathbf{w} \times \mathbf{p}) \cdot \mathbf{n}\right] \mathrm{d} s=\int_{P_{t}}\left[\mathbf{T}^{\mathrm{T}}(\mathbf{w} \times \mathbf{p})\right] \cdot \nabla \mathrm{d} v .
$$

que é a nova forma do primeiro membro da Eq. (2.40). Isso faz com que essa equação fique:

$$
\int_{P_{t}}\left[\mathbf{T}^{\mathrm{T}}(\mathbf{w} \times \mathbf{p})\right] \cdot \nabla \mathrm{d} v=\int_{P_{t}} \mathbf{w} \cdot[\mathbf{p} \times(\mathbf{T} \cdot \nabla)] \mathrm{d} v
$$

Porém, de acordo com a sexta propriedade das Eqs.(7. 89), tem-se:

$$
\left[\mathbf{T}^{\mathrm{T}}(\mathbf{w} \times \mathbf{p})\right] \cdot \nabla=\mathbf{T}: \nabla(\mathbf{w} \times \mathbf{p})+(\mathbf{w} \times \mathbf{p}) \cdot(\mathbf{T} \cdot \nabla)
$$

De acordo com a propriedade de circularidade do produto misto, verifica-se que a segunda parcela do segundo membro dessa última expressão ewquivale ao integrando do segundo membro da Eq. (2.44). Daí, a substituição desse resultado na Eq. (2.44) dá:

$$
\int_{P_{t}} \mathbf{T}: \nabla(\mathbf{w} \times \mathbf{p}) \mathrm{d} v=0
$$

O deslocamento infinitesimal rígido, w, possui a propriedade segundo a qual existe um único tensor que antissimétrico, $\mathbf{W}$, associado a esse vetor, tal que

$$
\mathbf{w} \times \mathbf{p}=\mathbf{W p}
$$

qualquer que seja p. Isto significa que, de acordo com a definição de tensor transposto e, levando-se em conta a definição de tensor antissimétrico, tem-se:

$$
\nabla(\mathbf{W} \times \mathbf{p})=\nabla(\mathbf{W} \mathbf{p})=\mathbf{W}^{\mathbf{T}}(\nabla \mathbf{p})=-\mathbf{W}(\nabla \mathbf{p})
$$

Daí, levando à Eq.(2.45), tem-se: 
$\int_{P_{t}} \mathbf{T}: \mathbf{W}(\nabla \mathbf{p}) \mathrm{d} v=0$

Considerando-se que $\nabla \mathbf{p}$ é o tensor identidade, então, finalmente:

$\int_{P_{t}} \mathbf{T}: \mathbf{W} \mathrm{d} v=0$

Desde que o deslocamento infinitesimal rígido, w, é arbitrário, e em razão da propriedade segundo a qual, ao ser nulo o produto interno de um dado tensor por um tensor antissimétrico, o primeiro é, obrigatoriamente, um tensor simétrico (ver Eq. (7.52), então, devido à Eq.(2.46), o tensor tensão T deve ser simétrico, isto é:

$\mathbf{T}=\mathbf{T}^{\mathrm{T}}$

Equação local, nos pontos situados nas faces das fissuras

Levando-se em conta a forma geral, definida pela Eq.(2.20), com as variáveis dadas pelas Eqs.(2.34), tem-se:

$$
\frac{D\left(\rho^{*} \mathbf{p} \times \mathbf{v}\right)}{D t}+\left(\rho^{*} \mathbf{p} \times \mathbf{v}\right) \operatorname{div} \mathbf{v}=\mathbf{0} .
$$

Desenvolvendo-se o primeiro membro, de maneira análoga ao que foi realizado com a Eq. (2.36), obtém-se:

$$
(\mathbf{p} \times \mathbf{v})\left(\dot{\rho}^{*}+\rho^{*} \operatorname{divv}\right)+\rho^{*} \mathbf{p} \times \dot{\mathbf{v}}=\mathbf{0} .
$$

Levando-se em conta a Eq.(2.24), que corresponde à conservação de massa, na superfície de avanço da fissura, tem-se:

$$
\begin{aligned}
& \rho^{*} \mathbf{p} \times \mathbf{v}=\mathbf{0} \\
& \text { ou seja: } \\
& \mathbf{p} \times\left(\rho^{*} \mathbf{v}\right)=\mathbf{0},
\end{aligned}
$$


resultado que nada acrescenta à compreensão do fenômeno, porquanto a Eq. (2.33) garante que a Eq. (2.50) seja sempre verdadeira, qualquer que seja o vetor $\mathbf{p}$.

d) No caso do princípio de conservação da energia, as variáveis a serem consideradas são:

$\Phi=\rho \varepsilon^{+} \frac{1}{2} \rho \mathbf{v} . \mathbf{v}, \quad \Phi=\rho \varepsilon^{+}+\frac{1}{2} \rho \mathbf{v} . \mathbf{v}, \quad=\mathbf{v} . \mathbf{T}-\mathbf{q} \quad$ e $\quad \mathbf{g}=\rho \mathbf{v} . \mathbf{f}+\rho r$

que substituídas na Eq. (2.15) levam a:

Equação global

$$
\begin{aligned}
\frac{D}{D t} \int_{P_{t}}\left(\rho \varepsilon+\frac{1}{2} \rho \mathbf{v} \cdot \mathbf{v}\right) \mathrm{d} v+\frac{D}{D t} \int_{s_{f}(t)}\left(\rho \varepsilon^{*}+\frac{1}{2} \rho^{*} \mathbf{v} \cdot \mathbf{v}\right) \mathrm{d} s= \\
\quad=\int_{\partial P_{t}}(\mathbf{v} \cdot \mathbf{T}-\mathbf{q}) \cdot \mathbf{n} \mathrm{d} s+\int_{P_{t}}(\rho \mathbf{v . f}+\rho r) d v .
\end{aligned}
$$

Equação local, válida para pontos do interior do sólido fora da superfície de avanço da fissura

De acordo com as Eqs. (2.17) e (2.51):

$$
\frac{D}{D t}\left(\rho \varepsilon+\frac{1}{2} \rho \mathbf{v} \cdot \mathbf{v}\right)+\left(\rho \varepsilon+\frac{1}{2} \rho \mathbf{v} \cdot \mathbf{v}\right) \operatorname{divv}-(\mathbf{v} \cdot \mathbf{T}-\mathbf{q}) \cdot \nabla-\rho(\mathbf{v} . \mathbf{f}+\mathrm{r})=0
$$

Desenvolvendo-se as derivações e agrupando os termos adequadamente, obtém-se:

$$
\rho \varepsilon+\left(\varepsilon+\frac{1}{2} \mathbf{v} \cdot \mathbf{v}\right)(\rho+\rho \operatorname{div})-(\mathbf{v} \cdot \mathbf{T}-\mathbf{q}) \cdot \nabla-\rho \mathbf{v}(\mathbf{f}-\mathbf{v})-\rho r=0
$$

Levando-se em conta as Eqs. (2.23) e (2.30), de conservação da massa e de conservação da quantidade de movimento linear, respectivamente, a equação anterior fica:

$$
\rho \varepsilon-(\mathbf{v} \cdot \mathbf{T}) \cdot \nabla+\mathbf{q} \cdot \nabla+\mathbf{v} \cdot(\mathbf{T} \cdot \nabla)-\rho r=0 .
$$

Porém, de acordo com a sexta propriedade das Eqs. (7.89):

$(\mathbf{v} \cdot \mathbf{T}) \cdot \nabla=\mathbf{T}:(\mathbf{v} \cdot \nabla)+\mathbf{v} \cdot(\mathbf{T} \cdot \nabla)$, 
que substituída na equação anterior leva a:

$$
\rho \varepsilon-\mathbf{T}:(\mathbf{v} \cdot \nabla)+\mathbf{q} \cdot \nabla-\rho r=0
$$

Em razão da simetria de $\mathbf{T}$, somente a parte simétrica do tensor $\mathbf{v} . \nabla$, que é o tensor taxa de deformação D, interfere nos cálculos. Obtém-se assim, finalmente, a forma local do princípio de conservação da energia, nos pontos do interior do sólido que estão fora da superfície de avanço da fissura, isto é:

$$
\rho \varepsilon-\mathbf{T}: \mathbf{D}+\mathbf{q} \cdot \nabla-\rho r=0,
$$

resultado que expressa o balanço de energia, ao nível local.

Equação local, nos pontos situados nas faces das fissuras

De acordo com a Eq.(2.20), e com a particularização das variáveis, feita através da Eq.(2.51), tem-se:

$$
\frac{D\left(\rho^{*} \varepsilon^{*}+\frac{1}{2} \rho^{*} \mathbf{v} \cdot \mathbf{v}\right)}{D t}+\left(\rho^{*} \varepsilon^{*}+\frac{1}{2} \rho^{*} \mathbf{v} \cdot \mathbf{v}\right) \operatorname{div} \mathbf{v}=0
$$

cujo desenvolvimento leva a:

$$
\rho^{*} \varepsilon^{*}+\rho^{*} \mathbf{v} \cdot \mathbf{v}+\left(\varepsilon^{*}+\frac{1}{2} \mathbf{v} \cdot \mathbf{v}\right)\left(\rho^{*}+\rho^{*} \operatorname{div} \mathbf{v}\right)=0
$$

A consideração do princípio de conservação da massa, dada pela Eq. (2.24), conduz à anulação da última parcela do segundo membro da Eq. (2.60), ficando:

$$
\rho^{*} \varepsilon^{*}+\rho^{*} \mathbf{v} \cdot \mathbf{v}=0
$$

Portanto, de acordo com a Eq. (2.33), a segunda parcela do segundo membro da Eq. (2.61) é nula, o que dá:

$$
\rho^{*} \varepsilon^{*}=0
$$


Isto significa que a densidade de energia interna, $\varepsilon$, mantém-se constante, na passagem do estado íntegro para o estado fissurado, na superfície de avanço da fissura.

Convém que se interprete esse resultado à luz da noção de energia livre de Helmholtz, através do qual a densidade de energia interna desdobra-se em duas parcelas: a primeira, $\psi^{*}$, densidade de energia livre, que representa a parcela máxima da energia interna que pode ser transformada em trabalho no processo, e a segunda, $T \eta^{*}$, que está associada ao calor envolvido, isto é,

$\varepsilon^{*}=\psi^{*}+T \eta^{*}$

Levando-se a Eq. (2.63) na Eq. (2.62), tem-se, finalmente:

$\frac{D}{D t} \psi^{*}=-\frac{D}{D t}\left(T \eta^{*}\right)$

Esse é um importante resultado, o qual demonstra que, no processo de fissuração, a taxa de variação da grandeza que representa a máxima quantidade passível de produzir trabalho, no instante em que a fissura avança, é equivalente ao valor negativo da taxa de variação do calor envolvido. Isto significa que, enquanto estiver sendo produzido calor nas superfície de avanço da fissura, então a tendência é que decaia a quantidade de trabalho disponível para a continuação do processo de fissuração. Pelo que indica a Eq. (2.64), a possibilidade de tal processo vir a se estabilizar, fica na dependência da taxa de variação da quantidade de calor (a produzida mais a fornecida ao sistema).

Trata-se, portanto, de uma informação que as abordagens de Griffith, Irwin e Rice nunca poderiam prever, isto é, de como a dinâmica do processo de fissuração está associada à taxa de calor envolvida no processo.

e) No caso do princípio da irreversibilidade, tomado como uma igualdade, segundo o raciocínio que levou à Eq. (2.9), as variáveis a serem consideradas na Eq. (2.6) são:

$\Phi=\rho \eta, \quad \Phi=\rho^{*} \eta, \quad=-\mathbf{q} / T \quad$ e $\quad \mathbf{g}=\rho\left(\frac{r}{T}+\xi\right)$

Equação global 


$$
\frac{D}{D t} \int_{P_{t}} \rho \eta \mathrm{d} v+\frac{D}{D t} \int_{f_{f}(t)} \rho^{*} \eta^{*} \mathrm{~d} s=\int_{P_{t}} \rho\left(\frac{r}{T}+\xi\right) \mathrm{d} v-\int_{\partial P_{t}} \frac{\mathbf{q} \cdot \mathbf{n}}{T} \mathrm{~d} s .
$$

Equação local, válida para pontos do interior do sólido fora da superfície de avanço da físsura

De acordo com a Eq.(2.17), e levando-se em conta a definição de variáveis dada através da Eq.(2.65), vem:

$$
\frac{D(\rho \eta)}{D t}+\rho \eta \operatorname{div} \mathbf{v}+\left(\frac{\mathbf{q}}{T}\right) \cdot \nabla-\rho\left(\frac{r}{T}+\xi\right)=0 .
$$

Desenvolvendo-se a derivação material no tempo e agrupando-se adequadamente, tem-se:

$$
\eta(\rho+\rho \operatorname{divv})+\rho \eta+\left(\frac{\mathbf{q}}{T}\right) \cdot \nabla-\rho \frac{r}{T}-\rho \xi=0 .
$$

Levando-se em conta o Princípio de Conservação da Massa, Eq. (2.23), e a identidade

$$
\left(\frac{\mathbf{q}}{T}\right) \cdot \nabla=\operatorname{div}\left(\frac{\mathbf{q}}{T}\right)=\frac{1}{T} \mathbf{q} \cdot \nabla-\frac{1}{T^{2}} \mathbf{q} \cdot \operatorname{grad} T
$$

então a Eq.(2.68) torna-se:

$$
\rho \xi T=\rho \dot{\eta} T+\mathbf{q} \cdot \nabla+\frac{1}{T} \mathbf{q} \cdot \operatorname{grad} T-\rho r
$$

Levando-se em conta, agora, a expressão local da Primeira Lei da Termodinâmica, representada pela Eq.(2.58), então, tem-se:

$\mathbf{q} \cdot \nabla=\mathbf{T}: \mathbf{D}-\rho \varepsilon+\rho r$

cuja substituição na Eq.(2.70) conduz, finalmente, à equação que exprime localmente o princípio da irreversibilidade: 
$\rho \xi T=\Lambda-\frac{1}{T} \mathbf{q} \cdot \operatorname{grad} T \geq 0$,

onde

$\Lambda=\rho \dot{\eta} T+\mathbf{T}: \mathbf{D}-\rho \dot{\varepsilon}$,

que corresponde à taxa de dissipação de energia por unidade de volume. A Eq. (2.72) revela que a taxa de produção de entropia em $P_{\mathrm{t}}$, quando dentro dela uma fissura está avançando, é dada por:

$\xi=\frac{\Lambda}{\rho T}-\frac{1}{\rho T^{2}} \mathbf{q} \cdot \operatorname{grad} T \geq 0$.

Equação local nos pontos situados nas faces das fissuras

Levando-se em conta a Eq.(2.20) e considerando-se as variáveis definidas na Eq.(2.65), tem-se:

$\frac{D\left(\rho^{*} \eta^{*}\right)}{D t}+\rho^{*} \eta^{*} \operatorname{div} \mathbf{v}=0$

Realizando-se a derivação material no tempo e reunindo os termos adequadamente, vem:

$\rho^{*} \eta^{*}+\eta^{*}\left[\rho^{*}+\rho^{*} \operatorname{divv}\right]=0$

Levando-se em conta o princípio de conservação da massa, dado pela Eq. (2.24), chega-se, finalmente, à equação que exprime o princípio da irreversibilidade, nos pontos das faces das fissuras, isto é:

$\rho^{*} \eta^{*}=0$

Partindo-se da definição de energia livre de Helmholtz, dada através da Eq. (2.63), chega-se á sua derivada material no tempo, isto é: 
$\varepsilon^{*}=\psi^{*}+\frac{D}{D t}\left(T \eta^{*}\right)$

No entanto, devido à Eq. (2.64), a Eq. (2.78) torna-se:

$\varepsilon^{*}=0$

o que significa que a função energia livre de Helmholtz não se altera com o tempo, nas superfícies de avanço das fissuras, durante a evolução do processo. Isto quer dizer que, caso o processo de fissuração se deflagre, então a parcela da energia de deformação (trabalho, no sentido termodinâmico) empregada no processo de avanço de uma fissura é toda transformada em calor.

Coerente com isso, se o resultado representado pela Eq. (2.77) for levado à segunda integral do segundo membro da igualdade, na Eq. (2.8), então:

$$
\int_{P_{t}} \rho \xi \mathrm{d} v=\int_{P_{t}} \rho\left(\dot{\eta}-\frac{r}{T}\right) \mathrm{d} v+\int_{\partial P_{t}} \frac{\mathbf{q} \cdot \mathbf{n}}{T} \mathrm{~d} s \geq 0 .
$$

Isso significa que o fenômeno de fissuração não afeta a taxa de produção de entropia no sólido. De fato, se o avanço do processo de fissuração é totalmente realizado às expensas do trabalho de deformação que nela se desenvolve, então a taxa de produção de entropia no sólido não deve ser influenciada por esse processo. O que ainda resta saber é como a energia de deformação relacionada a volume, no sólido, interage com a energia de deformação desenvolvida nas superfícies de avanço das fissuras, de modo a permitir a deflagração do processo de fissuração, sua continuidade, ou sua interrupção. Isto sugere a existência de um princípio de extremo cuja elaboração mereceu o exame de Bolotin (1994), que formulou um modelo de princípio de trabalhos virtuais com restrições unilaterais, no qual estão envolvidas duas classes de coordenadas generalizadas: as coordenadas comuns, de Lagrange, e as coordenadas por ele denominadas coordenadas de Griffith, características da forma e das dimensões de fissuras ou outros defeitos.

O conjunto dos resultados acima, decorrente da passagem das equações de balanço global para as de balanço local, é útil a uma reinterpretação do parâmetro ${ }^{*}$, denominado densidade de energia superficial termodinâmica de fratura, e definido por Eftis e Liebowitz (1976) como: 
$\gamma^{*}=\rho^{*}\left(\psi^{*}+T \eta^{*}\right)$

cuja derivada material no tempo dá:

$\frac{D}{D t} \gamma^{*}=\dot{\rho}^{*}\left(\psi^{*}+T \eta^{*}\right)+\rho^{*}\left[\psi^{*}+\frac{D}{D t}\left(\mathrm{~T} \eta^{*}\right)\right]$

A substituição das Eqs. (2.64) e (2.81) na Eq.(2.82) leva a:

$\frac{D}{D t} \gamma^{*}=\dot{\gamma}^{*}=\dot{\rho}^{*} \frac{\gamma^{*}}{\rho^{*}}$,

ou seja:

$\frac{\dot{\gamma}^{*}}{\gamma^{*}}=\frac{\dot{\rho}^{*}}{\rho^{*}}$,

cuja solução geral é

$\gamma^{*}=C \rho^{*}$

onde $C$ é uma grandeza constante, no tempo, com dimensão de energia por unidade de massa, que sugere dependência do fenômeno em relação ao material do sólido no qual se desenvolve.

Verifica-se, através da Eq. (2.85), que a densidade de energia superficial termodinâmica de fratura, $\gamma^{*}$, está relacionada somente com a massa específica superficial. Vale observar que esse resultado difere substancialmente daquele obtido por Zhang e Karihaloo (1993) que chegou-se à conclusão que tal grandeza não é constituída de três parcelas, a saber, $\rho, \psi$ e $\eta$, com

$\gamma=\rho[\psi+T \eta+(1 / 2) . \mathbf{v . v}]$

mas de uma somente, a atestar, pelo que mostra a Eq. (2.85), cuja simplicidade é aparente, na medida exige a interpretação do que seja a densidade superficial de massa.

Comprovada a possibilidade de aplicação da mecânica do contínuo à mecânica da fratura, a seção seguinte será dedicada à formulação de uma metodologia envolvendo 
experimentações, numérica e de laboratório, na pesquisa de um critério de fratura termodinamicamente consistente, limitado, porém, ao caso isotérmico. 


\title{
3 CRITÉRIO TERMODINAMICAMENTE CONSISTENTE DE FRATURA
}

Dois trabalhos (GRIFFITH, 1921, 1924) são considerados os pioneiros da mecânica da fratura. O estudo da previsão do início da fratura nos sólidos, desenvolvido nesses dois artigos começa com a formulação de um critério capaz de determinar se haverá, ou não, o crescimento de um vazio (elíptico) preexistente em uma chapa infinita submetida a um esforço uniaxial de tração.

$\mathrm{Na}$ fundamentação de seu critério, no primeiro dos citados trabalhos, afirma Griffith (1921, p. 165, grifo nosso):

\begin{abstract}
De acordo com o bem conhecido teorema da energia minima, o estado de equilíbrio de um sólido elástico deformado por forças de superfície é tal que, para ser atingido, a energia potencial de todo o sistema deve ser um minimum. $\mathrm{O}$ novo critério de ruptura é obtido mediante a adição a esse teorema da consideração segundo a qual a posição de equilíbrio, caso exista, deve ser aquela em que a ruptura do sólido ocorrerá quando o sistema passar da situação de integridade para a de ruptura, através de um processo em que ocorra um decréscimo da energia potencial... Para aplicar-se, entretanto, esse teorema estendido ao problema da determinação de cargas de ruptura em sólidos reais é necessário levar-se em conta o acréscimo na energia potencial que ocorre quando da formação de novas superfícies no interior dos sólidos. É sabido que, para a formação de uma fissura num sólido composto por moléculas que se atraem, deve ser realizado um trabalho contra as forças coesivas das moléculas, em cada lado da fissura. Esse trabalho aparece como uma energia potencial de superfície e, se a largura da fissura é maior que a muito pequena distância, denominada raio de ação molecular, então a energia por unidade de área é uma constante do material, isto é, sua tensão superficial. ${ }^{5}$ (tradução livre)
\end{abstract}

Vê-se, na citação acima, que a proposta de Griffith é de que o trabalho associado ao crescimento da fissura seja quantificado com auxílio do parâmetro por ele denominado

\footnotetext{
${ }^{5}$ No original: "According to the well-known theorem of minimum energy, the equilibrium state of an elastic solid body, deformed by specified surface forces, is such that the potential energy of the whole system is a minimum. The new criterion of rupture is obtained by adding to this theorem the statement that the equilibrium position, if equilibrium is possible, must be one in which rupture of the solid has occurred, if the system can pass from the unbroken to the broken condition by a process involving a continuous decrease in potential energy...In order, however, to apply this extended theorem to the problem of finding the breaking loads of real solids, it is necessary to take account of the increase in potential energy which occurs in the formation of new surfaces in the interior of such solids. It is known that, in the formation of a crack in a body composed of molecules which attract one another, work must be done against the coesive forces of the molecules on either side of the crack. ...This work appears as potential surface energy, and if the width of the crack is greater than the very small distance called the 'radius of molecular action', the energy per unit area is a constant of the material, namely, its surface tension."
} 
energia superficial específica (que daria conta de uma espécie de tensão superficial, segundo achava), uma constante física associada ao material. De acordo com esse raciocínio, certa quantidade de trabalho é realizada no processo de abertura da fissura, cujo valor é proporcional ao acréscimo de área das faces da fissura ocorrido durante o processo. Ressaltese que o critério é formulado dentro do pressuposto de que o material tem comportamento elástico linear, já que o ponto de partida de Griffith é o trabalho de Inglis (1913), no qual é examinado o problema da concentração de tensões na vizinhança de orifícios contidos em uma peça plana infinita.

Neste capítulo são examinados os pressupostos admitidos por Griffith (1921) para a formulação de seu critério, a partir, basicamente, do conteúdo da citação há pouco apresentada. $\mathrm{Na}$ sequência, seu critério é examinado com o auxílio da interpretação termodinâmica, cuja base conceitual encontra-se nos dois capítulos anteriores. Aqui, o objetivo é a obtenção de um critério termodinamicamente consistente de fratura, usando-se o de Griffith, em certo sentido, como modelo.

Embora a interpretação termodinâmica da fratura, que aqui se propõe, negue, por imprecisa, a ideia de Griffith (1921) de estender o princípio da mínima energia potencial total ao problema da fratura, aproveita-se a sua sugestão de fundamentar o estudo do fenômeno no exame do balanço de energia realizado entre dois estados: um anterior e outro posterior ao avanço da fissura. Além disso, considera-se importante a contribuição de sua formulação para o desenvolvimento da presente teoria termodinamicamente consistente da fratura, baseada consideração de parcelas de energia associada às superfícies de avanço da fissura.

\section{A FORMA ORIGINAL DE OBTENÇÃO DO CRITÉRIO DE GRIFFITH}

Aproveitando os resultados do trabalho de Inglis (1913), Griffith (1921) considera o caso de uma chapa plana contendo um furo elíptico achatado, de eixo maior $2 a$, livre de forças no seu contorno. A placa acha-se submetida a uma tração $\sigma_{\text {ap, no infinito, }}$ uniformemente distribuída nas bordas paralelas ao eixo maior da elipse. A partir das expressões das tensões é calculada a variação (redução) da energia de deformação entre o caso da chapa infinita sem furo e o da mesma chapa, porém com furo. Para o mesmo carregamento, o valor da variação, $U$, da energia de deformação, do segundo para primeiro caso é calculada como: 


$$
U=-\frac{\sigma_{\mathrm{ap}}^{2} \pi a^{2}}{E^{\prime}}
$$

onde $\quad a p$ é a tensão de tração aplicada nas bordas da placa, e $E^{\prime}$ é equivalente ao módulo de elasticidade $E$, do material, quando no estado plano de tensão. No estado plano de deformação, por sua vez, $E^{\prime}=E /\left(1-v^{2}\right)$, onde $v$ é o coeficiente de Poisson. A Eq. (3.1) quer significar que, para a mesma tensão de tração aplicada no infinito, a chapa com furo armazena menos energia de deformação do que a chapa íntegra.

Griffith (1924) supôs que, no decorrer do processo de deformação, as dimensões lineares do vazio elíptico achatado variavam de acordo com um único parâmetro, a saber, o comprimento do semieixo maior da elipse, de valor $a$. Assim sendo, para o caso de uma chapa de espessura unitária, a superfície interna do vazio é aproximadamente igual a $4 a$, representando a soma das áreas das faces superior e inferior da fissura preexistente, simulada como uma elipse.

Introduzindo o parâmetro $\gamma$, denominado energia superficial específica, e admitindo a variação da área da superfície interna da fissura, Griffith (1924) calcula a variação da energia, mediante a suposição de que é diretamente proporcional à área acrescida da fissura. Admitindo que a expansão do vazio elíptico, caso ocorra, seja realizada às expensas da energia de deformação, ele faz o balanço de energia entre o estado anterior e o estado posterior ao crescimento infinitesimal do eixo maior da elipse, a fim de chegar a seu critério, tal como é mostrado a seguir. Observe-se que Griffith (1924) cunha a expressão energia potencial total para a soma da energia de deformação, $U$, com a energia superficial associada ao vazio elíptico que simula uma fissura na chapa. Assim, considerando a Eq. (3.1) e admitindo que seja nula a variação da energia potencial total, no limite entre o estado fissurado e o não fissurado, ele chega ao critério que hoje leva o seu nome, isto é:

$$
\frac{d}{d a}(U+4 \gamma d a)=0 \Rightarrow \frac{-2 a \sigma_{\text {ap }}^{2} \pi}{E^{\prime}}+4 \gamma d a=0 .
$$

Daí:

$$
\sigma_{\text {ap }}=\sqrt{\frac{2 \gamma E^{\prime}}{\pi a}} .
$$


O valor absoluto de $d U / d a$, no desenvolvimento acima, corresponde a uma grandeza que, mais tarde, seria denominada strain-energy release rate, por Irwin (1957). Tal grandeza foi fisicamente interpretada, pelo próprio Irwin (1957), como uma espécie de força local capaz de provocar o crescimento da fissura, a partir de sua extremidade.

A Eq. (3.3) revela que a tensão aplicada, $\sigma_{\mathrm{ap}}$, comporta-se como se o seu valor assegurasse uma espécie de estado de equilíbrio à fissura, isto é, a fissura ficaria estável ao ter o exato comprimento do eixo maior da elipse, $2 a$, quando a tensão $\sigma_{\mathrm{ap}}$ fosse dada pela Eq. (3.3). Isso revela que se o valor de $a$ fosse menor, então deveria ser maior a tensão de tração aplicada, em equilíbrio com esse tamanho de fissura. Em função desse resultado, Griffith (1924) concluiu que, se fosse possível, mediante intervenção no processo de produção do material, diminuir o tamanho médio dos vazios no interior do sólido dele constituído, tamanho esse parametrizado por um comprimento $a$, então a tensão limite aplicada, $\sigma_{\mathrm{ap}}$, poderia ser artificialmente aumentada, o que significa que a capacidade resistente do material seria tanto maior quanto menor fosse $a$.

Foi devido ao sucesso tecnológico representado pela síntese de um material de alta resistência (a fibra de vidro), produzido com base nesse raciocínio, que se deu a grande difusão do critério de Griffith. Ao diminuir as dimensões dos vazios interiores no vidro, então poderia aumentar bastante o valor de $\sigma_{\text {ap }}$ sem que a fissura crescesse. Chegou a esse objetivo através da produção de finíssimas fibras de vidro, que seriam depois aglomeradas em uma matriz de resina, para formar painéis de fácil moldabilidade e grande resistência. Em síntese, como consequência da formulação do critério que leva seu nome, Griffith chamou atenção para o fato relevante de que a resistência mecânica está relacionada com as dimensões dos espaços vazios presentes no interior dos materiais. A partir daí, passou-se ao entendimento de que, para bem caracterizar os materiais, do ponto de vista do comportamento mecânico, não bastaria o conhecimento de tensões limites de resistência do material, mas também a determinação experimental de uma grandeza capaz de dar conta de sua tenacidade, isto é, a capacidade do material de se opor à fratura que, segundo Griffith (1924), estaria associada às dimensões dos vazios internos. 


\section{VERSÃO TERMODINÂMICA DO CRITÉRIO DE GRIFFITH}

Embora não tenha justificado seu critério, formalmente, a partir das leis da termodinâmica, não há dúvida que Griffith (1924), para formulá-lo, realizou um balanço de energia entre dois estados infinitesimalmente próximos, um anterior e outro posterior ao crescimento da fissura, tal como fica claro na citação original de um dos seus trabalhos, apresentada no início deste capítulo.

Numa reconstituição da essência do raciocínio de Griffith, admitindo-se o processo de fratura como quase estático, a expressão local que corresponde ao balanço termodinâmico (primeira lei da termodinâmica), segundo Dym e Shames (1973), é:

$d \varepsilon=d^{\prime} q+d^{\prime} w$

onde $\varepsilon$ é a energia interna (função de estado) por unidade de volume, $q$ é a quantidade de calor trocada com o exterior (positiva quando o sólido recebe calor), por unidade de volume, e $w$ é o trabalho por unidade de volume realizado sobre o sistema (positivo quando ações externas realizam trabalho sobre o corpo). À semelhança do que foi apresentado no capítulo 1, as parcelas d' $q$ e d'w são diferenciais inexatas, porque nem calor nem trabalho são funções de estado, mas funções do caminho seguido pelo processo de deformação ou de aquecimento, em cada ponto. No entanto, constata-se que a soma das duas grandezas, tal como indica a Eq.(3.4), é uma diferencial exata. Convém observar que a forma diferencial, tal como expressa na Eq. (3.4), diz respeito ao tempo (um instante antes, e outro, um infinitésimo adiante, exatamente quando a fissura avança).

Admitindo-se a existência de um vazio inicial no sólido, a partir do qual a fissura poderá evoluir, imagina-se que somente com a quebra subsequente das ligações materiais é que isso poderá ocorrer. Como consequência, alguma porção de calor deverá estar necessariamente associada à área da superfície irreversivelmente adicionada ao orifício inicial, quando do avanço da fissura. ${ }^{6}$ Conforme demonstra a citação de Griffith apresentada no início deste capítulo, sua ideia original não considera a possibilidade da presença de calor na formação da fissura, embora admita que se manifeste, nas superfícies internas correspondentes ao avanço da fissura, uma parcela de energia superficial que teria o caráter de

\footnotetext{
${ }^{6}$ É evidente que o orifício simulador da fissura, ao aumentar, elasticamente, sua superfície interna, no início do processo de deformação, realiza uma operação reversível.
} 
energia potencial. Isto significa que, para Griffith (1921), a fissuração poderia ser modelada como se fosse um fenômeno reversível.

A consideração da irreversibilidade do processo de fissuração é a novidade da presente análise que, auxiliada pela termodinâmica, admite a existência de duas densidades de energia associadas à superfície de avanço da fissura: uma, $\gamma$, com caráter de trabalho de deformação, reversível, e outra, $\gamma_{\text {diss }}$, na forma de calor gerado durante o processo. Introduz-se, portanto, com esta última, uma grandeza nova, não cogitada por Griffith (1921), associada ao processo irreversível desenvolvido na superfície de avanço da fissura, no qual sempre deve haver calor associado, que se dissipa.

Convém observar que poderia ocorrer alguma parcela extra de calor, dissipado localmente no entorno da extremidade da fissura, não necessariamente relacionada à evolução de uma superfície interna do sólido. É o caso, por exemplo, de fenômenos associados a volume, tais como plasticidade e dano. Por esse motivo, será adotado, daqui para frente, o uso de um asterisco como super-índice, para destacar as parcelas do calor, $q$, e do trabalho de deformação, w, associadas a volume, na Eq. (3.4), separando-as daquelas exclusivamente relacionadas com as superfícies de avanço da fissura.

Assim, se ações externas solicitam o sólido, a contrapartida interna é um acréscimo na parcela $w^{*}$ - o trabalho (energia de deformação) associado ao volume do sólido -, no qual o sinal positivo deve-se ao fato de que corresponde a trabalho realizado sobre o sistema. Caso o furo elíptico achatado preexistente, simulador da fissura, de semi-eixo maior $a$, vier a avançar, então sua área sofrerá um acréscimo aproximadamente igual a $4 \mathrm{~d} a$, e o trabalho elástico sobre o sistema sofrerá um acréscimo de $4 \gamma \mathrm{d} a$, que corresponde à contribuição relacionada com o crescimento reversível da superfície da fissura.

Admitindo-se, diferentemente de Griffith (1924), que o processo de fissuração tenha uma componente irreversível, quantificável através da densidade superficial de dissipação de energia, $\gamma_{\text {diss }}$, então o calor produzido quando do crescimento da fissura deverá ser igual a $4 \gamma_{d i s s} d a_{1}$. Esta quantidade de energia é fornecida ao sistema, já que decorre das ações externas ao sólido. Admite-se, porém, que, ao ser atingido o equilíbrio térmico, esse calor seja totalmente cedido ao reservatório térmico, isto é, o meio ambiente. Portanto, na hipótese de que tenha havido o avanço de alguma fisssura no interior do sólido então, o balanço de energia, antes e depois de iniciada a fissuração, após o equilíbrio térmico, leva a que a variação da energia interna seja dada por: 
$\mathrm{d} \varepsilon=\left(4 \gamma_{d i s s} \mathrm{~d} a_{1}+d^{\prime} q\right)+\mathrm{d} w^{*}+4 \gamma d a$

onde a parcela entre parênteses corresponde à troca de calor com o ambiente, sendo a primeira parcela o calor desenvolvido na fissura, durante o avanço. As duas restantes parcelas do segundo membro representam, respectivamente, o trabalho de deformação associado a volume e a parte reversível do trabalho de deformação realizado na fissura.

A perspectiva da construção de uma teoria que leve em conta a irreversibilidade do processo de fissuração exige a consideração da entropia $S$, do sólido, através da qual é estabelecida a relação entre a variação da quantidade de calor trocada com o exterior (entre o estado anterior e o posterior do sólido) e a temperatura absoluta de equilíbrio $T$, que é a temperatura do ambiente. Caso não houvesse a formação de fissura no interior do sólido, então d' $q^{*}$ seria igual a $T \mathrm{~d} S$. No entanto, admitindo-se que haja o crescimento de uma fissura no interior do sólido, como consta da Eq. (3.5), soma-se d' $q^{*}$ à parcela correspondente à dissipação de energia associada ao avanço da fissura, já que esta última é calor cedido ao sólido pelas ações externas. Portanto, a relação da entropia do sólido com o balanço calorífico, na hipótese de que o processo de fissuração haja se iniciado, será dada por:

$\mathrm{d}^{\prime} q^{*}+4 \gamma_{d i s s} \mathrm{~d} a_{1}=T \mathrm{~d} S$

De modo semelhante ao que foi feito no capítulo 1, introduz-se a grandeza $\psi=\varepsilon-T S$, energia livre de Helmholtz, onde $\psi$ é uma função de estado que, quando o processo é irreversível, corresponde à máxima quantidade de energia disponível no sólido para a realização de trabalho (LEWIS; RANDALL, 1961). Diferenciando-se essa grandeza, resulta:

$\mathrm{d} \psi=\mathrm{d} \varepsilon-T d s-s d T$

Substituindo-se as Eqs.(3.5) e (3.6) na Eq.(3.7), resulta:

$\mathrm{d} \psi=\mathrm{d} w^{*}+4 \gamma d a-s d T$

Admitindo-se que o processo seja isotérmico, já que ocorre no meio ambiente, então $d T=0$. A consideração desse fato conduz a:

$\mathrm{d} \psi=d w^{*}+4 \gamma d a$ 
A Eq.(3.9) evidencia a parcela da energia interna passível de ser transformada em trabalho, confirmando que equivale à energia livre de Helmholtz. Isso ocorre exatamente sobre a parcela elástica da energia de deformação, entre os dois estados, antes e depois do crescimento do furo elíptico. Baseada na intuição de Griffith (1924), a Eq. (3.2) coincide com a Eq. (3.9), agora obtida com o rigor da interpretação termodinamicamente consistente da fratura. $\mathrm{O}$ que há de novo é a prova de que, independentemente da relação constitutiva do material, a variação ocorre somente sobre a parcela elástica da energia de deformação, representada, de agora em diante, por $\mathrm{d} E_{\mathrm{d}}$. A Eq. (3.1) mostra que essa variação é negativa, após o crescimento de uma fissura na chapa.

O importante resultado expresso pela Eq. (3.9) deriva da interpretação do fenômeno da fratura, à luz da primeira e da segunda lei da termodinâmica, articulado com o conceito de energia livre de Helmholtz, segundo o qual, para ocorrer a iniciação espontânea de um fenômeno na natureza, fato que caracteriza a irreversibilidade, é necessário um decréscimo na energia livre $\psi$, decréscimo esse que será o menor possível (LEWIS; RANDALL, 1961).

Em virtude do que revela a Eq. (3.9), e fazendo-se um paralelo com a energy release rate, $G$, que é a derivada da energia potencial total em relação ao parâmetro de fratura, definese agora a derivada, $G_{t}$, da energia de deformação em relação ao parâmetro geométrico de fratura:

$G_{t}=d E_{d} / d a$

que é uma como uma grandeza capaz de medir a sensibilidade da energia de deformação do sólido em relação ao parâmetro geométrico de fissuração $a$.

A introdução do critério termodinâmico representado pela Eq. (3.10) é a parte essencial da contribuição trazida pelo presente trabalho que, no entanto, não teria sido concebido sem a notável intuição de Griffith (1924). A introdução do parâmetro termodinâmico, $G_{\mathrm{t}}$, no estudo da fratura traz, naturalmente, um questionamento sobre algumas concepções tidas como bem consolidadas na mecânica da fratura, a exemplo dos fatores de intensidade de tensões e da integral $J$. Por definição, essas grandezas estão relacionadas com $G$ que, por sua vez, está associado à extensão do princípio da mínima energia potencial total, à maneira de Griffith, para a mecânica da fratura. A utilização de tal princípio, como revela a citação do início deste capítulo, foi feita impropriamente por ele, por não incluir na análise a parcela de energia dissipada que ocorre, necessariamente, quando um fenômeno irreversível, tal como a fratura, tem lugar na natureza. 
Sem que se queira invalidar a extensa e significativa gama de trabalhos realizados com o auxílio das teorias clássicas da fratura, a interpretação termodinâmica revela que os fatores de intensidade de tensões, por exemplo, a despeito de serem parâmetros de larga utilização tecnológica, perdem a razão de ser. Isso porque a utilização dos três modos simples de fratura baseados na elasticidade linear não se enquadra na concepção segundo a qual a parte irreversível do crescimento da fissura está associada à dissipação de calor ocorrida no processo.

Naturalmente, para a construção de uma mecânica da fratura fundada no modelo termodinamicamente consistente, precisam ser superados alguns obstáculos, ao nível dos modelos matemáticos. Nesse sentido, muito do esforço anteriormente desenvolvido, principalmente por Griffith (1924), Irwin (1957) e Rice (1968), poderá ser aproveitado. As possibilidades metodológicas ensejadas pela ideia da integral $J$, por exemplo, serão examinadas no capítulo 4. Lá, com o auxílio da análise de sensibilidade à mudança de forma, será calculada a derivada material da energia de deformação em relação ao parâmetro geométrico de fratura, explorando-se a utilização do novo parâmetro $G_{\mathrm{t}}$.

Na sequência, será buscada a generalização do critério termodinâmico aqui obtido, esquematizado através da Eq. (3.11), com o auxílio de resultados dos capítulos 1 e 2, destacando-se a utilização da ideia de densidade de energia superficial termodinâmica de fratura.

\section{A DINÂMICA DA PROPAGAÇÃO DE UMA FISSURA E O CRITÉRIO DE GRIFFITH}

No processo de propagação da fissura, mesmo que o sólido esteja submetido a um carregamento estático, o próprio movimento da fissura gera a necessidade da inclusão, no balanço, de uma parcela de energia cinética, algo que não chegou a ser cogitado por Griffith (1924) na formulação de seu critério, até porque ele adotou a hipótese de que o fenômeno é quase estático e isotérmico.

A análise que a seguir se desenvolve, busca considerar o aspecto dinâmico do processo em uma formulação ainda não completamente geral, mas adequada à fixação de conceitos importantes para a generalização a ser realizada na seção seguinte. Seguem-se os mesmos passos da seção anterior, usados na interpretação termodinâmica que conduziu ao critério termodinâmico de Griffith, ainda se considerando, somente para simplificar, o 
problema em estado plano. ${ }^{7}$ Desse modo, vai-se substituir a energia superficial específica, $\gamma$, parâmetro do material obtido no caso de um processo quase estático, por outra, $\gamma_{\mathrm{d}}$, capaz de incorporar o aspecto dinâmico da propagação da fissura, denominada densidade de energia superficial dinâmica de fratura. Isso corresponde a um primeiro passo, no sentido da completa generalização do parâmetro $\gamma$, a ser feita adiante.

A grandeza $\gamma_{d}$ seria a anterior energia superficial específica, $\gamma$, acrescida de uma componente cinética, relacionada com o avanço da fissura. Da mesma forma, entraria também uma parcela dinâmica semelhante a $\gamma_{\text {diss }}$ do caso estático. Nessa versão, para se fazer o balanço energético local, basta que se tome a Eq.(3.4) e adicione a seu primeiro membro uma parcela $\mathrm{d} \kappa$, correspondente à energia cinética. $\mathrm{O}$ efeito dinâmico, em nível local, no volume do sólido, seria dado através de uma parcela semelhante trabalho d'w do caso estático. Assim:

$\mathrm{d} \varepsilon+\mathrm{d} \kappa=\mathrm{d}^{\prime} q+\mathrm{d}^{\prime} w$.

Refazendo-se, a partir da Eq. (3.11), uma sequência similar à realizada no desenvolvimento que levou a Eq. (3.5) à Eq. (3.9), definindo-se um parâmetro dinâmico, $G_{t_{d i n}}$, a partir de $E_{d_{d i n}}$, então:

$G_{t_{\text {din }}}=d E_{d_{\text {din }}} / \mathrm{d} a$

expressão que representa, esquematicamente, a versão do critério termodinâmico de Griffith em que o aspecto dinâmico do processo é considerado.

Comparada com a Eq.(3.9), a Eq.(3.12) revela que a influência dinâmica sobre o processo de fissuração faz-se, no primeiro membro dessa última, pela presença de uma função que representa a energia cinética do volume do sólido, e no segundo membro, através de $\gamma_{\mathrm{d}}$, uma grandeza influenciada também pela energia cinética dos pontos da superfície de avanço da fissura.

\footnotetext{
7 Embora o raciocínio esteja desenvolvido para um problema plano, a extensão para os problemas tridimensionais pode ser feita sem grande dificuldade.
} 


\section{CRITÉRIO TERMODINAMICAMENTE CONSISTENTE DE FRATURA}

O objetivo desta seção é a análise da possibilidade de um critério de fratura, o mais geral possível, capaz, de prever, tanto o início da fratura quanto a direção a ser tomada pela fissura, após iniciado oseu avanço. A base para a construção do critério geral é o balanço de energia no sólido fraturado, que deve levar em conta, por um lado o que ocorre no volume, e por outro, o fenômeno ocorrido nas superfícies imersas no interior do sólido, característico do processo de avanço da fissura.

Seria como se houvesse um limite máximo de dissipação energética capaz de ser acomodado pelo material, medido com o auxílio da densidade termodinâmica superficial de energia, $\gamma^{*}$, dada pela Eq. (2.85). Além disso, também seria definida a direção do avanço da fissura. Convém observar que a análise será realizada em uma parte do sólido contendo um só vazio preexistente. Partindo-se do pressuposto de que o número de fissuras desenvolvidas no sólido seja finito, sempre será possível isolar-se uma sub-região em cujo interior só haja uma fissura. Isso não impede, entretanto, que após o início do processo outra fissura venha a penetrar no domínio da região isolada para fins de estudo.

A respeito de outras causas de dissipação de energia que não aquelas inerentemente relacionadas com a fratura, tal como aqui foi descrito, a pergunta chave seria: é possível isolar-se, no presente modelo, as causas de dissipação associadas à plasticidade e ao dano, da causa da fratura? A resposta seria que esse não parece ser esse um problema da formulação termodinamicamente consistente. Pelo contrário, pois o tratamento integraria os três fenômenos, compreendendo plasticidade, dano e fratura como se fossem fases, em escala sucessiva, no rumo da perda da capacidade resistente ou da estabilidade material do sólido.

O ponto de partida será a equação de balanço global de entropia, Eq.(2.8), obtida em termos da taxa de produção de entropia $\xi$, tal como definida pela Eq.(2.74), na Seção 2.3. Assim, chega-se ao princípio da irreversibilidade ou desigualdade de Clausius-Duhem, no qual já se acha incorporada a primeira lei da termodinâmica, isto é:

$$
\int_{P_{t}} \rho \xi \mathrm{d} v=\int_{P_{t}} \rho\left(\frac{D}{D t} \eta-\frac{r}{T}\right) \mathrm{d} v+\int_{s_{f}(t)} \rho^{*} \frac{D}{D t} \eta^{*} \mathrm{~d} s+\int_{\partial P_{t}} \frac{\mathbf{q} \cdot \mathbf{n}}{T} \mathrm{~d} s \geq 0
$$

sendo $\xi$ é dada pela expressão: 
$\xi=\frac{\Lambda}{\rho T}-\frac{1}{\rho T^{2}} \mathbf{q} \cdot \operatorname{grad} T \geq 0$

onde

$\Lambda=\rho \eta T+\mathbf{T}: \mathbf{D}-\rho \varepsilon$

(2.73 repetida)

é a taxa de dissipação de energia por unidade de volume. A Eq. (2.8) é, portanto, a expressão do critério geral de fratura, válido para o caso geral, inclusive o não isotérmico. No caso particular do regime isotérmico, tal como já foi visto, as Eqs. (3.10) e (3.12), obtidas com auxílio da metodologia original de Griffith (1924), são expressões mais simples que a Eq. (2.8). Naquele caso, exatamente por conta de o regime ser isotérmico, a segunda lei da termodinâmica pode ser aplicada por meio da afirmação equivalente de que à ocorrência espontânea de um fenômeno associa-se uma diminuição da energia livre do sistema que é a máxima parcela da energia interna capaz de ser transformada em trabalho.

No caso do critério geral, da Eq. (2.8), no entanto, foram usadas, diretamente, as equações dos balanços de energia e de entropia apresentados no capítulo 2. É evidente que sua aparência foge completamente do aspecto da forma mais simples, obtida para o caso isotérmico. Convém observar que é a condição isotérmica que prevalece, na maioria dos fenômenos que ocorrem no meio ambiente, por conta de ser este um reservatório térmico (ver capítulo 1). A aparência simples, no caso dos critérios válidos para o caso isotérmico, deve-se, sem sombra de dúvida, à importante contribuição metodológica de Griffith.

Subjacente a esses critérios, pode-se pesquisar também a direção preferencial segundo a qual a fissura irá avançar. A orientação de tal avanço será fornecida, a partir do seguinte raciocínio: se, ao crescimento da fissura está associada à diminuição da energia livre, sendo essa diminuição a menor possível, então a direção (ou direções?) a ser seguida pela fissura deve ser aquela que corresponda ao mínimo decréscimo dessa grandeza. Isso é aproveitado na elaboração do programa automático Elcfrat (apêndice A).

Por oportuno, vale recordar que, no caso em que a deformação do sólido ocorre sem a presença de fissura no meio sendo o processo, por hipótese, reversível e isotérmico tal como o analisado no final do capítulo 1, então a energia livre corresponde à parcela da energia interna que pode ser transformada em trabalho. Nesse caso, e só nesse caso, como revela a Eq. (1.14), a energia livre equivale à energia de deformação armazenada no sólido (o mesmo que o trabalho realizado pelas ações externas sobre ele), na medida em que o processo é reversível. 
Até o presente capítulo, a ênfase foi colocada no aperfeiçoamento do modelo físico do fenômeno da fratura, buscando-se tratar o problema a partir da constatação da irreversibilidade do processo de fissuração. A consideração dessa possibilidade traz como consequência a exigência de novos esquemas numéricos de cálculo. A busca de soluções aproximadas, a ser encetada a partir do próximo capítulo, baseia-se na utilização de um recurso recente, a análise de sensibilidade à variação de forma. Essa ferramenta, já utilizada com sucesso no cálculo da integral $J$, via MEF, adiante será adaptada para o cálculo da variação da energia de deformação, considerada como o parâmetro decorrente da análise termodinâmica da fratura, a ser obtida com o auxílio do BEM. 


\section{ANÁLISE DE SENSIBILIDADE APLICADA AO PROBLEMA DA FRATURA}

No capítulo 3 apresentou-se o critério termodinâmico de fratura, representado pela Eq. (3.12). A consistência termodinâmica faz com que, em tese, esse critério seja capaz de dar conta do problema da fratura em um sólido deformável qualquer, sujeito às ações mais gerais, incluindo-se as de caráter térmico e dinâmico. Neste capítulo, no entanto, o critério de fratura será particularizado para o caso da Eq. (3.10), que corresponde a situações em que o processo é quase estático e isotérmico.

A aplicação da análise de sensibilidade à mecânica da fratura, como se verá, é serve para o cálculo da integral $J$, de maneira mais geral que aquela advinda da definição de Rice (1968). Para isso, será aproveitada a metodologia da análise de sensibilidade para o cálculo do parâmetro termodinâmico de fratura, $G_{\mathrm{t}}$ (identificado com a variação da energia de deformação), quando o parâmetro geométrico da fissura varia.

Antes, porém, serão feitas considerações sobre a integral $J$, de Rice. O paralelo entre a metodologia de interesse do presente trabalho e a do cálculo da integral $J$ prosseguirá por todo o desenvolvimento aqui elaborado, de modo que o mesmo programa automático, baseado no BEM, será utilizado para o cálculo aproximado, tanto do parâmetro termodinâmico, $G_{\mathrm{t}}$, quanto da integral $J$ (ver capítulo 5). Ressalte-se que a formulação aqui apresentada é absolutamente geral, valendo também para problemas tridimensionais e podendo ser estendida ao caso dinâmico. No entanto, o cálculo automático será realizado para o caso particular do problema bidimensional, quase estático e em regime isotérmico. O que será mostrado serve mais para a fixação de conceitos relacionados com a nova proposta, do que para explorar todas as potencialidades da presente formulação.

\section{A INTEGRAL $J$ DE RICE}

Para o estudo da fratura em problemas da elasticidade plana, Rice (1968) introduziu uma integral independente do caminho, conhecida como integral $J$. Para conceber a integral $J$, ele afirma ter se inspirado no tensor momentum energia, definido por Eshelby (1956) "como um ente matemático capaz de caracterizar as forças generalizadas nas discordâncias e nos defeitos pontuais em campos elásticos" (RICE, 1968, p.379). A integral $J$ seria, segundo seu criador, a componente estática do tensor momentum energia. 
No trabalho de Rice, a integral $J$ é definida para o caso plano, através da seguinte expressão:

$$
J=\int_{\Gamma} \frac{\partial \mathbf{u}}{\partial x_{1}}\left(\phi d x_{2}-\mathbf{t} \cdot d \Gamma\right),
$$

onde

$$
\phi=\phi\left(\varepsilon_{i j}\right)=\int_{0}^{\varepsilon_{i j}} T_{i j} d \varepsilon_{\mathrm{ij}}
$$

é a densidade de energia de deformação. $\mathrm{Na}$ integral da Eq. (4.1) $\Gamma$ é uma curva regular, arbitrária e fechada, que se desenvolve em torno da extremidade da fissura. Percorrida a curva no sentido anti-horário, a região interna fica sempre à esquerda do observador, sendo o vetor normal unitário, em qualquer ponto de $\Gamma$, orientado para fora. Ao vetor deslocamento, u, está associado o tensor de deformação infinitesimal cuja matriz é $\boldsymbol{\varepsilon}=\left[\varepsilon_{i j}\right]$. O vetor de tensão de Cauchy é notado por $\mathbf{t}$ [traction], e $\mathrm{d} \Gamma$ é o comprimento do elemento de arco do caminho $\Gamma$.

Havendo uma fissura no interior da região contornada por $\Gamma$, a integral $J$ capta um campo local associado ao estado tensional na vizinhança da extremidade da fissura. No caso contrário, em que não houver fissura no interior da região, então a integral $J$ será nula.

Considera-se que a principal vantagem do uso da integral $J$ está no fato de ser independente do caminho de integração. Essa propriedade permite a escolha de curvas $\Gamma$ distantes o suficiente da zona perturbada, para que os campos envolvidos no cálculo da integral possam ser determinados com melhor precisão, desde que o material seja caracterizado através de uma função densidade de energia, com o seu comportamento menos influenciado pelos efeitos da alta concentração das tensões que a vizinhança mais próxima da extremidade da fissura. A rigor, a integral $J$ só pode ser calculada se o caminho de integração for constituído de pontos nos quais seja possível definir-se uma função densidade de energia de deformação. 


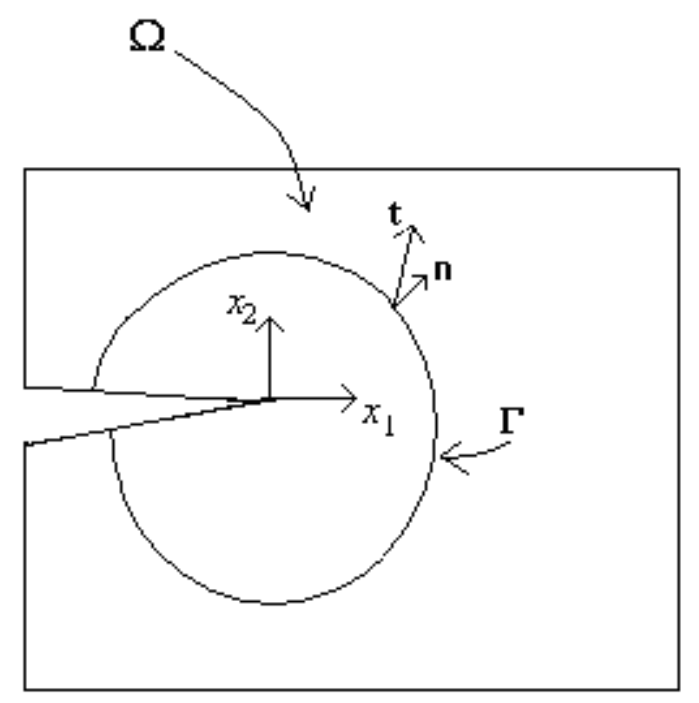

Figura 4 - Fissura reta crescendo na direção $x_{1}$

As hipóteses de Rice admitidas para a obtenção da integral $J$, segundo Cunha et al. (1995), podem ser sintetizadas da seguinte forma:

1. O material, nos pontos do caminho de integração, é hiperelástico, ou seja, caracteriza-se através da função densidade de energia, $\phi$, que é um potencial a partir do qual podem ser derivadas as componentes do tensor de tensão, isto é:

$$
T_{i j}=\frac{\partial \phi}{\partial \varepsilon_{i j}} ;
$$

2. Não existem deformações iniciais nem cargas no domínio, havendo somente cargas aplicadas no contorno, e as bordas da fissura estão livres de tensões;

3. A fissura inicial é reta e se propaga na mesma direção original;

4. A base de referência $\left(\mathbf{e}_{1}, \mathbf{e}_{2}\right)$ é ortogonal, e $\mathbf{e}_{1}$ coincide com a direção da fissura, tal como indicado na figura 4.

No caso do problema bidimensional, usando-se a definição de tensor transposto, e levando-se em conta, na Eq. (4.1), as relações:

$$
\mathrm{d} x_{2}=\mathbf{n . e} \mathrm{e}_{1} \mathrm{~d}, \mathbf{t}=\operatorname{Tne} \partial \mathrm{u} / \partial \mathrm{x}_{1}=(\nabla u) \mathbf{e}_{1},
$$

tem-se: 
$J=\int_{\Gamma}\left[\phi \mathbf{n} \cdot \mathbf{e}_{1}-\mathbf{T n} \cdot(\nabla u) \mathbf{e}_{1}\right] d \Gamma=\mathbf{e}_{1} \cdot \int_{\Gamma}\left[\phi \mathbf{I}-\nabla \mathbf{u}^{T} \mathbf{T}\right] \mathbf{n} d \Gamma=\mathbf{e}_{1} \cdot \int_{\Gamma}^{\Sigma} \mathbf{n} d \Gamma$

onde $\boldsymbol{\Sigma}=\phi \mathbf{I}-\nabla \mathbf{u}^{T} \mathbf{T}$ é conhecido como o tensor momentum energia de Eshelby.

Da interpretação termodinamicamente consistente do fenômeno da fratura emerge uma grandeza que considera a produção de calor ocorrida com a quebra de ligações materiais, responsável pela parte irreversível do avanço da fissura. Evita-se assim, portanto, o conceito impreciso de energia potencial total, tal como Griffith (1924) o pretendeu estender para a mecânica da fratura.

Em seu trabalho pioneiro de 1921, embora tenha definido uma grandeza que denominou energia potencial total, como sendo a soma da energia potencial elástica (ou de deformação) com a energia superficial desenvolvida nas faces da fissura, Griffith introduziu certa confusão, que ainda persiste. E o equívoco faz com que muitos recorram à verdadeira energia potencial total, da mecânica dos sólidos, no lugar da energia de deformação, para calcular a energy release rate. (GRIFFITH, 1921, p. 169) ${ }^{8}$. Ressalte-se ainda que, no seu trabalho de 1924, Griffith continou a defender o uso da energia de deformação como base para a construção de seu conhecido critério. A razão desse segundo trabalho, aliás, é quase que só para apresentar a expressão corrigida do primeiro membro da inequação que representa o critério (somente um coeficiente de Poisson é eliminado da fórmula original, nessa correção). Nele, Griffith assegura que o erro cometido no primeiro trabalho deveu-se a um equívoco que cometera em certa passagem matemática. Embora não seja mostrado o desenvolvimento matemático responsável pela correção do erro identificado, é certo ${ }^{9}$ que ele tenha continuado a usar (corretamente) sempre a energia de deformação, e não a energia potencial total tradicional, da mecânica dos materiais, em seus cálculos.

O fato de esse equívoco não ter sido percebido, parece ser explicável somente por achar-se que a sugestão de Griffith (1924) estaria de acordo com a extensão natural de um princípio de uso bastante generalizado na mecânica dos materiais, a saber, o clássico princípio da mínima energia potencial total, adaptado arbitrária e incorretamente por ele, para o estudo da fratura. Como pode ser verificado através da leitura de seus dois trabalhos aqui referidos, Griffith $(1921,1924)$ não definiu de maneira precisa a natureza da energia associada ao

\footnotetext{
${ }^{8}$ Ver especificamente Eqs. (4.7) a (4.10).

${ }^{9}$ A certeza baseia-se num fato ainda pouco conhecido da história da mecânica da fratura: trata-se da existência do trabalho Zur Bruchtheorie von A. Griffith, de 1923, cujo autor, K. Wolf, enviou ao criador da mecânica da fratura, sugerindo a correção, que foi feita no trabalho de 1924, embora Griffith não tenha feito o registro. O editor da publicação em que o trabalho corrigido de Griffith foi divulgado, no entanto, fez questão de registrálo, em nota afixada ao fim do texto do artigo corrigido.
} 
avanço da fissura. Daí a hipótese de que só seria plausível a reversibilidade se, cessada aplicação do carregamento, a elipse que simula a fissura voltasse à situação original. Imaginese, por exemplo, que existissem molas lineares ligando pontos opostos, nas duas faces de uma fissura preexistente, antes de começar a crescer. Se as molas, por hipótese os únicos elementos responsáveis pelo controle da abertura da fissura, pudessem manter-se íntegras e elásticas, de modo que, ao serem retiradas as ações sobre o sólido, ele voltasse a seu estado inicial, então essa parcela de energia poderia ser considerada como totalmente recuperável. No entanto, se pelo menos algumas molas se rompessem, assim caracterizando o avanço do processo irreversível de físsuração, não mais seria possível desprezar-se a parcela de calor produzido, evidentemente não recuperável, que se dissiparia no ambiente.

O equívoco fica bastante evidenciado, por exemplo, em Taroco (1996), para quem o conceito de integral $J$ estaria diretamente relacionado com a ideia de Griffith (1924) de estender o princípio da energia potencial total ao estudo da fratura. Taroco usa a energia potencial total, clássica, ao invés da energia de deformação, na sua engenhosa extensão da análise de sensibilidade para a mecânica da fratura, mas não é este, definitivamente, o sentido que Griffith atribui à energia potencial total.

Em trabalhos considerados clássicos (KNOWLES; STERNBERG, 1972; GURTIN, 1979), fica evidente a necessidade de que o caminho de integração usado para o cálculo de $J$ esteja totalmente inserido em uma região do sólido com comportamento hiperelástico. Além disso, esses últimos trabalhos associam a ideia de Eshelby (1956), base para a concepção da integral $J$ de Rice, ao teorema de Noether, segundo o qual pode-se partir da propriedade da invariância, em relação a determinados parâmetros, de funcionais associados a princípios variacionais, para a obtenção de certas leis de conservação da mecânica, tais como a da conservação de energia e da quantidade de movimento linear (NOETHER, 1918 apud LANCZOS, 1986). Com o auxílio desse raciocínio fica também resolvida a questão da adequação do uso da integral $J$, quando se leva em conta a acomodação plástica ocorrida na vizinhança da extremidade de uma fissura. Para todos os efeitos, o cálculo da integral $J$ tem legitimidade, desde que o caminho de integração sobre o qual seu cálculo seja realizado esteja imerso em uma região hiperelástica do sólido, da qual exclui-se, naturalmente, por precaução, vizinhanças muito próximas da extremidade da fissura, onde as tensões tendem a se afastar da condição de hiperelasticidade.

É difícil a obtenção de soluções fechadas, tanto para o cálculo da integral $J$ quanto para o parâmetro termodinâmico de fratura $G_{\text {t }}$ Essa dificuldade é superada, no entanto, com o cálculo indireto da integral $J$, auxiliado pela análise de sensibilidade á variação de forma, 
aplicada à mecânica da fratura. Tal técnica vale-se da analogia existente entre o problema da fratura e outro, no contexto da otimização estrutural, no qual é estudado o efeito particular da variação da forma do domínio do sólido e de seu contorno, em relação a um determinado parâmetro real. Utilizando-se, no essencial, o desenvolvimento matemático contido em Taroco (1996), para o cálculo da integral $J$, passa-se, a seguir, à apresentação dessa técnica, visando à obtenção de uma medida da sensibilidade da energia de deformação em relação a um parâmetro do domínio do problema. Tal parâmetro, como à frente se verá, é concebido de tal maneira que, com o auxílio de sua variação, pode-se simular o avanço da fissura.

\section{DERIVADA MATERIAL DA ENERGIA DE DEFORMAÇÃO}

O desenvolvimento que se segue, baseia-se na análise de sensibilidade á variação de forma, cujos fundamentos são apresentados no capítulo 7. O suporte teórico para as operações matemáticas aqui apresentadas encontra-se também naquele capítulo.

Para cada forma do corpo, associada ao domínio parametrizado $\Omega_{\imath}$, a energia de deformação, $E_{\mathrm{d} \tau}$, expressa-se como:

$E_{d \tau}=\int_{\Omega} \phi_{\tau} \mathrm{d} \Omega_{\tau}$

onde $\phi_{\tau}$ é a energia de deformação específica associada ao domínio $\Omega_{\tau}$.

Para se obter a taxa de variação da energia de deformação armazenada no sólido, quando o domínio sofre modificação, é necessário derivar ambos os membros da Eq. (4.4) em relação ao parâmetro $\tau$. Após, calcula-se o valor da derivada quando o valor desse parâmetro é nulo, o que fornece a medida da tendência de evolução da energia de deformação do sólido, na configuração considerada. A derivação em relação ao parâmetro $\tau$ guarda analogia com a derivação material no tempo, usada no balanço termomecânico da mecânica do contínuo. No capítulo 7 encontram-se os resultados da análise tensorial úteis ao desenvolvimento matemático que se segue.

A derivada $\dot{E}_{d}$, da energia de deformação em relação a $\tau$, em $\tau=0$, é uma grandeza associada ao sólido real, ou melhor, à configuração atualizada do sólido real, que mede a sensibilidade dessa configuração em relação à variação de forma do domínio. A derivada $\dot{E}_{d}$ 
pode ser obtida da mesma forma como se calcula a derivada material no tempo, da mecânica do contínuo, em que o ponto sobre a variável refere-se à derivada em relação ao parâmetro $\tau$. Assim:

$E_{d}=\left.\frac{\mathrm{d} E_{d \tau}}{\mathrm{d} \tau}\right|_{\tau=0}=\int_{\Omega}(\phi+\phi \operatorname{div} \mathbf{v}) \mathrm{d} \Omega$.

Ainda conforme o que se encontra no capítulo 7:

$\phi=\phi^{\prime}+(\nabla \phi) \cdot \mathbf{v}$

Considerando-se a simetria do tensor $\mathbf{T}$ e usando a comutatividade entre operações lineares, tem-se:

$\phi^{\prime}=\frac{\mathrm{d} \phi}{\mathrm{d}\left(\nabla \mathbf{u}^{\mathrm{s}}\right)}: \nabla \mathbf{u}^{\prime \mathrm{s}}=\mathrm{T}: \nabla \mathbf{u}^{\prime \mathrm{s}}=\mathbf{T}: \nabla \mathbf{u}^{\prime}$.

Então a Eq. (4.5) fica:

$E_{d}=\int_{\Omega}\left(\mathbf{T}: \nabla \mathbf{u}^{\prime}+\nabla \phi \cdot \mathbf{v}+\phi \operatorname{div} \mathbf{v}\right) \mathrm{d} \Omega$

Porém, de acordo com os resultados expressos pelas Eqs. (7.89b) e (7.89d), vem:

$\mathbf{T}: \nabla \mathbf{u}^{\prime}=\operatorname{div}\left(\mathbf{T} \mathbf{u}^{\prime}\right)-\mathbf{u}^{\prime} \cdot \operatorname{div} \mathbf{T}$

$\mathrm{e}$

$$
. \mathbf{v}+\operatorname{div} \mathbf{v}=\operatorname{div}(\mathbf{v})
$$

cuja substituição na Eq. (4.8) conduz a:

$$
E_{d}=\int_{\Omega}\left[\operatorname{div}\left(\mathbf{T} \mathbf{u}^{\prime}\right)-\mathbf{u}^{\prime} \cdot \operatorname{div} \mathbf{T}+\operatorname{div}(\phi \mathbf{v})\right] \mathrm{d} \Omega .
$$

Aplicando-se o teorema de Gauss (da divergência) à primeira e à terceira parcelas da integral do segundo membro da Eq. (4.11), tem-se: 
$E_{d}=\int_{\partial \Omega}\left[\mathbf{T} \mathbf{u}^{\prime} \cdot \mathbf{n}+\phi \mathbf{v} \cdot \mathbf{n}\right] \mathrm{d} \partial \Omega-\int_{\Omega} \mathbf{u}^{\prime} \cdot \operatorname{div} \mathbf{T} \mathrm{d} \Omega$.

Adotando-se o vetor das forças de corpo como identicamente nulo, e levando-se em conta o equilíbrio do sólido, então, divT= 0, e a Eq. (4.12) fica:

$E_{d}=\int_{\partial \Omega}\left[\mathbf{T} \mathbf{u}^{\prime} \cdot \mathbf{n}+\phi \mathbf{v} \cdot \mathbf{n}\right] \mathrm{d}(\partial \Omega)$.

Em virtude da simetria de $\mathbf{T}$, e considerando-se as definições de tensor transposto e de tensor identidade (capítulo 7), tem-se, finalmente:

$E_{d}=\int_{\partial \Omega}\left[\mathbf{T n} . \mathbf{u}^{\prime}+(\phi \mathbf{I}) \mathbf{n} \cdot \mathbf{v}\right] \mathrm{d}(\partial \Omega)$.

Essa expressão fornece a derivada material no parâmetro $\tau$, em $\tau=0$, da energia de deformação armazenada no sólido. Os campos T, $\phi$ e u' aí presentes estão associados ao estado inicial, isto é, ao sólido não perturbado pela variação de forma $(\tau=0)$. T e $\phi$ correspondem, portanto, à configuração do sólido associada a $\tau=0$. Quanto ao campo $\mathbf{u}^{\prime}$, verifica-se que adquire uma forma especial, relacionada com a estratégia utilizada para a simulação do avanço da fissura, com auxílio da análise da sensibilidade, tema que será tratado a seguir.

\section{A SIMULAÇÃO DO AVANÇO DA FISSURA VIA ANÁLISE DE SENSIBILIDADE}

Conforme ilustrado através das figuras 5 e 6, o avanço da fissura será simulado com auxílio de uma translação dos pontos do sólido e de sua fronteira, de modo que, para todos os pontos de $\Gamma, \mathbf{v}=\mathbf{- e}$ e, para todos os pontos de $\Gamma_{\mathrm{T}}, \mathbf{v}=\mathbf{0}$, tal como se a fissura estivesse parada e a fronteira $\Gamma$ estivesse em movimento, dirigindo-se para a fissura, em sentido inverso ao de sua propagação.

Assim, pode-se provar, tal como demonstrado no capítulo 7 , que $\mathbf{u}^{\prime}=\mathbf{0}$, tanto em $\Gamma$, como em $\Gamma_{\mathrm{T}}$. Vale relembrar que a exigência sobre $\mathbf{v}$ é que seja um campo, definido em $\Omega$, capaz de simular a perturbação causada no sólido por uma fissura, não necessariamente reta, de comprimento característico inicial igual a $a_{0}$. Considera-se que a fissura parte do contorno $\partial \Omega$ e evolui segundo a orientação dada pelo vetor unitário e, conforme mostrado na figura 5 . 
Já foi dito que a extensão $\Gamma_{\mathrm{T}}$, do contorno da parte $P$, é tomada tão próxima à extremidade da fissura quanto seja necessário para o isolamento de uma região $\Omega_{\mathrm{o}}$, a ela solidária, de forma a garantir que a parte $P$ esteja completamente contida em uma região na qual o material tenha comportamento hiperelástico. Os limites dessa região são implicitamente estabelecidos em função da extensão da zona de acomodação plástica, típica da vizinhança da extremidade da fissura. Isso corresponde a uma simulação bastante razoável do movimento da fissura, indicado na figura 5, cuja orientação é dada pelo vetor unitário e que, como se verá no capítulo 5, será considerado com orientação inicialmente variável, que se define a partir da condição de mínima variação da energia livre. Para completar o contorno fechado da parte $P$, passa-se a analisar como seria a descrição adequada para o campo $\mathbf{v}$, nas partes planas do contorno de $P$, i. e, em $\Gamma^{+}$e em $\Gamma^{-}$, de modo a se conformar adequadamente a simulação matemática do movimento da fissura.

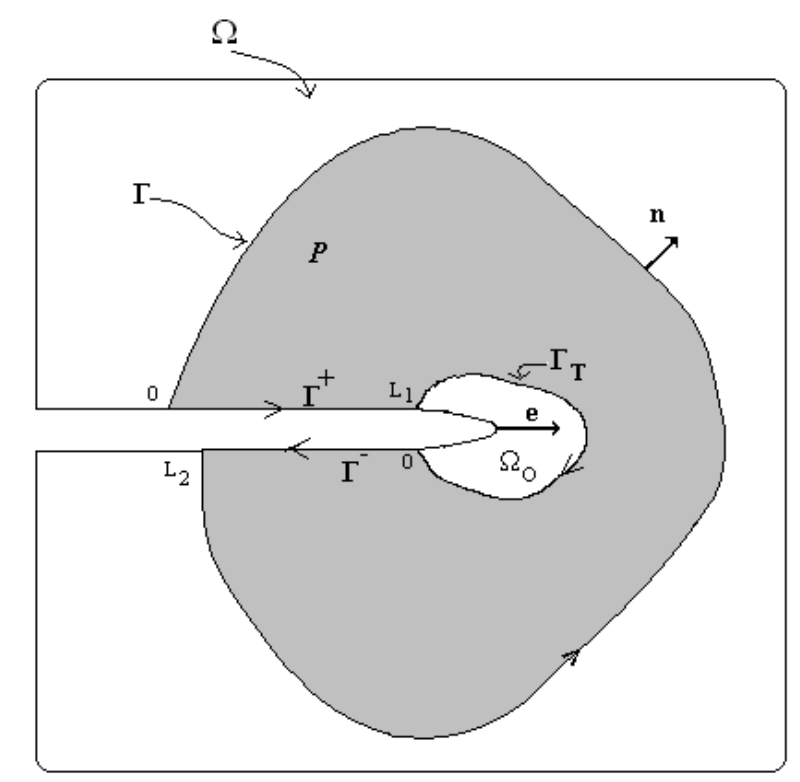

Figura 5 - A delimitação da parte $P$ e o avanço da fissura

Admite-se, por necessidade, que o vetor de tensão [traction] de Cauchy, em cada ponto das faces da fissura, deve ser nulo, isto é,

$$
\mathbf{T n}=\mathbf{0}, \mathrm{em} \Gamma^{+} \text {e } \Gamma^{-}
$$

Por conta do compromisso de manutenção da continuidade geométrica, será aqui adotado um campo de translações $\mathbf{v}$, variável segundo uma lei linear, em $\Gamma^{+}$e $\Gamma^{-}$, de tal modo 
que seu valor seja nulo nas intercessões de $\Gamma^{+}$e $\Gamma^{-} \operatorname{com} \Gamma_{\mathrm{T}}$, e igual a (- e) nas intercessões dos dois primeiros com $\Gamma$.

De acordo com o esquema acima exposto (figura 5), o desdobramento da Eq. (4.14) no contorno de $P$ fornece:

$$
\begin{aligned}
& \left(\dot{E}_{d}\right)_{P}=\int_{\partial \mathbb{P}}\left[\mathbf{T n} . \mathbf{u}^{\prime}+(\phi \mathbf{I}) \mathbf{n} . \mathbf{v}\right] \mathrm{d} \partial \Omega=\int_{\Gamma}[\mathbf{T n} .(\mathbf{0})+(\phi \mathbf{I}) \mathbf{n} .(-\mathbf{e})] \mathrm{d} \Gamma+ \\
& \int_{0}^{L_{1}}\left[\mathbf{T n} . \mathbf{u}^{\prime}+(\phi \mathbf{I}) \mathbf{n} .\left(\frac{S-L_{1}}{L_{1}}\right) \mathbf{e}\right] \mathrm{d} \Gamma+\int_{\Gamma_{\mathrm{T}}}[\mathbf{T n} . \mathbf{0}+(\phi \mathbf{I}) \mathbf{n . 0}] \mathrm{d} \Gamma+ \\
& +\int_{0}^{L_{2}}\left[\mathbf{T n} \cdot \mathbf{u}^{\prime}+(\phi \mathbf{I}) \mathbf{n} \cdot\left(\frac{-S}{L_{2}} \mathbf{e}\right] \mathrm{d} \Gamma\right. \text {. }
\end{aligned}
$$

Observe-se que, na segunda e na quarta integrais do segundo membro da última equação, em virtude de $\mathbf{v}$ não ser um campo de translações constante, nessas partes da fronteira de $P$, a derivada espacial $\mathbf{u}^{\prime}$ não foi substituída por $\mathbf{0}$, embora isso seja verdade, nos limites das integrações. Daí a exigência de que sejam nulas as tractions em $\Gamma^{+}$e $\Gamma^{-}$, para que as parcelas (desconhecidas), envolvendo $\mathbf{u}^{\prime}$, desapareçam dessas integrais.

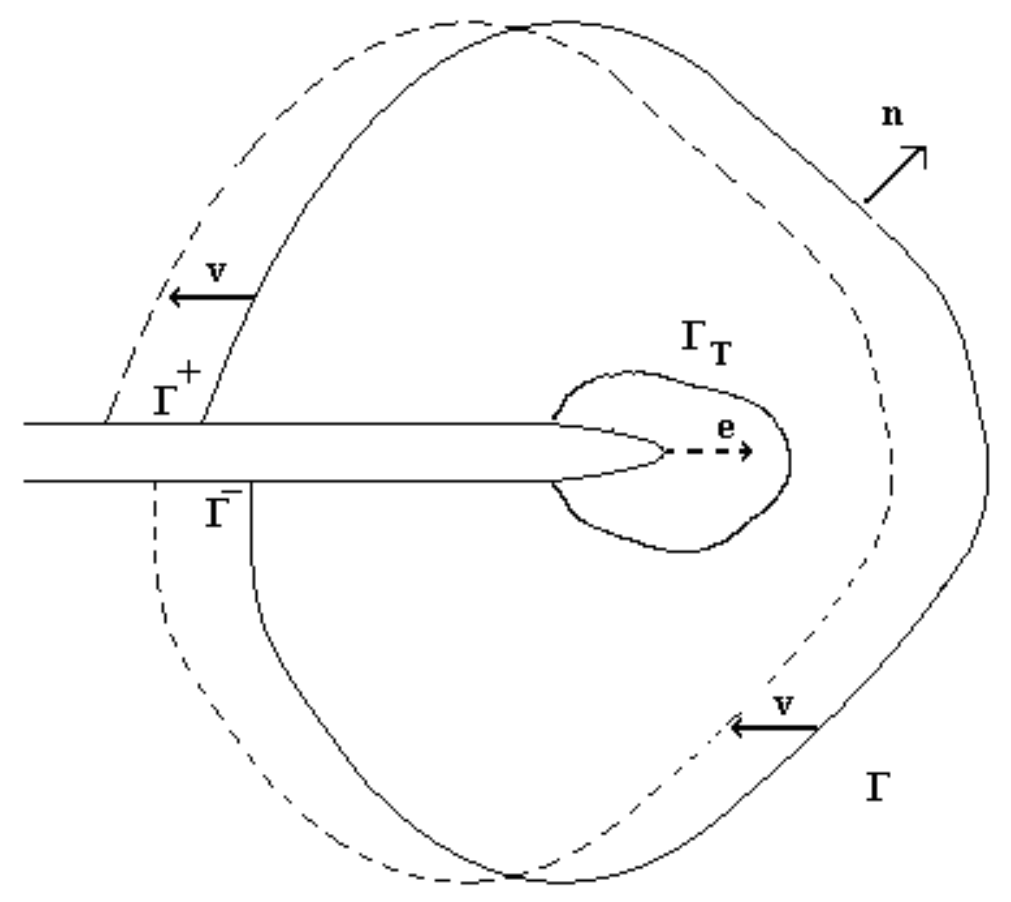

Figura 6- Simulação do avanço da fissura 
Assim, a Eq. (4.15) reduz-se a:

$\left(E_{d}\right)_{P}=\int_{\Gamma}(-\phi \mathbf{I}) \mathbf{n} . \mathbf{e d} \Gamma+b_{1} \int_{0}^{L_{1}}\left(\frac{s_{1}-L_{1}}{L_{1}} \phi\right) \mathrm{d} s-b_{2} \int_{0}^{L_{2}}\left(\frac{s_{2}}{L_{2}} \phi\right) \mathrm{d} s$,

onde

$b_{1}=$ n.e, constante em $\Gamma^{+}$,

$b_{2}=$ n.e, constante em $\Gamma^{-}$.

Como se observa na Eq. (4.16), as duas últimas integrais do segundo membro são realizadas nos trechos planos da superfície do entalhe. Vê-se, portanto, que os valores de $b_{1} \mathrm{e}$ $b_{2}$ serão nulos, quando o avanço da físsura for na direção do vetor unitário e, que é normal ao vetor unitário n nessas superfícies. No caso da integral $J$, por definição, exige-se que o vetor e tenha sempre a direção paralela às faces do entalhe (supondo-se que o ângulo entre elas seja bem próximo de zero). No caso de $G_{\mathrm{t}}$, no entanto, isso não ocorre, necessariamente, embora se possa admitir, com boa aproximação, no caso de entalhes de faces retas, que a contribuição das integrais nelas realizadas tende a se anular. Já no caso em que isso ocorre, a Eq. (4.16) fica:

$\left(\dot{E}_{d}\right)_{P}=\int_{\Gamma}(-\phi \mathbf{I}) \mathbf{n d} \Gamma . \mathbf{e}$

referida a certa parte $P$ do sólido contendo uma fissura, o valor da derivada material da energia de deformação, $\left(\dot{E}_{\mathrm{d}}\right)_{P}$, com o sinal trocado, será doravante denominado parâmetro termodinâmico de fratura, sendo notado por $G_{\mathrm{t}}$.

Com base na estrutura da Eq. (4.18), o programa automático também calculará a integral $J$, dada pela Eq. (4.3), que pode ser obtida, segundo Taroco (1996), como a derivada material da energia potencial total em relação ao parâmetro $\tau$, quando $\tau=0$. Para isso, basta que se troque o tensor ( $\phi \mathrm{I})$, da Eq. (4.18), pelo tensor momentum energia, $\Sigma$, da Eq. (4.3).

Desprezadas as forças de corpo, e sob um regime quase estático e isotérmico, a Eq.(4.16) é aplicável a qualquer parte $P$ do sólido que contenha uma fissura. Convém lembrar 
que a Eq. (4.18) foi deduzida com o intuito de permitir a análise do fenômeno desenvolvido na parte $P$ do domínio $\Omega$, partindo-se do que ocorre nos pontos do caminho regular $\Gamma$ que a delimita. Fica-se, portanto, com a liberdade de estendê-la, de modo a incluir pontos cada vez mais distantes da extremidade da fissura (alterando-se, por consequência, o contorno $\Gamma$ ).

E o que dizer sobre a fronteira $\Gamma_{\mathrm{T}}$ da figura 5 ? Como se viu na simulação do avanço da fissura, via análise de sensibilidade, a translação dos pontos dessa fronteira é tomada como nula. Isto simula uma espécie de adesão dos pontos da região próxima da extremidade da fissura ao provável movimento da mesma. Passa-se a usar, a propósito, a expressão zona de processo, tomada de empréstimo a Hillerborg (1991), para se caracterizar essa região plastificada, vizinha da extremidade da fissura. A delimitação estabelecida para $\Gamma_{\mathrm{T}}$ deve ser, portanto, aquela capaz de assegurar, implicitamente, a vigência da condição hiperelástica em todos os pontos da parte $P \subset \Omega$, lembrando-se que ela é delimitada por $\Gamma, \Gamma_{\mathrm{T}}$, e também pelas faces da fissura, $\Gamma^{+}$e $\Gamma^{-}$, como na figura 5 .

Do ponto de vista da organização do programa automático para o cálculo da integral $J$ e de $G_{\mathrm{t}}$, o risco só estaria em escolher-se um caminho de integração $\Gamma$, tal que algum de seus pontos estivesse fora da condição de hiperelasticidade.

\section{DISCUSSÃO SOBRE O SIGNIFICADO E A OBTENÇÃO DOS PARÂMETROS $J$ E $G_{\mathrm{t}}$}

A Eq. (4.18) mostra que o parâmetro $G_{\mathrm{t}}$ está associado ao tensor I, que guarda semelhança formal com o tensor momentum energia $\boldsymbol{\Sigma}=\mathbf{I}-(\nabla \mathbf{u})^{\mathrm{T}} \mathbf{T}$, motivo do trabalho de Taroco (1996). A partir do tensor $\Sigma$, a integral $J$ pode ser obtida mediante a Eq. (4.3), como há pouco foi explicado, isto quando o material é hiperelástico em todo contorno da parte $P$ no qual a integração é realizada. Válida esta última hipótese, sabe-se que a integral $J$ possui a propriedade de independência do caminho. Isso só se verifica, no entanto, porque o vetor unitário e está orientado em uma direção paralela às faces do entalhe a partir do qual a fissura avança, tal como indica a Eq. (4.3). Com maior precisão e generalidade, esse resultado é demonstrado por Gurtin (1979).

Vale destacar a importante distinção entre os tensores $\mathbf{I}$ e $\boldsymbol{\Sigma}$, refletida nos respectivos parâmetros $G_{\mathrm{t}}$ e integral $J$, gerados a partir desses tensores como as respectivas projeções dos fluxos definidos na fronteira de $P$, sobre o vetor e. O que resulta, em geral, é que são calculados como integrais no contorno de uma parte arbitrária do sólido próxima à 
extremidade da fissura (figura 5). O tensor I surge em decorrência da interpretação termodinâmica do fenômeno da fratura, com base em um modelo que considera a produção de calor e a consequente dissipação, em certa vizinhança $\Omega_{\mathrm{o}}$ da extremidade da fissura, quando a fissura sofre um avanço irreversível. Tal tensor, como se viu, é calculado como a variação da energia de deformação da parte $P$ em relação ao parâmetro geométrico da fissura. Já o tensor $\boldsymbol{\Sigma}$ não surge a partir de uma análise termodinamicamente consistente, sendo obtido como a variação da energia potencial total do sólido em relação ao parâmetro geométrico da fissura. Do ponto de vista prático, nisso se resume a diferença entre a abordagem com base na integral $J$ e a que aqui se desenvolve, baseada no parâmetro $G_{\text {t }}$.

Em razão do extenso uso tecnológico da integral $J$ como parâmetro de fratura, e da introdução de $G_{\mathrm{t}}$ como uma alternativa associada à formulação termodinamicamente consistente, cabe a busca de comparação entre eles. A propriedade de $J$, da independência do caminho, é atraente e julgada importante. No entanto, a obtenção dessa grandeza, a partir de integral realizada sobre uma superfície imersa no interior do sólido, baseia-se no pressuposto de que a fissura avançará segundo uma direção paralela às faces da fissura preexistente, para que a independência da integral $J$ em relação ao caminho se mantenha. No entanto, por ser um fenômeno natural, a evolução da fissura segue, quase sempre, uma orientação distinta dessa direção paralela às faces da fissura.

Assim, a utilização dos dados experimentais só teria sentido, para a finalidade de avaliação de integridade, no caso raro em que o crescimento da fissura, no sólido real, obedecesse estritamente à forma matematicamente prevista, para que o valor da integral ficasse independente do caminho. Se a fissura real precisa crescer segundo a direção paralela às faces da fissura preexistente, para que a integral $J$ seja um parâmetro significativo, então isso coloca uma séria objeção à sua utilidade na caracterização da integridade de um sólido real à fratura.

Reconhece-se, evidentemente, a importância de $J$ que, se bem utilizada, pode ser um eficiente sensor da presença, ou ausência, de fissura em uma região fechada, pois, no caso de o caminho de integração não circundar qualquer extremidade de fissura, seu valor é nulo. Do ponto de vista físico, no entanto, a simples propriedade de independência do caminho não acrescenta à integral $J$ qualquer qualidade objetiva especial, diferentemente do que parece, à primeira vista.

Dito de outro modo, a interpretação advinda da análise de sensibilidade, no caso de uma fissura reta, define a integral $J$ como a projeção (na direção original da fissura) do vetor 
fluxo do tensor de Eshelby (1978), tomado sobre o caminho de integração, e esse procedimento será aqui utilizado, no cálculo automático daquela integral, como um balizador da precisão na programação automática.

Sem o intuito de desmerecer as contribuições de Griffith (1924), Irwin (1957) e Rice (1968), referências históricas do estudo da fratura, este trabalho propõe-se a explorar os primeiros desdobramentos advindos da substituição, notoriamente imprecisa, do princípio da mínima energia potencial total, pela consideração da primeira e da segunda lei da termodinâmica, na interpretação do fenômeno da fratura.

A concepção da qual emerge o parâmetro $G_{\mathrm{t}}$, que ora se coloca como uma alternativa consistente, se comparada à integral $J$, tem sua legitimidade respaldada na ideia do modelo físico do problema que inclui como necessidade a consideração do caráter dissipativo do processo de fissuração. A determinação de $G_{\mathrm{t}}$ dá-se concomitantemente com a obtenção da direção do avanço real da fissura, não sendo necessário estabelecer-se, a priori, a direção do avanço, tal como na integral $J$. Entretanto, $G_{\mathrm{t}}$ depende do caminho de integração.

Uma consequência prática desse fato, no caso da determinação experimental do valor crítico, $\gamma_{\mathrm{E}}$, do parâmetro $G_{t}$, seria, a quebra da exigência de que o corpo de prova para o ensaio de fratura tivesse de conter uma pré-fissura de fadiga, com carregamento rigorosamente simétrico, para garantir que o avanço da fissura rigorosamente paralelo às faces originais do entalhe, diferentemente do que se exige na determinação de $J_{\text {ic }}$ e na construção da curva $J-R$ dos materiais.

Conquanto o resultado teórico obtido seja aplicável ao caso geral de problemas tridimensionais, daqui em diante a análise será particularizada para o caso de uma chapa finita, em regime isotérmico e quase estático, contendo uma fissura que se inicia no contorno. Será a oportunidade de se retomar o paralelo com a teoria original de Griffith (1924) cujo desenvolvimento foi discutido no capítulo 3, agora com base no resultado sintetizado na Eq.(4.18), útil ao propósito da determinação da direção de tendência de propagação da fissura.

Dentro dessa linha foi concebido um programa automático, em linguagem Fortran, com o intuito de demonstrar-se a possibilidade de aplicação da presente proposta. Na verdade, a fronteira $\Gamma_{\mathrm{T}}$ (figura 5) resulta, implicitamente, da exigência de que $P$ seja uma região em que os pontos de seu contorno estejam dentro da zona de comportamento hiperelástico do material do sólido.

A experimentação numérica aqui desenvolvida, com a utilização do programa automático (apêndice A), organiza-se com base no que consta do capítulo 5, no qual se faz uso de um modelo de elemento de contorno reto, isoparamétrico, cujo aumento da eficiência 
numérica foi conseguido com auxílio de uma técnica de subelementação, especialmente desenvolvida no presente trabalho.

O programa automático foi organizado para calcular, tanto a integral $J$ quanto o parâmetro $G_{\mathrm{t}}$, e cumpre o propósito de mostrar a simplicidade do processo de determinação dessas duas grandezas, através do BEM.

A comprovação da independência do caminho da integral $J$ é facilmente verificável, na experimentação numérica, já que escolha de caminhos de integração alternativos fica muito fácil de ser implementada, haja vista a vocação natural do BEM para o cálculo de integrais sobre caminhos. De fato, a independência do caminho, no cálculo da integral $J$, foi utilizada como balizamento, na elaboração do programa automático, a fim de controlar-se a própria correção e precisão do programa.

Para a avaliação prática da integridade dos sólidos, com o uso do critério termodinâmico apresentado no capítulo 3, sintetizado no resultado representado pela Eq. (3.10), seria necessária a determinação experimental de um valor crítico do parâmetro, isto é, $\gamma_{\mathrm{E}}$. No entanto, a experimentação numérica, auxiliada pelo programa automático, revela que é possível avançar-se um pouco na simulação, mesmo sem o conhecimento experimental do parâmetro crítico. Nesse sentido, foi incluído um processo iterativo, no programa automático, para permitir que se chegue, em cada problema particular, a um valor de $G_{\mathrm{t}}$ que, se ultrapassado, levará à instabilidade da fissura. $\mathrm{O}$ assunto será explorado no capítulo 7, no qual são apresentados exemplos numéricos.

\section{PARTICULARIZAÇÃO DE $G_{\mathrm{t}}$ PARA O CASO DE UMA CHAPA DE ESPESSURA} CONSTANTE CONTENDO UMA FISSURA INICIADA NO CONTORNO

O sentido do que se segue, é traçar-se um paralelo entre a metodologia aqui proposta e o critério de iniciação de fratura de Griffith (1924), propondo-se o exemplo de uma chapa de espessura constante, representada por uma região plana, $\Omega$, correspondente a seu plano médio, e com um carregamento contido nesse plano.

Admite-se que a chapa esteja em equilíbrio com um campo externo de cargas, $\overline{\mathbf{t}}$, aplicado em uma parte $\Gamma_{\mathrm{t}}$ da fronteira de $\Omega$, e submetida a restrições de deslocamento na parte complementar, $\Gamma_{\mathrm{u}}$, sendo que, nas faces da fissura, $\overline{\mathbf{t}}$ é nulo. Nessa chapa, que pode ser finita, supõe-se a presença de um entalhe de comprimento $a$, a partir de uma pequena abertura que 
se inicia no contorno (figura 5). Como a chapa tem espessura unitária, essa fissura possui uma área aproximadamente igual a $2 a$.

A grandeza $\gamma_{\mathrm{E}}$, a seguir introduzida, é o valor crítico do parâmetro termodinâmico $G_{\mathrm{t}}$. Tal valor crítico está associado à variação da energia livre de Helmholtz, na circunstância em que a fissura avança.

O critério a ser utilizado decorre da Eq. (3.9). No presente caso, entende-se que o acréscimo no trabalho de deformação, quando a fissura avança a partir do contorno, para um incremento da área de fissura igual a $2 \mathrm{~d} a$, deve ser dado, no limite, por:

$-\mathrm{d} E_{\mathrm{d}}=2 \gamma_{\mathrm{E}} \mathrm{d} a$

ou, de acordo com a Eq.(4.18):

$\left(-E_{d}\right)_{\Omega}=G_{\mathrm{t}}=\int_{\Omega \Omega}[(\phi \mathbf{I}) \mathbf{n} . \mathbf{e}] \mathrm{ds}=2 \gamma_{E}$.

Esta seria, portanto, a expressão do critério termodinâmico para o caso de uma chapa plana com espessura unitária, em regime isotérmico e quase estático, com a fissura iniciandose a partir do contorno.

Antecipando-se ao que vai ser feito nos capítulos 6 e 7, imagine-se que o valor crítico de $G_{\mathrm{t}}$, isto é, $\gamma_{\mathrm{E}}$, tenha sido obtido experimentalmente. A interpretação mais cabível seria a seguinte: se a variação da energia de deformação, entre um estado imediatamente anterior ao início do avanço da fissura, e outro, imediatamente posterior, for tal que o critério da Eq. (4.20) se verifique, então a fissura sofrerá um avanço inicial. Para saber se ela continuará avançando, será necessário, no curso da análise numérica do problema, que o domínio seja continuamente atualizado. Do ponto de vista mais completo da física do problema, entretanto, caberia a adoção de um critério semelhante ao representado pela Eq. (3.12), porquanto ele encarna a consideração do movimento, o que exige a utilização do parâmetro dinâmico, $\gamma_{\mathrm{E} d i n}$, ao invés de $\gamma_{\mathrm{E}}$, adequado somente para o caso quase estático 


\section{O MÉTODO DOS ELEMENTOS DE CONTORNO (BEM) APLICADO AO CÁLCULO DA INTEGRAL $J$ E DO PARÂMETRO TERMODINÂMICO DE FRATURA}

Conforme o capítulo anterior, se o material de uma parte genérica, $P$, de um sólido fissurado é hiperelástica, então é possível calcular-se uma integral de superfície (ou de linha, em problemas bidimensionais) que, no caso de uma fissura formada por faces planas (ou segmentos de reta, em casos bidimensionais), é independente do caminho. Trata-se da integral $J$, originalmente concebida por Rice (1968), para o caso bidimensional, que também pode ser obtida, de maneira generalizada, com o auxílio da análise de sensibilidade. Nesse último caso, é interpretada como sendo a projeção, em direção paralela à fissura, do fluxo do tensor momentum energia, sobre um caminho arbitrário que circunda a extremidade da fissura. Mediante o uso da análise de sensibilidade, a obtenção da integral $J$ faz-se a partir da derivação material da energia potencial elástica em relação a um parâmetro característico associado à variação geométrica do domínio, conforme mostra Taroco (1996).

Para a obtenção do parâmetro $G_{t}$, dado pela Eq. (4.20), através da via numérica, tudo é feito de forma semelhante, bastando que se substitua a variação da energia potencial total pela variação da energia de deformação em relação ao parâmetro geométrico da fissura.

Neste capítulo utiliza-se o BEM para calcular, com o auxílio da análise de sensibilidade, a grandeza $G_{\mathrm{t}}$, dada pela Eq. (4.20). Verifica-se que, diferentemente da integral $J$, o parâmetro $G_{\mathrm{t}}$ não é dado por uma integral independente do caminho. Sua importância decorre, entretanto, do fato de ter emergido da interpretação termodinâmica do fenômeno da fratura, isto é, de uma formulação consistente com as leis que melhor interpretam os fenômenos naturais.

Feita a particularização para os problemas bidimensionais, os resultados aproximados que à frente serão obtidos, com o auxílio dos desenvolvimentos elaborados no presente capítulo, visam, exclusivamente, demonstrar a possibilidade prática das conclusões teóricas decorrentes do conjunto da investigação descrita nos capítulos anteriores. Vale observar que o critério de fratura aqui adotado, na forma da Eq. (4.19), ainda não pode ser plenamente verificado, a não ser de maneira simulada, porquanto ainda não foi determinado experimentalmente o parâmetro termodinâmico crítico de fratura, $\gamma_{\mathrm{E}}$, para qualquer material real.

Optou-se por calcular a integral $J$ através do programa automático especialmente elaborado para este trabalho, pela razão já explicitada anteriormente. Para a finalidade de 
comparação de desempenho entre o programa aqui elaborado, que utiliza o BEM, e outros que também usam a análise de sensibilidade, embora apliquem o FEM, foram feitas comparações com resultados obtidos por Cunha e colaboradores (1995), Taroco e colaboradores (1994) e Taroco e Feijóo (1997).

Convém fazer a distinção entre a metodologia aqui utilizada para o tratamento do problema da fratura e as metodologias anteriores, em particular a da integral $J$. Aqui, o critério de fratura é obtido com o auxílio de dois procedimentos paralelos: um, analítico, que se realiza sobre o modelo de uma estrutura real, para uma parte genérica da qual se calcula o parâmetro de fratura; outro, o experimental, realizado sobre um modelo em escala da estrutura real, que fornece o valor crítico desse parâmetro. A comparação entre os dois valores obtidos é a base do critério de integridade à fratura.

No caso da presente proposta, o parâmetro crítico, $\gamma_{E}$, obtido experimentalmente, deve ser um dado inicial, que precisa ser oferecido ao programa, para a análise de fratura da estrutura real. Daí, o programa automático ser organizado para responder se a tendência da fissura é avançar ou se estabilizar. Caso avance,é possível obter-se a(s) direção(ões) em que isso tenderá a se dar.

Embora não conste da presente proposta a realização de experimentos em laboratório, apresenta-se, no capítulo 6, uma proposta sobre a forma como o experimento pode ser realizado, a fim de fornecer o valor crítico do parâmetro termodinamicamente consistente. Nessa sugestão de experimento exige-se que o esquema montado, para o cálculo computacional aproximado de $G_{\mathrm{t}}$, também seja aproveitado para a localização dos pontos em que as componentes de deformação devem ser medidas, com o auxílio de extensômetros elétricos de resistência (strain gages) do tipo roseta, no caso particular de uma chapa de espessura constante, em estado plano. Para melhor fidelidade da comparação, os strain gages devem ser colados em pontos que sejam os mesmos pontos de integração do método de Gauss-Legendre, definidos para a experimentação numérica. Mais detalhes sobre a proposta de determinação experimental de $\gamma_{E}$ são apresentados no capítulo 6.

$\mathrm{Na}$ sequência, desenvolvem-se os algoritmos para a construção do programa automático que calcula, sobre um caminho de integração elíptico arbitrário, os valores da integral $J$ e do parâmetro $G_{\text {t. }}$. 


\section{ESQUEMA TEÓRICO PARA A DETERMINAÇÃO APROXIMADA DE $G_{\mathrm{t}}$ NO ESTADO PLANO DE DEFORMAÇÃO}

Obtém-se, a seguir, para o estado plano de deformação, a integral da Eq.(4.20), que fornece o valor de $G_{\mathrm{t}}$ a partir de uma fissura inicial orientada segundo o vetor unitário e, consideradas nulas as forças de corpo (para caso do estado plano de tensão, basta que se forneça ao programa automático, o valor $v /(1+v)$ no lugar do coeficiente de Poisson $v$.

Assim, de acordo com o desenvolvimento apresentado no capítulo 4, tem-se:

$$
G_{\mathrm{t}}=\int_{\Gamma}[(\phi \mathbf{I}) \mathbf{n} \cdot \mathbf{e}] \mathrm{d} s
$$

Considerando-se o vetor normal unitário, $\mathbf{n}$, orientado para fora da parte do sólido escolhida, então, em cada ponto do contorno percorrido no sentido anti-horário, tem-se:

$\mathbf{n}=\left\{\begin{array}{c}\mathrm{d} x_{2} / \mathrm{d} \Gamma \\ -\mathrm{d} x_{1} / \mathrm{d} \Gamma\end{array}\right\}$

Daí, a integral do segundo membro da Eq. (4.20) fica:

$$
\int_{\Gamma}(\phi \mathbf{I}) \mathbf{n} d \Gamma=\int_{\Gamma}\left[\begin{array}{ll}
\phi & 0 \\
0 & \phi
\end{array}\right]\left\{\begin{array}{c}
d x_{2} / d \Gamma \\
-d x_{1} / d \Gamma
\end{array}\right\} d \Gamma=\int_{\Gamma}\left\{\begin{array}{c}
\phi d x_{2} \\
-\phi d x_{1}
\end{array}\right\}
$$

O contorno regular $\Gamma$, que pode ser arbitrário, será aqui adotado na forma de uma elipse de eixo maior $2 a$ (na direção $x_{2}$ ) e eixo menor $2 b$ (na direção $x_{1}$ ), cujo centro é o ponto $O$ (figura 7). Assim sendo:

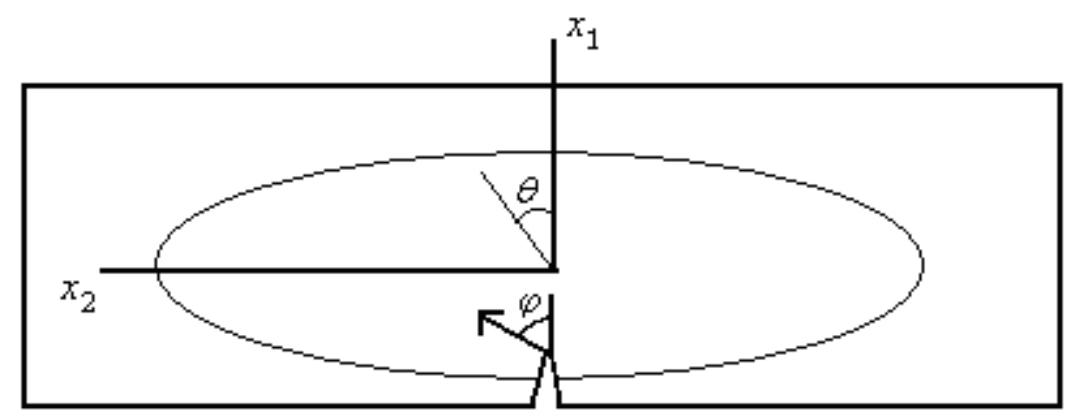

Figura 7- Convenções de eixos e de ângulos 
$x_{1}=b \cos \theta\left[k^{2} \operatorname{sen}^{2} \theta+\cos ^{2} \theta\right]^{-1 / 2}$ e $\quad x_{2}=a \operatorname{sen} \theta\left[\operatorname{sen}^{2} \theta+k^{-2} \cos ^{2} \theta\right]^{-1 / 2}$,

onde $k=b / a$. Daí:

$\mathrm{d} x_{1}=-k^{2} b \operatorname{sen} \theta\left(k^{2} \operatorname{sen}^{2} \theta+\cos ^{2} \theta\right)^{-3 / 2} \mathrm{~d} \theta$

$\mathrm{e}$

$\mathrm{d} x_{2}=k^{-2} a \cos \theta\left(\operatorname{sen}^{2} \theta+k^{-2} \cos ^{2} \theta\right)^{-3 / 2} \mathrm{~d} \theta$

sendo $h$ a espessura constante da chapa, então a Eq. (5.2) torna-se:

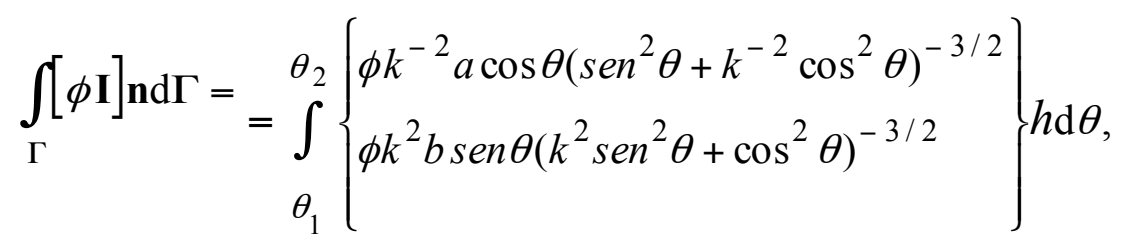

onde $\phi$, densidade de energia, no caso da elasticidade linear, vale

$\phi=\frac{1}{2} \mathbf{T} . \mathbf{E}$,

em que $\mathbf{T}$ é o tensor tensão de Cauchy e $\mathbf{E}$, o tensor de deformações infinitesimais nos pontos do caminho de integração $\Gamma$. Entenda-se que deve estar assegurado o comportamento hiperelástico do material, na medida em que se supõe o caminho escolhido longe de extremidades de fissuras.

Visando à aplicação do esquema de integração de Gauss-Legendre, será realizada a mudança da variável $\theta$ para a variável $\zeta$, de forma a que os limites de integração passem a ser -1 e +1. Assim:

$\theta=p \zeta+q \rightarrow d \theta=p d \zeta$

fazendo com que, para $\theta=\theta_{1}$, seja $\zeta=-1$ e, para $\theta=\theta_{2}$, seja $\xi=+1$. Daí:

$p=\frac{\theta_{2}-\theta_{1}}{2} e q=\frac{\theta_{1}+\theta_{2}}{2}$ 
Por conta de uma opção de programação, a função densidade de energia de deformação, $\phi$, será colocada em termos das componentes do tensor T. Assim, no caso do estado plano de deformação, tem-se:

$\mathbf{T}=\left[\begin{array}{ll}T_{11} & T_{12} \\ T_{12} & T_{22}\end{array}\right] \quad$ e $\quad \mathbf{E}=\begin{array}{ll}11 & 12 \\ 12 & 22\end{array}$

onde:

$$
\begin{aligned}
& \varepsilon_{11}=\frac{1}{3 \prime \prime}\left[(1-v) T_{11}-v T_{22}\right], \quad \varepsilon_{12}=\frac{1}{\jmath \prime \prime} T_{12}, \\
& T_{11}=\frac{2 \mu}{1-2 v}\left[(1-v) \varepsilon_{11}-v \varepsilon_{22}\right], T_{12}=2 \mu \varepsilon_{12} \quad \text { e } \quad T_{22}=\frac{2 \mu}{1-2 v}\left[(1-v) \varepsilon_{22}-v \varepsilon_{11}\right),
\end{aligned}
$$

em que $\mu$ é o módulo de elasticidade transversal do material.

Conhecidas as componentes de tensão e de deformação, pode-se obter o valor de $\phi$, no estado plano de deformação, explicitado nas componentes de tensão, isto é:

$$
\begin{aligned}
& \phi=\frac{1}{2} \mathbf{T} . \mathbf{E}=\frac{1}{2} \operatorname{tr}(\mathbf{T E})=\frac{1}{2}\left(T_{11} \varepsilon_{11}+2 T_{12} \varepsilon_{12}+T_{22} \varepsilon_{22}\right)= \\
& =\frac{1}{4 \mu}\left[(1-v)\left(T_{11}{ }^{2}+T_{22}{ }^{2}\right)+2 T_{12}{ }^{2}-2 v T_{11} T_{22}\right] .
\end{aligned}
$$

A mesma grandeza, explicitada em termos das deformações, também no estado plano de deformações, é dada por:

$$
\phi=\frac{\mu}{(1-2 v)}\left[(1-v)\left(\varepsilon_{11}^{2}+\varepsilon_{22}^{2}\right)+2(1-2 v) \varepsilon_{12}^{2}+2 v \varepsilon_{11} \varepsilon_{12}\right]
$$

Com o valor de $\phi$ dado pela Eq. (5.6), pode-se calcular $G_{\mathrm{t}}$ segundo a Eq. (4.20), em que o vetor unitário arbitrário, e, é dado por $\mathrm{e}=\{\cos \varphi, \operatorname{sen} \varphi\}$, onde $\varphi$ é o ângulo entre aquele vetor e o eixo dos $x_{1}$ (figura 7). Assim:

$$
G_{\mathrm{t}}=\int_{\Gamma}[(\Phi \mathrm{I}) \mathbf{n d} \Gamma] \cdot \mathbf{e}=\left(C_{1}, D_{1}\right) \cdot(\cos \varphi, \operatorname{sen} \varphi)=C_{1} \cos \varphi+D_{1} \operatorname{sen} \varphi
$$


onde, de acordo com a Eq. (5.4), vem:

$C_{1}=\frac{h\left(\theta_{2}-\theta_{1}\right)}{2} \int_{-1}^{+1}\left[\phi a k^{-2} \cos \theta\left(\operatorname{sen}^{2} \theta+k^{-2} \cos ^{2} \theta\right)^{-3 / 2}\right] d \xi$

e

$$
D_{1}=\frac{h\left(\theta_{2}-\theta_{1}\right)^{+1}}{2} \int_{-1}^{1}\left[\phi b k^{2} \operatorname{sen} \theta\left(k^{2} \operatorname{sen}^{2} \theta+\cos ^{2} \theta\right)^{-3 / 2}\right] d \zeta
$$

onde $\mathrm{d} \zeta=p \mathrm{~d} \theta$.

\section{OBTENÇÃO DA(S) DIREÇÃO(ÇÕES) SEGUNDO A(S) QUAL(AIS) A FISSURA VAI AVANÇAR}

A partir da Eq. (5.8) pode-se determinar o ângulo $\varphi$ (figura 7) que dá a direção segundo a qual a fissura avançará, no caso em que haja a sua deflagração. Trata-se de determinar o ângulo para o qual $G_{\mathrm{t}}$ atinge o valor crítico, $\gamma_{\mathrm{E}}$, isto é, para o qual a Eq. (5.8) fica:

$C_{1} \cos \varphi+D_{1} \operatorname{sen} \varphi=\gamma_{\mathrm{E}}$

O parâmetro termodinâmico crítico, $\gamma_{\mathrm{E}}$, deve ser medido experimentalmente, no exato instante da deflagração irreversível do processo de fissuração. Evidentemente, enquanto o processo for reversível a energia de deformação será recuperada, quando do descarregamento. No entanto, isso não ocorrerá completamente, no caso em que houver a componente irreversível da fissura, e é isso que deverá se refletir na medida experimental de $\gamma_{\mathrm{E}}$.

Elevando-se ambos os membros da Eq. (5.10) ao quadrado e efetuando-se as operações cabíveis, resulta:

$$
\left(C_{1}^{2}+D_{1}^{2}\right) \operatorname{sen}^{2} \varphi-2 \gamma_{\mathrm{E}} D_{1} \operatorname{sen} \varphi+\gamma_{\mathrm{E}}^{2}-C_{1}^{2}=0
$$


cuja solução é:

$\operatorname{sen} \varphi=\frac{\gamma_{E} D_{1} \pm C_{1} \sqrt{C_{1}^{2}+D_{1}^{2}-\gamma_{E}^{2}}}{C_{1}^{2}+D_{1}^{2}}$.

A depender do sinal da expressão sob o radical, na Eq. (5.12), a solução para a Eq. (5.11) poderá levar a:

a) Dois valores para o ângulo $\varphi$, no caso em que $C_{1}{ }^{2}+{D_{1}}^{2}>{\gamma_{E}}^{2}$, dados pela Eq. (5.12);

b) Um só valor, no caso em que $C_{1}^{2}+{D_{1}}^{2}={\gamma_{E}}^{2}$, dado por:

$\operatorname{sen} \varphi=\frac{\gamma_{E} D_{1}}{C_{1}^{2}+D_{1}^{2}}$

c) Nenhum valor para $\varphi$, caso $C_{1}^{2}+D_{1}^{2}<\gamma_{E}^{2}$.

No caso (a), em que são duas as soluções, tem-se uma bifurcação da fissura, nas direções definidas de acordo com as Eqs. (5.10) e (5.12), segundo os seguintes valores do ângulo $\varphi$ :

$\varphi_{1}=\operatorname{arctg}\left(\frac{\gamma_{E} D_{1}+C_{1} \sqrt{C_{1}^{2}+D_{1}^{2}-\gamma_{E}^{2}}}{\gamma_{E} C_{1}-D_{1} \sqrt{C_{1}^{2}+D_{1}^{2}-\gamma_{E}^{2}}}\right)$

e

$\varphi_{2}=\operatorname{arctg}\left(\frac{\gamma_{E} D_{1}-C_{1} \sqrt{C_{1}^{2}+D_{1}^{2}-\gamma_{E}^{2}}}{\gamma_{E} C_{1}+D_{1} \sqrt{C_{1}^{2}+D_{1}^{2}-\gamma_{E}^{2}}}\right)$.

No caso (b), as Eqs. (5.10) e (5.12) conduzem à solução:

$\varphi=\operatorname{arctg}\left(\frac{D_{1}}{C_{1}}\right)$. 
Vale observar que, diferentemente da integral $J$, cujo processo de obtenção será analisado a seguir, a interpretação das hipóteses (a), (b) e (c) revelam um resultado novo, decorrente da premissa de que é possível determinar-se o parâmetro experimental crítico $\gamma_{\mathrm{E}}$.

No caso da integral $J$, no entanto, tal não ocorre. Como se sabe, sua determinação baseia-se na hipótese segundo a qual o avanço da fissura deve ser simulado segundo uma direção paralela às faces da fissura, razão pela qual ela se torna independente do caminho. No caso do parâmetro $G_{\mathrm{t}}$, o valor é calculado para a parte $P$, do sólido, envolvida pelo caminho escolhido, e seu valor, ao contrário da integral $J$, é dependente do caminho. Por outro lado, não há exigência a respeito da direção para onde a fissura deva se dirigir, a priori. Evidentemente, a direção do processo de avanço da fissura é definida físicamente e, segundo a termodinâmica, a direção de seu avanço deverá ser aquela para a qual a variação da energia livre de Helmholtz seja mínima. Em suma, é isso que está por trás da Eq. (5.10). Sendo assim, suas raízes, que revelam o sentido do avanço da fissura, fornecem um resultado novo, creditado à consistência termodinâmica do modelo aqui desenvolvido.

\section{OBTENÇÃO APROXIMADA DA INTEGRAL $J$ NO ESTADO PLANO DE DEFORMAÇÃO}

Para o cálculo da integral $J$, a partir do que foi apresentado na seção anterior, basta que se mude o núcleo da integral do primeiro membro da Eq. (5.2), isto é, ao invés de $\phi \mathbf{I}$, ele será agora constituído pelo tensor momentum energia de Eshelby, tal como sugere Taroco (1996). Nessa última referência, o tensor momentum energia de Eshelby é calculado através de um desenvolvimento semelhante ao que aqui foi há pouco utilizado. Com vistas à implementação computacional, basta que se obtenham os valores $C$ e $D$, das expressões análogas às Eqs. (5.9a) e (5.9b), nas quais a única novidade reside na introdução, no programa, do gradiente do deslocamento $\nabla \mathbf{u}$, por suas componentes cartesianas $u_{i, j}$. Assim:

$$
J=\left[\int_{\Gamma}\left(\phi \mathbf{I}-(\nabla \mathbf{u})^{\mathrm{T}} \mathbf{T}+\right) \mathbf{n d} \Gamma\right] \cdot \mathbf{e}=(C, D) \cdot(\cos \varphi, \operatorname{sen} \varphi)=C \cos \varphi+D \operatorname{sen} \varphi
$$

na qual: 
$C=\frac{\left(\theta_{2}-\theta_{1}\right) h}{2}\left[\begin{array}{l}+1 \\ -1 \\ +1 \\ +\int_{-1}^{+1}\left(-u_{1,1} T_{12}-u_{2,1} T_{22}\right) b k^{2} \operatorname{sen} \theta\left(k^{2} \operatorname{sen}^{2} \theta+\cos ^{2} \theta\right)^{-3 / 2} d \zeta\end{array}\right]$

e

$$
D=\frac{\left(\theta_{2}-\theta_{1}\right) h}{2}\left[\begin{array}{l}
+1 \\
\int\left(-u_{1,2} T_{11}-u_{2,2} T_{12}\right) a k^{-2} \cos \theta\left(\operatorname{sen}^{2} \theta+k^{-2} \cos ^{2} \theta\right)^{-3 / 2} d \zeta- \\
-1 \\
+\int_{-1}^{+1}\left(\phi-u_{1,2} T_{12}-u_{2,2} T_{22}\right) b k^{2} \operatorname{sen} \theta\left(k^{2} \operatorname{sen}^{2} \theta+\cos ^{2} \theta\right)^{-3 / 2} d \zeta
\end{array}\right]
$$

A seguir, será apresentado o BEM, ferramenta numérica tal como o FEM, que pode ser utilizada na obtenção de soluções aproximadas na elasticidade. No caso, isto será feito especialmente para problemas da elastidade plana.

\section{O MÉTODO DOS ELEMENTOS DE CONTORNO (BEM) APLICADO A PROBLEMAS BIDIMENSIONAIS DE ELASTICIDADE}

O BEM, quando aplicado a problemas bidimensionais da elasticidade, é uma extensão do problema do potencial plano. A resposta, nesse caso, é obtida na forma da solução de uma equação diferencial, nas componentes do vetor deslocamento, após a aplicação de uma carga tipo distribuição $\delta$-Dirac na direção de um dos eixos coordenados do plano, em um ponto genérico do domínio do problema.

Obtêm-se, inicialmente, a partir das exigências de equilíbrio e de compatibilidade da elasticidade, as expressões das componentes do deslocamento em pontos do interior do domínio, como função dos valores prescritos no contorno, em termos de componentes de deslocamento e de vetores de Cauchy (tractions). Depois, estende-se esse resultado para pontos do próprio contorno, chegando-se, finalmente, às equações integrais que permitirão a 
aplicação do método aproximado, cuja solução final resultará da resolução de um sistema de equações algébricas em que as incógnitas são as componentes de deslocamento e as componentes das tractions, no contorno.

Mostra-se, a seguir, o esquema baseado no BEM, através do qual serão obtidos o tensor gradiente de deslocamentos e o tensor tensão, nos pontos de um caminho elíptico, em que os dois eixos tem valores arbitrariamente fixados.

No caso da mecânica da fratura necessita-se das componentes do tensor tensão e das componentes do tensor gradiente de deslocamentos, em pontos do interior do domínio plano, o que deverá ser fornecido, de forma aproximada, a partir da utilização de um programa automático no qual é utilizado um elemento de contorno reto, com funções de interpolação lineares.

A equação integral que fornece as duas componentes cartesianas do vetor deslocamento em pontos do domínio, segundo Brebbia e Dominguez (1989), é dada por:

$u_{i}(P)=-\int_{\partial \Omega} p_{i j}^{*}(P, S) u_{j}(S) \mathrm{d} S+\int_{\Omega} u_{i j}^{*}(P, S) p_{j}(S) \mathrm{d} S$,

onde $P$ é um ponto genérico no interior do domínio $\Omega$, e $S$ um ponto, também genérico, situado na fronteira $\Gamma$ desse domínio. As soluções fundamentais, $u_{\mathrm{ij}}^{*}$ e $p_{\mathrm{ij}}^{*}$, que aparecem nas integrais do segundo membro da Eq. (5.15), são respostas à aplicação de distribuições $\delta$-Dirac associadas à direção $j$. Essas funções, válidas para o caso bidimensional, são dadas, segundo Brebbia e Dominguez (1989), através das seguintes expressões:

$u_{i j}^{*}(P, S)=\frac{1}{8 \pi G(1-v)}\left[(4 v-3) \delta_{i j} \ln r+r_{, i} r_{, j}\right]$

e

$p_{i j}^{*}(P, S)=\frac{-1}{4 \pi(1-v) r}\left\{\left[(1-2 v) \delta_{i j}+2 r_{, i} r_{, j}\right] r_{, n}+(1-2 v)\left[n_{i} r_{, j}-n_{j} r_{, i}\right]\right.$

Para que se obtenham as componentes cartesianas do tensor gradiente de deslocamentos e do tensor de tensão é necessária a derivação da Eq. (5.18) em relação a $x_{\mathrm{k}}$. Assim:

$u_{i, k}(P)=\int_{\partial \Omega} u_{i j, k}^{*}(P, S) p_{j}(S) \mathrm{d} s-\int_{\partial \Omega} p_{i j, k}^{*}(P, S) u_{j}(S) \mathrm{d} s$. 
Observe-se que, por ser a derivação parcial feita em relação à variável $x_{\mathrm{k}}$, no ponto $P$ do interior do domínio, isso não afeta as variáveis dependentes de $S$, ponto da fronteira. Assim, desde que seja assegurada a continuidade das funções integrandas, passa-se a derivação para o interior das integrais do segundo membro da Eq. (5.21). Vê-se, portanto, que a derivação somente afeta as soluções fundamentais $u_{\mathrm{ij}}^{*}$ e $p^{*}{ }_{\mathrm{ij}}$, que dependem do ponto interior $P$. Em resumo, somente são calculadas as derivadas parciais das soluções fundamentais $u_{\mathrm{ij}}^{*}$ e $p^{*}{ }_{\mathrm{ij}}$, em relação à variável $x_{\mathrm{k}}$, entendendo-se que o seu sinal deva ser invertido, para que se mantenha a convenção tradicional de $r_{, i}$ como sendo a derivada do raio em relação à variável relacionada com o ponto da fronteira. Efetuando-se as devidas derivações, resulta:

$u_{i j, k}^{*}(P, S)=\frac{1}{8 \pi u(1-v) r}\left\{r_{, k}\left[(3-4 v) \delta_{i j}+2 r_{, i} r_{, j}\right]-r_{, i} \delta_{j k}-r_{, j} \delta_{i k}\right\}$

$\mathrm{e}$

$$
\begin{aligned}
& p_{i j, k}^{*}(P, S)=\frac{-1}{4 \pi(1-v) r^{2}}\left\{2 r_{, n}\left[(2 v-1) \delta_{i j} r_{, k}-4 r_{j} r_{, j} r_{, k}+r_{j} \delta_{j k}+r_{, j} \delta_{i k}\right]+\right. \\
& \left.+(1-2 v)\left[n_{j}\left(\delta_{i k}-2 r_{j} r_{, k}\right)+2 n_{i} r_{, j} r_{, k}-n_{i} \delta_{j k}-n_{k} \delta_{i j}\right]-2 r_{j} r_{, j} n_{k}\right\},
\end{aligned}
$$

onde $\mu$ é o módulo de elasticidade transversal e $r_{, n}=r_{, l} n_{l}$, com $i, j, k, l=1,2$. Substituindo-se as Eqs. (5.22) e (5.23) na Eq. (5.21), obtêm-se as derivadas das componentes do vetor deslocamento, com as quais pode ser composto o tensor gradiente do vetor deslocamento, isto é:

$(\nabla \mathbf{u})_{i j}=u_{i, j}$

Obtido esse tensor, pode-se chegar à expressão da densidade de energia, $\phi$, da qual se derivam as componentes do tensor tensão, a saber:

$$
T_{i j}=\frac{E}{2(1+v)}\left[\frac{2 v}{1-2 v} \delta_{i j} u_{m, m}+u_{i, j}+u_{j, i}\right] .
$$

Com as componentes do tensor gradiente dos deslocamentos $\nabla \mathbf{u}$ e do tensor tensão $\mathbf{T}$, nos pontos do caminho elíptico de integração, pode-se efetuar, tal como é feito no capítulo 4, o cálculo da interal $J$ e do parâmetro $G_{t}$. 


\section{A técnica de subelementação}

No intuito de melhorar a precisão dos resultados, já que as integrações, no método dos elementos de contorno, envolvem funções portadoras de elevado grau de singularidade, utiliza-se uma eficiente técnica que consiste na possível subdivisão de um dado elemento reto em subelementos, a decisão ficando por conta da distância do ponto de colocação em relação ao elemento. Em sequência, realiza-se a integração numérica no domínio do subelemento, com auxílio do método de Gauss-Legendre, usando-se, no caso do Elcfrat, o mesmo número de pontos de integração utilizado nas integrações sobre os elementos que não precisarem de subelementação.

Para isso usam-se duas opções, segundo o seguinte esquema: na primeira, imagine-se um elemento $P_{1} P_{2}$, e o ponto de colocação $P_{0}$, cujas posições relativas estão indicadas na figura 8. A localização de um ponto genérico do segmento $P_{1} P_{2}$ é feita através da seguinte expressão:

$P=P_{1}+\alpha \vec{t}$

onde $0 \leq \alpha \leq L$, sendo $L$ o comprimento do elemento, e

$$
\vec{t}=\left(\frac{x_{2}-x_{1}}{L}, \frac{y_{2}-y_{1}}{L}\right)
$$

o vetor unitário da direção $P_{1} P_{2}$.

Para se formular um critério de subdivisão do elemento $P_{1} P_{2}$, a seguinte condição será estabelecida, no primeiro caso, em termos de distâncias. Assim:

$$
d\left(P_{1}, P\right)=d\left(P_{0}, P\right)
$$

\section{Como}

$$
d\left(P_{1}, P\right)=\sqrt{\left(x-x_{1}\right)^{2}+\left(y-y_{1}\right)^{2}} \mathrm{e} d\left(P_{0}, P\right)=\sqrt{\left(x-x_{0}\right)^{2}+\left(y-y_{0}\right)^{2}},
$$


então, a substituição desses valores na Eq. (5.26) leva à definição do valor do parâmetro localizador $\alpha$, isto é:

$\alpha=-\frac{L}{2}\left[\frac{\left(x_{1}-x_{0}\right)^{2}+\left(y_{1}-y_{0}\right)^{2}}{\left(x_{2}-x_{1}\right)\left(x_{1}-x_{0}\right)+\left(y_{2}-y_{1}\right)\left(y_{1}-y_{0}\right)}\right]$.

Pelo observado na figura $8 a$, se $0<\alpha \leq L$, então o ponto $P(x, y)$ definirá o subelemento $P_{1} P$. No entanto, se $\alpha \leq 0$ ou $\alpha>L$, então um segundo critério deverá ser utilizado.

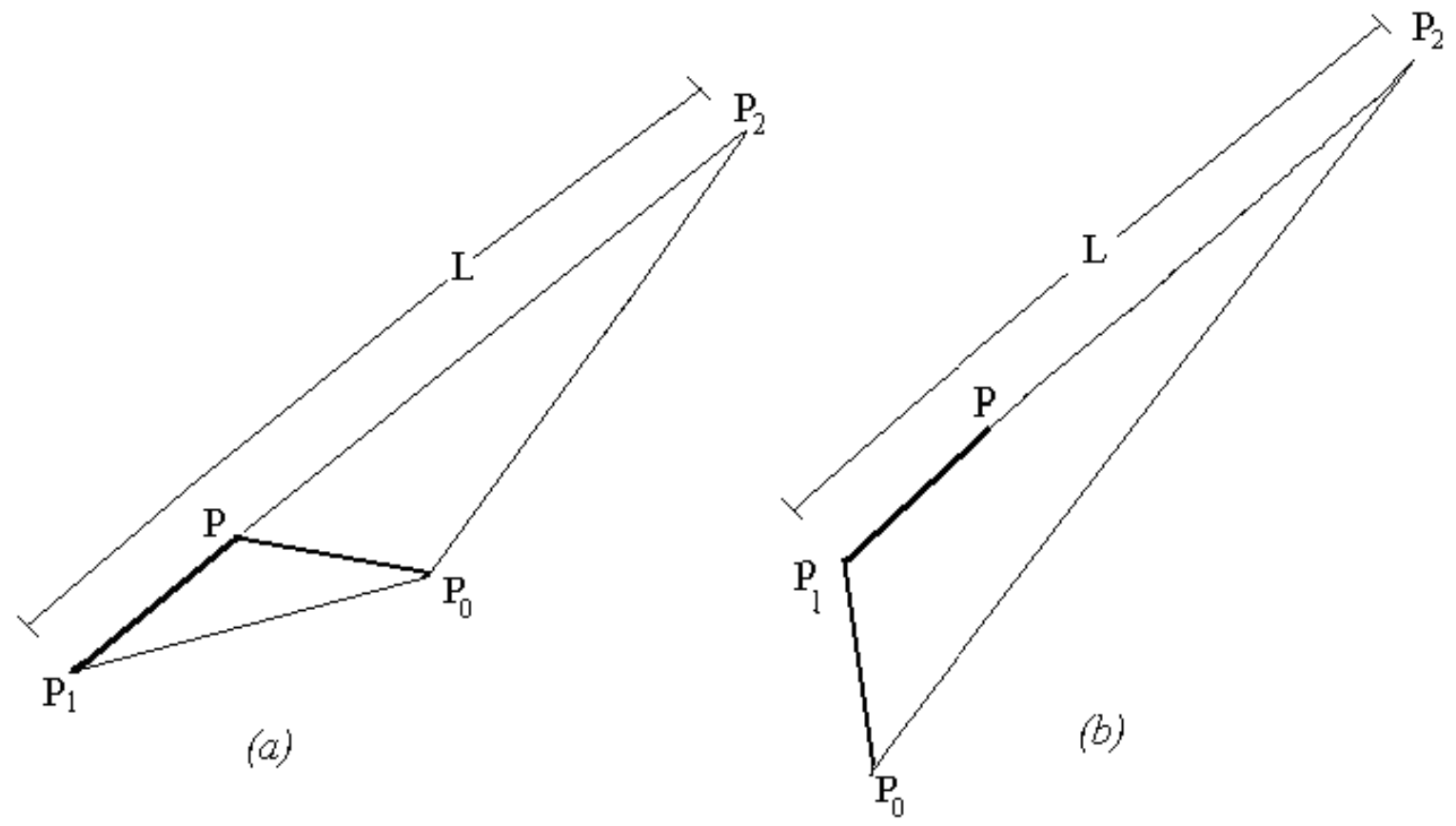

Figura 8 - Posições relativas do ponto de colocação em relação ao elemento retilíneo

A figura $8 b$ ilustra o segundo critério, para a definição do subelemento, caracterizado pela seguinte condição:

$d\left(P, P_{1}\right)=d\left(P_{1}, P_{0}\right)$.

onde o ponto genérico $P$, pertencente ao segmento $P_{1} P_{2}$, agora é dado através da seguinte expressão: 
$P=P_{1}+\beta \vec{t}$, sendo $0 \leq \beta \leq L$, e $\vec{t}=\left(\frac{x_{2}-x_{1}}{L}, \frac{y_{2}-y_{1}}{L}\right)$, o vetor unitário da direção $P_{1} P_{2}$. As distâncias de $P$ a $P_{1}$ e de $P$ a $P_{0}$ são dadas, respectivamente, por:

$d\left(P, P_{1}\right)=\sqrt{\left(x-x_{1}\right)^{2}+\left(y-y_{1}\right)^{2}}$ e $d\left(P, P_{0}\right)=\sqrt{\left(x-x_{0}\right)^{2}+\left(y-y_{0}\right)^{2}}$.

A aplicação da condição definida pela Eq (5.25) conduz ao seguinte valor de $\beta$ :

$\beta=\sqrt{\left(x_{1}-x_{0}\right)^{2}+\left(y_{1}-y_{0}\right)^{2}}$.

Fica evidente que o valor de $\beta$ é sempre positivo, devendo, no entanto, obedecer à condição $0<\beta \leq L$.

Em síntese, deverá ser seguido o seguinte roteiro para o teste e a aplicação do processo de divisão do elemento de contorno em subelementos:

1) Calcula-se $\alpha$ e $\beta$, correspondentes ao ponto de colocação $P_{0}$, usando-se as expressões (5.27) e (5.29), respectivamente;

2) Caso $\alpha$ atenda à condição $0<\alpha \leq L$, obtém-se o subelemento $P_{1} P$,

onde $P=\left(x_{1}+\alpha\left[x_{2}-x_{1}\right] ; y_{1}+\alpha\left[\mathrm{y}_{2}-y_{1}\right]\right)$;

3) Se a condição anterior não for verificada, testa-se, nessa ordem, a segunda condição, isto é, $\beta \leq L$. Caso esta seja atendida, então $P=\left(x_{1}+\beta\left(x_{2}-x_{1}\right) ; y_{1}+\beta\left(\mathrm{y}_{2}-y_{1}\right)\right)$;

4) Se ambas as condições não forem atendidas, não é necessária a aplicação da técnica de subelementação para o par $\left(P_{0}, P_{1} P_{2}\right)$;

5) Se couber a aplicação da técnica a um par $\left(P_{0}, P_{1} P_{2}\right)$, então a continuidade de sua utilização será testada, podendo os dois critérios irem se alternando, até esgotar-se o processo para esse par, passando-se, então, ao seguinte, e assim sucessivamente.

\section{A integração numérica no subelemento}

Imagine-se uma função $f(s)$, integrável, definida no elemento reto $A B$ cujas extremidades sejam dadas, respectivamente, através dos valores $s_{a}$ e $s_{b}$ do parâmetro $s$. Para sua integração numérica num elemento de contorno, através do método de Gauss-Legendre, 
deve-se realizar uma mudança da variável $s$ (comprimento de arco) para a variável adimensional $\xi$, de maneira que esta assuma os valores -1 e +1 , respectivamente, nas extremidades $A$ e $B$ desse elemento. Para que tal condição seja obedecida, admitindo-se que $s=a \xi+b$, tem-se:

$a=\frac{s_{b}-s_{a}}{2}, \quad b=\frac{s_{b}+s_{a}}{2}$ e $\mathrm{d} s=a \mathrm{~d} \xi$.

Para se realizar a integração em um subelemento contido nesse elemento reto, de extremidades $i$ e $j$, por seu turno, é necessário mudar-se da variável $\xi$ para a variável $\eta$, de forma a que a integral, nessa nova variável, seja realizada entre $\eta=-1$ e $\eta=+1$, porque o esquema de integração aproximado será o mesmo, com base no método de Gauss-Legendre. Assim:

$\xi=p \eta+q$, onde

$p=\frac{\xi_{j}-\xi_{i}}{2}, \quad q=\frac{\xi_{j}+\xi_{i}}{2}$ e $\mathrm{d} \xi=p \mathrm{~d} \eta$

O caso do elemento reto com uma função de interpolação linear está ilustrado na figura 9 .

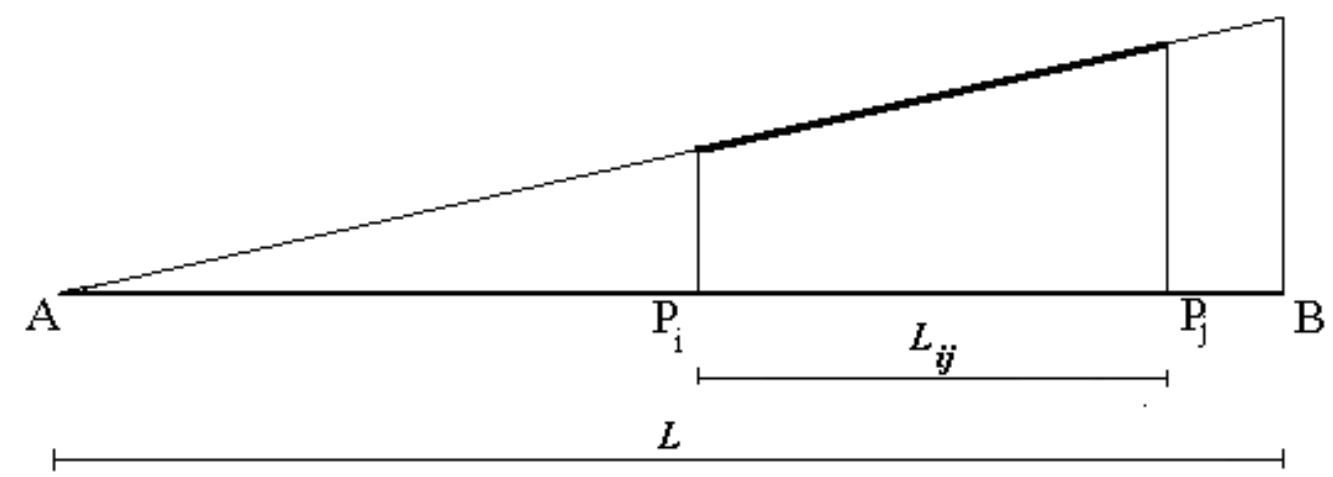

Figura 9 - Subelemento de um elemento de contorno retilíneo

Pode-se, também, concluir, usando as expressões de $s=s(\xi)$ e $\xi=\xi(\eta)$, que:

$$
a=\frac{s_{j}-s_{i}}{\xi_{j}-\xi_{i}} \quad \text { e } b=s_{i}-\xi_{i} \frac{s_{j}-s_{i}}{\xi_{j}-\xi_{i}} .
$$


Considerando-se as Eqs.(5.30) e (5.31), a integral da função $f(s)$ será:

$$
\int_{s_{i}}^{s_{j}} f(s) d s=a \int_{\xi_{i}}^{\xi_{j}} f(s(\xi)) d \xi=a p \int_{\eta=-1}^{\eta=+1} f(s(\xi(\eta))) d \eta=a p \int_{-1}^{+1} g(\eta) d \xi
$$

onde $g(\eta)=f(s(\xi(\eta)))$. Mas, de acordo com as Eqs. (5.31) e (5.32):

$$
a p=\frac{s_{j}-s_{i}}{2}=\frac{L_{i j}}{2}
$$

onde $L_{i j}$, tal como indica a figura 9, é o comprimento do subelemento considerado. Conclui-se ainda, a partir da manipulação dessas duas últimas equações, que:

$$
p=\frac{L_{i j}}{L} \quad \text { e } \quad q=\frac{L_{i j}+2\left(s_{i}-b\right)}{L}
$$

onde $b$ é dado pela Eq. (5.30).

Embora, no presente caso, a opção tenha sido por uma função de interpolação linear, observe-se que o esquema é válido, desde que o elemento seja reto, quaisquer que sejam as funções de interpolação, pois, em nenhum momento cogitou-se de particularizar a função $f=f(s)$.

No programa automático Elcfrat (apêndice A), a técnica de subelementação é usada, tanto para as integrações visando à montagem do sistema de equações algébricas do BEM quanto para o cálculo das componentes do tensor gradiente do deslocamento. Além disso, também é utilizada para calcular os tensores tensão e de deformação nos pontos internos da chapa, produzindo-se uma sensível melhora na aproximação. No caso desse programa automático, a função $f(s)$ foi tomada como linear, tal como ilustra a figura 9.

\section{A APLICAÇÃO DO MÉTODO DOS ELEMENTOS DE CONTORNO AO PROBLEMA DA FRATURA}

Mostra-se, a seguir, o esquema baseado no BEM, através do qual serão obtidos, nos pontos de um caminho elíptico, com a origem e os eixos arbitrariamente fixados, o gradiente 
do vetor deslocamento e o tensor de tensão, permitindo o cálculo aproximado das integrais das Eqs. (5.9) e (5.14), mediante a aplicação do esquema de integração de Gauss-Legendre.

O ponto de partida é a expressão que fornece as componentes: 1) do vetor deslocamento nos pontos do interior do domínio $\Omega$, em função dos valores das componentes dos deslocamentos em cada ponto do contorno $\partial \Omega$ e 2) do vetor deslocamento e do vetor de Cauchy (traction), no caso do problema elástico bidimensional, ${ }^{10}$ isto é:

$u_{i}(P)=-\int_{\partial \Omega} p_{i j}^{*}(P, S) u_{j}(S) d \Gamma+\int_{\partial \Omega} u_{i j}^{*}(P, S) p_{j}(S) d \Gamma$,

onde $P$ indica um ponto genérico, no interior do domínio $\Omega$, e $S$, um ponto também genérico, porém no contorno $\partial \Omega$ desse domínio. Daí, as derivadas parciais das componentes do vetor deslocamento são dadas por:

$u_{i, k}(P)=\int_{\partial \Omega} u_{i j, k}^{*}(P, S) p_{j}(S) d \Gamma-\int_{\Omega} p_{i j, k}^{*}(P, S) u_{j}(S) d \Gamma$

Observe-se que a derivação parcial no índice $k$, em razão de ser aplicada ao ponto $P$ do interior do domínio, não afeta as variáveis dependentes de $S$, ponto do contorno. Assim, desde que seja assegurada a exigência de continuidade das funções, a derivação transfere-se para os integrandos, no segundo membro da Eq. (5.35), indo afetar somente as soluções fundamentais, $u_{i j}^{*}$ e $p_{i j}^{*}$, que dependem da variável $P$. As derivadas parciais das soluções fundamentais $u^{*}{ }_{\mathrm{ij}}$ e $p^{*}{ }_{\mathrm{ij}}$, em relação a $x_{\mathrm{k}}$, obtidas na Seção 5.4, são:

$u_{i j, k}^{*}(P, S)=\frac{1}{8 \pi E(1-v) r}\left\{r_{, k}\left[(3-4 v) \delta_{i j}+2 r_{, i} r_{, j}\right]-r_{, i} \delta_{j k}-r_{, j} \delta_{i k}\right\}$

$\mathrm{e}$

$$
\begin{aligned}
& p_{i j, k}^{*}(P, S)=\frac{-1}{4 \pi(1-v) r^{2}}\left\{2 r_{, n}\left[(2 v-1) \delta_{i j} r_{, k}-4 r_{, i} r_{, j} r_{, k}+r_{, i} \delta_{j k}+r_{, j} \delta_{i k}\right]+\right. \\
& \left.+(1-2 v)\left[n_{j}\left(\delta_{i k}-2 r_{, i} r_{, k}\right)+2 n_{i} r_{, j} r_{, k}-n_{i} \delta_{j k}-n_{k} \delta_{i j}\right]-2 r_{, i} r_{, j} n_{k}\right\}
\end{aligned}
$$

\footnotetext{
${ }^{10}$ A esse respeito, ver seção 5.4.
} 
onde $r_{, n}=r, n_{l}$, com $i, j, k, l=1,2$.

Com o auxílio das Eqs. (5.36a, b), obtém-se, através da substituição na Eq. (5.16), as componentes do tensor de tensão $\mathbf{T}$ e do tensor gradiente dos deslocamentos, $\nabla \mathbf{u}$, para os pontos do caminho elíptico de integração.

Tendo em vista as aplicações que serão apresentadas, a título de exemplo, com auxílio do programa automático aqui desenvolvido, convém utilizar as expressões que dão as componentes desses tensores em função das derivadas das componentes do tensor deslocamento em um sistema cartesiano ortogonal. Assim:

$(\nabla \mathbf{u})_{i j}=u_{i, j}$

$\mathrm{e}$

$T_{i j}=\frac{E}{2(1+v)}\left[\frac{2 v}{1-2 v} \delta_{i j} u_{m, m}+u_{i, j}+u_{j, i}\right]$

onde $i, j$ e $m$ assumem os valores 1 e 2 . 


\section{ASPECTOS EXPERIMENTAIS E NORMATIVOS SOBRE PARÂMETROS DE FRATURA}

A determinação experimental de parâmetros de fratura serve à análise de estruturas (ou de seus componentes) submetidas a ações (mecânicas, térmicas etc.), auxiliando no projeto, para garantir a integridade dos componentes e a estabilidade da estrutura, durante a vida útil da construção. Além disso, serve também à manutenção ou à recuperação de estruturas, com o objetivo de prolongar a sua vida segura útil. Para isso, a mecânica da fratura formula critérios através dos quais parâmetros resultantes da análise, em geral obtidos com o auxílio dos métodos numéricos aplicados à mecânica dos materiais, são comparados a seus respectivos valores críticos, determinados experimentalmente.

A mecânica da fratura é, de fato, uma alternativa à teoria da elasticidade e à mecânica dos materiais, já que nessas duas últimas a hipótese é de que o sólido esteja íntegro, sendo válida a hipótese de continuidade do material. Na mecânica da fratura imagina-se que descontinuidades estejam presentes desde o início, sendo que se busca avaliar, por seu intermédio, o quanto o sólido é sensível à presença dessas descontinuidades, isto é, o quanto a presença delas pode levá-lo à ruína ou, no caso de se estabilizarem, à continuidade da utilização da estrutura pelo tempo de sua vida útil. O caso clássico é considerar-se a descontinuidade modelada, seja como uma pré-fissura elíptica, no interior do sólido, seja como um entalhe, caso que corresponde a uma fissura que se inicia a partir da fronteira.

Seguindo-se o desenvolvimento histórico da mecânica da fratura, a partir de Griffith, no início da década de 1920, o primeiro parâmetro desse tipo que se buscou determinar em laboratório foi a energia superficial específica de fratura, que aparece no seu conhecido critério de iniciação de fratura. Segundo Griffith, esse parâmetro seria uma característica do material, o que, mais tarde, mostrou-se não ser verdade. Além disso, devido à limitação da aplicabilidade do critério de Griffith somente para casos de materiais quase que perfeitamente frágeis, seu critério caiu em desuso.

A interpretação do fenômeno da fratura advinda da contribuição de Irwin, no final da década de 1940, ensejou uma nova concepção sobre a determinação experimental de parâmetros de fratura. A noção de fator de intensidade de tensão, decorrente da análise da singularidade de tensões em problemas bidimensionais, levou Irwin (1957) a propor a determinação experimental de valores críticos de três fatores de intensidade de tensão, o que daria a base para a mecânica da fratura elástica linear. 
A determinação dos valores críticos dos fatores de intensidade de tensão traria o desenvolvimento dos métodos experimentais, particularmente na caracterização de materiais metálicos, permitindo a realização de ensaios de grande porte, já que a necessidade de se garantir a realização dos ensaios no estado plano de deformação exigiria o rompimento de chapas com grande espessura. Tabelas de fatores de intensidade de tensão, para as mais diversas configurações de pré-fissuras, em variados casos de condições ambientais (altas ou baixas temperaturas, presença de hidrogênio, radiação, agentes corrosivos etc.), passaram a ser preparadas com o intuito de prover os projetistas e os engenheiros de manutenção de instrumentos capazes de auxiliá-los na avaliação da integridade de estruturas e seus componentes.

A ênfase na produção de novos materiais e a competitividade internacional baseada na exigência de qualidade, características da crescente corrida tecnológica mundial, principalmente após a Segunda Grande Guerra, fizeram com que se estendesse bastante o campo de aplicação da mecânica da fratura, levando-a, naturalmente, a gerar diversas subespecializações nos campos de estudo das rochas, das cerâmicas, dos polímeros, do concreto, do gelo, dos compósitos em geral e da madeira, além de ter de se sofisticar ainda mais, nos casos das aplicações às indústrias da construção metálica, ferroviária, naval e offshore, aeronáutica, nuclear e espacial.

Em razão de o objetivo do presente trabalho ser a formulação de uma proposta teórica, visando ao aperfeiçoamento da contribuição da mecânica dos materiais (mais particularmente da mecânica do contínuo) à mecânica da fratura, aqui será dada especial atenção à experimentação relacionada com a integral $J$. O intuito não é, propriamente, fornecer-se um exaustivo conjunto de técnicas de ensaios e, muito menos, sugerir-se que os resultados teóricos apresentados nos capítulos anteriores são aplicáveis exclusivamente aos aços. O real propósito é organizar o cenário para a apresentação, em caráter inicial, de uma proposta de ensaio de laboratório que permita a determinação do valor crítico do parâmetro termodinâmico de fratura (e também da própria integral $J$ ).

Optou-se pela descrição sumária de procedimentos de ensaio de laboratório normalizados pela American Society for Testing and Materials (ASTM) aplicados aos materiais metálicos, cujo uso é mais frequente em nosso país. Para a organização do resumo que se segue, foi de muita valia, tanto o volume de informações quanto o conteúdo de caráter didático encontrado em DeAquino e outros (1998)

Diversos organismos internacionais vêm elaborando procedimentos normalizados de ensaios, visando a medir a tenacidade à fratura dos materiais. Entre eles, destacam-se a 
Deutsche Industrie Normen (DIN), da Alemanha, a Britsh Standards Institute (BSI), do Reino Unido, e a ASTM, dos EUA. A maior parte dos países industrializados possui suas próprias entidades normativas, mas a International Standard Organization (ISO) vem realizando esforços no sentido de que seja criado um padrão internacional de normalização técnica.

\section{ENSAIOS PARA AS MEDIDAS DA INTEGRAL $J$ E DO CTOD}

O primeiro ensaio proposto para a obtenção da integral $J$ foi normatizado através da E 813, da ASTM. A metodologia baseia-se na utilização de uma curva que relaciona $J$ com a variação do parâmetro geométrico da trinca, $\Delta a$ (valor estimado do avanço da fissura, como é definido nessa norma), a fim de se determinar um ponto da curva em que seja possível caracterizar-se a tenacidade à fratura. Este ponto, denominado $J_{\mathrm{Ic}}$, é definido como o valor de $J$ correspondente ao ponto próximo à iniciação do processo de rasgamento dúctil, responsável pelo processo de crescimento da trinca, característico do caso da fratura dúctil.

Em 1987, a $A S T M$ elaborou seu segundo procedimento de ensaio para a determinação da integral $J$, baseado na norma $\mathrm{E} 1152$. A figura 10 mostra a curva denominada $J-R$, ou curva de resistência, que representa a variação de $J$ em relação à variação $\Delta a$, a partir de um comprimento inicial de trinca, $a_{0}$. Essa curva expressa a propriedade básica da tenacidade à fratura, em regime elastoplástico. O desenvolvimento do procedimento de ensaio foi de tal forma aperfeiçoado que passou a bastar um único corpo de prova para a determinação de $J$. Exigências de tamanho são especificadas, de modo a se garantir a manutenção das condições geométricas capazes de assegurar o small scale yielding, ou escoamento de pequena escala, que corresponde à localização do fenômeno da plastificação, de forma a resguardar a independência do resultado em relação a variações de tamanho e de geometria. 


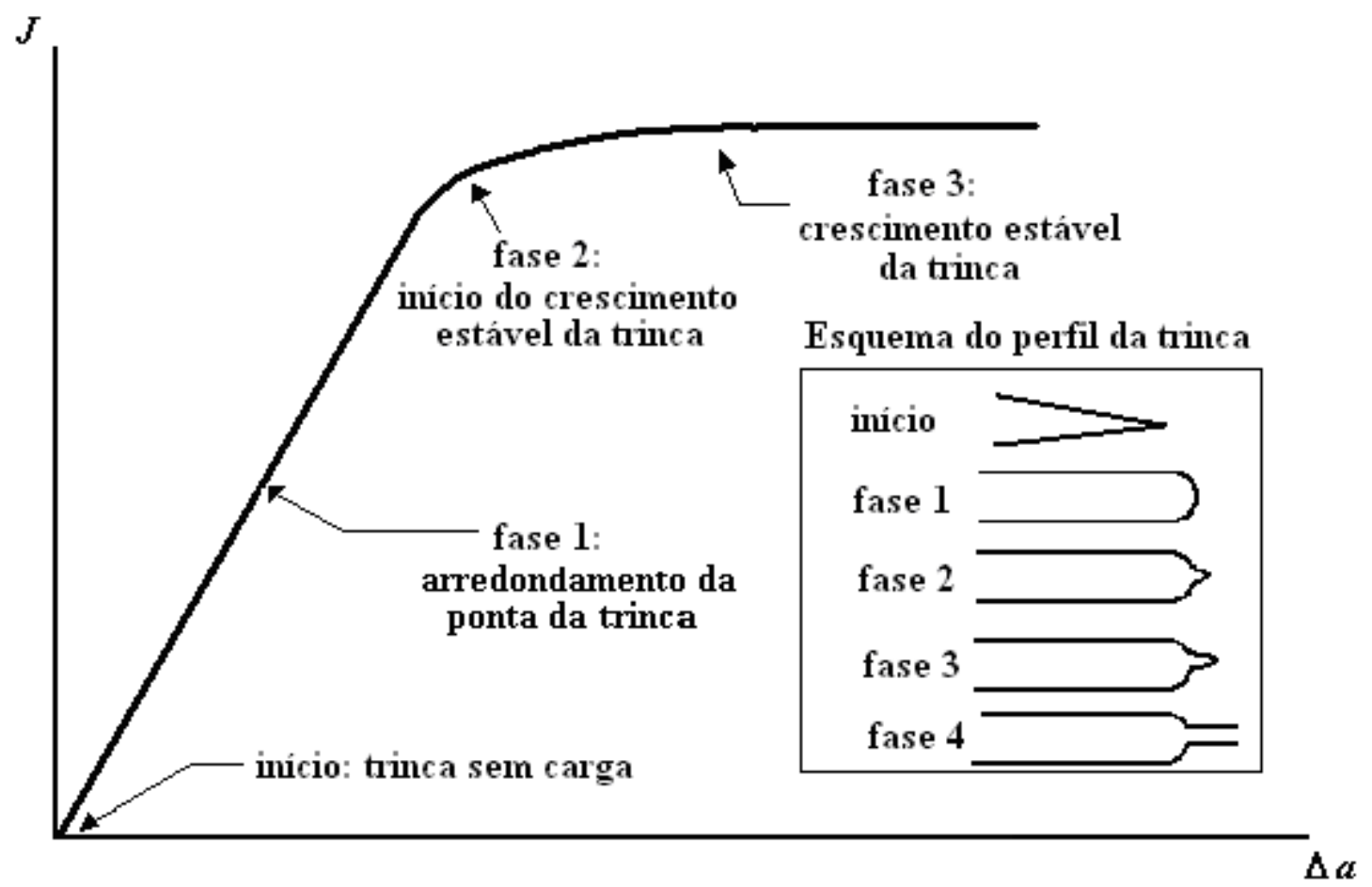

Figura 10 - Evolução de uma fissura típica dos aços Fonte: Adaptada de DeAquino e outros (1998).

Os ensaios de fratura visando à obtenção de $J$ correspondem à metodologia predominante na determinação da tenacidade à fratura, particularmente nos casos em que o comportamento do material extrapola o limite elástico linear. Nos EUA e em muitas outras partes do mundo, incluindo o Brasil, a preferência é por ensaios desse tipo. No Reino Unido, entretanto, predomina o uso do ensaio de tenacidade baseado no Crack Tip Opening Displacement (CTOD). Esse procedimento de ensaio foi primeiramente normalizado pela BSI, em 1979. No entanto, a ASTM, pressionada por algumas indústrias dos EUA, principalmente as de soldagem, padronizou ensaios baseados no CTOD, publicados em 1989 como a norma $E 1290$.

\section{OUTROS ENSAIOS PADRONIZADOS}

Os ensaios anteriormente descritos são realizados sob carregamentos lentos, aplicados em forma quase estática. A aplicação de um carregamento dinâmico pode influenciar bastante o comportamento dos materiais à fratura. A norma E 399, da ASTM, possui um anexo que 
trata do ensaio dinâmico para a determinação do $K_{\mathrm{Id}}$, a tenacidade dinâmica, medida em estado plano de tensão. Note-se que, até agora, ainda não existe qualquer norma estabelecida para a obtenção de $J$ em regime dinâmico, mas somente para o fator de intensidade de tensão dinâmico, $K_{\mathrm{Id}}$.

A capacidade de interrupção do crescimento de uma trinca, para um dado material, também é quantificada através de um parâmetro característico da tenacidade. $O$ ensaio que fornece a tenacidade de parada de trinca (crack arrest) é normatizado através da E 1221, de 1988.

Embora ainda não divulgada, está sendo desenvolvida pela ASTM uma metodologia específica para o tratamento de problemas relacionados às soldas, tais como: localização da trinca, processo de pré-trincamento no corpo de prova, tensões residuais etc. Nesse método, de acordo com os estudos já realizados, a tendência é para que os ensaios e a análise dos resultados sejam baseados em normas já existentes.

\section{OS PROCEDIMENTOS NORMATIVOS MAIS RECENTES DE ENSAIOS}

Os comitês técnicos da ASTM trabalham sob a exigência de que as normas sejam reavaliadas de cinco em cinco anos. O Comitê E08, dessa entidade, responsável pelas áreas de fadiga e de fratura, passou a adotar a tendência mundial de unificação dos procedimentos de ensaios para a obtenção da tenacidade à fratura. Dentre tais procedimentos, destacam-se:

a) A norma combinada de $J$

Trata-se da norma E 1737, aprovada em 1996, que inclui os procedimentos de ensaios para a obtenção da curva $J-R$, e do valor de $J_{\text {Ic }}$, além de estabelecer regras para a caracterização de uma tenacidade à fratura associada a um ensaio de $J$ terminado por uma fratura instável, ou frágil ( $J_{\mathrm{c}}$, ou $J$ de clivagem). Outra novidade, trazida pela $E 1737$, é a da inicialização dos dados, para a definição do tamanho da trinca inicial, na curva $J-R$. Através dessa determinação, evitam-se erros na obtenção de $J_{\text {Ic }}$, a partir de um ajuste linear dos pontos da curva $J \times \Delta a$, conforme mostra a figura 11 . 


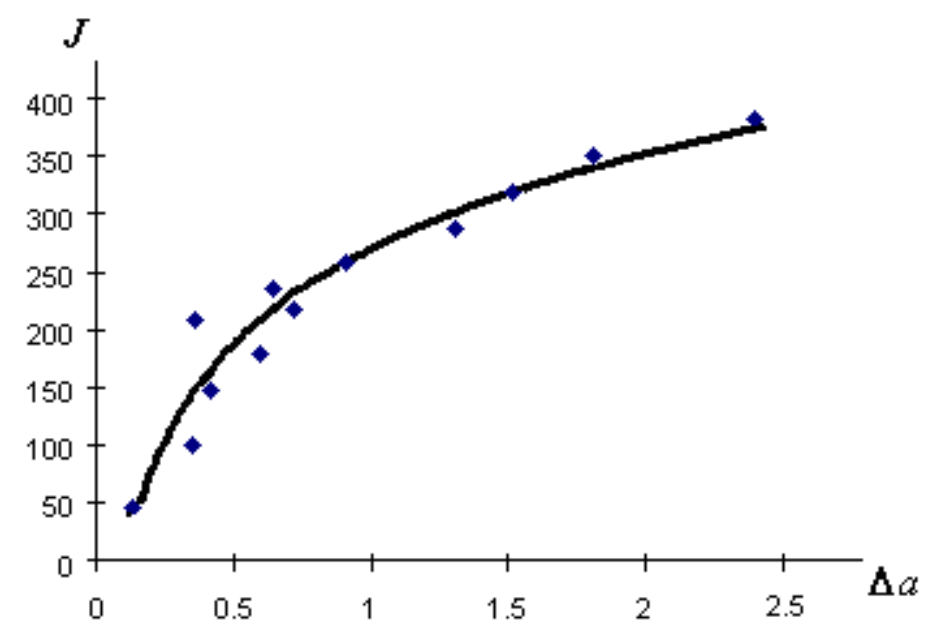

Figura 11 - Ajuste de inicialização de $\Delta a$

Fonte: Adaptada de DeAquino e outros (1998).

b) A norma unificada de tenacidade à fratura

Desenvolvida para incorporar praticamente todas as metodologias de ensaios de obtenção da tenacidade à fratura, a E 1820, publicada pela ASTM em 1997, objetiva medir, através de um único procedimento, os valores de $K, J$ e CTOD. Isso porque as metodologias para a determinação desses parâmetros utilizam, essencialmente, os mesmos corpos-de-prova e os mesmos procedimentos. Dessa forma, a norma unificada produz resultados de tenacidade, em termos de $K_{\mathrm{Ic}}$, sempre que o ensaio revela um comportamento do material próximo ao elástico linear; no caso da ocorrência predominante de um comportamento elastoplástico, os valores da tenacidade são baseados em $J$ ou no CTOD.

c) A norma de fratura para a transição dúctil-frágil

Aprovada em 1997, é a E 1921 a norma ASTM centrada na obtenção de valores médios e limites de confiança para a tenacidade à fratura, na região de transição dúctil-frágil em aços. A caracterização da tenacidade, na transição dúctil-frágil, tem grande utilidade prática, em particular na indústria de vasos de pressão e nuclear. 


\section{SUGESTÃO DE EXPERIMENTO PARA A DETERMINAÇÃO DO PARÂMETRO TERMODINÂMICO CRÍTICO $\gamma_{E}$}

Como consequência da proposta teórica esboçada no presente trabalho, sugerem-se aqui as linhas gerais de um método experimental para a determinação do valor crítico, $\gamma_{E}$, do parâmetro termodinâmico de fratura. Evidentemente, entende-se que não é o caso de entrar em minúcias, pois somente a experimentação real poderá dar conta de aspectos importantes, no sentido da eliminação completa de toda dubiedade, exigência fundamental para a padronização de um método de ensaio. Pretende-se, pois, que esses elementos iniciais sirvam apenas como sugestão para um projeto de trabalho experimental que, caso se confirme a utilidade da proposta teórica aqui sugerida, seja capaz de produzir um verdadeiro método de ensaio para a determinação precisa de $\gamma_{\mathrm{E}}$. Esse parâmetro, que tem a dimensão de força, cuja concepção é apresentada no capítulo 4, fornece, experimentalmente, a medida da sensibilidade da energia de deformação de uma parte $P$ da chapa, em relação à variação de um parâmetro geométrico da fissura (comprimento do entalhe).

Considerações gerais - Denomina-se parte $P$, uma região da chapa plana a ser ensaiada, limitada externamente por um segmento de superfície cilíndrica de base elíptica. $P$ ortanto, $P$ é um segmento de cilindro oco, cuja altura é a espessura da chapa, que contorna a aresta vertical de um dos entalhes. A modelagem teórica simplificada do problema, como um estado bidimensional de elasticidade, permite que a chapa seja representada por seu plano médio. Assim, a descrição da região $P$, quase sempre será feita como se ela fosse contida nesse plano médio, e a fronteira tida como elíptica, ${ }^{11}$ ao invés de uma superfície cilíndrica. A utilidade de $\gamma_{\mathrm{E}}(\mathrm{F})$ é constituir um critério de fratura termodinamicamente consistente, isto é, baseado num modelo no qual tenha sido considerada a produção e dissipação de calor na vizinhança da extremidade de uma fissura que avança. A obtenção desse parâmetro, que não possui a propriedade da independência do caminho, refere-se a uma determinada parte da chapa, delimitada por um dado caminho elíptico. Assim, o parâmetro $\gamma_{\mathrm{E}}(\mathrm{F})$ depende da parte $P$ escolhida no sólido. Logo, ele não é uma propriedade do material, mas de uma porção do sólido, tanto que, no critério de fratura em que entrar, a comparação tem de ser feita com um valor teórico, obtido pela via do modelo matemático e computacional, referente àquela mesma parte $P$. Naturalmente, é conveniente a realização de análise dimensional, que forneça relações de semelhança entre protótipo e modelo.

\footnotetext{
${ }^{11}$ Ver figura 5, no capítulo 4.
} 
Objetivo do ensaio - Determinar o parâmetro termodinâmico crítico de fratura $\gamma_{\mathrm{E}}(F)$, associado a uma parte arbitrária, $P$, de uma chapa de espessura $B(L)$ constante.

Preparação do corpo de prova. Devem ser feitos, previamente, na chapa, dois entalhes angulares iguais, e simétricos (figura 12) em relação ao eixo longitudinal da peça, devendo ser realizados os procedimentos capazes de assegurar a máxima atenuação possível das tensões residuais surgidas em decorrência do processo de entalhamento. Extensômetros elétricos de resistência (strain gages), do tipo roseta, devem ser colados em ambas as faces da chapa, em pontos previamente determinados do segmento de elipse que delimita a região $P$. A fixação dos pontos de colagem das rosetas deve guardar coerência com o experimento numérico feito, previamente, com um modelo semelhante ao da chapa utilizada como corpo de prova.

Quanto à espessura da chapa, sabe-se que uma chapa fina, submetida a carregamentos e a restrições de deslocamentos especiais, orientados segundo direções contidas em seu plano médio, reproduzem o que se convenciona chamar, na elasticidade bidimensional, de Estado Plano de Tensão (EPT). Na verdade, é uma situação que não guarda consistência com as equações de compatibilidade da Elasticidade, embora tenha grande utilidade, enquanto aproximação, quanto menor seja a espessura da chapa. A outra possibilidade de problema plano é o Estado Plano de Deformação (EPD), em que um sólido, também com um carregamento especial do mesmo tipo, pode ser estudado em uma seção plana, representativo do que ocorre a certa distância de seus apoios laterais. O EPD é um estado elasticamente compatível, mas não adianta aumentar-se a espessura de uma chapa, em um ensaio de laboratório, na ilusão de que o EPD venha a ser atingido, porque isso levaria à necessidade de chapas tão espessas que os equipamentos de laboratório teriam de ser extremamente potentes. Mesmo assim, o resultado ainda seria aproximado, porque só seria exato se a espessura fosse infinita.

Do ponto de vista do cálculo automático, o mesmo programa pode resolver problemas no EPD e no EPT, bastando, para isso, no caso de um sólido isótropo, por exemplo, que se mude um único valor no arquivo de dados, alterando o valor coeficiente de Poisson. Desse modo, a espessura da chapa, no ensaio, deve ser a menor possível, levando-se em conta, para isso, principalmente a questão da boa fixação das garras do equipamento, para produzir a restrição de deslocamentos controlada, nas extremidades do corpo de prova. 


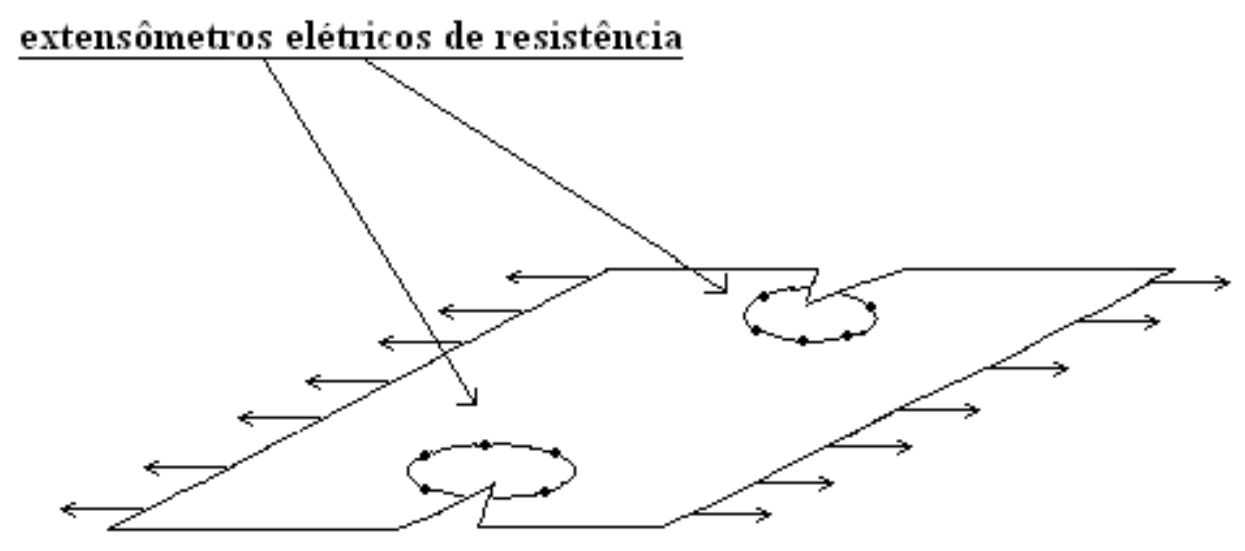

Figura 12 - Chapa a ser ensaiada para a obtenção de $G_{t}$

As demais dimensões, no plano da chapa, devem ser tais que deixem o espaço adequado para a boa colagem das rosetas de extensômetros elétricos de resistência e garantam um razoável afastamento das extremidades ligadas à máquina, para diminuir a perturbação devida a inevitáveis efeitos localizados, decorrentes da fixação do corpo de prova.

Descrição do ensaio - Na direção do eixo longitudinal da peça devem ser aplicadas, em ambas as extremidades, uma restrição positiva de deslocamento, constante em todos os pontos de ambas as seções transversais acionadas pelo equipamento de carga. O processo de deformação deve ser o mais lento possível, de forma a assegurar o regime quase estático e isotérmico.

As medidas das três componentes planas de deformação, sobre os predeterminados pontos dos caminhos elípticos iguais, desenhados sobre as faces da chapa, deverão ser tomadas pelos strain gages, em intervalos de tempo regulares, durante o período de realização do ensaio. Os resultados deverão ser as respectivas médias dessas medidas em cada par de pontos da placa opostos pelo plano médio. O esquema de aquisição de dados deverá alimentar um equipamento capaz de realizar as médias, para cada qual das três componentes planas de deformação medidas. Essas médias, entre os respectivos valores, tomados nas duas faces, deverão, por sua vez, alimentar um sistema capaz de realizar a integral sobre o caminho elíptico, em tempo real, fornecendo o valor de $G_{\mathrm{t}}(\mathrm{F})$, em intervalos de tempo regulares. A informação sobre o instante de iniciação do processo de fratura, que deverá ser obtida opticamente, no momento em que a medida $G_{\mathrm{t}}$ fornecerá o valor crítico $\gamma_{\mathrm{E}}(\mathrm{F})$, deverá ser registrada, dentro da cronologia do ensaio. A saída dos resultados também poderá ser na forma gráfica, fornecendo algo semelhante a uma curva de $G_{\mathrm{t}} \mathrm{x}$ tempo. 
Sobre a metodologia - A experimentação numérica, complementar à de laboratório, centra-se na obtenção aproximada de dois resultados importantes: o primeiro, anterior à experimentação de laboratório, refere-se à determinação das coordenadas dos pontos do método de Gauss, para a integração numérica aproximada, nos quais deverão ser coladas as rosetas de strain gages no corpo de prova. O segundo resultado diz respeito ao cálculo do valor limite do parâmetro $G_{\mathrm{t}}(F)$, com o auxílio do BEM, ou do MEF, que deverá ser feito para o mesmo caminho elíptico usado na experiência de laboratório. Em particular, o programa automático desenvolvido no presente trabalho (apêndice A), realiza, via BEM, o processo numérico iterativo que conduz ao valor limite de $G_{\mathrm{t}}(F)$. Uma parte desse esquema, que realiza o processo de integração numérica, pelo esquema de Gauss-Legendre, deverá ser adaptada ao equipamento de integração acoplado ao equipamento de aquisição dos dados no laboratório.

Obtido o valor de $\gamma_{\mathrm{E}}(F)$, a partir do ensaio de laboratório, deve-se realizar uma nova experimentação numérica, usando-se o programa automático em que o dado GAMMA, que poderia ser fornecido como um valor positivo arbitrário, será fornecido como o valor medido, $\gamma_{E}(F)$. Tal como mostra o apêndice A, a saída do programa inclui o ângulo de orientação da fissura e o valor limite de $G_{\mathrm{t}}(\mathrm{F})$. Caso esse último valor venha a ser diferente do $\gamma_{\mathrm{E}}(\mathrm{F})$ medido, podem-se aventar, por exemplo, algumas hipóteses, não necessariamente exclusivas:

1. O experimento foi mal realizado, por conta da falta de cuidados com a colagem dos extensômetros ou com a fixação do verdadeiro ponto, a partir do qual o processo de crescimento da fissura se iniciou etc.;

2. A velocidade do ensaio foi maior do que aquela capaz de assegurar o caráter de regime quase estático e isotérmico do processo;

3. Os valores do módulo de elasticidade transversal e do coeficiente de Poisson fornecidos ao programa automático não correspondem aos do verdadeiro material do corpo de prova;

4. A dissipação de energia na vizinhança da extremidade do entalhe alterou de tal maneira os valores das deformações, nos pontos do circuito elíptico, mesmo estando este circuito imerso em uma região hiperelástica, que o modelo elástico, do programa automático, foi incapaz de simular uma razoável aproximação. Evidentemente, só a experimentação poderá levar ao aperfeiçoamento da ideia de se caracterizar um material à fratura, a partir do parâmetro termodinâmico aqui proposto. A intenção é mostrar que a proposta teórica apresentada tem possibilidade de ser posta à prova, na prática. 
Por último, convém registrar que Faucher (1994), partindo de uma série de contribuições anteriores por ele sistematizadas, propôs a medida experimental de $J$ crítico com auxílio de um ensaio de tração. Sua justificativa está baseada numa referência a Hancock e outros (1993 apud FAUCHER, 1994), segundo o qual, a curva $J-R$ pode alterar-se significativamente, em razão do tipo de carregamento aplicado, não valendo, segundo ele, a crença de que os ensaios do tipo ASTM forneçam uma medida standard, capaz de caracterizar plenamente o comportamento à fratura, seja da peça, seja do material. Embora o sentido da presente proposta não seja o mesmo daquela de Faucher, vale registrar que a ideia da realização de ensaios de tração, visando a obtenção de parâmetros de fratura, não é uma original, definida no presente trabalho. 


\section{FUNDAMENTOS MATEMÁTICOS}

Apresenta-se, a seguir, um conjunto de desenvolvimentos matemáticos e resultados úteis ao objetivo da construção da teoria termodinamicamente consistente da fratura. Naturalmente, a maior parte das proposições não são demonstradas, mas isso pode ser encontrado em textos sobre mecânica do contínuo e análise de sensibilidade apresentados nas referências.

\section{ELEMENTOS DE ÁLGEBRA E DE ANÁLISE TENSORIAL ${ }^{12}$}

\section{Tensores}

Seja $E$ o espaço euclidiano pontual tridimensional. Os elementos desse espaço são denominados pontos. A expressão vetor será adotada para os elementos do espaço vetorial associado, $V$. A diferença entre dois pontos quaisquer, $x$ e $y$ de $E$, define um vetor $\mathbf{v}$, tal que:

$\mathbf{v}=x-y \quad \mathrm{e} \quad-\mathbf{v}=y-x$

A soma de um ponto e um vetor define um ponto, isto é:

$$
y=x+\mathbf{v}
$$

A soma de dois pontos não possui significado.

Escolhida uma base ortonormal $\left\{\mathbf{e}_{\mathrm{i}}\right\}$, em $V$, a origem $o$ de $E$ e essa base formam um sistema de referência, ou referencial de $E$. Daí, todo ponto de $E$ pode ser escrito como

$x=(x-o)+o$,

sendo suas coordenadas relativas a $\left\{\mathbf{e}_{\mathbf{i}}\right\}$, definidas por:

$x_{i}=(x-o) \cdot \mathbf{e}_{\mathbf{i}}$

${ }^{12}$ Para a organização desta seção, valeu-se basicamente da síntese encontrada em Feijóo (1978). 
na qual o ponto é usado para indicar o produto interno (ou escalar) de dois vetores. A definição de produto interno de um vetor qualquer u por si mesmo, leva, de uma forma natural, ao conceito de norma de um vetor:

$$
\|\mathbf{u}\|=\sqrt{\mathbf{u} \cdot \mathbf{u}} .
$$

Tensor: chama-se tensor a qualquer transformação linear $\mathbf{T}: V \rightarrow V$, sendo $V$ o espaço vetorial associado ao espaço euclidiano pontual $E$. Isto significa que $T$ associa a cada vetor $\mathbf{v} \in V$ um único vetor $\mathbf{u} \in V$ :

$\mathbf{u}=\mathbf{T} \mathbf{v}$

Entende-se por transformação linear a aplicação que possui as seguintes propriedades:

$$
\begin{array}{lc}
\mathbf{T}(\mathbf{u}+\mathbf{v})=\mathbf{T u}+\mathbf{T} \mathbf{v} & \forall \mathbf{u}, \mathbf{v} \in V, \\
\mathbf{T}(\alpha \mathbf{u})=\alpha \mathbf{T} \mathbf{u} & \forall \alpha \in I R, \forall \mathbf{u} \in V .
\end{array}
$$

O conjunto de todos os tensores T: $V \rightarrow V$, é denominado Lin. Se em Lin definimos a adição de dois tensores por:

$$
\left(\mathbf{T}_{1}+\mathbf{T}_{2}\right) \mathbf{u}=\mathbf{T}_{1} \mathbf{u}+\mathbf{T}_{2} \mathbf{u} \quad \forall \mathbf{u} \in V
$$

e a multiplicação por escalar:

$$
(\alpha \mathbf{T}) \mathbf{u}=\alpha \mathbf{T u} \quad \forall \mathbf{T} \in L i n, \forall \alpha \in I R, \forall \mathbf{u} \in V
$$

então Lin, munido dessas duas operações, é um espaço vetorial. Neste espaço existe um tensor nulo, representado por $\mathbf{0}$, tal que:

$$
\mathbf{0} \mathbf{u}=\mathbf{0} \quad \forall \mathbf{u} \in V
$$

Observe-se que o símbolo 0 também está sendo usado para representar o vetor nulo de $V$. O tensor identidade, designado por I, é tal que:

$$
\mathbf{I} \mathbf{u}=\mathbf{u}, \quad \forall \mathbf{u} \in V
$$


O produto de dois tensores, $\mathbf{T}$ e $\mathbf{S}$, indicado por $\mathbf{T S}$, é definido como a composição de ambas aplicações, isto é:

$\mathbf{T S}=\mathbf{T} \circ \mathbf{S}$, onde

$(\mathbf{T S}) \mathbf{u}=\mathbf{T}(\mathbf{S u})$

Verifica-se que o produto de tensores possui as seguintes propriedades:

a) Associativa:

$$
\mathbf{T}(\mathbf{S D})=(\mathbf{T S}) \mathbf{D}
$$

b) Distributiva, em relação à adição de dois tensores:

$$
\mathbf{T}(\mathbf{S}+\mathbf{D})=\mathbf{T S}+\mathbf{T D},
$$

$$
(\mathbf{S}+\mathbf{D}) \mathbf{T}=\mathbf{S T}+\mathbf{D T}
$$

e distributiva, em relação à adição escalar:

$$
(a+b) \mathbf{T}=a \mathbf{T}+b \mathbf{T} \quad \forall a, b \in I R,
$$

e

$$
\mathbf{I} \mathbf{T}=\mathbf{T} \mathbf{I}=\mathbf{T} .
$$

Quando $\mathbf{T S}=\mathbf{S T}$, diz-se que $\mathbf{T}$ e $\mathbf{S}$ comutam, embora esta não seja uma propriedade válida no conjunto de todas as aplicações lineares de $V$ em $V$.

A definição do produto de tensores permite que se tenham potências de um tensor. Assim:

$\mathbf{T}^{0}=\mathbf{I}, \mathbf{T}^{1}=\mathbf{T}, \mathbf{T}^{2}=\mathbf{T} \mathbf{T} .$. etc.

A associatividade do produto permite que se tenha:

$$
\mathbf{T}^{m+n}=\mathbf{T}^{m} \mathbf{T}^{n}=\mathbf{T}^{n} \mathbf{T}^{m}
$$


A partir dos conceitos anteriores, define-se polinômio de um tensor $\mathbf{T}$ como sendo:

$\mathbf{f}(\mathbf{T})=a_{0} \mathbf{I}+a_{1} \mathbf{T}^{l}+\ldots a_{i} \mathbf{T}^{i}+\ldots a_{n} \mathbf{T}^{n}, a_{i} \in I R$

uma função tensorial de argumento tensorial, que pode ser associada a um polinômio de grau $n$, com coeficientes $a_{0}, a_{1}, \ldots a_{\mathrm{n}}$.

Tensor transposto: o transposto de um tensor arbitrário $\mathbf{T}$ é o único tensor, $\mathbf{T}^{\mathrm{T}}$, com a sequinte propriedade:

$\mathbf{T u} . \mathbf{v}=\mathbf{u} . \mathbf{T}^{\mathrm{T}} \mathbf{v}, \forall \mathbf{u}, \mathbf{v} \in V$.

Daí resulta que:

$(\mathbf{S}+\mathbf{T})^{\mathrm{T}} \mathbf{u} \cdot \mathbf{v}=\mathbf{u} \cdot(\mathbf{S}+\mathbf{T}) \mathbf{v}=\mathbf{u} . \mathbf{S v}+\mathbf{u} \cdot \mathbf{T} \mathbf{v}=\mathbf{S}^{\mathrm{T}} \mathbf{u} \cdot \mathbf{v}+\mathbf{T}^{\mathrm{T}} \mathbf{u} \cdot \mathbf{v}=\left(\mathbf{S}^{\mathrm{T}}+\mathbf{T}^{\mathrm{T}}\right) \mathbf{u} \cdot \mathbf{v}$

e

$(\alpha \mathbf{S})^{\mathrm{T}} \mathbf{u} . \mathbf{v}=\mathbf{u} .(\alpha \mathbf{S}) \mathbf{v}=\alpha \mathbf{u} . \mathbf{S v}=\alpha \mathbf{S}^{\mathrm{T}} \mathbf{u} . \mathbf{v} \quad \forall \alpha \in I R$,

o que assegura ser a transposição uma operação linear que associa cada tensor de Lin a seu transposto, também em Lin.

O transposto do produto de dois tensores possui a seguinte propriedade:

$(\mathbf{S T})^{\mathrm{T}}=\mathbf{T}^{\mathrm{T}} \mathbf{S}^{\mathrm{T}}$

De fato:

$(\mathbf{S T})^{\mathrm{T}} \mathbf{u} . \mathbf{v}=\mathbf{u} .(\mathbf{S T}) \mathbf{v}=\mathbf{u} . \mathbf{S}(\mathbf{T V})=\mathbf{S}^{\mathrm{T}} \mathbf{u} \cdot \mathbf{T} \mathbf{v}=\left(\mathbf{T}^{\mathrm{T}} \mathbf{S}^{\mathrm{T}}\right) \mathbf{u} \cdot \mathbf{v}$

Da mesma maneira, pode-se mostrar que:

$\left(\mathbf{S}^{\mathrm{T}}\right)^{\mathrm{T}}=\mathbf{S}$

Diz-se que um tensor é simétrico se: 
$\mathbf{S}=\mathbf{S}^{\mathrm{T}}$,

e antissimétrico se:

$\mathbf{S}=-\mathbf{S}^{\mathrm{T}}$

Todo tensor admite uma decomposição única:

$\mathbf{S}=\operatorname{sym} \mathbf{S}+\operatorname{skw} \mathbf{S}$

em que

$\operatorname{sym} \mathbf{S}=\left(\frac{\mathbf{S}+\mathbf{S}^{\mathrm{T}}}{2}\right)$

é a parte simétrica de $\mathbf{S}$, e

$\operatorname{skw} \mathbf{S}=\left(\frac{\mathbf{S}-\mathbf{S}^{\mathrm{T}}}{2}\right)$

é a parte antissimétrica de $\mathbf{S}$.

Por ser a transposição uma aplicação linear de Lin em Lin, segue-se que:

(1) Toda combinação linear de tensores simétricos é um tensor simétrico, e

(2) Toda combinação linear de tensores antissimétricos é um tensor antissimétrico.

Assim, o conjunto de todos os tensores simétricos, que será denominado Sym, e o dos tensores antissimétricos, que será denominado $S k w$, são dois subespaços de Lin. Convém observar que o produto de dois tensores simétricos (respectivamente, antissimétricos) não é necessariamente um tensor simétrico (respectivamente, antissimétrico).

Outros resultados dignos de nota são os seguintes:

(1) Seja $\mathbf{E} \in S y m$ e $\mathbf{W} \in S k w$, tensores arbitrários, logo:

$\mathbf{u} \cdot \mathbf{W u}=0, \quad \forall \mathbf{u} \in V$ 
que, para ser demonstrado, basta usar-se a definição de tensor transposto, da Eq. (7.17), e de tensor antissimétrico, dada pela Eq. (7.22). Para um vetor $\mathbf{u}$, arbitrário, tem-se:

$\mathbf{u} \cdot \mathbf{W u}=\mathbf{W}^{\mathrm{T}} \mathbf{u} \cdot \mathbf{u}=-\mathbf{W u} \mathbf{u} \quad \Rightarrow \quad 2(\mathbf{u} \cdot \mathbf{W u})=0$.

Seja $\mathbf{S}=\mathbf{E}+\mathbf{W}$, logo:

$\mathbf{u} . \mathbf{S u}=\mathbf{u} .(\mathbf{E}+\mathbf{W}) \mathbf{u}=\mathbf{u} . \mathbf{E u} \quad \forall \mathbf{u} \in V$.

Produto tensorial: o produto tensorial de dois vetores $\mathbf{u}, \mathbf{v} \in V$, representado por $\mathbf{u} \otimes \mathbf{v}$, é um tensor que a cada vetor $\mathbf{w} \in V$ associa um vetor paralelo a $\mathbf{u}$, dado por (v.w) $\mathbf{u}$, isto é:

$(\mathbf{u} \otimes \mathbf{v}) \mathbf{w}=(\mathbf{v} \cdot \mathbf{w}) \mathbf{u}, \quad \forall \mathbf{w} \in V$

Observe-se que $\mathbf{u} \otimes \mathbf{v}: V \rightarrow V$ é uma aplicação linear, portanto, um tensor. Com base na definição de produto tensorial, verifica-se que:

(a) $(\mathbf{u} \otimes \mathbf{v})^{\mathrm{T}}=(\mathbf{v} \otimes \mathbf{u})$.

Demonstração:

Sejam $\mathbf{d}, \mathbf{w} \in V$, vetores arbitrários. Utilizando-se propriedades anteriores, tem-se:

$(\mathbf{u} \otimes \mathbf{v})^{\mathrm{T}} \mathbf{d} . \mathbf{w}=\mathbf{d} \cdot(\mathbf{u} \otimes \mathbf{v}) \mathbf{w}=\mathbf{d} \cdot \mathbf{u}(\mathbf{v} \cdot \mathbf{w})=(\mathbf{v} . \mathbf{w})(\mathbf{u . d})=\mathbf{v}(\mathbf{u . d}) \cdot \mathbf{w}=(\mathbf{v} \otimes \mathbf{u}) \mathbf{d} . \mathbf{w} ;$

(b) $(\mathbf{u} \otimes \mathbf{v})(\mathbf{c} \otimes \mathbf{d})=(\mathbf{v} \cdot \mathbf{c})(\mathbf{u} \otimes \mathbf{d})$.

Demonstração:

Seja $\mathbf{w} \in V$, logo:

$(\mathbf{u} \otimes \mathbf{v})(\mathbf{c} \otimes \mathbf{d}) \mathbf{w}=(\mathbf{d . w})(\mathbf{u} \otimes \mathbf{v}) \mathbf{c}=(\mathbf{w . d}) \mathbf{u}(\mathbf{v . c})=(\mathbf{v . c})(\mathbf{u} \otimes \mathbf{d}) \mathbf{w}$

(c) Seja $\left\{\mathbf{e}_{\mathrm{i}}\right\}$ uma base ortonormal de $V$, isto é, $\mathbf{e}_{\mathrm{i}} \cdot \mathbf{e}_{\mathrm{j}}=\delta_{\mathrm{ij}}$, delta de Kronecker, então:

$\mathbf{I}=\left(\mathbf{e}_{1} \otimes \mathbf{e}_{1}\right)+\left(\mathbf{e}_{2} \otimes \mathbf{e}_{2}\right)+\left(\mathbf{e}_{3} \otimes \mathbf{e}_{3}\right)$. 
Demonstração: Basta provar que $\delta_{r j}\left(\mathbf{e}_{\mathbf{r}} \otimes \mathbf{e}_{\mathbf{j}}\right) \mathbf{v}=\mathbf{v}$. De fato, se $\mathbf{v}=v_{\mathrm{i}} \mathbf{e}_{\mathrm{i}}$, tem-se:

$\delta_{k j}\left(\mathbf{e}_{\mathrm{k}} \otimes \mathbf{e}_{\mathrm{j}}\right) \mathbf{v}=\delta_{k j} v_{r}\left(\mathbf{e}_{\mathrm{k}} \otimes \mathbf{e}_{\mathrm{j}}\right) \mathbf{e}_{\mathrm{r}}=\delta_{k j} v_{r} \mathbf{e}_{\mathrm{k}} \delta_{j r}=v_{k} \mathbf{e}_{\mathrm{k}}=\mathbf{v}$

Produto antissimétrico: dados $\mathbf{u}, \mathbf{v} \in V$, arbitrários, o tensor antissimétrico $\mathbf{u} \otimes \mathbf{v}-\mathbf{v} \otimes \mathbf{u}$ será representado por $\mathbf{u} \quad \mathbf{v}$, denominado produto antissimétrico ou produto externo.

Componentes de um tensor: Até aqui o trabalho com tensores limitou-se a estudá-los com o auxílio das definições e regras de composição. Da mesma forma como os vetores, em $V$, são independentes da base escolhida para representá-los, os tensores, em Lin, também são entidades independentes de qualquer base desse conjunto. No entanto, escolhida uma certa base, podem-se determinar as componentes do tensor nessa base de Lin.

Considere-se em $V$ uma base $\left\{\mathbf{e}_{\mathrm{i}}\right\}$, não necessariamente ortogonal, chamando-se $g_{\mathrm{ij}}$ os escalares provenientes do produto interno $\mathbf{e}_{\mathbf{i}} \cdot \mathbf{e}_{\mathbf{j}}$, isto é:

$\mathbf{e}_{\mathrm{i}} \cdot \mathbf{e}_{\mathrm{j}}=g_{i j}$

Em razão de $\left\{\mathbf{e}_{\mathrm{i}}\right\}$ ser uma base, segue-se que o determinante da matriz $\left[g_{i j}\right]$ é diferente de zero. Existe, portanto, a matriz inversa, denominada $\left[\mathrm{g}^{\mathrm{ij}}\right]$. Logo:

$g^{i j} g_{j k}=\delta^{i}{ }_{k}$

Resulta da Eq. (7.32) que $\left[g_{\mathrm{ij}}\right]$ é uma matriz simétrica. Por outro lado, dada uma base $\left\{\mathbf{e}_{\mathrm{i}}\right\}$ pode-se definir outra base, $\left\{\mathbf{e}^{\mathrm{i}}\right\}$, denominada base dual de $\left\{\mathbf{e}_{\mathrm{i}}\right\}$, que fica determinada de modo único, através da condição:

$\mathbf{e}^{\mathbf{i}}=g^{i j} \mathbf{e}_{\mathbf{j}} \quad$ ou $\quad \mathbf{e}_{\mathbf{i}}=g_{i j} \mathbf{e}^{\mathbf{j}}$.

Das Eqs. (7.32), (7.33) e (7.34) resulta que:

$\mathbf{e}^{\mathbf{i}} \cdot \mathbf{e}_{\mathbf{j}}=\delta^{i}{ }_{j} \quad$ e $\quad \mathbf{e}^{\mathbf{i}} \cdot \mathbf{e}^{\mathbf{j}}=g^{i j}$,

$\operatorname{com} \mathrm{i}, \mathrm{j}=1,3$. 
Demonstra-se que são bases de Lin os seguintes conjuntos de tensores:

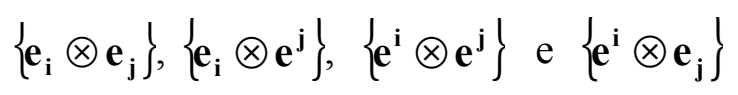

Dessa maneira, um tensor pode possuir as seguintes representações possíveis, em função de suas componentes nessas bases:

$$
\mathbf{T}=T_{i j}\left\{\mathbf{e}^{\mathbf{i}} \otimes \mathbf{e}^{\mathbf{j}}\right\}=T^{i j}\left\{\mathbf{e}_{\mathbf{i}} \otimes \mathbf{e}_{\mathbf{j}}\right\}=T^{i}{ }_{j}\left\{\mathbf{e}_{\mathbf{i}} \otimes \mathbf{e}^{\mathbf{j}}\right\}=T_{i}{ }^{j}\left\{\mathbf{e}^{\mathbf{i}} \otimes \mathbf{e}_{\mathbf{j}}\right\}
$$

As relações entre as diversas componentes podem ser deduzidas a partir da definição de produto tensorial e das Eqs. (7.32) a (7.35). Por exemplo:

$$
T_{i j}\left\{\mathbf{e}^{\mathbf{i}} \otimes \mathbf{e}^{\mathbf{j}}\right\}=T^{i j} \mathrm{~g}^{\mathrm{ik}} \mathbf{e}_{\mathbf{k}} \otimes \mathbf{e}^{\mathbf{j}}=T_{j}^{k} \mathbf{e}_{\mathbf{k}} \otimes \mathbf{e}^{\mathbf{j}}
$$

Daí,

$$
T_{\mathrm{j}}^{\mathrm{k}}=T_{\mathrm{ij}} g^{\mathrm{ik}}
$$

Em particular, $T^{\mathrm{ij}}$ e $T_{\mathrm{ij}}$ recebem os nomes, respectivamente, de componentes contravariantes e covariantes de $\mathbf{T}$, enquanto $T_{\mathrm{j}}^{\mathrm{i}}$ e $T_{\mathrm{i}}^{\mathrm{j}}$ são denominadas componentes mistas. A notação explicitada através da Eq.(7.37) permite que se reconheça, facilmente, dado um vetor $\mathbf{v}$, em que base o vetor $\mathbf{T v}$ está representado, quando $\mathbf{T}$, por exemplo, está expresso como $\mathbf{T}=T_{\mathrm{ij}} \mathbf{e}^{\mathrm{i}} \otimes \mathbf{e}^{\mathrm{j}}$. De fato, em razão da definição de produto tensorial, resulta que $\mathbf{T} \mathbf{v}$ está representado por suas componentes relativas à base $\left\{\mathbf{e}^{\mathrm{k}}\right\}$. Com efeito, suponha-se $\mathbf{v}=v^{\mathrm{k}} \mathbf{e}_{\mathrm{k}}$. Então:

$$
\mathbf{u}=\mathbf{T} \mathbf{v}=T_{i j}\left(\mathbf{e}^{\mathbf{i}} \otimes \mathbf{e}^{\mathbf{j}}\right) v^{k} \mathbf{e}_{\mathbf{k}}=T_{i j} v^{k}\left(\mathbf{e}^{\mathbf{i}} \otimes \mathbf{e}^{\mathbf{j}}\right) \mathbf{e}_{\mathbf{k}}=T_{i j} v^{k} \mathbf{e}^{\mathbf{i}} \delta_{k}^{j}=T_{i j} v^{j} \mathbf{e}^{\mathbf{i}}
$$

onde $\mathbf{u}=u_{\mathrm{i}} \mathrm{e}^{\mathrm{i}}, \operatorname{com} u_{i}=T_{\mathrm{ij}} v^{\mathrm{j}}$.

A partir das definições anteriores, pode-se expressar a multiplicação de tensores e o tensor transposto em termos de suas componentes, tal como a seguir.

a) Multiplicação de tensores: 
$\mathbf{B}=\mathbf{T S}=T_{\mathrm{ij}}\left(\mathbf{e}^{\mathrm{i}} \otimes \mathbf{e}^{\mathrm{j}}\right) S_{\mathrm{m}}^{\mathrm{k}}\left(\mathbf{e}_{\mathrm{k}} \otimes \mathbf{e}^{\mathrm{m}}\right)=T_{\mathrm{ij}} S_{\mathrm{m}}^{\mathrm{k}}\left(\mathbf{e}^{\mathrm{i}} \otimes \mathbf{e}^{\mathrm{m}}\right) \delta_{\mathrm{k}}{ }^{\mathrm{j}}=T_{\mathrm{ik}} S_{\mathrm{m}}^{\mathrm{k}}\left(\mathbf{e}^{\mathrm{i}} \otimes \mathbf{e}^{\mathrm{m}}\right)$.

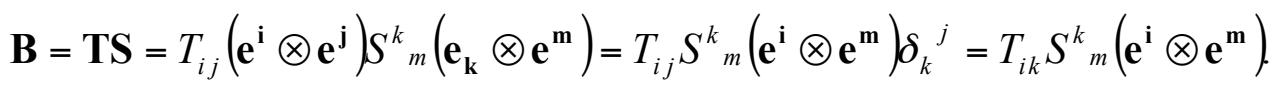

Por sua vez,

$\mathbf{B}=B_{i m} \mathbf{e}^{\mathbf{i}} \otimes \mathbf{e}^{\mathbf{m}} \quad \Rightarrow \quad B_{i m}=T_{i k} S_{m}^{k}$.

b) Transposto de um tensor:

$\mathbf{T}=T_{i j}\left(\mathbf{e}^{\mathbf{i}} \otimes \mathbf{e}^{\mathbf{j}}\right) \Rightarrow \mathbf{T}^{\mathrm{T}}=T_{i j}\left(\mathbf{e}^{\mathbf{i}} \otimes \mathbf{e}^{\mathbf{j}}\right)^{\mathrm{T}}=T_{i j}\left(\mathbf{e}^{\mathbf{j}} \otimes \mathbf{e}^{\mathbf{i}}\right)$.

Por outro lado: $\mathbf{T}^{\mathrm{T}}=T_{j i}^{\mathrm{T}}\left(\mathbf{e}^{\mathrm{j}} \otimes \mathbf{e}^{\mathrm{i}}\right)$,

$\log 0 T_{i j}=T_{j i}^{T}$.

Se a base $\left\{\mathbf{e}^{\mathrm{i}}\right\}$ for ortonormal, então a posição dos índices é indiferente. Nesse caso as componentes do tensor são chamadas componentes cartesianas.

Traço de um tensor: define-se traço de um tensor $\mathbf{T} \in$ Lin como a aplicação que associa ao tensor um escalar, representado por $t r \mathbf{T}$, que satisfaz à condição:

$\operatorname{tr}(\mathbf{u} \otimes \mathbf{v})=\mathbf{u} . \mathbf{v}$.

Decorrentes da definição de traço de um tensor, valem as seguintes propriedades:

(1) A aplicação trT é linear, já que o produto interno o é;

(2) A expressão do trT, em função das componentes, é a seguinte:

$\operatorname{tr} \mathbf{T}=T_{i j} \operatorname{tr}\left(\mathbf{e}_{\mathbf{i}} \otimes \mathbf{e}_{\mathbf{j}}\right)=T_{i j} g^{i j}=T_{i}{ }^{i}=T^{i}{ }_{i}=T^{i j} g_{i j}$,

o que significa que $\operatorname{tr} \mathbf{T}$ está bem definido;

(3) Seja $\mathbf{u} \otimes \mathbf{v}$ um tensor arbitrário $\mathbf{S}$, então:

$\operatorname{tr} \mathbf{S}=\operatorname{tr} \mathbf{S}^{\mathrm{T}}$ 
Com efeito,

$\operatorname{tr} \mathbf{T}=\operatorname{tr}(\mathbf{u} \otimes \mathbf{v})=\mathbf{u} \cdot \mathbf{v}=\mathbf{v} \cdot \mathbf{u}=\operatorname{tr} \mathbf{S}^{\mathrm{T}}, \mathrm{e}$

(4) Se S e T são dois tensores arbitrários de Lin, então:

$\operatorname{tr}(\mathbf{S T})=\operatorname{tr}(\mathbf{T S})$

De fato, da Eq. (7.30) tem-se:

$\operatorname{tr}[(\mathbf{u} \otimes \mathbf{v})(\mathbf{c} \otimes \mathbf{d})]=\operatorname{tr}[(\mathbf{v . c}) \mathbf{u} \otimes \mathbf{d})]=(\mathbf{v . c}) \mathbf{u . d}=\operatorname{tr}[(\mathbf{d} . \mathbf{u}) \mathbf{c} \otimes \mathbf{v})]=\operatorname{tr}[(\mathbf{c} \otimes \mathbf{d})(\mathbf{u} \otimes \mathbf{v})]$

e, da Eq. (7.31):

(5) $\operatorname{tr}(\mathbf{I})=\operatorname{tr}\left(\delta_{\mathrm{ij}} \mathbf{e}_{\mathbf{i}} \otimes \mathbf{e}_{\mathbf{j}}\right)=\delta_{\mathrm{ij}} \mathbf{e}_{\mathbf{i}} \cdot \mathbf{e}_{\mathbf{j}}=\delta_{\mathrm{ij}} \delta_{\mathrm{ij}}=3$.

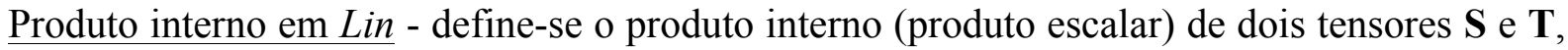
simbolizado por $\mathbf{S}: \mathbf{T}$, como o escalar definido por:

$\mathbf{S}: \mathbf{T}=\operatorname{tr}\left(\mathbf{S}^{\mathrm{T}} \mathbf{T}\right)$

Mostra-se, a seguir, que essa definição satisfaz as propriedades do produto interno:

(1) Simetria: $\mathbf{S}: \mathbf{T}=\mathbf{T}: \mathbf{S}$; de fato, $\mathbf{S}: \mathbf{T}=\operatorname{tr}\left(\mathbf{S}^{\mathrm{T}} \mathbf{T}\right)=\operatorname{tr}\left(\mathbf{S}^{\mathrm{T}} \mathbf{T}\right)^{\mathrm{T}}=\operatorname{tr}\left(\mathbf{T}^{\mathrm{T}} \mathbf{S}\right)=\mathbf{T}: \mathbf{S}$;

(2) $\mathbf{S}: \mathbf{S} \mathbf{0}, \forall \mathbf{S}$, sendo que o valor nulo ocorre se e somente se $\mathbf{S}=\mathbf{0}$. De fato, em função das componentes cartesianas de $\mathbf{S}$, tem-se:

$\mathbf{S}: \mathbf{S}=\operatorname{tr}\left[S_{i j}\left(\mathbf{e}_{\mathbf{j}} \otimes \mathbf{e}_{\mathbf{i}}\right) S_{k m}\left(\mathbf{e}_{\mathbf{k}} \otimes \mathbf{e}_{\mathbf{m}}\right)\right]=S_{i j} S_{k m} \delta_{i k} \delta_{j m}=S_{i j} S_{i j}=\sum_{i, j}\left(S_{i j}\right)^{2} \geq 0$

Daí, se $\mathbf{S}: \mathbf{S}=0$, então $S_{\mathrm{ik}}=0$, para todo i, $\mathrm{k}$. $\log \mathrm{S}=\mathbf{0}$, sendo a recíproca imediata.

A introdução do produto interno induz, de forma natural, o conceito de norma de um tensor, representada por $\|$.$\| . Então:$

$\|\mathbf{S}\|=\sqrt{\operatorname{tr}\left(\mathbf{S}^{\mathrm{T}} \mathbf{S}\right)}, \quad \forall \mathbf{S} \in$ Lin 
Algumas propriedades do produto interno de dois tensores:

(1) $\operatorname{tr}(\mathbf{I S})=\operatorname{tr}(\mathbf{S I})=\mathbf{I}: \mathbf{S}=\mathbf{S}: \mathbf{I}$;

(2) $\mathbf{R}:(\mathbf{S T})=\left(\mathbf{S}^{\mathrm{T}} \mathbf{R}\right): \mathbf{T}$.

De fato, $\mathbf{R}:(\mathbf{S T})=\operatorname{tr}\left(\mathbf{R}^{\mathrm{T}} \mathbf{S T}\right)=\operatorname{tr}\left(\mathbf{T}^{\mathrm{T}} \mathbf{S}^{\mathrm{T}} \mathbf{R}\right)=\mathbf{T}: \mathbf{S}^{\mathrm{T}} \mathbf{R}=\mathbf{S}^{\mathrm{T}} \mathbf{R}: \mathbf{T}$;

(3) $\mathbf{u} . \mathbf{S v}=\mathbf{S} .(\mathbf{u} \otimes \mathbf{v})$,

pois $\mathbf{S .}(\mathbf{u} \otimes \mathbf{v})=\operatorname{tr}\left[\mathbf{S}^{\mathrm{T}}(\mathbf{u} \otimes \mathbf{v})\right]=\operatorname{tr}\left[\mathbf{S}^{\mathrm{T}} \mathbf{u} \otimes \mathbf{v}\right\rfloor=\mathbf{S}^{\mathrm{T}} \mathbf{u . v}=\mathbf{u . S v}$,

onde se fez uso da identidade $\mathbf{S}^{\mathrm{T}}(\mathbf{u} \otimes \mathbf{v})=\left(\mathbf{S}^{\mathrm{T}} \mathbf{u}\right) \otimes \mathbf{v}$, que é verdadeira, porquanto:

$\mathbf{S}^{\mathrm{T}}(\mathbf{u} \otimes \mathbf{v}) \mathbf{w}=\mathbf{S}^{\mathrm{T}}[(\mathbf{u} \otimes \mathbf{v}) \mathbf{w}]=\mathbf{S}^{\mathrm{T}} \mathbf{u}(\mathbf{v} \cdot \mathbf{w})=\left(\mathbf{S}^{\mathrm{T}} \mathbf{u} \otimes \mathbf{v}\right) \mathbf{w} ;$

(4) Se $\mathbf{S} \in S y m$, então:

$\left.\mathbf{S}: \mathbf{T}=\mathbf{S}: \mathbf{T}^{\mathrm{T}}=\mathbf{S} .(1 / 2)(\mathbf{T}+\mathbf{T})=\mathbf{S}: \operatorname{Sym} \mathbf{T}\right), \forall \mathbf{T} \in \operatorname{Lin}$,

de fato:

$\mathbf{S}: \mathbf{T}=\operatorname{tr}\left(\mathbf{S}^{\mathrm{T}} \mathbf{T}\right)=\operatorname{tr}\left(\mathbf{S} \mathbf{T}^{\mathrm{T}}\right)=\mathbf{S}: \mathbf{T}^{\mathrm{T}}$

(5) Se W $\in S k w$, então:

$\mathbf{W}: \mathbf{T}=\mathbf{W}^{\mathrm{T}}: \mathbf{T}^{\mathrm{T}}=-\mathbf{W}: \mathbf{T}^{\mathrm{T}}=(1 / 2) \mathbf{W}\left(\mathbf{T}-\mathbf{T}^{\mathrm{T}}\right)=\mathbf{W}:$ Skw $\mathbf{T}, \forall \mathbf{T} \in \operatorname{Lin} ;$

(6) Se $\mathbf{S} \in S y m$ e $\mathbf{W} \in S k w$, então:

$\mathbf{S}: \mathbf{W}=0$

consequência da propriedade (4), ou da (5), acima;

(7) Se $\mathbf{T}: \mathbf{S}=\mathbf{0} \quad \forall \mathbf{S}$, então $\mathbf{T}=\mathbf{0}$;

(8) Se $\mathbf{T}: \mathbf{S}=\mathbf{0} \quad \forall \mathbf{S} \in S y m$, então $\mathbf{T} \in S k w$;

(9) Se $\mathbf{T}: \mathbf{S}=\mathbf{0} \quad \forall \mathbf{T} \in S k w$, então $\mathbf{S} \in S y m$. 
Determinante de um tensor: define-se como determinante, $\operatorname{det} \mathbf{S}$, de um tensor $\mathbf{S}$, o determinante da matriz $[\mathrm{S}]$ associada a $\mathbf{S}$, a partir da escolha de uma base, isto é:

$\operatorname{det} \mathbf{S}=\operatorname{det}[\mathrm{S}]$

Pode-se demonstrar que esta função é bem definida, no sentido de que, a cada tensor $\mathbf{S}$ corresponde um único det $\mathbf{S}$, isto significando que o determinante independe da representação de S. Pode-se mostrar, também, que esta função é não linear.

$\mathbf{S}$ é inversível, se existe um tensor, $\mathbf{S}^{-1}$, chamado tensor inverso de $\mathbf{S}$, tal que:

$\mathbf{S S}^{-1}=\mathbf{S}^{-1} \mathbf{S}=\mathbf{I}$.

Partindo-se da definição de determinante de um tensor, pode-se mostrar que $\mathbf{S}$ é inversível, se e somente se $\operatorname{det} \mathbf{S} \neq 0$.

Valem as seguintes identidades:
(1) $\operatorname{det}(\mathbf{S T})=(\operatorname{det} \mathbf{S})(\operatorname{det} \mathbf{T})$;
(2) $\operatorname{det}\left(\mathbf{S}^{\mathrm{T}}\right)=\operatorname{det} \mathbf{S}$.

As demonstrações dessas duas identidades dependem de alguns resultados encadeados de Álgebra Linear que não estão contemplados neste capítulo; podem-se encontrá-las em Feijóo (1972).

(3) $\operatorname{det}\left(\mathbf{S}^{-1}\right)=(\operatorname{det} \mathbf{S})^{-1}$.

Demonstração:

Basta considerar que $\mathbf{I}=\mathbf{S S}^{-1}$ e, pela Eq.(7.55):

$\operatorname{det}\left(\mathbf{S S}^{-\mathbf{1}}\right)=(\operatorname{det} \mathbf{I})=1=\operatorname{det} \mathbf{S} \operatorname{det} \mathbf{S}^{-\mathbf{1}}$

Decorre desse último resultado que:

(4) $(\mathbf{S T})^{-1}=\mathbf{T}^{-1} \mathbf{S}^{-1}$ 
(5) $\left(\mathbf{S}^{-1}\right)^{\mathrm{T}}=\left(\mathbf{S}^{\mathrm{T}}\right)^{-1}$,

o que justifica a notação $\mathbf{S}^{-\mathrm{T}}=\left(\mathbf{S}^{-1}\right)^{\mathrm{T}}$.

Diz-se que um tensor $\mathbf{Q}$ é ortogonal se preserva o produto interno, quando aplicado a um vetor de $V$, isto é:

$\mathbf{u . v}=(\mathbf{Q u}) \cdot(\mathbf{Q v})$.

A condição necessária e suficiente para que um tensor $\mathbf{Q}$ seja ortogonal é:

$\mathbf{Q Q}^{\mathrm{T}}=\mathbf{Q}^{\mathrm{T}} \mathbf{Q}=\mathbf{I}$,

o que equivale a:

$\mathbf{Q}^{\mathrm{T}}=\mathbf{Q}^{-1}$.

Demonstração: Suponha-se que $\mathbf{Q}$ preserva o produto interno, então, da definição de tensor transposto, tem-se:

$\mathbf{u . v}=(\mathbf{Q u}) \cdot(\mathbf{Q v})=\left(\mathbf{Q}^{\mathrm{T}} \mathbf{Q u}\right) \cdot \mathbf{v}$ e, portanto:

$\mathbf{Q Q}^{\mathrm{T}}=\mathbf{Q}^{\mathrm{T}} \mathbf{Q}=\mathbf{I} \Rightarrow \mathbf{Q}^{\mathrm{T}}=\mathbf{Q}^{-1}$.

A recíproca, prova-se a partir da Eq. (7.62), mostrando-se que, se

$\mathbf{Q}^{\mathrm{T}} \mathbf{Q}=\mathbf{Q Q}^{\mathrm{T}}=\mathbf{I}$,

então o produto interno é preservado e, portanto, $\mathbf{Q}$ é ortogonal, isto é:

$\left(\mathbf{Q}^{\mathrm{T}} \mathbf{Q} \mathbf{u}\right) . \mathbf{v}=\mathbf{I} \mathbf{u . v}=\mathbf{u . v} ;$

também $\left(\mathbf{Q}^{\mathrm{T}} \mathbf{Q u}\right) \cdot \mathbf{v}=\mathbf{Q u . Q v}$, o que significa:

$(\mathbf{Q u}) \cdot(\mathbf{Q v})=\mathbf{u . v}$. 
Dado $\mathbf{Q} \in$ Orth, o conjunto de todos os tensores ortogonais, então:

$\operatorname{det} \mathbf{Q}=+1 \quad$ ou $\operatorname{det} \mathbf{Q}=-1$

que se prova mediante consideração das Eqs. (7.51), (7.52) e (7.62).

Se $\mathbf{Q} \in$ Orth e det $\mathbf{Q}=1$, diz-se que o tensor $\mathbf{Q}$ é uma rotação. O conjunto de todas as rotações é representado pela notação $\operatorname{Orth}^{+}$.

Um tensor é positivo definido se a seguinte condição seja verificada:

u.Su 0 , sendo que $\mathbf{u . S u}=0$ se e somente se $\mathbf{u}=\mathbf{0}$.

\section{DIFERENCIAÇÃO}

Sejam $U$ e $V$ dois espaços vetoriais normados e seja $f: U \rightarrow V$, definida em uma vizinhança do zero de $U$. Diz-se que $f(\mathbf{u})$ aproxima-se de zero mais rapidamente que $\mathbf{u}$, ou que é de ordem u, se a seguinte condição é verificada:

$\lim _{\|\mathbf{u}\| 0_{\mathbf{u}} \mathbf{0}} \frac{\|f(\mathbf{u})\|}{\|\mathbf{u}\|}$.

Se $f(\mathbf{u})$ satisfizer a essa condição, diz-se que:

$f(\mathbf{u})=o(\mathbf{u})$, para $\mathbf{u} \rightarrow \mathbf{0}$ ou, simplesmente:

$f(\mathbf{u})=o(\mathbf{u})$.

Da mesma maneira, dadas duas funções, $f$ e $g$, diz-se que:

$f(\mathbf{u})=g(\mathbf{u})+o(\mathbf{u})$

se a seguinte condição se verifica:

$f(\mathbf{u})-g(\mathbf{u})=o(\mathbf{u})$. 
Observe-se que essa última definição tem sentido, mesmo se $f$ e $g$ assumem valores em $E$ (espaço euclidiano pontual). De fato, segundo se viu, $(f-g)$ é um vetor que assume valores em um espaço vetorial associado a $E$.

Seja $g$ uma função a valores escalares, ou vetores, ou tensores, ou até mesmo pontos. Suponha-se que seu domínio, $\mathrm{D}(g)$, seja um intervalo aberto de $I R$, então a derivada $\dot{g}(t)$, de $g$ em relação a $t$, caso exista, é definida como:

$g(t)=\frac{\mathrm{d}}{\mathrm{d} t} g(t)=\lim _{\alpha \rightarrow 0} \frac{1}{\alpha}[g(t+\alpha)-g(t)]$.

Verifica-se, a partir da Eq. (7.68), que, se $g$ é uma função que toma valores em $E$, então sua derivada é um vetor. Da mesma maneira, a derivada de uma função de valor vetorial é um vetor e, para uma função de valor vetorial, é um tensor.

Diz-se que $g$ é regular se existe $\dot{g}(t)$, para cada $t \in \mathrm{D}(g)$, e se $g(t)$ é contínua em $\mathrm{D}(g)$.

Da definição (7.68), segue-se que:

$g(t+\alpha)=g(t)+\alpha g(t)=o(\alpha)$, para $\alpha \rightarrow 0$.

A parcela $\dot{g}(t)$, em particular, é linear em $\alpha$, logo, de acordo com a Eq. (7.69), a diferença

$g(t+\alpha)-g(t)$

é igual a um termo linear em $\alpha$ mais um termo da ordem de $\alpha$.

Para tratar com derivadas, em espaços de dimensão maior que 1 , a definição de derivada estará fundamentada no resultado anterior, do qual decorrem as seguintes definições:

(1) A derivada de uma função $g$ é uma aplicação linear que se aproxima de $g(t+\alpha)-g(t)$, para valores pequenos de $\alpha$;

(2) Sejam $U$ e $W$ dois espaços vetoriais normados de dimensão finita, sendo $C$ um subconjunto aberto de $U$. Então $g: \mathrm{D} \rightarrow W$ é diferenciável em $\mathbf{x}$, se existe uma transformação linear:

$\operatorname{Dg}(\mathbf{x}): U \rightarrow W$ 
tal que

$$
g(\mathbf{x}+\mathbf{u})=g(\mathbf{x})+D g(\mathbf{x})[u]+o(\mathbf{u}) \quad \text { para }\|\mathbf{u}\| \quad 0 .
$$

A seguir, mostra-se que, se $\operatorname{Dg}(\mathbf{x})$ existe, então é única. De fato, da Eq (7.71), tem-se:

$$
g(\mathbf{x}+\mathbf{u})-g(\mathbf{x})-D g(\mathbf{x})[\mathbf{u}]=o(\mathbf{u}) .
$$

logo:

$$
D g(\mathbf{x})[\mathbf{u}]=\lim _{\substack{\alpha \rightarrow 0 \\ \alpha \in I R}} \frac{1}{\alpha}[g(\mathbf{x}+\alpha \mathbf{u})-g(\mathbf{x})]=\left.\frac{\mathrm{d}}{\mathrm{d} \alpha} g(\mathbf{x}+\alpha \mathbf{u})\right|_{\alpha=0}
$$

Seguindo-se as definições, $\operatorname{Dg}(\mathbf{x})$ é a derivada de $g$ em $\mathbf{x}$. Como quaisquer normas em espaços vetoriais finitos são equivalentes, então $\operatorname{Dg}(\mathbf{x})$ é independente das normas adotadas em $U$ e $W$.

Um caso particular importante é aquele em que $D(g) \subset I R$, para o qual, aplicando-se as Eqs. (7.69) e (7.71), resulta:

$D g(t)[\alpha]=\alpha g(t) \operatorname{Dg}(t)[\alpha]=g(t)$, para todo $\alpha \in I R$

A seguir, serão apresentados alguns exemplos que correspondem a casos de interesse do presente trabalho:

Exemplo 1 - Seja a aplicação $\phi: V \rightarrow I R$, definida pela lei $\phi(\mathbf{v})=\mathbf{v} \cdot \mathbf{v}$. Tem-se:

$\phi(\mathbf{v}+\mathbf{u})=(\mathbf{v}+\mathbf{u}) \cdot(\mathbf{v}+\mathbf{u})=\mathbf{v} \cdot \mathbf{v}+2 \mathbf{v} \cdot \mathbf{u}+\mathbf{u} \cdot \mathbf{u}=\phi(\mathbf{v})+2 \mathbf{v} \cdot \mathbf{u}+\mathbf{u} \cdot \mathbf{u}=\phi(\mathbf{v})+2 \mathbf{v} \cdot \mathbf{u}+o(\mathbf{u})$.

Daí,

$D \phi(\mathbf{v})[\mathbf{u}]=\mathbf{2} \mathbf{v} . \mathbf{u}$.

Exemplo 2 - Seja a aplicação $G: \operatorname{Lin} \rightarrow \operatorname{Lin}$, definida por $G(\mathbf{A})=\mathbf{A}^{3}$;

tem-se, então, que, $\forall \mathbf{U} \in \operatorname{Lin}$ : 
$\mathbf{G}(\mathbf{A}+\mathbf{U})=(\mathbf{A}+\mathbf{U})^{3}=\mathbf{A}^{3}+\mathbf{A}^{2} \mathbf{U}+\mathbf{A} \mathbf{U A}+\mathbf{U A}^{2}+\mathrm{o}(\mathbf{U})$.

Portanto,

$D G(\mathbf{A})[\mathbf{U}]=\mathbf{A}^{2} \mathbf{U}+\mathbf{A} \mathbf{U A}+\mathbf{U A}^{2}$.

Exemplo 3 - Seja a transformação linear $\mathbf{L}: U \rightarrow V$ (observe-se que $\mathbf{L}$ é um tensor). Então:

$\mathbf{L}(\mathbf{u}+\mathbf{v})=\mathbf{L}(\mathbf{v})+\mathbf{L}(\mathbf{u}), \log 0:$

$D \mathbf{L}(\mathbf{v})[\mathbf{u}]=\mathbf{L}(\mathbf{u})=\mathbf{L u}$, o que mostra ser a derivada em $\mathbf{v}$ igual ao próprio tensor, isto é:

$D \mathbf{L}(\mathbf{v})=\mathbf{L}$.

Exemplo 4 - Seja $\phi: \operatorname{Lin} \rightarrow I R$, definida através da seguinte lei:

$\phi(\mathbf{A})=\mathbf{A}: \mathbf{A t r A} ; \log , \forall U \in L i n$, tem-se:

$\phi(\mathbf{A}+\mathbf{U})=\operatorname{tr}(\mathbf{A}+\mathbf{U})(\mathbf{A}+\mathbf{U}):(\mathbf{A}+\mathbf{U})=[\operatorname{tr}(\mathbf{A})+\operatorname{tr}(\mathbf{U})][\mathbf{A}: \mathbf{A}+\mathbf{2} \mathbf{A}: \mathbf{U}+\mathbf{U}: \mathbf{U}]=$

$=\mathbf{A}: \mathbf{A} \operatorname{tr}(\mathbf{A})+\mathbf{2} \mathbf{A}: \mathbf{U} \operatorname{tr}(\mathrm{A})+\mathbf{A}: \mathbf{A} \operatorname{tr}(\mathbf{U})+o(\mathbf{U})$.

Daí decorre que:

$D \phi(\mathbf{A})[\mathbf{U}]=\mathbf{2} \mathbf{A}: \mathbf{U} \operatorname{tr}(\mathbf{A})+\mathbf{A}: \mathbf{A} \operatorname{tr}(\mathbf{U})$.

Exemplo 5 - Seja $\phi: V \rightarrow V$, definida por:

$\phi(\mathbf{v})=(\mathbf{a . v}) \mathbf{v}$, para todo $\mathbf{v} \in V$, sendo a um vetor fixo de $V$. Logo:

$\phi(\mathbf{v}+\mathbf{u})=[\mathbf{a} \cdot(\mathbf{v}+\mathbf{u})](\mathbf{v}+\mathbf{u})=(\mathbf{a} \cdot \mathbf{v}) \mathbf{v}+(\mathbf{a} \cdot \mathbf{u}) \mathbf{v}+(\mathbf{a} \cdot \mathbf{v}) \mathbf{u}+(\mathbf{a} \cdot \mathbf{u}) \mathbf{u}=$

$=\phi(\mathbf{v})+(\mathbf{a} \cdot \mathbf{u}) \mathbf{v}+(\mathbf{a} \cdot \mathbf{v}) \mathbf{u}+\mathrm{o}(\mathbf{u})$.

Daí, a diferencial de $\phi$, calculada em $\mathbf{v}$, para um incremento $\mathbf{u}$, é dada por:

$D \phi(\mathbf{v})[\mathbf{u}]=(\mathbf{a . u}) \mathbf{v}+(\mathbf{a . v}) \mathbf{u}$. 
Exemplo 6 (diferencial de um determinante) - Seja $\phi$ uma função definida no conjunto de todos os tensores inversíveis $\mathbf{A}$, tal que:

$\phi(\mathbf{A})=\operatorname{det}(\mathbf{A})$.

Aqui será usado um resultado da álgebra de matrizes, aplicado também aos tensores, em consequência da definição de determinante de um tensor, segundo o qual:

$\operatorname{det}(\mathbf{S}-\alpha \mathbf{I})=-\alpha^{3}+I_{1}(\mathbf{S}) \alpha^{2}-I_{2}(\mathbf{S}) \alpha+I_{3}(\mathbf{S})$

onde $I_{1}, I_{2}$ e $I_{3}$ são invariantes em relação à base de $V$, por meio da qual $\mathbf{S}$ é representado. Os valores dos invariantes são:

$I_{1}(\mathbf{S})=\operatorname{tr} \mathbf{S}$

$\left.\left.I_{2}(\mathbf{S})=(1 / 2)\right)[\operatorname{tr} \mathbf{S})^{2}-\operatorname{tr} \mathbf{S}^{2}\right]$

$\mathrm{e}$

$I_{3}(\mathbf{S})=\operatorname{det} \mathbf{S}$.

Fazendo $\alpha=-1$, na Eq. (7.73), tem-se:

$\operatorname{det}(\mathbf{I}+\mathbf{A})=1+\operatorname{tr} \mathbf{A}+o(\mathbf{A})$

para $\|\mathbf{A}\| \quad$ 0. Logo, se A é inversível, e $\mathbf{U} \in$ Lin é arbitrário, então:

$\operatorname{det}(\mathbf{A}+\mathbf{U})=\operatorname{det}\left[\left(\mathbf{I}+\mathbf{U} \mathbf{A}^{-1}\right) \mathbf{A}\right]=\operatorname{det}\left(\mathbf{I}+\mathbf{U} \mathbf{A}^{-1}\right) \operatorname{det} \mathbf{A}=\operatorname{det} \mathbf{A}\left[1+\operatorname{tr}\left(\mathbf{U} \mathbf{A}^{-1}\right)+o(\mathbf{U})\right]=$

$\left.=\operatorname{det} \mathbf{A}+\operatorname{det} \mathbf{A} \operatorname{tr}\left(\mathbf{U} \mathbf{A}^{-1}\right)+o(\mathbf{U})\right]$, para $\|\mathbf{U}\| \rightarrow 0$.

Como a aplicação $\left.f: U \rightarrow \operatorname{det} \mathbf{A}+\operatorname{det} \mathbf{A} \operatorname{tr}\left(\mathbf{U A}^{-1}\right)+o(\mathbf{U})\right]$ é linear, pelo fato de ser linear a operação traço, então:

$D \phi(\mathbf{A})[\mathbf{U}]=\operatorname{det} \mathbf{A} \operatorname{tr}\left(\mathbf{U A}^{-1}\right)$, para todo $\mathbf{U} \in$ Lin. 
Regra do produto: No desenvolvimento da mecânica do contínuo costumam aparecer operações com uma estrutura comum de produto, que merecem ser vistas segundo uma regra unificadora. Dentre elas destacam-se:

(1) produto de um escalar por um vetor: $\operatorname{prod}(\alpha, \mathbf{v})$;

(2) produto interno, ou escalar, entre dois vetores: $\operatorname{prod}(\mathbf{u}, \mathbf{v})$;

(3) produto interno de dois tensores: $\operatorname{prod}(\mathbf{U}, \mathbf{V})=\mathbf{U}: \mathbf{V}$;

(4) produto tensorial entre dois vetores: $\operatorname{prod}(\mathbf{u}, \mathbf{v})=\mathbf{u} \otimes \mathbf{v}$;

(4) aplicação de um tensor $\mathbf{S}$ sobre um vetor $\mathbf{v}: \operatorname{prod}(\mathbf{S}, \mathbf{v})=\mathbf{S} \mathbf{v}$ etc.

O objetivo, aqui, é estabelecer uma regra geral para o cálculo da derivada do produto de duas funções. Para isso, observe-se que as operações-produto, do tipo das definidas de (1) a (5) têm uma propriedade comum: são todas bilineares. Generalizando, considere-se a seguinte operação produto:

prod: $F \times G \rightarrow W$,

onde $F, G$ e $W$ são espaços normados de dimensão finita, e prod é uma aplicação bilinear. Deste modo, o produto é h $(x)=\operatorname{prod}(f(x), g(x))$, para todo $x \in D$. Suponha-se que o domínio comum, D, das funções $f$ e $g$, seja um subconjunto aberto de um espaço normado de dimensão finita $U$, ou do espaço euclidiano pontual $E$ associado ao espaço vetorial $V$.

LEMA. Regra do produto. Sejam $f$ e $g$ duas funções diferenciáveis em $x \in \mathrm{D}$. Logo o produto $h=\operatorname{prod}(f, g)$ é diferenciável em $x$, e:

$D h(x)[u]=\operatorname{prod}\{f(x), D g(x)[u]\}+\operatorname{prod}\{D f(x)[u], g(x)\}$,

para todo $u \in U$.

Demonstração:

Como os espaços $F, G, W$ e $U$ são de dimensão finita, a aplicação bilinear prod é limitada, e as aplicações lineares $D f(x)$ e $D g(x)$ são finitas. Logo, para todo $a \in F, b \in G$, e $u \in U$, existem escalares $k_{0}, k_{1}$ e $k_{2}$, tais que: 


$$
\begin{aligned}
& \|\operatorname{prod}(a, b)\| \leq k_{0}\|a\|\|b\|, \\
& \|D f(x)[u]\| \leq k_{1}\|u\| \\
& \mathrm{e} \\
& \|D g(x)[u]\| \leq k_{2}\|u\| .
\end{aligned}
$$

Por outro lado:

$$
\begin{aligned}
& f(x+u)=f(x)+D f(x)[u]+o(u) . \\
& \mathrm{e} \\
& g(x+u)=g(x)+D g(x)[u]+o(u) .
\end{aligned}
$$

Usando-se a bilinearidade da operação prod, conjuntamente com as propriedades listadas anteriormente, resulta:

$$
\begin{aligned}
& h(x+u)=\operatorname{prod}[f(x+u), f(x+u)]= \\
& =\operatorname{prod}[f(x), g(x)]+\operatorname{prod}\{f(x), D g(x)[u]\}+\operatorname{prod}\{D f(x)[u], g(x)\}+o(u) .
\end{aligned}
$$

Como se vê, a primeira parcela do segundo membro é a função $h$, calculada em $x$, e a soma da segunda com a terceira parcela é uma função linear de $u$. Logo, a expressão anterior demonstra a Eq. (7.75).

No caso particular em que $f$ é uma função constante, a Eq. (7.75) reduz-se a :

$$
\operatorname{Dh}(x)[u]=\operatorname{prod}\{f(x), \operatorname{Dg}(x)[u]\},
$$

Em situação mais particular ainda, quando o conjunto D é um intervalo aberto de $I R$, tem-se que a Eq. (7.76) reduz-se a:

$$
h(t)=\operatorname{prod}(f(t), g(t))+\operatorname{prod}(f(t), g(t)),
$$

onde $x$ é substituído por $t, u$ por $\alpha$, e $\mathrm{D} f(x)$ por $\dot{f}(t)$, em que se faz uso da bilinearidade de prod. Observe-se que a ausência de $\alpha$ na Eq. (7.77), faz com que $\dot{h}(t)$ se caracterize como uma derivada, e não como uma diferencial. 
A utilização da regra do produto permite que se chegue aos seguintes resultados:

$$
\begin{aligned}
& (\phi \mathbf{v})=\phi \mathbf{v}+\phi \mathbf{v}, \\
& (\mathbf{v} \cdot \mathbf{w})=\mathbf{v} \cdot \mathbf{w}+\mathbf{v} \cdot \mathbf{w}, \\
& (\mathbf{T S})=\mathbf{T S}+\mathbf{T S}, \\
& (\mathbf{T} \cdot \mathbf{S})=\mathbf{T} \cdot \mathbf{S}+\mathbf{T} . \mathbf{S} \quad \mathrm{e} \\
& (\mathbf{S v})=\mathbf{S v}+\mathbf{S v} .
\end{aligned}
$$

Regra da cadeia: Considere-se $U, F$ e $G$ espaços normados de dimensão finita (ou espaços euclidianos pontuais). Sejam $\mathrm{C}$ e D subconjuntos abertos de $G$ e $U$, respectivamente, e :

$f: \mathrm{C} \rightarrow F \quad$ e $\quad g: \mathrm{D} \rightarrow G$, onde $R(g) \subset \mathrm{C}$.

Seja $g$ diferenciável em $x$, e $f$ diferenciável em $y=g(x)$. Logo, a composição $h=f_{\text {o }} g$ é diferenciável em $x$, e

$$
D h(x)=D f(y) \circ D g(x)
$$

expressão que corresponde a uma simplificação de:

$D h(x)[u]=D f(g(x))\{D g(x)[u]\}$, para todo $u \in U$.

Em particular, se $U=I R$, então $g$ será uma função de variável real. Escrevendo-se $t$ em lugar de $x, g(t)$ em lugar de $\operatorname{D} g(x)$, e $\alpha$ em lugar de $u$, tem-se a derivada definida por:

$$
D f(g(t))=D f(g(t))[\dot{g}(t)]
$$

Proposição: Seja $\mathbf{S}$ uma função de valor tensorial definida em um intervalo aberto $\mathrm{D}$, de $I R$, então:

$\left(\mathbf{S}^{\mathrm{T}}\right)^{\cdot}=(\dot{\mathbf{S}})^{\mathrm{T}} \equiv \dot{\mathbf{S}}^{\mathrm{T}}$

e se $\mathbf{S}$ é inversível em todo $x \in \mathrm{D}$, tem-se:

$$
(\operatorname{det} \mathbf{S})=(\operatorname{det} \mathbf{S}) \operatorname{tr}\left(\mathbf{S S ~ S}^{-1}\right)
$$


Demonstração: Inicialmente, define-se a operação transposição como sendo

$(.)^{\mathrm{T}}:$ Lin $\rightarrow$ Lin, tal que :

$(.)^{\mathrm{T}}(\mathbf{A})=\mathbf{A}^{\mathrm{T}}, \forall \mathbf{A} \in \operatorname{Lin}$, que é uma operação linear (v. definição de tensor transposto). Portanto, os operadores transposição e derivação, por serem lineares, podem comutar, isto é:

$\left(\mathbf{S}^{\mathrm{T}}\right)=\left[(.)^{\mathrm{T}}(\mathbf{S})\right]=(.)^{\mathrm{T}}(\mathbf{S})=(\mathbf{S})^{\mathrm{T}}$,

com a qual se demonstra a Eq.(7.81). O resultado representado pela Eq.(7.82) é uma consequência direta das Eqs. (7.74) e (7.80).

\section{GRADIENTE E DIVERGÊNCIA}

Pelo teorema da representação das formas lineares, seja $\phi: V \rightarrow I R$ linear, então existe um único vetor $\mathbf{a}$, tal que:

$\phi(\mathbf{v})=\mathbf{a} . \mathbf{v}, \forall \mathbf{v} \in V$.

Campo escalar: Seja $\phi$ um campo escalar regular, definido em um conjunto aberto $\mathrm{R} \subset V$. Portanto, para cada $\mathbf{x} \in \mathrm{R}, D \phi(\mathbf{x})$ é uma aplicação de $V$ em $I R$. Pelo teorema da representação das formas lineares, existe um único vetor, $\nabla \phi(\mathbf{x})$, chamado gradiente de $\phi$ em $\mathbf{x}$, tal que:

$$
D \phi(\mathbf{x})[\mathbf{u}]=\nabla \phi(\mathbf{x}) \cdot \mathbf{u}
$$

de maneira que a Eq. (7.71) torna-se:

$$
\phi(\mathbf{x}+\mathbf{u})=\phi(\mathbf{x})+\nabla \phi(\mathbf{x}) \cdot \mathbf{u}+o(\mathbf{u})
$$

Campo vetorial e campo pontual: De maneira semelhante à anterior, seja $\phi$ um campo vetorial (ou pontual) regular, definido em $\mathrm{R} \subset V$. Então, para cada $\mathbf{x} \in \mathrm{R}$, então $D \mathbf{v}(\mathbf{x})$ é uma transformação linear de $V$ em $V$, isto é, um tensor. Neste caso, $\nabla \mathbf{v}(\mathbf{x})$, chamado gradiente de $\mathbf{v}$ em $\mathbf{x}$, será usado para representar $\operatorname{Dv}(\mathbf{x})$.Assim:

$D \mathbf{v}(\mathbf{x})[\mathbf{u}]=\nabla \mathbf{v}(\mathbf{x}) \mathbf{u}$ 
Considere-se agora um campo vetorial regular $\mathbf{v}$, definido em R. O campo escalar:

$\operatorname{div} \mathbf{v}=\operatorname{tr}(\nabla \mathbf{v})$

é denominado divergência de $\mathbf{v}$.

Com o operador definido pela Eq. (7.87), pode-se introduzir o conceito de divergência de um tensor, a ser representado por $\operatorname{div} \mathbf{S}$. Com efeito, div $\mathbf{S}$ é o único vetor com a seguinte propriedade:

$(\operatorname{div} \mathbf{S}) \cdot \mathbf{a}=\operatorname{div}\left(\mathbf{S}^{\mathrm{T}} \mathbf{a}\right)$

para um vetor a arbitrário.

Proposição: Sejam $\phi$, v, w e $\mathbf{S}$ campos regulares, sendo $\phi$ escalar, $\mathbf{v}$ e $\mathbf{w}$ vetoriais e $\mathbf{S}$ tensorial, então valem as seguintes identidades:

1) $\nabla(\phi \mathbf{v})=\phi \nabla \mathbf{v}+\mathbf{v} \otimes(\nabla \phi)$

2) $\operatorname{div}(\phi \mathbf{v})=\phi \operatorname{div} \mathbf{v}+(\nabla \phi) . \mathbf{v}$

3) $\nabla(\mathbf{v} \cdot \mathbf{w})=(\nabla \mathbf{v}) \mathbf{w}+(\nabla \mathbf{w})^{\mathbf{T}} \mathbf{v}$;

4) $\operatorname{div}(\mathbf{v} \otimes \mathbf{w})=\mathbf{v} \operatorname{div} \mathbf{w}+(\nabla \mathbf{v}) \mathbf{w}$;

5) $\operatorname{div}\left(\mathbf{S}^{\mathrm{T}} \mathbf{v}\right)=\mathbf{S}: \nabla \mathbf{v}+\mathbf{v} \cdot \operatorname{div} \mathbf{S}$

e

6) $\operatorname{div}(\phi \mathbf{S})=\phi \operatorname{div} \mathbf{S}+\mathbf{S}(\nabla \phi)$.

Demonstração: Seja $\mathbf{h}=\phi \mathbf{v}$. Logo, decorre da regra do produto, isto é, da Eq. (7.75) e das Eqs. (7.85) e (7.86), que:

$\{\nabla(\phi \mathbf{v})\}[\mathbf{u}]=\{\phi(\mathbf{x}) \nabla \mathbf{v}(\mathbf{x})+\mathbf{v}(\mathbf{x}) \otimes(\nabla \phi(\mathbf{x})\}[\mathbf{u}]$

$\mathrm{ou}$ 
$\nabla(\phi \mathbf{v})=\phi \nabla \mathbf{v}+\mathbf{v} \otimes(\nabla \phi)$

que prova a primeira das identidades da Eq. (7.89).

Para provar a segunda das identidades da Eq. (7.89), considere-se a primeira identidade e tome-se a definição dada através da Eq. (7.87), segundo a qual:

$\operatorname{div}(\phi \mathbf{v})=\operatorname{tr}[\nabla(\phi \mathbf{v})]=\operatorname{tr}(\phi \nabla \mathbf{v}+\mathbf{v} \otimes \nabla \phi)=\phi \operatorname{div} \mathbf{v}+\operatorname{tr}(\mathbf{v} \otimes \nabla \phi)$

Utilizando a Eq. (7.39), nesse último resultado, tem-se, finalmente:

$\operatorname{div}(\phi \mathbf{v})=\phi \operatorname{div} \mathbf{v}+(\nabla \phi) . \mathbf{v}$

Para a prova da terceira das Eqs. (7.89), seja $h=\mathbf{v} . \mathbf{w}$, então, da Eq. (7.75), que é a regra do produto, resulta:

$\left.\left.\nabla \mathbf{h}(\mathbf{x})[\mathbf{u}]=\mathbf{v}(\mathbf{x}) \cdot\{\nabla \mathbf{w}(\mathbf{x})\}[\mathbf{u}]+\{\nabla \mathbf{v}(\mathbf{x})[\mathbf{u}]\} \cdot \mathbf{w}(\mathbf{x})=\left\{(\nabla \mathbf{w}(\mathbf{x}))^{\mathrm{T}}\right\} \cdot \mathbf{v}(\mathbf{x})+(\nabla \mathbf{v}(\mathbf{x}))\right\} \cdot \mathbf{w}(\mathbf{x})\right\}[\mathbf{u}]$

ou

$\nabla(\mathbf{v} \cdot \mathbf{w})=(\nabla \mathbf{v}) \cdot \mathbf{w}+(\nabla \mathbf{w})^{\mathrm{T}} \cdot \mathbf{v}$

Observe-se que, se na terceira das Eqs.(7.89) faz-se $\mathbf{w}=\mathbf{v}$, então:

$\nabla(\mathbf{v} . \mathbf{v})=\left[\nabla \mathbf{v}+(\nabla \mathbf{v})^{\mathrm{T}}\right] \cdot \mathbf{v}$

Para provar a quarta das Eqs. (7.89), basta que se considere a definição dada pela Eq.(7.88), que permite definir-se a divergência de um tensor, isto é:

$\operatorname{div}(\mathbf{v} \otimes \mathbf{w}) \cdot \mathbf{a}=\operatorname{div}[(\mathbf{w} \otimes \mathbf{v}) \mathbf{a}]=\operatorname{div}[\mathbf{w}(\mathbf{v} \cdot \mathbf{a})]=(\mathbf{v} \cdot \mathbf{a}) \operatorname{div} \mathbf{w}+\mathbf{w} \cdot \nabla(\mathbf{v} \cdot \mathbf{a})=$ $=(\mathbf{v} \cdot \mathbf{a}) \operatorname{div} \mathbf{w}+\mathbf{w} \cdot[\nabla(\mathbf{v})]^{\mathrm{T}} \mathbf{a}$,

onde se fez uso do fato de que a é um vetor qualquer, que não depende de $\mathbf{x}$. Logo:

$\operatorname{div}(\mathbf{v} \otimes \mathbf{w}) \cdot \mathbf{a}=[\mathbf{v} \operatorname{div} \mathbf{w}+(\nabla \mathbf{v}) \mathbf{w}] \cdot \mathbf{a}$,

que prova a quarta das Eqs.(7.89). 
Para provar a quinta das Eqs. (7.89), parte-se do seguinte: seja $\mathbf{v}$ um campo vetorial regular, logo:

$\mathbf{v}(\mathbf{x}+\mathbf{u})=\mathbf{v}(\mathbf{x})+\nabla \mathbf{v}(\mathbf{x}) \mathbf{u}+o(\mathbf{u})$

Se A é um tensor arbitrário, independente de $\mathbf{x}$, então:

$\nabla(\mathbf{A v})=\mathbf{A} \nabla \mathbf{v}$

para todo tensor A e todo campo vetorial regular v. Tomando-se o traço de ambos os membros da Eq. (7.91) e considerando-se as definições (7.87) e (7.43), tem-se:

$\operatorname{div}(\mathbf{A v})=\operatorname{tr} \nabla(\mathbf{A v})=\operatorname{tr}(\mathbf{A} \nabla \mathbf{v})=\mathbf{A}^{\mathrm{T}} \nabla \mathbf{v}$

Pode-se, agora, provar a quinta das Eqs. (7.89). De fato, partindo-se da definição (7.87), tem-se:

$\operatorname{div}\left(\mathbf{S}^{\mathrm{T}} \mathbf{v}\right)=\operatorname{tr} \nabla\left(\mathbf{S}^{\mathrm{T}} \mathbf{v}\right)$

Pela regra do produto, $\left(\mathbf{S}^{\mathrm{T}} \mathbf{v}\right)[\mathbf{x}]$ é a soma do gradiente, mantido $\mathbf{S}$ constante com valor $\mathbf{S}_{0}=\mathbf{S}(\mathbf{x})$, mais o gradiente, mantido $\mathbf{v}$ constante com valor $\mathbf{v}_{0}=\mathbf{v}(\mathbf{x})$, isto é:

$\nabla\left(\mathbf{S}^{\mathrm{T}} \mathbf{v}\right)[\mathbf{x}]=\nabla\left(\mathbf{S}_{0}^{\mathrm{T}} \mathbf{v}\right)[\mathbf{x}]+\nabla\left(\mathbf{S}^{\mathrm{T}} \mathbf{v}_{0}\right)[\mathbf{x}]$.

Logo:

$\operatorname{div}\left(\mathbf{S}^{\mathrm{T}} \mathbf{v}\right)[\mathbf{x}]=\operatorname{tr}\left\{\nabla\left(\mathbf{S}_{0}^{\mathrm{T}} \mathbf{v}\right)[\mathbf{x}]+\nabla\left(\mathbf{S}^{\mathrm{T}} \mathbf{v}_{0}\right)[\mathbf{x}]\right\}=\operatorname{div}\left(\mathbf{S}_{0}^{\mathrm{T}} \mathbf{v}\right)[\mathbf{x}]+\operatorname{div}\left(\mathbf{S}^{\mathrm{T}} \mathbf{v}_{0}\right)[\mathbf{x}]$

Da Eq. (7.92), com $\mathbf{A}=\mathbf{S}_{0}^{\mathrm{T}}$, tem-se:

$\operatorname{div}\left(\mathbf{S}^{\mathrm{T}} \mathbf{v}\right)[\mathbf{x}]=\mathbf{S}(\mathbf{x}) \cdot \nabla \mathbf{v}(\mathbf{x})+\operatorname{div}\left(\mathbf{S}^{\mathrm{T}} \mathbf{v}_{0}\right)[\mathbf{x}]$

A aplicação da Eq. (7.88), faz com que a última expressão resulte em:

$\operatorname{div}\left(\mathbf{S}^{\mathrm{T}} \mathbf{v}\right)[\mathbf{x}]=\mathbf{S}(\mathbf{x}) \cdot \nabla \mathbf{v}(\mathbf{x})+\mathbf{v}(\mathbf{x}) \cdot \operatorname{div}(\mathbf{S})$,

completando-se a demonstração. 
A demonstração da sexta das Eqs. (7.89) faz-se de maneira semelhante à anterior. Assim:

$\operatorname{div}(\phi \mathbf{S})[\mathbf{x}]=\operatorname{div}\left(\phi_{0} \mathbf{S}\right)[\mathbf{x}]+\operatorname{div}\left(\phi \mathbf{S}_{\mathbf{0}}\right)[\mathbf{x}]$

Da definição de divergência de um tensor, através da Eq. (7.88), resulta:

$\operatorname{div}\left(\phi_{0} \mathbf{S}\right)=\phi_{0} \operatorname{div}(\mathbf{S})$

e para um vetor qualquer $\mathbf{a}$, independente de $\mathbf{x}$, tem-se:

$\mathbf{a} \cdot \operatorname{div}\left(\phi \mathbf{S}_{0}\right)=\phi \operatorname{div}\left(\phi \mathbf{S}_{0}^{\mathrm{T}} \mathbf{a}\right)$. Considerando agora, $\mathbf{v}=\mathbf{S}_{0}^{\mathrm{T}} \mathbf{a}$ na identidade (7.89) $)_{2}$, tem-se:

$\operatorname{a} \cdot \operatorname{div}\left(\phi \mathbf{S}_{\mathbf{0}}\right)=\phi \operatorname{div}\left(\mathbf{S}_{0}^{\mathrm{T}} \mathbf{a}\right)+\mathbf{S}_{0}^{\mathrm{T}} \mathbf{a} \cdot \nabla \phi=\mathrm{a} \cdot \mathbf{S}_{\mathbf{0}} \nabla \phi$, então,

$\operatorname{div}\left(\phi \mathbf{S}_{0}\right)=\mathbf{S}_{\mathbf{0}} \nabla \phi$

Finalmente, introduzindo as Eqs. (7.94) e (7.95) na Eq. (7.93), chega-se à prova da sexta das Eqs. (7.89), isto é:

$\operatorname{div}(\phi \mathbf{S})[\mathbf{x}]=\phi(\mathbf{x}) \operatorname{div} \mathbf{S}(\mathbf{x})+\mathbf{S}(\mathbf{x})(\nabla \phi(\mathbf{x}))$.

\section{TEOREMA DA DIVERGÊNCIA (GAUSS)}

A seguir, apresenta-se a terminologia essencial para a enunciação, sem demonstração, desse teorema de grande aplicação em todas as áreas científicas.

Seja X um espaço métrico. Para as seguintes definições, todos os pontos referidos são pertencentes a $\mathrm{X}$, assim como todos os subconjuntos estão contidos em X.

1. A vizinhança de um ponto $p$ é um subconjunto $N_{\rho}(p)$, formada por todos os pontos $q$, para os quais $d(p, q)<\rho$. A distância $\rho$ é chamada de raio de $N_{\rho}(p)$.

2. O ponto $p$ é dito um ponto limite de um conjunto $E$, se toda vizinhança de $p$ contém ao menos um ponto $q \neq p$, com $q \in E$.

3. Diz-se que um conjunto $E$ é fechado, se todo ponto limite de $E$ é um ponto de $E$.

4. Um ponto $p$ é um ponto interior de $E$, se existe uma vizinhança $N(p)$, tal que $N \subset E$.

5. Um conjunto $E$ é aberto, se todo ponto de $E$ é um ponto interior. 
6. Diz-se que $E$ é limitado se existe um número real $M$, e um ponto $q \in \mathrm{X}$, tal que $d(q, p)<M$, para todo $p \in E$.

7. Se $E^{\prime}$ for designado como o conjunto de todos os pontos limites de $E$, em $X$, então a cobertura de $E$ é o conjunto $\bar{E}=E \cup E$.

8. Dois conjuntos são ditos separados se as interseções $A \cap \bar{B}$ e $\bar{A} \cap B$ são vazias.

9. Um conjunto $E$ é conexo se e somente se não é a união de dois conjuntos separados não vazios.

10. Uma região aberta é um conjunto conexo aberto, em $E$. A cobertura de uma região aberta é uma região fechada.

Diz-se que uma região é regular, se é fechada, com contornos seccionalmente regulares. Entende-se por contornos seccionalmente regulares a união de um número finito de superfícies fechadas regulares, que não se interceptam, sendo que, em cada uma dessas superfícies o vetor normal à mesma está definido em todos os pontos.

Teorema (Gauss): Seja $\Omega$ uma região regular, limitada, e seja $\Upsilon$ um campo regular (vetorial, ou tensorial de segunda ordem), para o qual faça sentido (no segundo membro) a operação (.) sobre o vetor normal unitário $n$.

Então: $\int_{\Omega}(\Upsilon \cdot \nabla) d v=\int_{\partial \Omega}(\Upsilon \cdot \mathbf{n}) \mathrm{d} s$

onde a notação $Y . \nabla$ é o mesmo que divY.

Enuncia-se a seguir, outro importante resultado, isto é, o teorema da localização.

\section{TEOREMA DA LOCALIZAÇÃO}

Seja $\phi$ um campo escalar, ou vetorial, contínuo e definido em conjunto aberto $\Omega$ de $E$. Então, dado $x \in \Omega$ arbitrário, tem-se:

$\phi(x)=\lim _{\rho \rightarrow 0} \frac{1}{\operatorname{vol}\left(N_{\rho}(x)\right.} \int_{N_{\rho}(x)} \phi \mathrm{d} V$. 
$\int_{\Omega} \phi \mathrm{d} V=0$, para todo $-\subset \Omega$, então: $\phi 0$.

\section{DERIVAÇÕES MATERIAIS NO TEMPO}

A derivada material no tempo é aquela que acompanha a evolução do ponto material, no tempo, por sua coordenada no sistema de referência, isto é, a variável material $\mathbf{X}$ (maiúsculo). A seguir será feito o cálculo desse tipo de derivada aplicada a duas integrais cujos integrandos são funções especiais, $\Phi(\mathbf{x}, t)$ e $\Phi^{*}(\mathbf{x}, t)$, descritas em termos da variável espacial x (minúsculo), sendo:

$\mathbf{x}=\mathbf{x}(\mathbf{X}, t)$

Admitindo-se que $\Phi(\mathbf{x}, t)$ e $\Phi^{*}(\mathbf{x}, t)$ sejam campos, na configuração atualizada, com valores escalares ou vetoriais, e tenham propriedades compatíveis com as operações abaixo realizadas, então:

$\frac{D}{D t} \int_{P_{t}} \Phi(\mathbf{x}, t) d v=\lim _{\Delta t \rightarrow 0} \frac{\Delta\left(\int_{P_{t}} \Phi(\mathbf{x}, t) d v\right)}{\Delta t}$,

onde

$\Delta\left(\int_{P_{t}} \Phi(\mathbf{x}, t) d v\right)=\left.\int_{P_{t+\Delta t}} \Phi(\mathbf{x}(\mathbf{X}, t+\Delta t), t+\Delta t) d v\right|_{t+\Delta t}-\left.\int_{P_{t}} \Phi(\mathbf{x}(\mathbf{X}, t), t) d v\right|_{t}$

A seguir, desenvolve-se $\Phi(\mathbf{x}(\mathbf{X}, t+\Delta t), t+\Delta t)$ em série, isto é,

$$
(\mathbf{x}(\mathrm{X}, t+t), t+t)=(\mathbf{x}(\mathbf{X}, t), t)+\left[(\operatorname{grad}) \mathbf{v}+/\left.t\right|_{\mathrm{t}}\right] \mathrm{t}+O(t)
$$

onde $\operatorname{grad} \Phi$ é o gradiente de $\Phi$ em relação a $\mathbf{x} ; O(\Delta t)$ representa a soma das parcelas de ordens superiores a $\Delta t \mathrm{e}$

$\mathbf{v}=\frac{D}{D t} \mathbf{x}(\mathbf{X}, t)$

Por outro lado: 
$\left.d v\right|_{t}=\left.(\operatorname{det} F)\right|_{t} d V \quad$ e $\left.\quad d v\right|_{t+\Delta t}=\left.(\operatorname{det} F)\right|_{t+\Delta t} d V$

onde $\mathrm{d} V$ é o elemento de volume em $P_{0}$. As Eqs. (7.100) mostram as relações entre volumes de elementos infinitesimais, em $P_{t}$ e $P_{t+\Delta t}$, respectivamente, com o volume de um elemento infinitesimal em $P_{0}$. Os determinantes $\left.\operatorname{det} F\right|_{t}$ e $\left.\operatorname{det} F\right|_{t+\Delta t}$ são os jacobianos, nos instantes $t$ e $\quad t$ $+\Delta t$, de $F$ que é o gradiente de $\Phi$ em relação a $\mathbf{X}$. O desenvolvimento em série, para $\left.\operatorname{det} F\right|_{t+{ }_{\Delta} t}$, dá:

$\left.(\operatorname{det} F)\right|_{t+\Delta t}=\left.(\operatorname{det} F)\right|_{t}+\left.\left(\frac{D(\operatorname{det} F)}{D t}\right)\right|_{t} \Delta t+O(\Delta t)$

Mas, de acordo com a Eq. (7. 74), para $\mathbf{A}=F$ tem-se:

$\left.\left.\left(\frac{D(\operatorname{det} F)}{D t}\right)\right|_{t}=(\operatorname{det} F) \operatorname{tr}\left(F F^{-1}\right)\right]\left.\right|_{t}$

onde $F=(\mathrm{D} / \mathrm{D} t) F$. Substituindo a Eq. (7.102) na Eq. (7.101) e levando-se o resultado à segunda das Eqs.(7.100), vem:

$\left.d v\right|_{t+\Delta t}=\left\{(\operatorname{det} F)+(\operatorname{det} F) t r\left(\dot{F} F^{-1}\right)(\Delta t+O(\Delta t))\right\}_{t} d V$.

Substituindo-se a Eq.(7.103) na Eq.(7.97), e levando-a, depois, à Eq.(7.96), tem-se:

$$
\begin{aligned}
& \frac{D}{D t} \int_{P_{t}} \Phi(x, t) d v=\lim _{\Delta t \rightarrow 0} \frac{1}{\Delta t}\left\{\int_{P_{o}}[\Phi(x(t+\Delta t), t+\Delta t)] \cdot[\operatorname{det} F+\right. \\
& \left.\left.+(\operatorname{det} F) t r\left(F F^{-1}\right)\right]_{t} d V-\left.\int_{P_{o}} \Phi(x(X, t), t)(\operatorname{det} F)\right|_{t} d V\right\} .
\end{aligned}
$$

Considerando-se a Eq. (7.98), reunindo-se em $O(\Delta t)$ as parcelas de ordem $(\Delta t)^{2}$ em diante, e calculando-se o limite, então a Eq. (7.104) fica:

$$
\frac{D}{D t} \int_{P_{t}} \Phi d v=\int_{P_{0}}[\operatorname{grad} \Phi) \mathbf{v}+\frac{\partial \Phi}{\partial t}+\Phi \operatorname{tr}\left(F F^{-1}\right](\operatorname{det} F) d V
$$

onde $\Phi=\Phi(\mathbf{x}(\mathbf{X}, t), t)$. A substituição da primeira das Eqs. (100). na Eq. (7.105) permite que a integração volte para a configuração atualizada, isto é: 
$\frac{D}{D t} \int_{P_{t}} \Phi \mathrm{d} v=\int_{P_{t}}\left[(\operatorname{grad} \Phi) \mathbf{v}+\frac{\partial \Phi}{\partial t}+\Phi \operatorname{tr}\left(\dot{F} F^{-1}\right)\right] \mathrm{d} v$.

Levando-se em conta que

$F F^{1}=\operatorname{grad} \mathbf{v}$,

$\operatorname{tr}\left(\dot{F F}{ }^{1}\right)=\operatorname{div} \mathbf{v}$

e

$(\operatorname{grad} \Phi) \mathbf{v}+\partial \Phi / \partial t=(\mathrm{D} / \mathrm{D} t) \Phi$

então,

$\frac{D}{D t} \int_{P_{t}} \Phi \mathrm{d} v=\int_{P_{t}}\left[\frac{D \Phi}{D t}+\Phi \mathrm{div} \mathbf{\mathrm { d }} v\right.$.

Na sequência, será calculada a derivada material no tempo da função $\Phi^{*}(\mathbf{x}, t)$. O procedimento é bastante semelhante ao anterior, no entanto é necessário atentar-se que a aplicação, nesse caso, leva pontos de $S_{\mathrm{f}}(t)$, na configuração de referência, a pontos de $s_{\mathrm{f}}(t)$, na configuração atualizada. Assim:

$\frac{D}{D t} \int_{s_{f}(t)} \Phi^{*}(\mathbf{x}, t) d s=\lim _{\Delta t \rightarrow 0} \frac{\Delta\left(\int_{s_{f}(t)} \Phi^{*}(\mathbf{x}, t) d s\right)}{\Delta t}$

onde $\Phi^{*}(\mathbf{x}, t)$, definida em $s_{\mathrm{f}}(t)$, é um campo (vetorial ou escalar), com propriedades de continuidade e derivabilidade compatíveis com as operações realizadas; e d $s$ é o elemento de área em $s_{\mathrm{f}}(t)$. Assim:

$\Delta\left(\int_{s_{f}(t)} \Phi^{*}(\mathbf{x}, t) \mathrm{d} s\right)=\left.\int_{s_{f}(t+\Delta t)} \Phi^{*}(\mathbf{x}(\mathbf{X}, t+\Delta t), t+\Delta t) \mathrm{d} s\right|_{t+\Delta t}-\left.\int_{s_{f}(t)} \Phi^{*}(\mathbf{x}(\mathbf{X}, t), t) \mathrm{d} s\right|_{t}$.

Desenvolvendo $\Phi^{*}(\mathbf{x}(\mathbf{X}, t+\Delta t), t+\Delta t)$ em série, tem-se: 


$$
\begin{aligned}
& \Phi^{*}(\mathbf{x}(\mathbf{X}, t+\Delta t), t+\Delta t)= \\
& =\Phi^{*}(\mathbf{x}(\mathbf{X}, t), t)+\left[\left(\operatorname{grad} \Phi^{*}\right) \mathbf{v}+\partial \Phi^{*} / \partial t\right]_{t} \Delta t+O(\Delta t),
\end{aligned}
$$

onde $\operatorname{grad} \Phi^{*}$ é o gradiente da função $\Phi^{*}$ em relação a $\mathbf{x}$, e $O(\Delta t)$ representa a soma das parcelas de ordens superiores a $\Delta t$.

Por outro lado:

$$
\left.d S\right|_{t+\Delta t}=\left.\left.\left(\operatorname{det} F^{*}\right)\right|_{t+\Delta t} d S \quad \mathrm{e} \quad d s\right|_{t}=\left.\left(\operatorname{det} F^{*}\right)\right|_{t} d S,
$$

onde $\mathrm{d} S$ é o elemento de área de $S_{\mathrm{f}}(\mathrm{t})$. As Eqs. (7.111) mostram as relações entre áreas de elementos infinitesimais, na configuração atualizada e na configuração de referência, nos instantes $t+\Delta t$ e $t$, respectivamente. Os determinantes jacobianos de superfície, do gradiente $F^{*}$, nos instantes $t$ e $t+\Delta t$, são, respectivamente, $\left.\operatorname{det} F^{*}\right|_{\mathrm{t}}$ e $\left.\operatorname{det} F^{*}\right|_{\mathrm{t}+\mathrm{\Delta}+}$. Considerando-se o desenvolvimento em série, para $\left.\operatorname{det} F^{*}\right|_{\mathrm{t}+\Delta \mathrm{t}}$, tem-se:

$$
\left.\left(\operatorname{det} F^{*}\right)\right|_{t+\Delta t}=\left.\left(\operatorname{det} F^{*}\right)\right|_{t}+\left.\left(\frac{D\left(\operatorname{det} F^{*}\right)}{D t}\right)\right|_{t} \Delta t+O(\Delta t)
$$

Mas, de acordo com a Eq. (7. 74), para $\mathbf{A}=F^{*}$, tem-se:

$$
\left.\left(\frac{D\left(\operatorname{det} F^{*}\right)}{D t}\right)\right|_{t}=\left.\left(\operatorname{det} F^{*}\right) \operatorname{tr}\left(\dot{F}^{*} F^{*-1}\right)\right|_{t},
$$

onde $\dot{F}^{*}=\left(D F^{*} / D t\right)$

Substituindo as Eqs. (7. 101), (7. 102) e (7. 103) na Eq. (7. 108), fica:

$$
\begin{aligned}
& \frac{D}{D t} \int_{s_{f}(t)} \Phi^{*}(\mathbf{x}, t) d s=\lim _{\Delta t \rightarrow 0} \frac{1}{\Delta t} . \\
& \left\{\begin{array}{l}
\left.\left.\left.\int_{s_{f}(t+\Delta t)}\left[\Phi^{*}(\mathbf{x}(t+\Delta t), t+\Delta t)\right]\left[\operatorname{det}\left(F^{*}\right)+\operatorname{det}\left(F^{*}\right) \operatorname{tr}\left(F^{*} F^{*}-1\right)\right]\right|_{t} d s-\int_{s_{f}(t)} \Phi^{*}(\mathbf{x}(\mathbf{X}, t), t)\left(\operatorname{det} F^{*}\right) d_{(7.1}\right\}_{14}\right)
\end{array}\right.
\end{aligned}
$$


Considerando-se a Eq.(7.110), e calculando-se o limite, a Eq.(7.105) fica:

$\frac{D}{D t} \int_{s_{f}} \Phi^{*} d s=\int_{s_{f}}\left\{\left(\operatorname{grad} \Phi^{*}\right) \mathbf{v}+\frac{\partial \Phi^{*}}{\partial t}+\Phi^{*} \operatorname{tr}\left[F^{*}\left(F^{*}\right)^{-1}\right]\right\}\left(\operatorname{det} F^{*}\right) d S$

onde $\Phi^{*}=\Phi^{*}(\mathbf{x}(\mathbf{X}, t), t)$. Na equação acima, a omissão do lugar e do instante em que as variáveis estão sendo calculadas implica que tudo se refere a $\mathbf{x}(\mathbf{X}, t)$ e $t$. A substituição da segunda Eq.(7.101) na Eq.(7.105) permite que a integração volte para a configuração atualizada. Assim:

$\frac{D}{D t} \int_{s_{f}} \Phi^{*} d s=\int_{s_{f}}\left\{\left(\operatorname{grad} \Phi^{*}\right) \mathbf{v}+\frac{\partial \Phi^{*}}{\partial t}+\Phi^{*} \operatorname{tr}\left[\dot{F}^{*}\left(F^{*}\right)^{-1}\right]\right\} d s$

Como $\dot{F}^{*}\left(F^{*}\right)^{-1}=\operatorname{grad} \mathbf{v}$, então

$\operatorname{tr}\left[F^{*}\left(F^{*}\right)^{-1}\right]=\operatorname{div} \mathbf{v}$

$\mathrm{e}$

$\left(\operatorname{grad} \Phi^{*}\right) \mathbf{v}+\frac{\partial \Phi^{*}}{\partial t}=\frac{D}{D t} \Phi^{*}$

Daí, por substituiçao na Eq.(7.116), tem-se, finalmente:

$\frac{D}{D t} \int_{s_{f}} \Phi^{*} d s=\int_{s_{f}}\left[\frac{D \Phi^{*}}{D t}+\Phi^{*} \operatorname{div} \mathbf{v}\right] d s$

\section{ANÁLISE DE SENSIBILIDADE À MUDANÇA DE FORMA DO DOMÍNIO}

De maneira sumária, pretende-se analisar o que ocorre quando um sólido sujeito a determinado estado de tensões, decorrente da aplicação de ações externas e de deslocamentos prescritos no contorno, sofre mudança de forma ocasionada por uma transformação dependente de um parâmetro. O material será considerado homogêneo e hiperelástico, o que assegura a existência de uma densidade de energia de deformação, $\phi$, função escalar de variável tensorial, assim definida: 
$\phi: S y m \mapsto R ; \quad \mathbf{T}=\frac{\mathrm{d} \phi}{\mathrm{d} \mathbf{E}}=\phi, \mathbf{E}$,

onde Sym é o espaço dos tensores simétricos de terceira ordem (transformações lineares do $I R^{3}$ em si mesmo), e ,E é a derivada de $\phi$ em relação ao tensor $\mathbf{E}=\nabla \mathbf{u}^{\mathrm{s}}$, parte simétrica do gradiente material dos deslocamentos. Essa derivada é simplesmente um tensor, tal que, no lugar de cada componente de $\mathbf{E}$ tem-se a derivada parcial da função $\phi$, em relação à respectiva componente deste tensor.

Apresenta-se, a seguir, o conceito de mudança de forma, sendo estudado o comportamento de funções definidas na representação do sólido, no $I R^{3}$, quando sua forma é modificada (TAROCO, 1996).

\section{Conceitos básicos}

Inicialmente, o sólido é identificado com um domínio $\Omega \subset I R^{3}$, limitado pelo contorno $\partial \Omega \subset I R^{2}$. No contorno há dois subconjuntos de pontos, em geral disjuntos, o primeiro, $\partial \Omega_{\mathrm{t}}$, no qual há vetores de Cauchy [tractions] prescritos, e o segundo, $\partial \Omega_{\mathrm{u}}$, no qual há deslocamentos prescritos. A mudança de forma é descrita com o auxílio de um parâmetro adimensional, $\tau$, e de um campo vetorial, $\mathbf{v}=\mathbf{v}(\mathbf{x})$, considerado conhecido a priori, que define a transformação de $\Omega$ em um domínio modificado, $\Omega_{\tau}$, como sendo:

$\mathbf{x}_{\tau}=\mathbf{x}_{\tau}(\mathbf{x})=\mathbf{v}(\mathbf{x})$

expressão na qual o subscrito $\tau$ lembra a dependência em relação a esse parâmetro. Admite-se que a regularidade do campo $\mathbf{v}(\mathbf{x})$ seja tal que sua aplicação não afete a regularidade geométrica da configuração do sólido e de seu contorno.

O domínio modificado, $\Omega_{t}$, pode ser entendido como o que resulta de uma pequena perturbação do domínio inicial $\Omega$, e a transformação de $\Omega$ em $\Omega_{r}$ como sendo uma função do ponto $\mathbf{x}$ e do parâmetro $\tau$, de maneira que:

$\Omega \mapsto \Omega_{\tau} ; \partial \Omega \mapsto \partial \Omega_{\tau} ; \mathbf{x} \mapsto \mathbf{x}_{\tau}$

A mudança de forma é simulada, portanto, com o auxílio de uma família de transformações parametrizadas através de $\tau$, conforme mostra a figura 13. Pode-se fazer uma 
analogia entre a mudança de forma e o movimento de um corpo: para diferentes valores do parâmetro $\tau$, o domínio $\Omega_{\tau}$ é o equivalente da trajetória, na mecânica do contínuo, sendo que agora o parâmetro $\tau$ faz as vezes da variável tempo $t$ (GURTIN, 1981; MALVERN, 1969 apud TAROCO, 1996). Nesse sentido, $\Omega_{\tau}$ pode ser visto como o lugar ocupado por $\Omega$, no tempo $\tau$. Quando $\tau=0$, o domínio $\Omega_{\tau}$ reduz-se ao domínio inicial $\Omega_{0}$, que, a rigor, poderia ser qualquer configuração atualizada do movimento (mecânica do contínuo). Aqui, escolhe-se uma configuração de referência (não necessariamente a configuração de referência do movimento), denominada $\Omega$, por simplicidade, porque não está em questão o tempo verdadeiro $t$, do movimento real, e sim o parâmetro $\tau$. Daí:

$\Omega_{\tau}=\left\{\mathbf{x}_{\tau} ; \mathbf{x}_{\tau}=\mathbf{x}+\tau \mathbf{v}(\mathbf{x}), \mathbf{x} \in \Omega, \tau \in I R\right.$.

Desde que, para cada $\tau$, a mudança de forma é uma transformação biunívoca de $\Omega$ em $\Omega_{\tau}$, existe a transformação inversa, isto é:

$\Omega_{\tau} \rightarrow \Omega \quad \partial \Omega_{\tau} \rightarrow \partial \Omega$

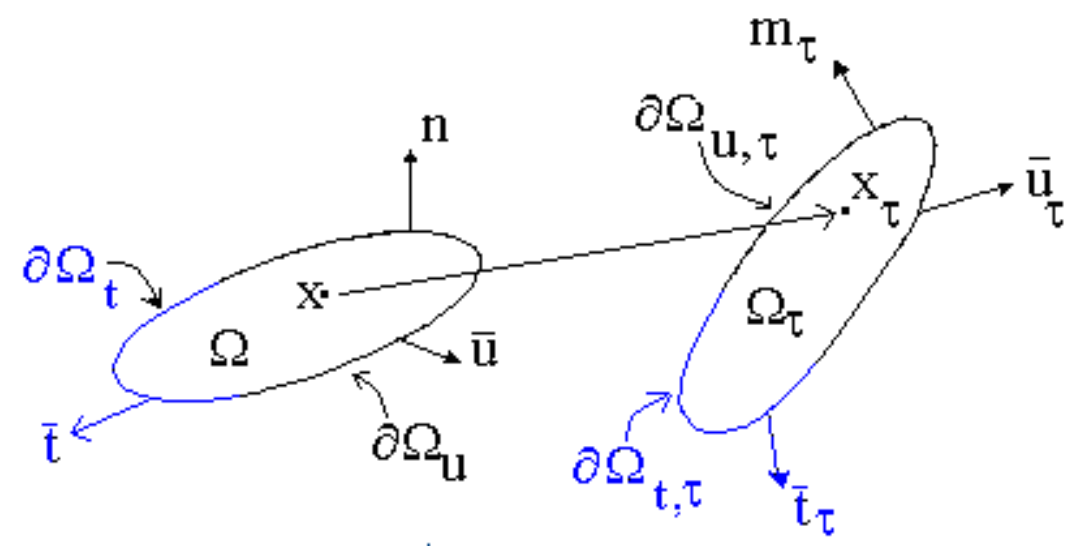

Figura 13 - Variação de forma do domínio e de seu contorno

Assim, qualquer campo (escalar, vetorial ou tensorial) associado à mudança de forma pode ser expresso, tanto por uma função definida em $\Omega$ quanto por outra definida em $\Omega_{r}$. Continuando com a analogia entre mudança de forma e movimento, da mecânica do contínuo, essas duas transformações serão chamadas de descrição material e descrição espacial, respectivamente. No caso de um deslocamento $\mathbf{u}$, por exemplo, pode-se escrever:
$\mathbf{u}=\mathbf{u}(\mathbf{x}, \tau)$
e
$\mathbf{u}_{\mathrm{r}}=\mathbf{u}_{\mathrm{r}}\left(\mathbf{x}_{\mathrm{r}}, \tau\right)$ 
onde $\mathbf{x} \in \Omega ; \tau \in \mathrm{R} \quad \mathbf{x}_{r} \in \Omega_{r}, \tau \in \mathrm{R}$

Introduz-se, a seguir, o conceito de gradiente da mudança de forma, ainda dentro da analogia proposta, isto é:

$\mathbf{F}=\nabla[\mathbf{x}+\tau \mathbf{v}(\mathbf{x})]=\mathbf{I}+\tau \nabla \mathbf{v}$

onde $\nabla$ é o gradiente material, uma operação definida no domínio inicial $\Omega$, que é a configuração atualizada, da mecânica do contínuo. Da mesma forma, (div) é a divergência material, definida no mesmo domínio. De maneira similar, (Grad) e (Div), definidos em $\Omega_{\star}$, correspondem ao gradiente e à divergência espacial, respectivamente.

Para a análise de sensibilidade à mudança de forma, será introduzido, como na mecânica do contínuo, um conceito semelhante ao de derivada de campos espaciais. Por exemplo, no caso do campo de deslocamentos $\mathbf{u}_{\mathrm{v}}$, a derivada espacial no parâmetro $\tau$, em $\tau=$ 0 , é dada por:

$\mathbf{u}^{\prime}=\left.\frac{\partial}{\partial \tau} \mathbf{u}_{\tau}\left(\mathbf{x}_{\tau}, \tau\right)\right|_{\tau=0}$

Além disso, define-se a derivada material de $\mathbf{u}$ em relação a $\tau$, na direção de $\mathbf{v}$, em $\mathbf{x}$, como sendo:

$\dot{\mathbf{u}}=\frac{\partial}{\partial \tau} \mathbf{u}_{\tau}\left(\left.\left(\mathbf{x}\left(\mathbf{x}_{\tau}, \tau\right), \tau\right)\right|_{\tau=0}=\left.\left[\frac{\partial}{\partial \tau} \mathbf{u}_{\tau}+\operatorname{div} \mathbf{u}_{\tau} \frac{\partial \mathbf{x}_{\tau}}{\partial \tau}\right]\right|_{\tau=0}=\mathbf{u}^{\prime}+\left.\mathbf{v} \operatorname{div} \mathbf{u}_{\tau}\right|_{\tau=0}\right.$

\section{Cálculo de u' no caso em que v é arbitrado como uma translação dos pontos do contorno}

Em decorrência da análise de sensibilidade, aparece no desenvolvimento, em algumas integrais no contorno, a grandeza $\mathbf{u}^{\prime}$, que é a derivada espacial do vetor deslocamento, tal como é definido na Eq. (7.122). Para simular o movimento da fissura, imagina-se que um ponto genérico $\mathbf{x}$, do sólido, sofre uma translação, segundo a transformação dada pela Eq. (7.119), da qual decorre que:

$\mathbf{x}=\mathbf{x}_{\tau}-\tau \mathbf{v}(\mathbf{x})$. 
Imaginando que, da Eq. (7.124), seja possível explicitar-se o valor de $\mathbf{x}$ com o auxílio de uma função vetorial $\boldsymbol{f}$, tem-se:

$\mathbf{x}=\boldsymbol{f}\left(\mathbf{x}_{\tau}, \tau\right)$

O objetivo, agora, é obter-se a expressão de $\mathbf{u}_{\tau}$ em função de $\mathbf{x}_{\tau}$ e $\tau$, que é a transformação sofrida pelo vetor deslocamento $\mathbf{u}=\mathbf{x}-\mathbf{X}$. Assim:

$\mathbf{u} \rightarrow \mathbf{u}_{\tau}=\mathbf{x}_{\tau}-\mathbf{X}$

onde $\mathbf{X}$ é a representação de referência do ponto $\mathbf{x}$. Daí:

$\mathbf{u} \rightarrow \mathbf{u}_{\tau}=\mathbf{x}+\tau \mathbf{v}(\mathbf{x})-\mathbf{X}$

onde $\mathbf{v}(\mathbf{x})$ é um vetor qualquer. Substituindo $\mathbf{x}$, da Eq. (7.125), na Eq. (7.127), tem-se:

$\mathbf{u}_{\tau}=f\left(\mathbf{x}_{\tau}, \tau\right)+\tau \mathbf{v}\left(f\left(\mathbf{x}_{\tau}, \tau\right)\right)-\mathbf{X}$

Então, pela definição da derivada material u , dada pela Eq. (7.122), tem-se, para um $\mathbf{X}$ fixo, a partir da Eq. (7.128), que:

$\mathbf{u}^{\prime}=\left.\frac{\partial}{\partial \tau} \mathbf{u}_{\tau}\left(\mathbf{x}_{\tau}, \tau\right)\right|_{\tau=0}=\left.\frac{\partial}{\partial \tau} f\left(x_{\tau}, \tau\right)\right|_{\tau=0}+\left.\mathbf{v}\left(f\left(x_{\tau}, \tau\right)\right)\right|_{\tau=0}$

No caso particular de interesse do problema da fratura, para simular-se a movimentação da fissura, na direção do vetor unitário e, faz-se um movimento da parte $\Gamma$ da fronteira em sentido contrário, isto é, $\mathbf{v}=$-e. Por outro lado, em $\Gamma_{\mathrm{T}}$, imagina-se que $\mathbf{v}=\mathbf{0}$. Então, as Eqs. (7.124) e (7.125) levam a:

$f(\mathbf{x}, \tau)=\mathbf{x}+\tau \mathbf{e}, \mathrm{em} \Gamma$,

e a

$\boldsymbol{f}(\mathbf{x}, \tau)=\mathbf{x}, \mathrm{em} \Gamma_{\mathrm{T}}$ 
Daí, chega-se, finalmente, com auxílio da Eq. (7.129), aos seguintes resultados:

$\mathbf{u}^{\prime}=\mathbf{e}-\mathbf{e}=\mathbf{0}, \mathrm{em} \Gamma$

e $\mathbf{u}^{\prime}=\mathbf{0}+\mathbf{0}=\mathbf{0}, \mathrm{em} \Gamma_{\mathrm{T}}$. 


\section{REFERÊNCIAS}

ARORA, J. S. An exposition of the material derivative approach for structural shape sensitivity analysis. Computer Methods in Applied Mechanics and Engineering, v.105, p.4162, 1993.

BARENBLATT, G. I. Equilibrium cracks formed during brittle fracture rectilinear cracks in plane plates. Journal of Applied Mathematics and Mechanics, v.23, n.4, p.706-721, 1959.

On finiteness conditions in the mechanics of continuous media. Static problems of the theory of elasticity. Journal of Applied Mathematics and Mechanics, v.24, n. 2, p.316-22, 1960 .

. On some general concepts of the mathematical theory of brittle fracture. Journal of

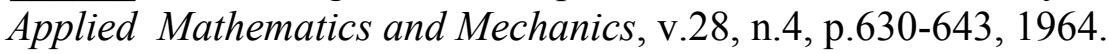

BAZANT, Z. P. Scaling of quasibrittle fracture: hypothesis of invasive and lacunar fractality, their critique and Weibull connection. International Journal of Fracture, v. 83, p. 41-65, 1997.

BAZANT, Z. P.; KAZEMI, T. K. Size dependence of concret fracture energy determined by RILEM work-of-fracture method. International Journal of Fracture, v. 51, p.121-138, 1991.

BELYTSCHKO, T.; LU, Y. Y.; GU, L. Element-free Galerkin methods. International Journal for Numerical Methods in Engineering, v.37, p.229-256, 1994.

BEREMIN, F. M. A local criterion for cleavage fracture of a nuclear pressure vessel steel. Metallurgical Transactions, v.14 A, p.2277-2287, 1983.

BETEGON, C.; HANCOCK, J. W. Two-parameter characterization of elastic-plastic crack tip field. Journal of Applied Mechanics, v. 58, p. 104-113, 1991.

BILLARDON, R.; ADAM, C.; LEMAITRE, J. Study of the non-uniform growth of a plane crack in a three-dimensional body subjected to non-proportional loadings. International Journal of Solids and Structures, v.22, n.7, p.677-692, 1986.

BISKOV, E. The calculation of stress intensity factors using the finite element method with cracked elements. International Journal of Fracture Mechanics, v.6, n.2, p.159-167, 1970.

BOLOTIN, V.V. Crack growth and fracture as instability phenomena. In: TAPLIN, D. M. R. et al. (Ed.). Advances in Fracture Resistance and Structural Integrity. New York: Elsevier, 1994, p. 83-97.

BONNET, M.; XIAO, H. Computation of energy release rate using material differentiation of elastic BIE for 3-D elastic fracture. Engineering Analysis with Boundary Elements, v. 15, p.137-149, 1995.

BROPHY, J. H.; ROSE, R. M.; WULFF, J. Ciência dos materiais: propriedades termodinâmicas, Rio de Janeiro: LTC, 1972.

BREBBIA, C. A.; DOMINGUEZ, J. Boundary elements: an introductory course. New York: McGraw-Hill Book,1989.

BUDIANSKY, B.; RICE, J. R. Conservation laws and energy release rates. Journal of Applied Mechanics, v. 40, march. 1973.

CARDOSO, J. B. Um princípio variacional de sensibilidades de $1^{\mathrm{a}}$ e $2^{\mathrm{a}}$ ordens para o projeto de estruturas não lineares. In: V ENCONTRO NACIONAL DE MECÂNICA 
COMPUTACIONAL, 5., 1997, Guimarães. Anais... Guimarães: Universidade do Minho, 1997.

CARDOSO, J. B.; ARORA, J.S. Variational method for design sensitivity analysis in nonlinear structural mechanics. AIAA Journal, v.26, n.5, p.595-603, 1988.

CARPINTERI, A. Size-scale transition ductile to brittle failure: structural response vs. crack growth resistance curve. International Journal of Fracture, v.51, p.151-186, 1991.

CIMINI JR., C. A.; TAROCO, E. O.; LAS CASAS, E. B. Fatores de intensidade de tensão em componentes estruturais mediante avaliação numérica da integral J. Rio de Janeiro, 1991. Relatório de Pesquisa $n^{0}$ 020/91, do Laboratório Nacional de Computação Científica.

CISILINO, A. P.; ALIABADI, M. H. Three-dimensional elastoplastic analysis of cracked bodies using the dual boundary element method. IV WORLD CONGRESS ON COMPUTATIONAL MECHANICS, 4., 1998. Buenos Aires. Proceedings..., Buenos Aires: Universidad de Buenos Aires, 1998. 1 CD ROM.

CUNHA, D. J. S.; TAROCO, E. O. Lei de invariância e a integral $J$ em sólidos de revolução. Rio de Janeiro, 1996. Relatório de Pesquisa n ${ }^{\circ}$ 04/96, do Laboratório Nacional de Computação Científica .

CUNHA, D. J. S. et al. Decréscimo de energia potencial em mecânica da fratura de sólidos axissimétricos mediante cálculo numérico das integrais $J$ e $M$. Rio de Janeiro, 1996. Relatório de Pesquisa $n^{\circ}$ 05/96, do Laboratório Nacional de Computação Científica.

CUNHA, D. J. S.; TAROCO, E.; FEIJÓO, R. A. Avaliação numérica da integral J para estados planos de tensão e de deformação. Rio de Janeiro, 1995. Relatório de Pesquisa $\mathrm{n}^{0}$ 02/95, do Laboratório Nacional de Computação Científica.

DeAQUINO, C. T. E.; FERRREIRA, I.; LANDES, J. D. A Mecânica da fratura no projeto de componentes estruturais fabricados com aços. Campinas: Unicamp, 1998. (Estudos de engenharia mecânica. Série Pesquisas de Engenharia de Materiais, No 98/DEMA/0001).

DIAO, X. A statistical equation of damage evolution. Engineering Fracture Mechanics, v.52, n.1, p.33-42, 1995.

DODDS, R. H.; SHIH, C. F.; ANDERSON, T. L. Continuum and micro-mechanics treatment of constraint in fracture. International Journal of Fracture, v. 64, p.101-133, 1993.

EFTIS, J. Load biaxiality and fracture: a two-sided history of complementing errors. Engineering Fracture Mechanics, v.26, n.4, p.567-592, 1987.

EFTIS, J.; SUBRAMONIAN, N.; LIEBOWITZ, H. Crack border stress and displacement equations revisited. Engineering Fracture Mechanics, v. 9, p. 189-210, 1977.

EFTIS, J.; LIEBOWITZ, H. On surface energy and the continuum thermodynamics of brittle fracture. Engineering Fracture Mechanics, v.8, n.3, p.459 - 485, 1976.

ENGLAND, A. On stress singularities in linear elasticity. International Journal of Engineering de Science, v.9, p.571-585, 1971.

ESHELBY, J. D. The continuum theory of lattice defects. In: EHRENREICH, Henri; SPAEPEN, Frans. (Ed.). Solid State Physics. New York: Academic Press, 1956. v.3, p. 79-114.

The energy-momentum tensor in continuum mechanics. In: KANNINEN, M. F. et al. (Ed.). Inelastic Behavior of Solids. New York: McGraw-Hill, 1970. 
1975.

. The elastic energy-momentum tensor. Journal of Elasticity, v. 5, n. 3-4, p. 321-335,

FAUCHER, B. Crack length and $J$-integral expressions for specimens loaded in tension. Journal of Testing and Evaluation, v.22, n.1, p.30-35, 1994.

FEIJÓO, R. A. Introducción a Mecanica del Continuo. Rio de Janeiro: CBPF, 1972.

GALILEI, G. Diálogos acerca de dos nuevas ciencias, Tradução de José San Román Vilassante. Buenos Aires: Losada,1945.

GRIFFITH, A. A. The phenomena of rupture and flow in solids. Philosophical Transactions of the Royal Society, Series A, 221, p.163-198, 1921.

GRIFFITH, A. A. The theory of rupture. In: FIRST INTERNATIONAL CONGRESS OF APPLIED MECHANICS, 5.,1924, Delft. Proceedings... Delft, 1924. p.55-63.

GUIMARÃES, S.; TELLES, J. C. F. On the hyper-singular boundary-element formulation for fracture-mechanics applications. Engineering Analysis with Boundary Elements, v. 13, p.353363, 1994.

GURTIN, M. E. On the energy release rate in quasi-static elastic crack propagation. Journal of Elasticity, v.9, n.2, p.187-195,1979.

An introduction to continuum mechanics: mathematics in science and engineering.

New York: Academic Press, 1981.

HERNÁNDEZ-GÓMEZ, L. H.; RUIZ, C. Assessment data for dynamic crack initiation under shock pressure loading: part 1 - Experiment. Theoretical and Applied Fracture Mechanics, $\mathrm{n}$. 19, p. 75-83. 1993.

HILLERBORG, A. Application of the fictitious crack model to different types of materials. International Journal of Fracture, v. 51, n.2, p.95-102, 1991.

INGLIS, C. E. Stresses in a plate due to the presence of cracks and sharp corners.

Transactions of the Royal Institution of Naval Architects, v. 60, p.219-241,1913.

IRWIN, G. R. Analysis of stress and strains near the end of a crack traversing a plate. Journal of Applied Mechanics, v.24, n. 3, p. 361-364,1957.

JEULIN, D. Modèles probabilistes de rupture des materiaux hétérogènes: efetts de taille et effets d'échelle. Annales des Ponts et Chaussées, n.74, 1995.

KEUM, D. J.; KWAK, B. M.. Energy release rates of crack kinking by boundary condition sensitivity analysis. Engineering Fracture Mechanics, v.41, n.6, p.833-841, 1992.

KNOTT, J. F. The science and engineering of fracture. Materials Science, New York, v. 29, n. 3, p. 229-248, may 1993. Advances in fracture résistence and structural integrity: select papers from $8^{\text {th }}$ Int. Conf. on Fracture (ICF8), Ukraine, 08-14 jun. 1993, p.13-50.

KNOWLES, J. K.; STERNBERG, E. On a class of conservation laws in linearized and finite elastostatics. Archive for Rational Mechanics and Analysis, v.44, n.3, p.187-211, 1972.

KOLEDNIK, O.; TURNER, C. E. Application of energy dissipation rate arguments to ductile instability. Fatigue and Fracture of Engineering Materials and Structures, v.17, n.10, p.11291145, 1994.

KRAJCINOVIC, D.; MASTILOVIC, S. Some fundamental issues of damage mechanics. Mechanics of Materials, v.21, p.217-230, 1995. 
KRÄMER, D. On the applicability of the $I$-integral in Fracture Mechanics. Archive of Applied Mechanics, v. 63, p.551-555, 1993.

LANCZOS, C. The Variational Principles of Mechanics, 4 ed. New York: Dover Publications, 1986.

LANDES, J. D.; ZHOU, Z.; LEE, K.; HERERA, R. Normalization method for developing J-R curves with the LMN function. Journal of Testing and Evaluation, v.19, n.4, p. 305-311, 1991.

LAVIT, I. M. Boundary integral equation for a curvilinear boundary crack. Journal of Applied Mathematics and Mechanics, v.58, n.1, p.161-170,1994.

LEMAITRE, J.; J-L. CHABOCHE. Mechanics of solid material. Cambridge: Cambridge University Press, 1990.

LEWIS, G. N.; RANDALL, M. Thermodynamics. 2.ed. New York: McGraw-Hill, 1961.

LIEBOWITZ, H. et al. Computational fracture mechanics: research and application.

Engineering Fracture Mechanics, v.50, n.5-6, p.653-670,1995.

LIU, H. W. A review of fatigue crack growth analysis. Theoretical and Applied Fracture Mechanics, v.16, p.91-108, 1991.

MAITI, S. K. Finite element computation of the strain energy release rate for kinking of a crack. International Journal of Fracture, v.43, p.161-174, 1990.

MALVERN, L. E. Introduction to the mechanics of a continuous medium. Englewood Cliffs: Prentice-Hall, 1969.

MATSUO, Y. Statistical theory for multiaxial stress states using Weibull's three-parameter function. Engineering Fracture Mechanics, v. 14, p. 527-538, 1981.

MINAMI, F. et al. Estimation procedure for Weibull parameters used in the local approach. International Journal of Fracture, v.54, p.197-210, 1992.

MINDLIN, R. D. Force at a point in the interior of a semi-infinite solid. Physics, v.7, p.195202, 1936.

MIRENKOV, V. E. Finite stress in fracture mechanics. Engineering Fracture Mechanics, v. 48, n.1, p.63-68, 1994.

MÜLLER, W. H.; HERRMANN, G.; GAO, H.. Elementary theory of cracked beams.

Theoretical and Applied Fracture Mechanics, v.18, p.163-167, 1993.

NGUYEN, Q. S. Bifurcation and post-bifurcation analysis in plasticity and brittle fracture. Journal of the Mechanics and Physics of Solids, v.35, n.3, p.303-324, 1987.

NOGUCHI, H.; SMITH, R. A. An analysis of a semi-infinite solid with three dimensional cracks. Engineering Fracture Mechanics, v.52, n.1, p.1-14, 1995.

NUSSENZVEIG, H. M. Curso de física básica. v.2. São Paulo: Edgard Blücher, 1990.

OLIVER, J. Continuum modelling of strong discontinuities in solid mechanics using damage models. Computational Mechanics, v.17, p.49-61, 1995.

OROWAN, E. Fundamentals of. brittle behavior in metals .In: MURRAY, W. M. Fatigue and Fracture of Metals, New York: Wiley, 1950. p 139-157.

OWEN, D. R. J.; FAWKES, A. J. Engineering fracture mechanics: numerical methods and applications. Swansea: Pineridge Press, 1983. 
OWEN, T. H.; PIN TONG; LUK, C. Elastic crack analysis by a finite element hybrid method,. Procedings Third Air Force Conference on Matrix Methods in Structural Mechanics. Daytona: NTIS, 1971.

PIAN, T. H. H.; TONG, P.; LUK,C. H. Elastic crack analysis by a finite element hybrid method. [S.1.: s.n.], 1991.

PLANAS, J.; ELICES, M. Nonlinear fracture coesive materials. International Journal of Fracture, v.51,n.2, p.139-157,1991.

PLANAS, J.; ELICES, M.; GUINEA, G. V. Cohesive cracks versus nonlocal models: closing the gap. International Journal of Fracture, v.63, p.173-187, 1991.

RICE, J. R. A path independent and the approximate analysis of strain concentration by notches and cracks. Journal of Applied Mechanics, v.35, p.379-86, 1968.

RICE, J. R.; THOMSON, R. M .Ductile vs. brittle behaviour of crystals. Philosophical Magazine, v.29, p.73-97.1974.

RICE, J. R.; SORENSEN, E. P. Continuing crack-tip deformation and fracture for planestrain crack growth in elastic-plastic solids. Journal of the Mechanics and Physics of Solids, v.26, p.163-186, 1978.

RIGBY, R. H.; ALIABADI, M. H. . Mixed-mode $J$-integral method for analysis of 3D fracture problems using BEM. Engineering Analysis with Boundary Elements, v. 11, p.239256, 1993.

ROCHA. João Augusto de Lima. Contribuição para a teoria termodinamicamente consistente da fratura, 1999. Tese (Doutorado em Engenharia de Estruturas) - Escola de Engenharia de São Carlos, Universidade de São Paulo, São Paulo,1999.

ROCHA, J. A. de L.; BARREIRO, J. C.; PROENÇA, S. P. B. Condição fundamental para a compatibilização da mecânica da fratura com a mecânica do contínuo. In: SIMPÓSIO BRASILEIRO SOBRE TUBULAÇÕES E VASOS DE PRESSÃO, 9, 1996, Rio de Janeiro. Anais..., Rio de Janeiro: PUC, 1996, p.177-181.

ROCHA J. A. de L.; PROENÇA, S. P. B. On the necessary condition for the validity of the continuum mechanics' principles in fracture mechanics. In: FIFTH INTERNATIONAL CONFERENCE ON COMPUTATIONAL PLASTICITY, 5, 1997, Barcelona. Proceedings... Barcelona, CIMNE: 1997, p.381-386.

ROCHA J. A. L.; VENTURINI, W. S. Critério termodinamicamente consistente para previsão de início de fratura. In: CONGRESSO LATINO-AMERICANO SOBRE MÉTODOS COMPUTACIONAIS 18, 1997, Brasília. Anais... Brasília: UNB, 1997, v.3. p.1137-1145.

RUGGIERI,C.; DODDS, R. H Transferability of elastic-plastic fracture toughness $\left(J_{\mathrm{c}}\right)$ using the Weibull stress approach. São Paulo, 1997. Relatório Técnico, BT-PNV-34 EPUSP.

. Probabilistic modeling of brittle fracture including 3-D effects on constraint loss and ductile tearing. Journal de Physique, v.6, p. 353-362, 1996 .

. A transferability model for brittle fracture including constraint and ductile tearing effects: a probabilistic approach. International Journal of Fracture, v. 79, n. 4, p.309340,1996b.

RUGGIERI, C. et al. Transferability of elastic-plastic fracture toughness $\left(J_{\mathrm{c}}\right)$ using the Weibull stress approach. São Paulo: EPUSP, 1997. Publicação técnica (BT-PNV-34) do Departamento de Arquitetura Naval e Engenharia Oceânica da USP. 
SCHÜTZ, W. A History of fatigue. Engineering Fracture Mechanics, v.54, n.2, p.263-300, 1996.

SHE, S. et al. Statistical theory for predicting the failure of brittle materials. Journal of Applied Mechanics, v.58, p.43-49, mar. 1991.

SPENCER, A. J. M. On the energy of the Griffith crack. International Journal of Engineering Science, v.3, p.441- 449, 1965.

STEVENS, R. N. ;GUIU, F. Energy balance concepts in the physics of fracture. Proceedings of Royal Society, v. 435, p.169-183, 1991.

TAROCO, E.; CIMINI, C. A.; LAS CASAS, E. Fracture mechanics via sensitivity analysis and numerical evaluation of $J$ integral in cracked sheets. Journal of Constructional Steel Research, v.28, n. 2, p.153-166, 1994.

TAROCO, E. ; FEIJÓO, R. A. Rate of change of J-Rice integral in elastic fractured membranes. THE FIFTH PAN AMERICAN CONGRESS OF APPLIED MECHANICS 5.,1997, Porto Rico. Proceedings...Porto Rico,1997.

. Variational formulations in shape sensivity analysis and fracture mechanics. In: SYMPOSIUM DEDICATED TO THE 70TH BIRTHDAY OF WOLF ALTMAN, 1996, Rio de Janeiro. Recent Developments in Solid Mechanics. Rio de Janeiro: Laboratório Nacional de Computação Científica/CNPq, 1996, p. 61-69.

TIMOSHENKO, S. P. History of the Strength of Materials. New York: McGraw-Hill Book, 1953.

TURNER, C. E.; KOLEDNIK, O .Application of energy dissipation rate arguments to table crack growth. Fatigue \& Fracture of Engineering. Material \& Structures, v.17, n.10, p.11091127, 1994.

VALENTE, S. Heuristic softening strip model in the prediction of crack trajectories.

Theoretical and Applied Fracture Mechanics, v.19, p.119-125, 1993.

VENTURINI, W. S. Dual reciprocity BEM for non-linear problems. Boundary Elements Communications, v.6, p.259-263. 1995a.

. Análise de problemas de fratura coesiva usando o método dos elementos de contorno. In: CONGRESSO IBERO LATINO-AMERICANO SOBRE MÉTODOS COMPUTACIONAIS EM ENGENHARIA,16,1995, Curitiba. Anais... Curitiba: UFRP, 1995b, p.112-118.

VOLTERRA, V. Sur l'équilibre de corps élastique multiplement connexes. Annales École Normale, v. 24, p.401-517,1907.

WANG, B.; HWANG, K-C. $J_{1}$-integral for non- $J$-controlled crack growth. Engineering Fracture Mechanics, v.47, n.1, p.49-57, 1994.

WANG, G. S. The plasticity aspect of fatigue crack growth. Engineering Fracture Mechanics, v.46, n.6, p.909-930, 1993.

WEIBULL, W . A statistical distribution function of wide applicability. Journal of Applied Mechanics, v. 18, n.3, 1951.

A statistical theory of the strength of materials. Ing. Vetenskaps Akad. Handl, v. 151, n. 1, p. 1-45, 1939.

WEICHERT, R.; SCHÖNERT, K. Heat generation at the tip of a moving crack. Journal of Mechanics and Physics of Solids, v.26, p.151-161, 1978. 
WESTERGAARD, H. M. Bearing pressures and cracks. Journal of Applied Mechanics, v.6, p.49-53, 1939.

WILLIS, J. R. A comparison of the fracture criteria of Griffith and Barenblatt. Journal of Mechanics and Physics of Solids, v.15, p.151-162, 1967.

ZAMANI, N. G.; SUN, W. A direct method for calculating the stress intensity factor in BEM. Engineering Analysis with Boundary Elements, v.11, p.28, 1993.

ZHANG, C.; KARIHALOO, B. L. A thermodynamic framework of fracture mechanics. Engineering Fracture Mechanics, v.46, n.6, p.1023-1030, 1993. 


\section{APÊNDICE A - PROGRAMA AUTOMÁTICO PARA O CÁLCULO DA INTEGRAL $J$ E DO PARÂMETRO TERMODINÂMICO DE FRATURA $\left(G_{t}\right)$}

Desenvolvido com a finalidade de ilustrar as possibilidades de utilização prática do critério termodinâmico de fratura, formulado teoricamente no capítulo 4, o programa automático Elcfrat, em linguagem Fortran, aplica-se a problemas de elasticidade plana. A ideia que presidiu sua concepção foi a de testar procedimentos de cálculo baseados na análise de sensibilidade à variação de forma do domínio, tanto aquele que permite a obtenção da integral $J$, a partir do tensor momentum-energia de Eshelby (1975) quanto o que calcula $G_{\mathrm{t}}$ a partir do tensor diagonal ao qual se chegou no presente trabalho, cujas componentes são iguais à energia de deformação. Embora a teoria tenha sido desenvolvida em sua forma mais geral, isto é, para o caso tridimensional, ambos os tensores são aqui particularizados para problemas bidimensionais, sendo o programa Elcfrat elaborado para estes.

O programa utiliza o BEM como ferramenta de cálculo numérico. A efíciência de programação foi bastante melhorada, ao tirar-se proveito da propriedade da integral $J$ da independência do caminho. Para isso, ia-se variando o número de pontos de integração de Gauss-Legendre, na programação, enquanto se calculava a integral $J$ para distintos caminhos. A eficiência ia sendo aferida, à medida que os resultados se tornavam mais próximos entre si, quando alternativas de caminhos elípticos alternativos passavam a ser, sucessivamente, utilizadas. Considerou-se a eficiência satisfatória quando o número de pontos de Gauss chegou a 48, para a integração no circuito elíptico, o que se justifica pelo alto grau de singularidade das integrais envolvidas. Para além desse número de pontos de Gauss não mais foi percebida melhoria significativa na precisão, para além de três algarismos significativos, isto após já se ter verificado um sensível aumento na eficiência do cálculo de $J$, mediante a utilização da técnica de subelementação. Usou-se um elemento de contorno retilíneo, isoparamétrico, com funções de interpolação lineares.

Ao final, conseguiu-se gerar uma ferramenta com perspectiva de ampla utilização tecnológica, para a caracterização de estruturas à fratura, tanto por calcular bem a integral $J$, quanto por aplicar a metodologia desenvolvida no presente trabalho, que tira proveito da vocação natural do BEM, no cálculo de integrais sobre caminhos situados no plano médio de uma chapa.

O programa Elcfrat contém dois subprogramas acoplados: o primeiro, que calcula o tensor tensão, o tensor deformação e o tensor gradiente do vetor deslocamento, em um problema bidimensional contendo uma ou mais trincas no domínio; e o segundo, um pós- 
processador desses valores, para o cálculo da integral $J$ e para a aplicação do esquema termodinamicamente consistente, baseado no parâmetro $G_{\text {t }}$.

A inovação trazida neste trabalho está contida, basicamente, no segundo subprograma, cuja generalização para o caso tridimensional, completamente geral, não é muito difícil. Assim, desde que o tensor tensão, o tensor gradiente de deslocamento e o tensor deformação sejam fornecidos, até mesmo por um programa automático não especializado em fratura, o segundo subprograma do Elcfrat se encarregará do cálculo de $J$ e de $G_{\text {t }}$.

\section{Saída do programa automático, do valor da integral $J$, do valor limite de $G_{t}$ e do ângulo formado pela direção do avanço da fissura com o eixo $x_{1}$}

Mostra-se, a seguir, o trecho final de uma saída de resultados do programa Elcfrat, com o intuito de interpretar-se, no caso do exemplo processado, o fato de saírem, para um dado valor crítico de $G_{\mathrm{t}}$, duas soluções para a direção dos ramos de avanço da fissura. De fato, o programa reflete o resultado teórico, elaborado no capítulo 4, segundo o qual o problema da determinação do valor desses ângulos poderia ter: duas, uma, ou nenhuma solução, a indicar três possibilidades excludentes entre si: 1) a fissura avança, segundo caminhos bifurcados; 2) a fissura avança, sem se bifurcar e 3) a fissura não avança.

Fornecido ao programa o valor crítico de $G_{\mathrm{t}}$, isto é, $\gamma_{\mathrm{E}}$ a ser obtido experimentalmente para um dado material, o resultado do processo de cálculo automático indica, ao final, se a fissura pára; continua sem se bifurcar ou, ainda, se ela se bifurca.

No caso abaixo, o resultado indica que o valor crítico do parâmetro $G_{\mathrm{t}}$ está muito próximo do valor limite da estrutura. Para este caso, o valor crítico fornecido ao programa foi $.2437034 \mathrm{E}+04 \mathrm{~J} / \mathrm{m}$.

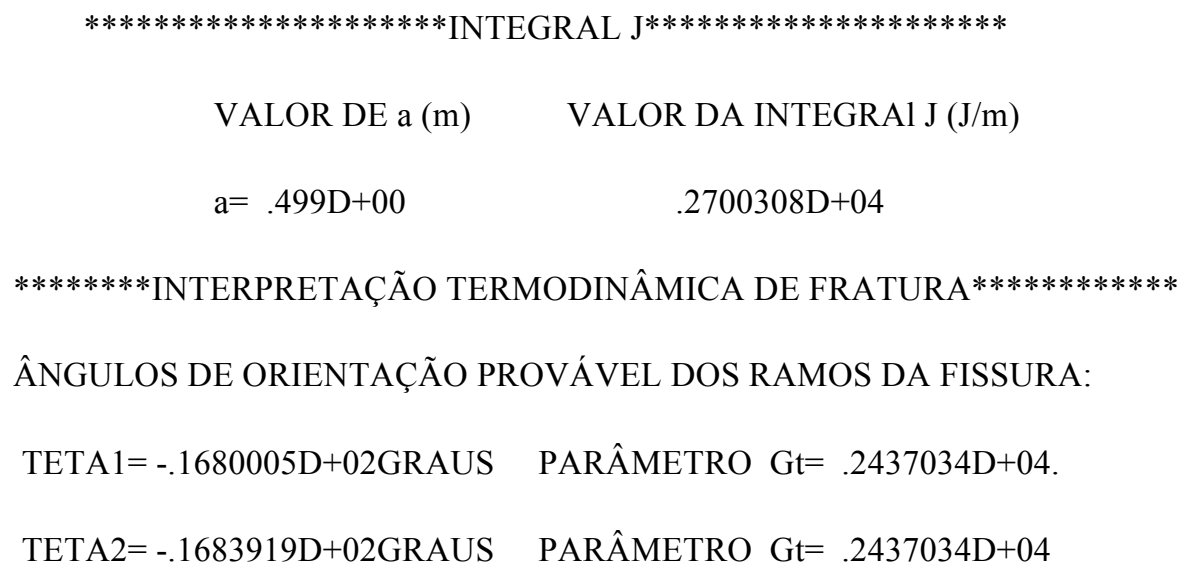


No caso seguinte, o valor dado para $G_{\mathrm{t}}$ crítico, por ter sido um pouco maior, isto é, $.3000000 \mathrm{D}+04 \mathrm{~J} / \mathrm{m}$, levou a fissura a não avançar, tal como mostra o relatório abaixo:

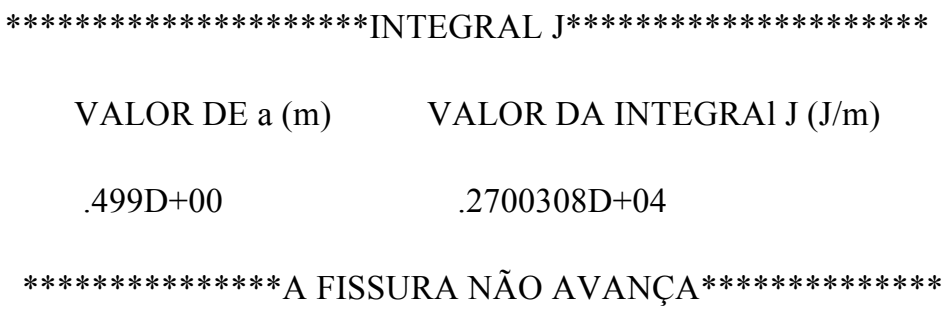

A integral J vale $.2700308 \mathrm{D}+04 \mathrm{~J} / \mathrm{m}$.

\section{Exemplos de aplicação}

Os resultados abaixo são obtidos com o auxílio do programa automático Elcfrat. Os primeiros exemplos correspondem a dois casos de carregamento para uma mesma haste, constituída de material elástico linear (figuras 14 e 15), contendo um entalhe na forma de ângulo agudo.

Antes das considerações sobre fratura, mostra-se, com o auxílio das figuras 17 e 18, o resultado do experimento numérico, no qual se ressalta a tendência à singularidade da tensão, na vizinhança da extremidade da fissura. O exemplo 1 corresponde ao caso da tração simples sobre uma haste. Já no Exemplo 2, a haste é submetida a uma força tangencial distribuída na extremidade livre. É de se esperar que, quanto mais as dimensões da peça, no plano, tendam para valores infinitos, e o ângulo entre as faces do entalhe se aproxime de zero, a singularidade da tensão torne-se próxima de $1 / \sqrt{ } r$, tal como prevê a teoria da elasticidade. Nessa situação, de acordo com Irwin (1957), podem-se obter os fatores de intensidade de tensão $K_{\mathrm{I}}$ e $K_{\mathrm{II}}$, a partir da consideração de que os coeficientes das respectivas parcelas singulares das expressões das tensões, em casos como os dos exemplos 1 e 2 .

EXEMPLO 1- HASTE SUBMETIDA À TRAÇÃO SIMPLES (FIGURA 11) e EXEMPLO 2. HASTE SUBMETIDA A FORÇA TANGENCIAL NA EXTREMIDADE LIVRE (FIGURA 12)

DADOS:

NÚMERO DE NÓS DO CONTORNO = 51

NÚMERO DE PONTOS INTERNOS $=48$

NÚMERO DE PARES DE NÓS DUPLOS= 13 
NÚMERO DE ELEMENTOS DE COTORNO= 38

CARGA DISTRIBUÍDA NA EXTREMIDADE LIVRE $=.2000000 \mathrm{E}+09 \mathrm{~Pa}$

MÓDULO DE ELASTICIDADE TRANSVERSAL $=.8000000 \mathrm{E}+11 \mathrm{~Pa}$

COEFICIENTE DE POISSON $=.2000000 \mathrm{E}+00$

ESPESSURA DA CHAPA $=0.3000000 \mathrm{E}-2$

VALOR INICIAL DO PARÂMETRO TERMODINÂMICO CRÍTICO GAMMA $=.5000000 \mathrm{E}+05$

TOLERÂNCIA DE GAMA e $=.3000000 \mathrm{E}-03$

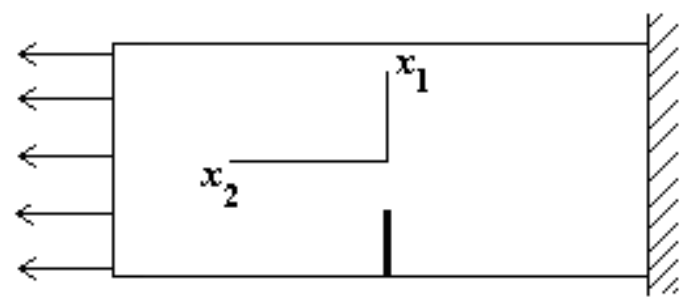

Figura 14 - Exemplo 1

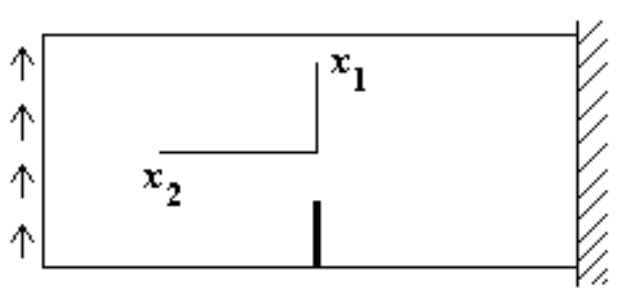

Figura 15 - Exemplo 2

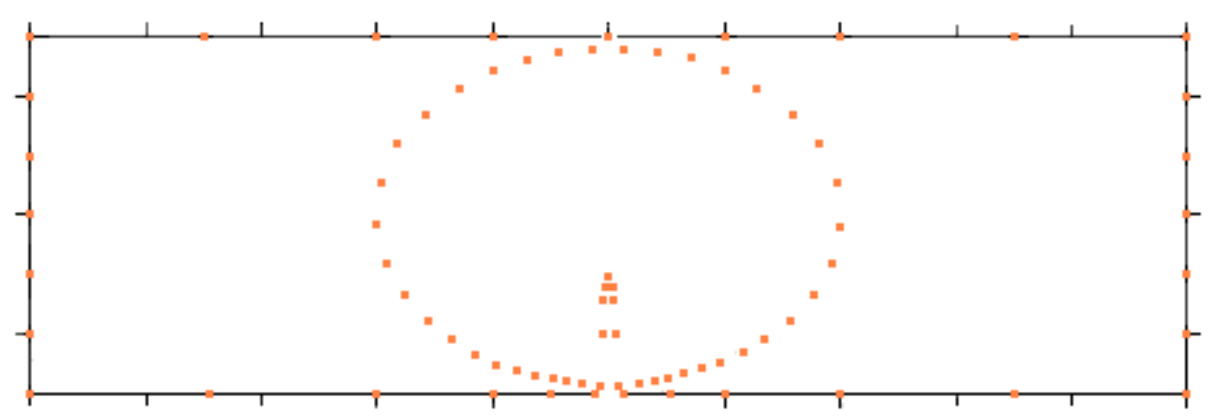

Figura 16 - Haste dos Exemplos 1 e 2, indicando os pontos de integração do contorno elíptico e os nós do contorno

Observações: i) A unidade de comprimento adotada para as medidas indicadas na figura 15 é o metro e; ii) Diferentemente do que é feito nos textos sobre fratura, a unidade considerada para a integral $J$ é Joule/metro ou Newton, em razão de incluir-se no cálculo, por conveniência, a multiplicação pela medida da espessura da chapa (constante), o que é excluído da definição clássica de Rice (1968). Esta opção foi escolhida com o intuito de fazer com que seja uma só a unidade de medida da integral $J$ e do parâmetro termodinâmico $G_{\mathrm{t}}$, da forma como são definidos para o caso geral, de sólidos tridimensionais, no capítulo 5 . 


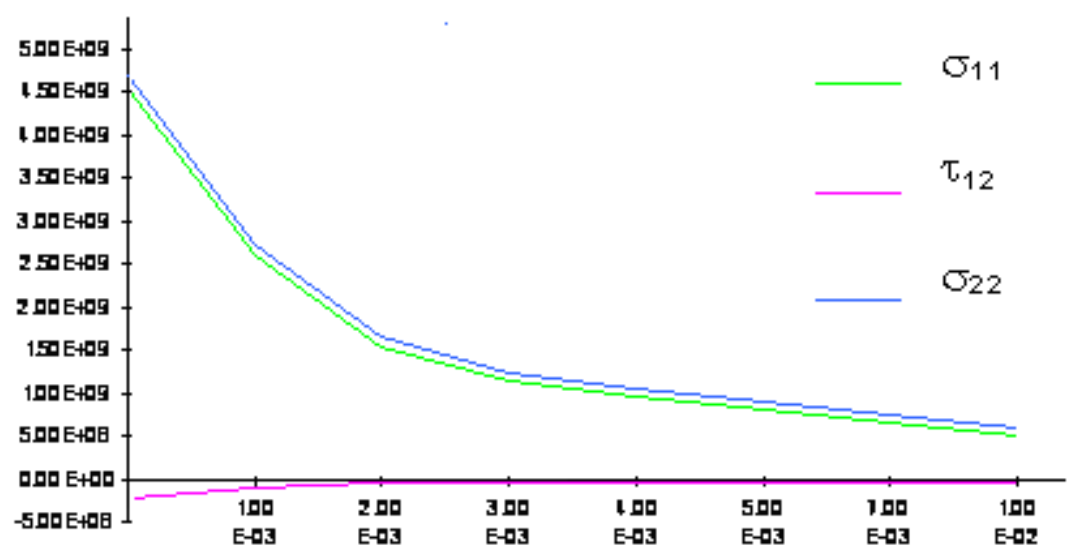

Figura 17- Componentes $\sigma_{22}, \sigma_{11}$ e $\tau_{12}$ como funções de $r$ no exemplo 1

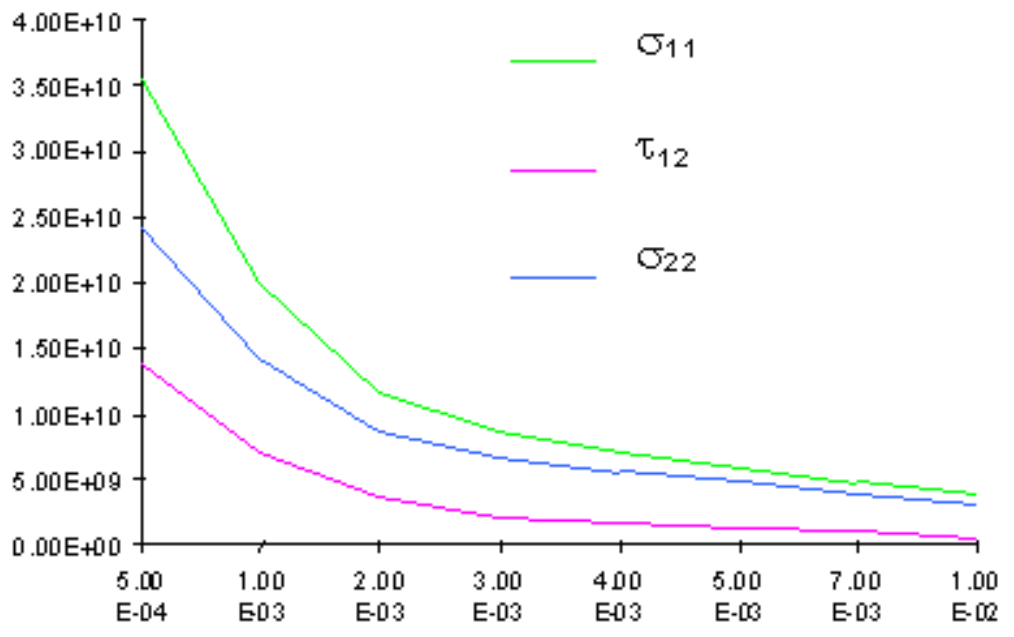

Figura 18 - Componentes $\sigma_{22}, \sigma_{11}$ e $\tau_{12}$ como funções de $r$ no exemplo 2

A seguir, apresentam-se os valores da integral $J$ calculados para o caso dos exemplos 1 , e 2, respectivamente, para diversos valores da medida do semieixo maior $(a)$, conformando os caminhos elípticos sobre os quais é calculada aquela grandeza. De acordo com a tabela 1, verifica-se a propriedade da independência do caminho da integral $J$, com boa aproximação.

Tabela 1-Valores da integral $J$ calculada pelo BEM (ELCFRAT) para o caso de uma haste com entalhe em ângulo $\left(\theta=11,42^{\circ}\right.$; abertura inferior $\left.=2.10^{-2} \mathrm{~m}\right)$

\begin{tabular}{|c|c|c|}
\hline $\begin{array}{c}\text { Valor de } a \\
\mathrm{~m}\end{array}$ & $\begin{array}{c}\text { Exemplo } 1 \\
\mathrm{~J} / \mathrm{m}\end{array}$ & $\begin{array}{c}\text { Exemplo 2 } \\
\mathrm{J} / \mathrm{m}\end{array}$ \\
\hline 0,250 & 629,749 & 21774,2 \\
\hline 0,300 & 630,183 & 21809,2 \\
\hline 0,400 & 630,640 & 21872,5 \\
\hline 0,450 & 630,457 & 21980,4 \\
\hline 0,490 & 630,156 & 22253,8 \\
\hline
\end{tabular}


A tabela 2, na sequência, dá uma ideia da influência do tipo do entalhe sobre a integral $J$. Para os mesmos Exemplos 1 e 2, obtém-se, agora, o resultado quando o entalhe tem a forma retangular. Na comparação entre as tabelas 1 e 2, é curioso observar que, mesmo para uma abertura muito pequena $\left(2 \times 10^{-4} \mathrm{~m}\right)$ do entalhe retangular, o fato de a fissura ter um trecho horizontal reto, em seu final, e não um ponto, faz com que o valor da integral $J$, tanto no Exemplo 1, quanto no Exemplo 2, sofra uma alteração significativa, segundo uma razão próxima de $4: 1$.

Tabela 2 - Valores da integral $J$, calculada pelo BEM (Elcfrat) nos exemplos 1 e 2

Entalhe retangular (abertura $=10^{-4} \mathrm{~m}$, comprimento $=10^{-1} \mathrm{~m}$ )

\begin{tabular}{|c|c|c|}
\hline Valor de $a$ & Ex 1: Tração simples: & Ex 2: Força tangencial \\
\hline 0,250 & 144,982 & 5698,08 \\
\hline 0,300 & 144,976 & 5695,27 \\
\hline 0,400 & 144,954 & 5681,16 \\
\hline 0.450 & 144,931 & 5664,14 \\
\hline 0.490 & 144,903 & 5643,33 \\
\hline
\end{tabular}

O Exemplo 3, ilustrado pela figura 16, é útil a uma comparação com o resultado obtido para a integral $J$, por Cunha e outros (1995), através do MEF. Trata-se de uma chapa de espessura constante, com uma fissura reta, central, cuja simetria permite que a análise seja realizada na quarta parte da chapa, de acordo com a figura 16. Na resolução via BEM, tomase metade do caminho, isto é uma semielipse de pontos de Gauss-Legendre, em torno de uma das extremidades da fissura.

EXEMPLO 3: HASTE TRACIONADA, CONTENDO UMA FISSURA INTERNA

DADOS:

NÚMERO DE NÓS DO CONTORNO = 44

NÚMERO DE PONTOS INTERNOS $=48$

NÚMERO DE PARES DE NÓS DUPLOS

NÚMERO DE ELEMENTOS DE CONTORNO=39

CARGA DE TRAÇÃO, DISTRIBUÍDA NA EXTREMIDADE LIVRE $=.1000000 \mathrm{E}+09 \mathrm{~Pa}$

MÓDULO DE ELASTICIDADE TRANSVERSAL $=.8080000 \mathrm{E}+11$ 
COEFICIENTE DE POISSON $=.2300000 \mathrm{E}+00$

ESPESSURA DA CHAPA $=0.1000000 \mathrm{E}-2$

VALOR INICIAL DO PARÂMETRO TERMODINÂMICO CRÍTICO GAMMA $=.5000000 \mathrm{E}+05$

TOLERÂNCIA DE GAMA $\mathrm{e}=.3000000 \mathrm{E}-03$

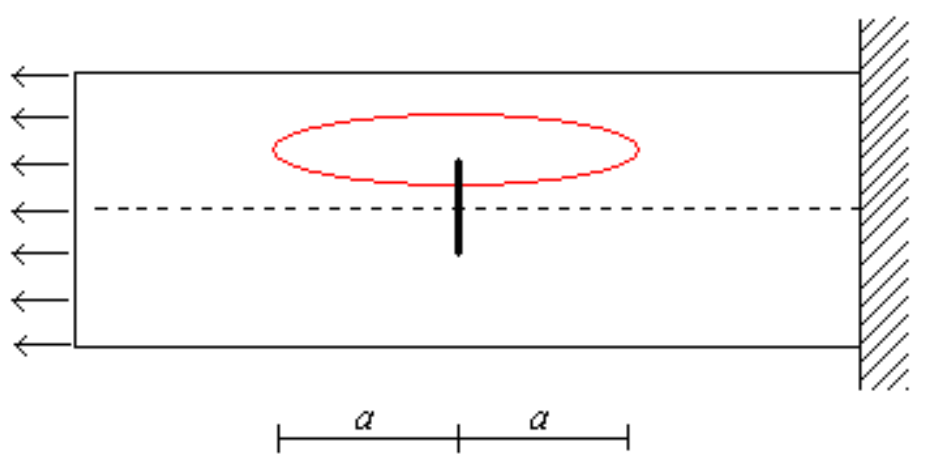

Figura 19 - Exemplo 3: Peça com fissura central

$\mathrm{Na}$ figura 20 estão indicados os nós dos elementos de contorno e os pontos de integração situados na semi-elipse da parte superior esquerda da figura 19. Sendo assim, o valor real da integral $J$, referente a uma extremidade da fissura, deverá ser igual a duas vezes o valor calculado pelo Elcfrat (os valores colocados na terceira coluna da tabela 3, já estão duplicados). Observe-se que, com esse programa, só será possível o cálculo da integral $J$, no caso de fissura interna (figura 19), quando o carregamento for simétrico em relação a um eixo, tal como a linha pontilhada longitudinal daquela figura. Assim, ao ser subdividida a peça, com base na simetria, para efeito de cálculo, o seja de tal forma a simular-se uma fissura iniciando-se no contorno. No caso, o contorno será a linha pontilhada longitudinal da figura 16.

A seguir, apresentam-se, na tabela 3, os resultados referentes ao exemplo 3, comparando-os com os obtidos para a integral $J$, por Cunha e outros (1995). Nesse trabalho foi utilizada uma malha refinada de elementos finitos para efetuar a análise do equilíbrio, realizando o cálculo da integral $J$, em pós-processamento, com base no recurso ao tensor momentum energia de Eshelby. Três caminhos de integração foram utilizados nesse estudo. 


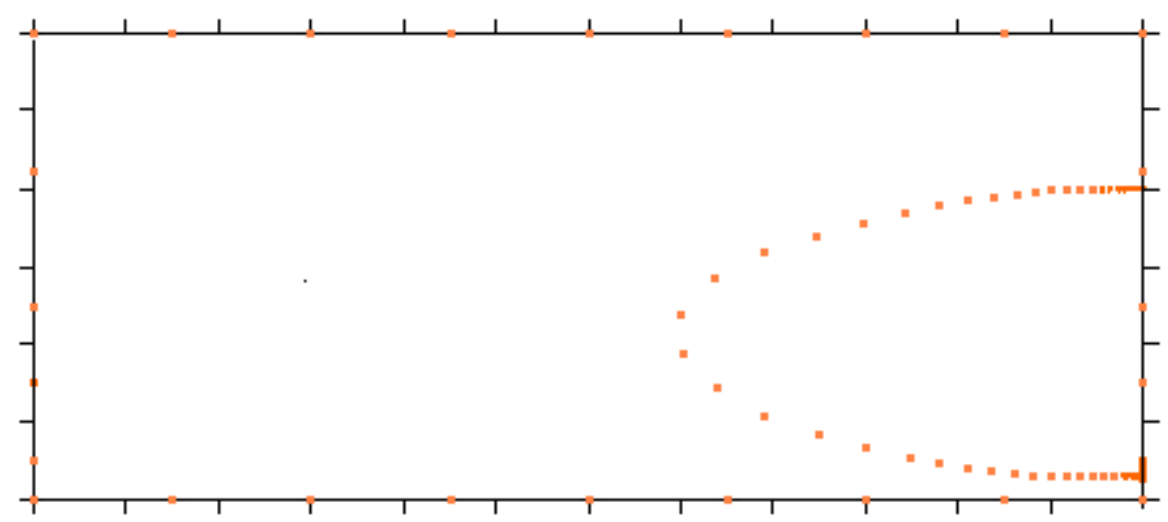

Figura 20 - Exemplo 3: Caminho da integral $J$ em torno de uma das extremidades da fissura

A malha II, tal como referida no citado trabalho, é obtida por um processo adaptativo, ou seja, é uma malha que permite boa representação das tensões próximo à trinca. São considerados elementos triangulares de 3 nós, e depois elementos triangulares de 6 nós. Consta, ainda, daquele trabalho, a referência a um valor de $K_{\mathrm{I}}$ calculado para o mesmo problema, tomado de Owen e Fawkes (1983), que seria $K_{\mathrm{I}}=560$ (unidade: ?), o que, pela expressão $J=K_{\mathrm{I}}^{2} / \mathrm{E}$, no caso do Exemplo 3, daria o valor de $J=1,4933$. No entanto, não fica claro, com a consulta à fonte acima indicada, porque esse valor de $K_{\mathrm{I}}$ pode ser tomado como correto. Os resultados, para o cálculo da integral $J$, com base no programa Elcfrat, que aparecem na última coluna da tabela 3, são obtidos para três caminhos elípticos distintos, e revelam, com razoável aproximação, a propriedade da independência do caminho da integral $J$. Porém, se comparados com os valores apresentados por Cunha e outros (1995), eles diferem entre si em torno de 3\% até $9 \%$. Como há pouco foi dito, o valor de $J=1,4933$, tomado do referido trabalho, como base para avaliação da eficiência, por ser obtido a partir de $K_{\mathrm{I}}$, fator de intensidade de tensão do modo de abertura, não pode ser considerado como a expressão mais próxima da verdade. Assim, pode-se aceitar que a tabela 3 revele uma razoável aproximação entre os resultados baseados no BEM e no MEF, para a integral $J$. Quanto à questão do sistema de unidades, embora não haja referência ao que foi utilizado por Cunha e outros (1995), e nem mesmo seja explicitada a unidade de medida de $K_{\mathrm{I}}$, o recurso foi admitir-se que o exemplo apresentado deveria estar algo próximo de um que foi incluído em Cimini Junior e outros (1991), no qual a unidade de força adotado é o Newton, e a unidade de comprimento é o milímetro. 
Tabela 3 - Comparação do cálculo de $J(\mathrm{~J} / \mathrm{M})$ pelo MEF e pelo BEM

\begin{tabular}{|c|c|c|c|}
\hline & CUNHA et al (1995) & CUNHA et al (1995) & Presente trabalho \\
\hline Caminho 1 & 1,4520 & 1,4120 & - \\
\hline Caminho 2 & 1,4074 & 1,4934 & - \\
\hline Caminho 3 & 1,4618 & 1,4990 & - \\
\hline Elipse 1 $(a=0,10 \mathrm{~m})$ & - & - & 1,53851 \\
\hline Elipse 2 $(a=0,16 \mathrm{~m})$ & - & - & 1,53912 \\
\hline Elipse 3 $(a=0,18 \mathrm{~m})$ & - & - & 1,53914 \\
\hline
\end{tabular}

Assim sendo, os valores constantes em Cunha e outros (1995) devem ser $K_{\mathrm{I}}=560 \mathrm{~N} / \mathrm{mm}^{3 / 2}$ e $E=210000 \mathrm{~N} / \mathrm{mm}^{2}$. E o valor da integral $J$, retirado de Owen e Fawkes (1983) e calculada através da expressão $J=K_{\mathrm{I}}^{2} / E$, deve ter o valor $1,4933 \mathrm{Nmm} / \mathrm{mm}^{2}$. Com base nessa hipótese, adotou-se uma espessura de $1 \mathrm{~mm}$ para a chapa, a fim de serem compatibilizados os resultados constantes das colunas 2 e 3 da tabela 3 .

No intuito de explicar detalhadamente a metodologia baseada no parâmetro termodinâmico de fratura, serão apresentados, a seguir, dois exemplos, o 4 e o 5, com base nos mesmos dados geométricos dos exemplos 1 e 2, respectivamente. No entanto, ao invés de uma carga uniforme, aplicada em uma das extremidades da haste, têm-se agora deslocamentos uniformes prescritos, em ambas as extremidades. No caso do exemplo 4, o valor dos deslocamentos prescritos aplicados no sentido do aumento do comprimento da peça, é igual a $10^{-3} \mathrm{~m}$. Na tabela 4 são apresentados os resultados referentes a esse exemplo, ficando evidenciado que, diferentemente da integral $J$, não vale a propriedade de independência do caminho no caso do parâmetro termodinâmico $G_{\mathrm{t}}$. Observe-se que é bastante razoável a previsão para a orientação do possível avanço da fissura, indicada pelos ângulos das duas últimas colunas da tabela 4: a simetria dos deslocamentos prescritos sugere que o ângulo da fissura com o eixo $x_{1}$ seja zero, e nessa tabela verifica-se que dão sempre algo em torno de um décimo de grau.

Neste ponto, vale descrever em linhas gerais o procedimento para a realização dos experimentos numéricos cujos resultados estão sendo apresentados. Inicialmente, fornece-se como dado, ao programa Elcfrat, o valor do parâmetro crítico $\gamma_{\mathrm{E}}$ e, também, um valor de tolerância para o cálculo iterativo do valor limite de $G_{\mathrm{t}}$. A convergência do processo iterativo, para um só valor do limite de $G_{\mathrm{t}}$, revela-se bastante boa. 
Tabela 4 - Valores de $J, G_{\mathrm{t}}$ e a direção de possível propagação da fissura: exemplo 4

\begin{tabular}{|c|c|c|}
\hline $\begin{array}{c}\text { Valor de } a \\
\mathrm{~m}\end{array}$ & \multicolumn{2}{|c|}{$\begin{array}{c}\text { Caso de deslocamento constante prescrito nas extremidades da } \\
\text { haste }(\mathrm{J} / \mathrm{m})\end{array}$} \\
\hline & $J$ & $G_{\mathrm{t}}$ \\
\hline 0,200 & 1056,285 & 241,3896 \\
\hline 0,280 & 1056,589 & 365,0595 \\
\hline 0,345 & 1056,516 & 473,57781 \\
\hline 0,472 & 1058,628 & 703,0787 \\
\hline 0,495 & 1057,548 & 744,8425 \\
\hline
\end{tabular}

No exemplo 5, a seguir, prescreve-se um deslocamento constante, $10^{-2} \mathrm{~m}$, na direção tangencial, em todos os nós da face extrema esquerda, na figura 12, ficando a outra com deslocamento nulo na mesma direção. Note-se que há uma tendência clara de convergência para um valor do ângulo de avanço da fissura em torno de $16,8^{\circ}$, sentido horário em relação ao eixo $x_{1}$ (Tabela 5 ).

Tabela 5 - valores de $J$, de $G_{\mathrm{t}}$ e da direção de avanço da fissura: exemplo 5

\begin{tabular}{|c|c|c|}
\hline Valor de $a(\mathrm{~m})$ & \multicolumn{2}{|c|}{$\begin{array}{c}\text { Caso de deslocamento constante prescrito nas extremidades } \\
\text { da haste }(\mathrm{J} / \mathrm{m})\end{array}$} \\
\hline & $J$ & $G_{\mathrm{t}}$ \\
\hline 0,200 & 687,9999 & 356,3301 \\
\hline 0,280 & 689,42519 & 438,4738 \\
\hline 0,345 & 690,8777 & 486,9242 \\
\hline 0,405 & 692,3343 & 522,0943 \\
\hline 0,472 & 689,7161 & 548,6402 \\
\hline 0,495 & 680,7566 & 550,9933 \\
\hline 0,499 & 678,3267 & 550,9299 \\
\hline
\end{tabular}

Evidentemente, $G_{\mathrm{t}}$ é um parâmetro que depende do tamanho da parte $P$ contornada pelo correspondente caminho elíptico. Isso faz com que a concepção de $G_{\mathrm{t}}$ seja a do que se denomina, na termodinâmica, de uma grandeza extensiva. Assim, quanto maior for a extensão da parte $P$, mais aumenta a possibilidade do valor de $G_{\mathrm{t}}$ representar o que ocorre, na realidade, com o sólido inteiro. 
A metodologia utilizada no estudo da fratura que usa a integral $J$ como parâmetro inclui a determinação experimental de valores críticos $\left(J_{\text {ic }}\right.$, por exemplo) dessa grandeza, que deverão servir de referência para critérios de integridade baseados na comparação com o valor de $J$ obtido modelo teórico aplicado ao sólido em análise. 
Este livro foi publicado no formato 21 x $29,7 \mathrm{~cm}$

Tiragem de 400 exemplares

Impressão de capa e acabamento: BIGRAF

Salvador, 2010 